\title{
Application of the TEMPEST Computer Code to Canister- Filling Heat Transfer Problems
}

R. K. Farnsworth

D. W. Faletti

M. J. Budden

March 1988

Prepared for the U.S. Department of Energy under Contract DE-AC06-76RLO 1830

Pacific Northwest Laboratory Operated for the U.S. Department of Energy by Battelle Memorial Institute 


\title{
DISCLAIMER
}

This report was prepared as an account of work sponsored by an agency of the United States Government. Neither the United States Government nor any agency thereof, nor Battelle Memorial Institute, nor any of their employees, makes any warranty, expressed or implied, or assumes any legal liability or responsibility for the accuracy, completeness, or usefulness of any information, apparatus, product, or process disclosed, or represents that its use would not infringe privately owned rights. Reference herein to any specific commercial product, process, or service by trade name, trademark, manufacturer, or otherwise, does not necessarily constitute or imply its endorsement, recommendation, or favoring by the United States Government of any agency thereof, or Battelle Memorial Institute. The views and opinions of authors expressed herein do not necessarly state or reflect those of the United States Government or any agency thereof, or Battelle Memorial Institute.

\author{
PACIFIC NORTHWEST LABORATORY \\ operated by \\ BATTELLE MEMORIAL INSTITUTTE \\ for the \\ UNITED STATES DEPARTMENT OF ENERGY \\ under Contract DE-AC06-76RLO 1830
}

\begin{tabular}{c} 
Printed in the United States of America \\
Available from \\
National Technical Intormation Service \\
United States Department of Commerce \\
5285 Port Royal Road \\
Springfield, Virginia 22161 \\
NTIS Price Codes \\
Microfiche A01 \\
Printed Copy \\
\multicolumn{3}{c}{} \\
Pages \\
$001-025$ \\
$026-050$
\end{tabular}


Nuclear Waste Treatment Program

APPLICATION OF THE TEMPEST COMPUTER CODE

TO CANISTER-FILLING HEAT TRANSFER PROBLEMS

R. K. Farnsworth

D. W. Faletti

M. J. Budden

March 1988

Prepared for

the U.S. Department of Energy under Contract DE-AC06-76RLO 1830

Pacific Northwest Laboratory Richland, Washington 99352 


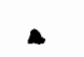




\section{SUMMARY}

Pacific Northwest Laboratory (PNL) researchers used the TEMPEST computer code to simulate thermal cooldown behavior of nuclear waste glass after it was poured into steel canisters for long-term storage. The objective of this work was to determine the accuracy and applicability of the TEMPEST code when used to compute canister thermal histories.

First, experimental data were obtained to provide the basis for comparing TEMPEST-generated predictions. Five canisters were instrumented with appropriately located radial and axial thermocouples. The canisters varied in diameter (12 in., 13 in., and 24 in.), height ( 45 in., 56 in., and 85 in.), internal insulation thickness ( 0 to $1 / 2$ in.), and external insulation thickness ( 0 to 3 in.). The canisters were filled using the pilot-scale ceramic melter (PSCM) at PNL. Each canister was filled in either a continuous or a batch filling mode. One of the canisters was also filled within a turntable simulant (a group of cylindrical shells with heat transfer resistances similar to those in an actual meiter turntable). This was necessary to provide a basis for assessing the ability of the TEMPEST code to also model the transient cooling of canisters in a melter turntable.

After the data were obtained from the PSCM runs, two versions of TEMPEST-the batch fill (L4X) and the continuous fill (M)--were used to simulate the experimental conditions. The thermal histories predicted by these TEMPEST versions were then compared to the experimentally-measured data.

Researchers found that the batch-fill model (L4X) predicted canister centerline temperatures that agreed closely with experimental temperatures, varying from only 50 to $125^{\circ} \mathrm{C}$ over most of the canister cooldown period. However, during periods immediately following a glass pour, temperatures were overpredicted by as much as $250^{\circ} \mathrm{C}$.

The continuous-fill model, Version $M$, was found to predict temperatures with more accuracy. Variation from experimentally-measured temperatures was within $50^{\circ} \mathrm{C}$ or better over most of the cooldown. Close agreement was also achieved for temperatures at other radial positions away from the centerline and for times long after the glass surface rose above a given elevation. 
The turntable simulant experiment demonstrated that TEMPEST can adequately model the asymmetric temperature field caused by the turntable geometry. Further, TEMPEST can acceptably predict the canister cooling history within a turntable, despite code limitations in computing simultaneous radiation and convection heat transfer between shells, along with uncertainty in stainlesssteel surface emissivities.

Based on the successful performance of TEMPEST Version $M$, development was initiated to incorporate 1) full viscous glass convection, 2) a dynamically adaptive grid that automatically follows the glass/air interface throughout the transient, and 3) a full enclosure radiation model to allow radiation heat transfer to non-nearest neighbor cells. At the end of FY 1987, the first feature was fully incorporated and the second feature had been partially accomplished. This advanced version of TEMPEST, designated Version N29, is still under development.

Based on the results obtained using TEMPEST versions $L 4 X$ and $M$, recommendations for future work include continuing the developmental efforts for Version $\mathrm{N} 29$ and improving the accuracy of materials properties and initial conditions inherent in the glass-filling process. 


\section{CONTENTS}

SUMMARY

1.0 INTRODUCTION $\ldots \ldots \ldots \ldots \ldots \ldots \ldots \ldots \ldots \ldots \ldots \ldots \ldots \ldots \ldots \ldots \ldots \ldots \ldots \ldots \ldots \ldots \ldots \ldots$

2.0 CONCLUSIONS AND RECOMMENDATIONS $\ldots \ldots \ldots \ldots \ldots \ldots \ldots \ldots \ldots \ldots \ldots \ldots \ldots \ldots \ldots \ldots$

2.1 CONCLUSIONS $\ldots \ldots \ldots \ldots \ldots \ldots \ldots \ldots \ldots \ldots \ldots \ldots \ldots \ldots \ldots \ldots \ldots \ldots \ldots \ldots \ldots \ldots . \ldots \ldots$

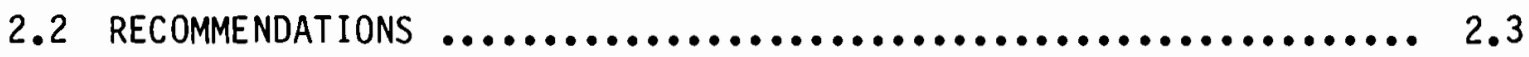

3.0 TEMPEST CODE DESCRIPTION $\ldots \ldots \ldots \ldots \ldots \ldots \ldots \ldots \ldots \ldots \ldots \ldots \ldots \ldots \ldots \ldots \ldots \ldots \ldots$

3.1 CAPABILITIES AND FEATURES $\ldots \ldots \ldots \ldots \ldots \ldots \ldots \ldots \ldots \ldots \ldots \ldots \ldots \ldots \ldots \ldots \ldots$

3.2 CODE LIMITATIONS $\ldots \ldots \ldots \ldots \ldots \ldots \ldots \ldots \ldots \ldots \ldots \ldots \ldots \ldots \ldots \ldots \ldots \ldots \ldots \ldots \ldots \ldots \ldots \ldots \ldots$

3.2.1 Radiation Model ............................... 3.3

3.2.2 Transient Duration $\ldots \ldots \ldots \ldots \ldots \ldots \ldots \ldots \ldots \ldots \ldots \ldots \ldots \ldots \ldots . \ldots . \ldots . \ldots$

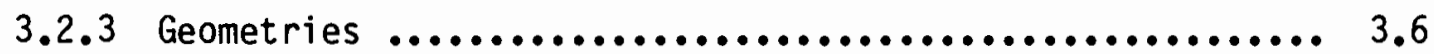

3.2.4 Grid Boundaries (Glass/Air Interface) $\ldots \ldots \ldots \ldots \ldots \ldots \ldots \ldots . . \ldots$

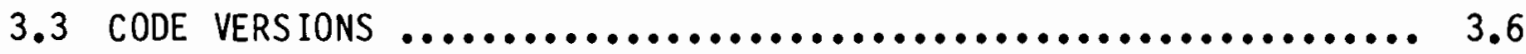

4.0 EXPERIMENTAL DATA COLLECTION $\ldots \ldots \ldots \ldots \ldots \ldots \ldots \ldots \ldots \ldots \ldots \ldots \ldots \ldots \ldots \ldots . \ldots . \ldots$

4.1 CANISTER DESCRIPTION $\ldots \ldots \ldots \ldots \ldots \ldots \ldots \ldots \ldots \ldots \ldots \ldots \ldots \ldots \ldots \ldots \ldots \ldots \ldots \ldots \ldots$

4.2 TURNTABLE SIMULANT $\ldots \ldots \ldots \ldots \ldots \ldots \ldots \ldots \ldots \ldots \ldots \ldots \ldots \ldots \ldots \ldots \ldots \ldots \ldots \ldots$

4.3 THERMOCOUPLE LOCATION $\ldots \ldots \ldots \ldots \ldots \ldots \ldots \ldots \ldots \ldots \ldots \ldots \ldots \ldots \ldots \ldots \ldots \ldots . \ldots \ldots$

4.4 CANISTER FILLING METHODS $\ldots \ldots \ldots \ldots \ldots \ldots \ldots \ldots \ldots \ldots \ldots \ldots \ldots \ldots \ldots \ldots . \ldots \ldots$

4.5 GLASS MEASUREMENTS $\ldots \ldots \ldots \ldots \ldots \ldots \ldots \ldots \ldots \ldots \ldots \ldots \ldots \ldots \ldots \ldots \ldots \ldots \ldots \ldots \ldots \ldots \ldots$

5.0 TEMPEST INPUT MODELS AND ASSUMPTIONS $\ldots \ldots \ldots \ldots \ldots \ldots \ldots \ldots \ldots \ldots \ldots \ldots \ldots \ldots$

5.1 MODEL DEVELOPMENT CONSIDERATIONS $\ldots \ldots \ldots \ldots \ldots \ldots \ldots \ldots \ldots \ldots \ldots \ldots \ldots$

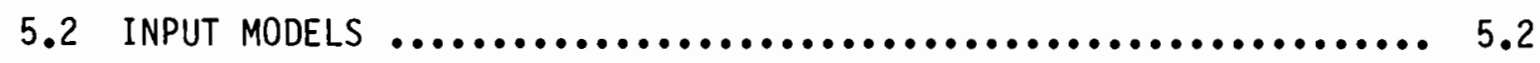

$5.2 .1 \quad 12 \mathrm{LI}$ and $12 \mathrm{HI}$ Canisters $\ldots \ldots \ldots \ldots \ldots \ldots \ldots \ldots \ldots \ldots \ldots \ldots . \ldots . \ldots \ldots$

5.2.2 13-in.-Diameter Canister ...................... 5.5 
5.2.3 24-in.-Diameter Canister ......................... 5.5

5.3 UNDERLYING ASSUMPTIONS $\ldots \ldots \ldots \ldots \ldots \ldots \ldots \ldots \ldots \ldots \ldots \ldots \ldots \ldots \ldots . \ldots \ldots$

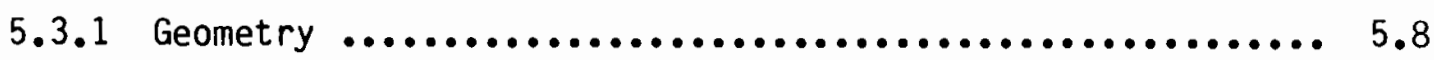

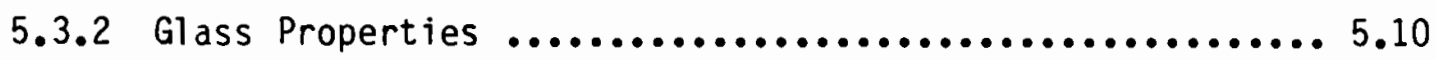

5.3.3 Insulation Properties $\ldots \ldots \ldots \ldots \ldots \ldots \ldots \ldots \ldots \ldots \ldots \ldots . . \ldots \ldots \ldots \ldots$

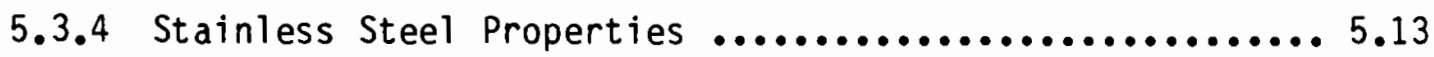

5.3.5 Initial Glass Temperatures ........................ 5.14

6.0 COMPARISON OF TEMPEST PREDICTIONS WITH EXPERIMENTAL

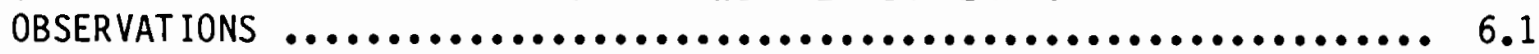

6.1 CANister internal Temperatures $\ldots \ldots \ldots \ldots \ldots \ldots \ldots \ldots \ldots \ldots \ldots \ldots .1$

6.1 .1 TEMPEST Batch-Fill Model $\ldots . \ldots \ldots \ldots \ldots \ldots \ldots \ldots \ldots \ldots \ldots . . . \ldots .1$

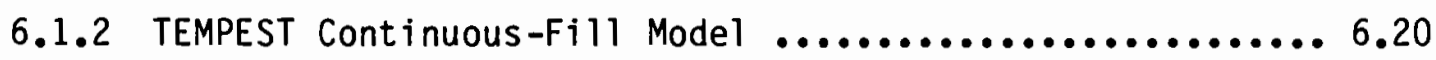

6.2 TURNTABle Simulant EXPERIMENT $\ldots \ldots \ldots \ldots \ldots \ldots \ldots \ldots \ldots \ldots \ldots \ldots ., 6.27$

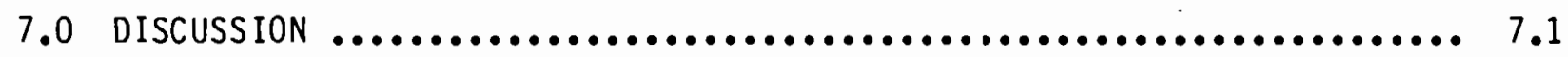

7.1 TEMPEST BATCH-FILL MODEL RESULTS $\ldots \ldots \ldots \ldots \ldots \ldots \ldots \ldots \ldots \ldots, 7.1$

7.2 TEMPEST CONTINUOUS-FILL MODEL RESULTS $\ldots \ldots \ldots \ldots \ldots \ldots \ldots \ldots \ldots \ldots . . \ldots$

7.3 IMPLICATIONS OF THE TURNTABLE SIMULANT RESULTS $\ldots \ldots \ldots \ldots \ldots \ldots .7$

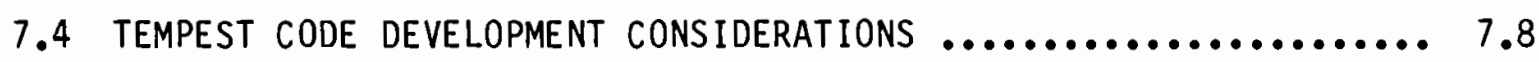

8.0 QUALITY ASSURANCE AND TRACEABILITY $\ldots \ldots \ldots \ldots \ldots \ldots \ldots \ldots \ldots \ldots \ldots . \ldots . \ldots . \ldots$

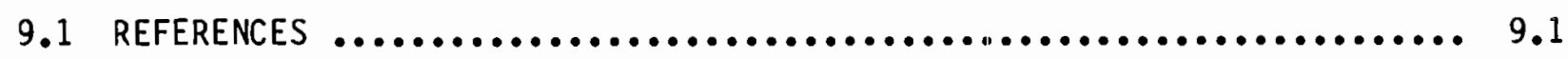

APPENDIX A - IMPLICIT VISCOUS DIFFUSION CHANGES TO TEMPEST $\ldots \ldots \ldots \ldots \ldots \ldots$ A. 1

APPENDIX B - FRONT TRACKER CHANGES TO TEMPEST $\ldots \ldots \ldots \ldots \ldots \ldots \ldots \ldots \ldots \ldots$ B. 1

APPENDIX $C$ - HISTORIAN SOFTWARE UTILITY $\ldots \ldots \ldots \ldots \ldots \ldots \ldots \ldots \ldots \ldots \ldots . \ldots . \ldots . \ldots$ 
FIGURES

3.1 Gap Radiation Approximation Compared to Enclosure

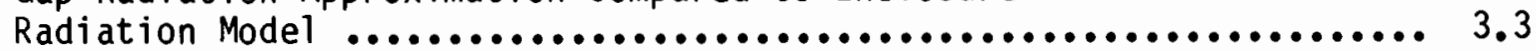

3.2 Geometry for Radiation from Glass Surface Cells to Canister

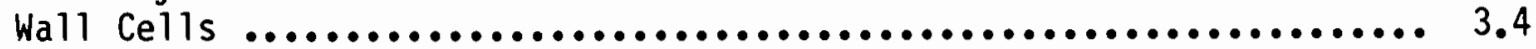

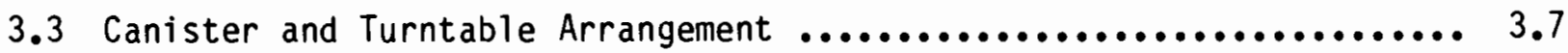

4.1 Cross Section of 12-in.-Diameter Canisters ..................... 4.3

4.2 Canister Placement Under Melter for 13-in.-Diameter Canister ....... 4.5

4.3 Turntable Simulant Model Configuration ........................ 4.7

4.4 Thermocouple Locations for Canisters $12 \mathrm{LI}$ and $12 \mathrm{HI} \quad \ldots . . . \ldots \ldots . . . .4 .10$

4.5 Typical Placement and Structural Support of Internal

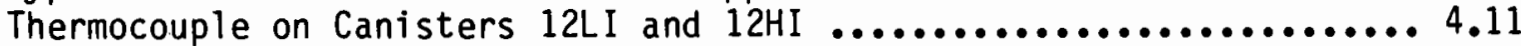

5.1 TEMPEST Mesh for Canisters 12LI and 12HI After First

Glass Batch Pour ........................................... 5.3

5.2 TEMPEST Mesh for Canisters 12LI and 12HI After Final

(Third) Glass Batch Pour ....................................... 5.4

5.3 TEMPEST Mesh for Continuous-Fill Modelling of the 13-in-Diameter Canister .................................... 5.6

6.1 TEMPEST Predictions and Experimental Temperatures Measured in Canister 12H at Axial Level 3.75 in. from Canister Bottom........... 6.3

6.2 TEMPEST Predictions and Experimental Temperatures Measured in Canister 12HI at Axial Level 9.5 in. from Canister Bottom ........... 6.3

6.3 TEMPEST Predictions and Experimental Temperatures Measured in Canister 12HI at Axial Level 12.125 in. from Canister Bottom ........ 6.4

6.4 TEMPEST Predictions and Experimental Temperatures Measured in Canister 12HI at Axial Level 20.0 in. from Canister Bottom .......... 6.5

6.5 TEMPEST Predictions and Experimental Temperatures Measured in Canister 12HI at Axial Level 24.875 in. from Canister Bottom ........ 6.5

6.6 TEMPEST Predictions and Experimental Temperatures Measured in Canister 12HI at Axial Level 32.75 in. from Canister Bottom ......... 6.7 
6.7 TEMPEST Predictions and Experimental Temperatures Measured in Canister $12 \mathrm{HI}$ at Axial Levels 37.625 and 35.875 in. from

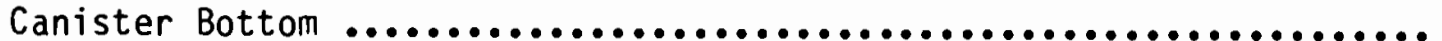

6.8 TEMPEST High- and Low-Temperature Radiation Model Predictions and Experimental Temperatures Measured in Canister $12 \mathrm{HI}$ at

Axial Level 3.75 in. from Canister Bottom ..................... 6.8

6.9 TEMPEST High- and Low-Temperature Radiation Model Predictions and Experimental Temperatures Measured in Canister $12 \mathrm{HI}$ at Axial

Level 9.5 in. from Canister Bottom ............................ 6.8

6.10 TEMPEST High- and Low-Temperature Radiation Model Predictions and Experimental Temperatures Measured in Canister $12 \mathrm{HI}$ at Axial Level 12.125 in. from Canister Bottom .................... 6.9

6.11 TEMPEST High- and Low-Temperature Radiation Model Predictions and Experimental Temperatures Measured in Canister $12 \mathrm{HI}$ at

Axial Level 20.0 in. from Canister Bottom ...................... 6.9

6.12 TEMPEST High- and Low-Temperature Radiation Model Predictions and Experimental Temperatures Measured in Canister $12 \mathrm{HI}$ at

Axial Level 24.875 in. from Canister Bottom ......................6.10

6.13 TEMPEST High- and Low-Temperature Radiation Model Predictions and Experimental Temperatures Measured in Canister $12 \mathrm{HI}$ at Axial Level 32.75 in. from Canister Bottom .......................6.10

6.14 TEMPEST High- and Low-Temperature Radiation Model Predictions and Experimental Temperatures Measured in Canister $12 \mathrm{HI}$ at

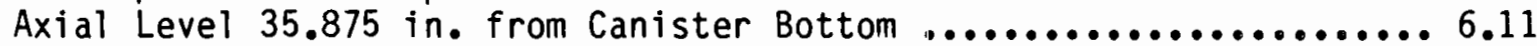

6.15 TEMPEST High- and Low-Temperature Radiation Model Predictions and Experimental Temperatures Measured in Canister $12 \mathrm{HI}$ at

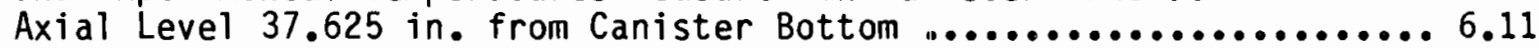

6.16 TEMPEST Predictions and Experimental Temperatures Measured in Canister 12LI at Axial Level 3.75 in. from Cánister Bottom .........6.13

6.17 TEMPEST Predictions and Experimental Temperatures Measured in Canister 12LI at Axial Level 9.50 in. from Canister Bottom .........6.13

6.18 TEMPEST Predictions and Experimental Temperatures Measured in Canister 12LI at Axial Level 12.175 in. from Canister Bottom .......6.6.14

6.19 TEMPEST Predictions and Experimental Temperatures Measured in Canister 12LI at Axial Level 20.0 in. from Canister Bottom .........6.14

6.20 TEMPEST Predictions and Experimental Temperatures Measured in Canister 12LI at Axial Level 24.875 in. from Canister Bottom 
6.21 TEMPEST Predictions and Experimental Temperatures Measured in Canister 12LI at Axial Level 32.75 in. from Canister Bottom .........6.15

6.22 TEMPEST Predictions and Experimental Temperatures Measured in Canister 12LI at Axial Levels 35.875 and 37.625 in. from

Canister Bottom .......................................6.16

6.23 Axial Profiles for Canister $12 L I \ldots \ldots \ldots \ldots \ldots \ldots \ldots \ldots \ldots \ldots \ldots \ldots \ldots \ldots . \ldots \ldots$

6.24 TEMPEST High- and Low-Temperature Radiation Model Predictions and Experimental Temperatures Measured in Canister $12 \mathrm{LI}$ at Axial Level 12.175 in. from Canister Bottom ...................... 6.21

6.25 TEMPEST High- and Low-Temperature Radiation Model Predictions and Experimental Temperatures Measured in Canister $12 \mathrm{LI}$ at Axial Level 20 in. from Canister Bottom ...................... 6.21

6.26 TEMPEST High- and Low-Temperature Radiation Model Predictions and Experimental Temperatures Measured in Canister $12 \mathrm{LI}$ at Axial Level 24.875 in. from Canister Bottom ...................... 6.22

6.27 TEMPEST Predictions and Experimental Temperatures for the 13-in.-Diameter Canister at Axial Level 3.5 in. from Canister Bottom

6.28 TEMPEST Predictions and Experimental Temperatures for the 13-in.-Diameter Canister at Axial Level 13.3 in. from Canister Bottom .........................................6.23

6.29 TEMPEST Predictions and Experimental Temperatures for the 13-in.-Diameter Canister at Axial Level 21.1 in. from Canister Bottom 6.24

6.30 TEMPEST Predictions and Experimental Temperatures for the 13-in.-Diameter Canister at Axial Level 26.1 in. from Canister Bottom 6.24

6.31 TEMPEST Predictions and Experimental Temperatures for the 13-in.-Diameter Canister at Axial Level 38.4 in. from Canister Bottom 6.25

6.32 TEMPEST Predictions and Experimental Temperatures for the 13-in.-Diameter Canister at Axial Level 34.0 in. from Canister Bottom

C.1 Directory Tree Structure on LANL Common File System Where Appropriate TEMPEST Versions are Stored ....................... C.2

C.2 HISTORIAN Source File Example ............................ C.4 


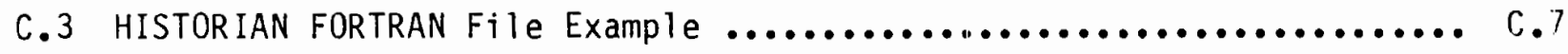

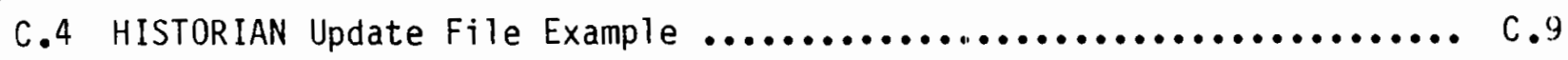




\section{TABLES}

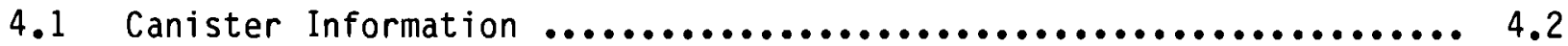

4.2 Measured Distances from the Bottom of the Reverse Flanged 24-in.-Diameter Canister ............................. 4.4

4.3 TEMPEST-Determined Thermocouple Conduction Factors for Canisters with

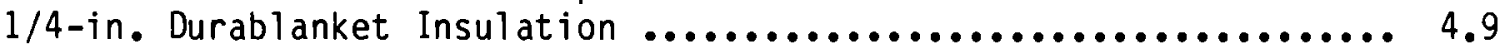

4.4 TEMPEST Determined Thermocouple Conduction Factors for Canisters with 3-in. Durablanket Insulation ................................. 4.9

4.5 Axial Thermocouple Locations for the 13-in. Diameter Canister ...... 4.12

4.6 Axial Thermocouple Locations for the 24-in.-Diameter Canister ...... 4.12

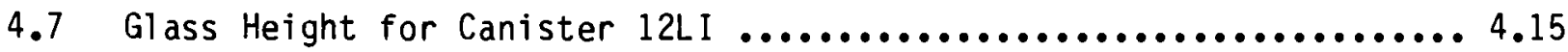

4.8 Glass Height for Canister $12 \mathrm{HI} \ldots \ldots \ldots \ldots \ldots \ldots \ldots \ldots \ldots \ldots \ldots \ldots \ldots \ldots \ldots . \ldots . \ldots . \ldots$

4.9 Glass Height for the 13-in.-Diameter Canister ................. 4.16

4.10 Glass Height for the 24-in.-Diameter Canister ................. 4.17

5.1 Monitor Cell Locations for Canisters $12 \mathrm{LI}$ and $12 \mathrm{HI} \ldots \ldots \ldots \ldots \ldots . \ldots . . . .5$

5.2 Monitor Cell Locations for the 13-in.-Diameter Canister ......... 5.7

5.3 Monitor Cell Locations for the 24-in.-Diameter Canister .......... 5.7

5.4 Comparison of SRL 411 and PSCM-20 Glass Properties .............. 5.11

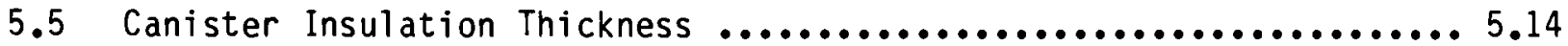

5.6 Initial Glass Temperatures Used for Canisters $12 \mathrm{LI}$ and $12 \mathrm{HI}$
During Batch-Fill Modeling $\ldots \ldots \ldots \ldots \ldots \ldots \ldots \ldots \ldots \ldots \ldots \ldots \ldots \ldots \ldots \ldots \ldots \ldots$

6.1 Comparison of Computer-Predicted Temperature Drops with Experimental Results Between Shells of the PSCM Turntable Simulant 



\subsection{INTRODUCTION}

The liquid-fed ceramic melter (LFCM) is being developed in the United States and abroad as a promising method for treatment of high-level radioactive wastes. In the LFCM process, radioactive materials are combined with other glass-forming materials. The resultant mixture is then melted to form a chemically stable glass. This molten glass will subsequently be poured into canisters; the canisters will then be placed in a waste repository.

One of the factors that has been considered in determining the suitability of glass as a disposal material is the extent of glass devitrification and cracking in the waste canisters. These behaviors are determined largely by the cooling history of the glass. Hence, a method is needed to accurately compute the thermal history of canisters filled in the LFCM, from the time that canister filling begins until the canisters reach thermal equilibrium with the environment.

To investigate the code's effectiveness in predicting canister thermal behavior, Pacific Northwest Laboratory $(P N L)(a)$ researchers applied the TEMPEST computer code to various canister-filling scenarios. This study was conducted for the U.S. Department of Energy (DOE) through the Nuclear Waste Treatment Program at PNL.

The TEMPEST computer code (Trent, Eyler, and Budden 1983[b]; Trent and Eyler 1985; Eyler and Trent 1984), solves the partial differential equations governing the conservation of mass, momentum, and thermal energy in either cylindrical or cartesian geometries. The code is well-documented and has undergone an extensive verification and benchmarking effort to establish its accuracy and range of validity. Despite its relatively large size $(>30,000$ lines), TEMPEST is flexible and relatively easy to use.

(a) Operated for the U.S. Department of Energy by Battelle Memorial Institute under Contract DE-AC06-76RLO 1830.

(b) Discussion is contained in Trent, D.S., L. L. Eyler, and M. J. Budden. 1983. TEMPEST - A Three-Dimensional Time-Dependent Computer Program for Hydrothermal Analys is. Volume I: Numerical Methods and Input Instruction. Pacific Northwest Laboratory, Richland, Washington. 
This report documents the comparison of TEMPEST-generated thermal history predictions with experimentally derived data for several different canister designs and filling scenarios. The report also provides a description of PNL's work to date on modifications to TEMPEST to improve the code's predictive capabilities when used to model canister filling.

The conclusions and recommendations stemming from this study are presented in Chapter 2. In Chapter 3, the TEMPEST code and its application to the problems of canister cooling are described. This chapter also provides discussions of various TEMPEST models, from the base Version L4 to the advanced Version N29, which is currently in the development stage. Chapter 4 discusses the canister-filling experiments and the resulting data against which the TEMPEST predictions were compared. In Chapter 5, the TEMPEST input models used to simulate canister filling and cooling are described. Chapter 6 presents the results of the comparisons in both text and graphic form. These results are discussed and explained in Chapter 7. This chapter also provides detailed suggestions for future code development work that would make TEMPEST simulations more accurate, cost-effective, and convenient. In Chapter 8, quality assurance considerations related to TEMPEST development are presented. Input file information is included in Appendixes $A$ through $C$. 


\subsection{CONCLUSIONS AND RECOMMENDATIONS}

The experiments described in this report covered a wide range of scenarios typical of nuclear waste glass melter operations. Canisters of two sizes were instrumented, various types of insulation at various locations were tested, and both batch- and continuous-fill strategies were simulated. The conclusions and recommendations based on the results of this experiment are presented in this chapter.

\subsection{CONCLUSIONS}

The experimental data provided a sufficiently accurate basis for this code validation and will continue to be valuable for any future code validation study of glass pour and cooldown phenomena. The thermocouple $(T / C)$ temperature readings were accurate to within $20^{\circ} \mathrm{C}$ or better, and the glass heights were accurately measured to within 1 in.

Generally, the TEMPEST-generated predictions were in good agreement with the experimental data, even though the radiation and front tracking models were quite crude and some uncertainty existed in the temperature of the initial glass pour. Version L4X of TEMPEST was basically a conduction-only model with a crude radiation correction. It was used for the batch-pouring scenario and assumed an instantaneous pour. Version M of TEMPEST incorporated the crude radiation correction but also tried to model the constantly rising glass surface. As might be expected, Version M predicted canister thermal history better than did Version L4X. There is a well-founded hope that Version N29, when completed, will provide temperatures accurate enough for complete engineering design specifications. Specific conclusions about the individual TEMPEST models are presented in the following paragraphs.

The TEMPEST batch-fill model, Version L4X, was sufficiently accurate to be useful for many LFCM applications, giving temperatures near the centerline that were accurate within a range of 50 to $125^{\circ} \mathrm{C}$ over most of the cooldown. However, during periods immediately following a pour, this TEMPEST model overpredicted temperatures by as much as $250^{\circ} \mathrm{C}$. 
These deviations were caused by a large underprediction of the cooldown immediately following a pour and by another, less severe, underprediction of the cooldown rate at times later than $10 \mathrm{~h}$ after a pour.

The Version L4X underprediction of the cooldown immediately following a pour was judged to be caused by two factors:

- Version L4X of TEMPEST apparently underpredicts the heat loss from the glass surface. This is due to the crude radiation model, the necessary temperature averaging, and the instantaneous batch-fill assumptions that allow no heat transfer during the filling process.

- Version L4X of TEMPEST also apparently underpredicts the radial and axial heat transfer just below the glass surface. This result is thought to be due to the TEMPEST code assumption that the glass is a nonconvective (conductive-only) medium. It could also be due to the use of a low thermal diffusivity at the very high glass temperatures in the canister.

The advanced TEMPEST Version N29 should eliminate both of these problems. Redoing the simulations with Version $\mathrm{N} 29$ should then result in much better agreement with experimental data.

The underprediction of the cooldown at times later than $10 \mathrm{~h}$ after a pour is probably the result of the canister insulation having about a $25 \%$ higher effective thermal conductivity than that used by TEMPEST. Further analysis is necessary to confirm this hypothesis.

The TEMPEST continuous-fill mode1, Version $M$, did a better job of predicting temperatures than did the batch-model. Temperatures predicted near the centerline were within $50^{\circ} \mathrm{C}$ or better over most of the cooldown. This was also true for temperatures at locations off the centerline for times after the glass surface passed a given axial level.

The continuous-fill model produced significant deviations in time (late predictions) and temperature (up to $400^{\circ} \mathrm{C}$ ) for the hour or two after the glass surface passed a thermocouple leve1. However, the cooldown underpredictions were still better than those of the batch-fill mocel. The deviations are believed to be caused by a combination of the crude radiation model, the zero 
viscosity assumption used for the convecting glass, the poor resolution of heat transfer from the glass/air interface, and the lack of any heat transfer in the air above the glass. Again, use of advanced Version 29 should remedy this situation.

The turntable simulant experiments demonstrated that:

- The asymmetrical temperature profile caused by the asymmetrical turntable geometry can be modeled by TEMPEST.

- TEMPEST produces reasonable predictions of the temperatures within a turntable simulant, in spite of the code's limitations in computing simultaneous radiation and convective heat transfer, and in spite of considerable uncertainty in the emissivities of the stainless-steel surfaces.

- The best agreement between predicted and observed temperatures was found between the overpack to seal liner, the seal liner to thimble, and the thimble to turntable wall. Poorest agreement was observed between the canister wall to the overpack and the turntable wall to the ambient.

The validation would have been significantly improved, particularly for the turntable simulant experiment, if the experimental design had incorporated a heat balance. Additional improvements could have been made if there had been a direct means of measuring the glass temperature of the input pour stream directiy at the point of impact with the glass surface. This would not only have helped specify initial conditions for TEMPEST, but would have provided valuable information about the heat loss from the stream of molten glass to the canister walls.

\subsection{RECOMMENDATIONS}

TEMPEST did an excellent job of qualitatively predicting the thermal response of the canister, and a fairly good job (subject to a few caveats) of predicting the quantitative behavior of the canister. The excellent qualitative agreement is due primarily to the kind of code TEMPEST is: a bestestimate code that solves the governing equations from fundamental physical 
principles--the conservation laws of mass, momentum, and energy. It provides the user with considerable latitude in selecting and refining a mesh to discretize a problem and, for codes of its size (a 30,000-1ine code representing more than 10 man-years of development effort), TEMPEST is very user-friendly. Improved modeling in three main areas is needed for the base Version L4 of TEMPEST. These areas are

1. an implicit viscous diffusion model to simulate glass convection

2. an adaptive grid model capable of tracking the moving front of the air/glass interface

3. a graybody enclosure radiation model that will work efficiently in conjunction with the current convection solution algorithm.

We therefore recommend that these superior models be installed into a new advanced version of TEMPEST. The N29 version of TEMPEST currently under development already has some of the above-mentioned features installed. Specifically, the implicit viscous diffusion model has already been installed and successfully tested; the $\mathrm{N} 29$ version of TEMPEST will allow the efficient computation of the convection of any fluid, regardless of how high the fluid viscosity is.

The $\mathrm{N} 29$ version of TEMPEST is a1 ready well along the path to becoming a best-estimate code for modeling canister pouring and cooldown. We recommend that the development effort on TEMPEST Version $N 29$ be continued according to the following agenda:

1. Complete the front tracker model; install, test, and debug.

2. Carryover the crude radiation model from Versions $L 4 X$ and $M$ into Version N29.

3. Test the resulting code on one canister run, and assess the code accuracy.

4. If the code accuracy is acceptable, rerun the remaining cases. 
5. If the code accuracy is unacceptable, install the general graybody radiation model; then test the resulting code on one canister run and assess the accuracy.

6. If the code accuracy is acceptable, rerun the remaining cases.

7. Document the final advanced version of the code and publish it. In addition to improvements with TEMPEST, several features of the glass pouring and canister cooldown that were uncovered by the PSCM runs merit further attention. Specific recommendations include:

- Establish the actual thermal properties (thermal conductivity, specific heat, and density), over the entire temperature range, up to $1150^{\circ} \mathrm{C}$, for the waste glasses described in this report.

- Establish, through modeling and further experimentation, the temperatures of the glass stream when it impacts the glass surface inside the canister.

- Establish the emissivity of the stainless-steel canisters and the speed with which the canisters oxidize and change. This is a major source of uncertainty in the modeling efforts.

- Establish the actual conductivities of the Durablanket and Fiberfrax insulation, especially in the semi-crushed state. If the actual conductivities are about 25\% lower than the manufacturer-stated value, the TEMPEST predictions would be more accurate.

- Improve the accuracy in determining the position of the glass/air interface with time. This would be accomplished by using improved methods of measuring canister weight and glass volumetric flow.

- Improve the understanding of the thermocouple response to the rising glass surface just before and after the glass surface covers the thermocouples. 


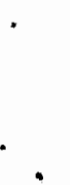

s.

(⿸丆口

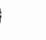

. 


\subsection{TEMPEST CODE DESCRIPTION}

The TEMPEST code was chosen for modeling glass temperatures during canister filling and cooldown. TEMPEST is a transient, three-dimensional, thermofluid computer program developed by PNL to analyze a broad range of fast transient, coupled fluid dynamic, and heat transfer systems. (Trent, Eyler, and Budden 1983[a]; Trent and Eyler 1985; Eyler and Trent 1984.) The code solves the full three-dimensional, time-dependent equations of motion, continuity, and heat transport for either laminar or turbulent fluid flow (including heat diffusion and generation) in both solids and liquids. TEMPEST provides finite difference solutions to these equations in either cylindrical or cartesian coordinates for incompressible flows with small density variations. The capabilities, limitations, and versions of the TEMPEST code are described in this chapter.

\subsection{CAPABILITIES AND FEATURES}

The TEMPEST code was selected for use in this study for five primary reasons:

- TEMPEST can compute combined conduction and convection directly based on fundamental physical principles (the physical conservation laws) without having to use empirical convection-related heat transfer coefficients.

- TEMPEST al lows for three-dimensional solutions of transient thermofluid phenomena using temperature-dependent material properties that can be specified by the user. TEMPEST can model density-induced flows and the large changes in viscosity with temperature that are typical of glasses.

(a) Trent, D. S., L. L. Eyler, and M. J. Budden. 1983 TEMPEST - A ThreeDimensional Time-Dependent Computer Program for Hydrothermal Analysis. Volume I: Numerical Methods and Input Instructions. Pacific Northwest Laboratory, Richland, Washington. 
- TEMPEST is accurate and user-friendly. Sigrificant verification and bench-marking experience with the code has been accumulated and documented (Eyler, Trent, and Budden 1983) [a]

- TEMPEST is portable; it is written in ANSI FORTRAN-77 and will run on virtually any machine. It is currently being used on CDC-7600 computers, as well as CRAY-1S, CRAY-XMP, DEC-VAX, and IBM machines.

- TEMPEST is available for continued code development and refinement, so that discrepancies in the comparison of any results with computer predictions can be rectified.

\subsection{CODE LIMITATIONS}

Despite its advantages, the base version of TEMPEST, designated L4, is not entirely without weaknesses when modeling the complex thermofluid phenomena associated with pouring waste glass into canisters and the following cooldown.

The original TEMPEST code was developed primarily to provide a useroriented thermofluid analysis tool capable of simulating a wide range of fast breeder reactor component flow problems. Such flow problems involve fast transients where conduction and convection are the primary heat transfer mechanisms (except possibly at the boundaries). Because sodium is opaque to thermal radiation, a general graybody enclosure radiation model is not necessary.

However, the glass pouring and cooldown procedures result in relatively slow transients in which radiation is also a dominant mode of heat transfer. Inside the glass, conduction and, at high temperatures, convection are also important. The large temperature changes result in extremely wide ranges of viscosity that TEMPEST was not designed to handle.

Related to potential cracking and devitrification is the cooldown history of a canister when emplaced on a turntable with other canisters in various

(a) Eyler, L. L., A. S. Trent, and M. J. Budden. 1983. TEMPEST - A ThreeDimensional Time-Dependent Computer Program for Hydrothermal Analysis. Volume II. Assessment and Verification Results. Pacific Northwest Laboratory, Richland, Washington. 
stages of fill/cooldown themselves. Modeling the cooldown history requires a nonconcentric cylindrical coordinate system, or even a multi-region coordinate system. TEMPEST does not currently have such a capability.

Finally, TEMPEST, like most codes, is a fixed grid code. Pouring glass into the canisters causes a moving boundary or interface between glass and air. For best accuracy, the moving glass/air interface must also be modeled.

For these reasons, the actual TEMPEST models described in this report contain simplifications and approximations, some of which are significant. These limitations, approximations, and modeling procedures are explained in the following four sections.

\subsubsection{Radiation Model}

A general graybody enclosure radiation model is needed if TEMPEST is to be used to effectively address the glass-pouring problem. Currently, the base version of TEMPEST (Version L4) has only a gap radiation model (see Figure 3.1a). With the gap radiation model, TEMPEST calculates the cell edge temperatures for use in the Stefan-Boltzmann law, implicitly assuming that the shape factor between any two cells separated by a radiation connector is 1 . For example, in Figure $3.1 \mathrm{a}$ this means that radiant energy flows from cell 3 to cell 4 only. In reality, energy flows as depicted in Figure 3.1b, where cell 3 radiates to cells 2,4 , and 6 , each with a different shape factor.

The TEMPEST gap radiation model is sufficient for use as an external boundary condition or in the interior of a region across a truly narrow gap where the details of what goes on in the gap (e.g., convection) are not important. However, it is not appropriate for modeling the heat transfer from the glass surface to the canister side walls or out the top of the canister. The glass surface/canister wall geometry for which a radiation model is needed is shown in Figure 3.2.

To improve on the radiation model available in Version $L 4$ of TEMPEST, a new version, designated $L 4 X$, was built to better approximate the thermal phenomena in the canisters. A crude radiation model was included in this version. In this model, the average glass surface temperature was calculated, and the canister wall temperatures above the glass surface were calculated. 
- Normal Cell Centered Temperature

$\times$ TEMPEST Surface Temperature Computed for Radiation

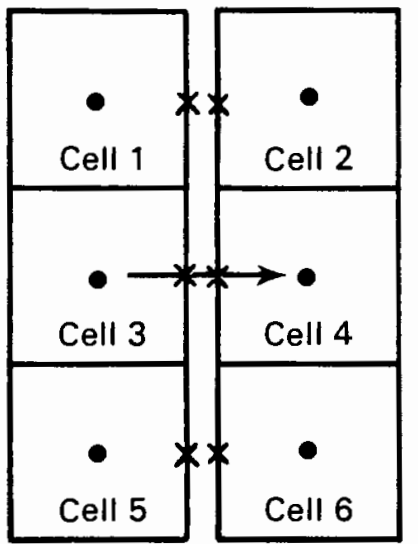

a. Gap Radiation Model

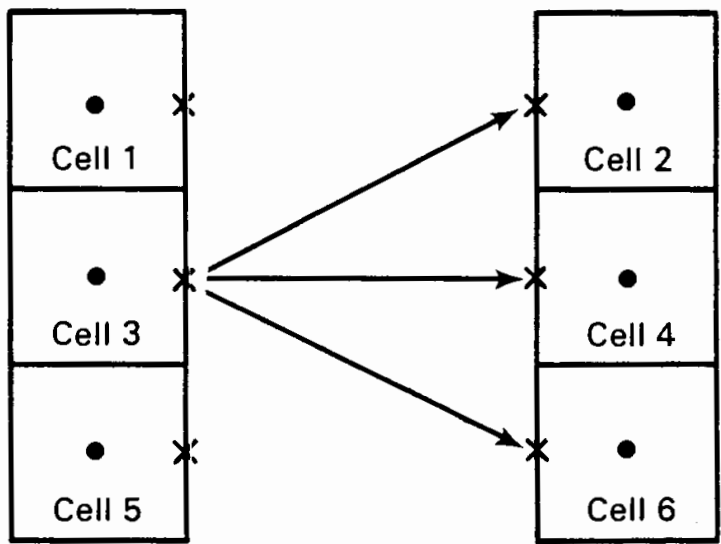

b. Enclosure Mode 1

FIGURE 3.1. Gap Radiation Approximation Compared to Enclosure Radiation Model

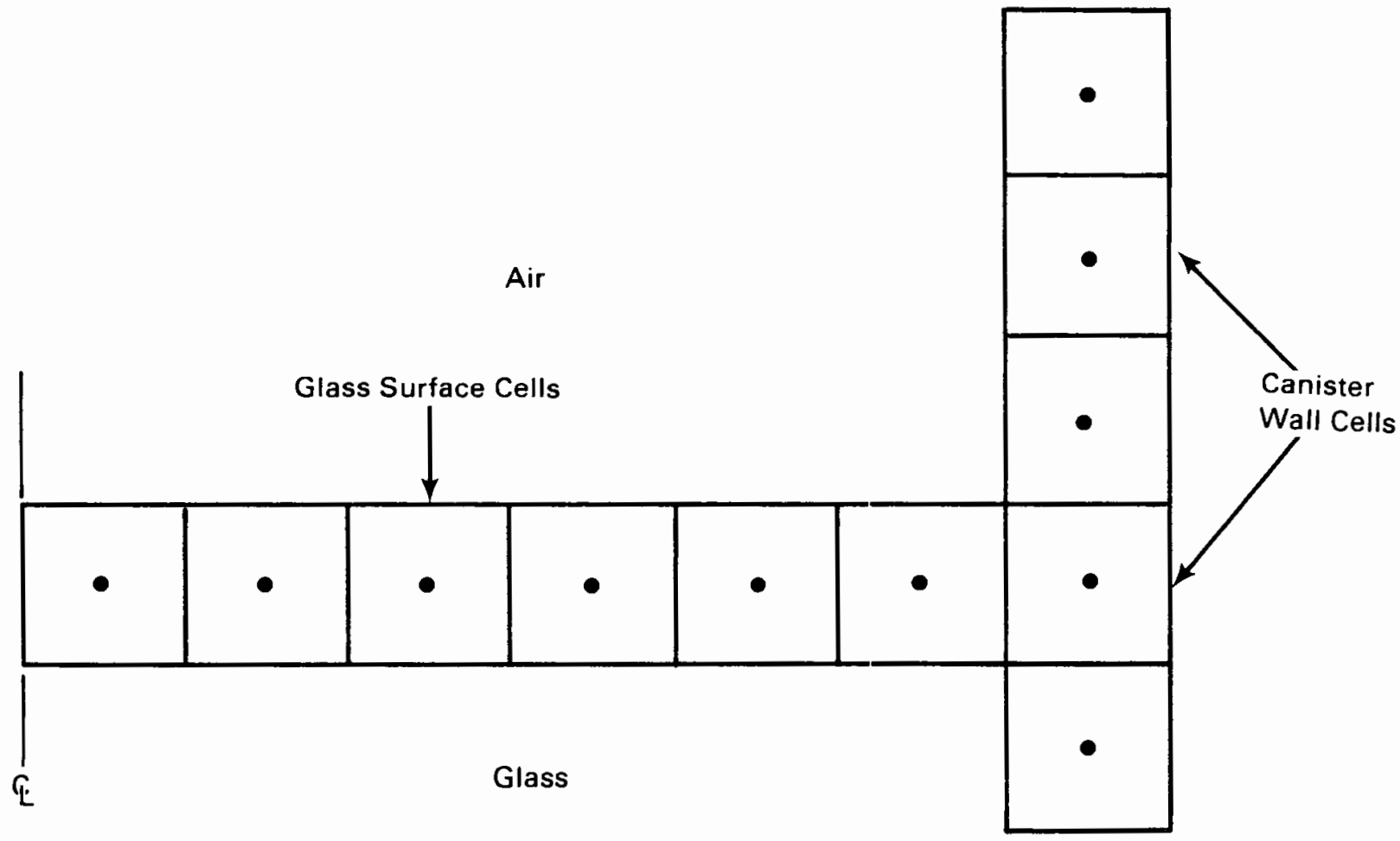

FIGURE 3.2. Geometry for Radiation from Glass Surface Cells to Canister Wall Cells 
These temperatures were used to calculate the thermal energy leaving the glass surface. The canister wall temperature was evaluated in two ways, designated $H I$ and LO.

For the HI model, the average canister wall temperature was taken to be the temperature of the canister wall cell at the same height as the glass surface. Because the canister surface above the glass is cooler than the canister surface at the glass contact, this approximation probably overestimates the average canister temperature, which underestimates the radiant loss from the glass surface.

For the L0 model, the average canister temperature was assumed to be the arithmetic average between the canister wall temperature at the glass surface level and the canister wall temperature at the top of the canister. This should generally underestimate the average canister temperature and, thus, overestimate the heat loss from the glass surfaces.

For both models, the calculated radiant energy lost from the glass surface cells was subtracted from those cells, but not added elsewhere. Stability reasons precluded adding that energy to the canister walls. It was thought that the HI and LO models would bracket the experimental results.

A more exact treatment of thermal radiation is needed. The gap radiation model of the $L 4$ version is not adequate, and the crude approximation installed in the interim $M$ version, although qualitatively correct, should be made more exact and flexible.

\subsubsection{Transient Duration}

The original TEMPEST Version $L 4$ is best able to handle transients that are "fast," on the order of seconds. Because of the explicit nature of the numerical algorithm for momentum convection, relatively small time steps are required if fluid flow is to be simulated. However, the canister filling and cooldown transients are much slower, lasting several hours. This period is caused by the long pour time and the large thermal inertia of the glass and canister combination. Furthermore, the allowable time-step size for the glass pouring problem is much smaller than it would be if a different fluid (e.g., water, sodium, or air) were being used. This difference is due to the inverse 
relationship between time-step size and fluid viscosity typical of any explicit convection scheme (Roache 1976). Therefore, Version L4 is not suited for modeling glass flow where the flow field needs to be calculated. On the other hand, the heat transfer solution in TEMPEST is implicit, and heat-transfer-only simulations can be calculated efficiently by using large time steps.

\subsubsection{Geometries}

Currently, TEMPEST is able to handle either cartesian or cylindrical geometries. It is not able to handle mixed geometries (a problem where some regions are cartesian and some regions are cylindrical) or nonconcentric cylindrical geometries.

Nonconcentric cylindrical geometries are of interest to the glass-pouring and cooldown problem because of the geometry of most melter turntables, where the canisters are rotated from underneath the melter and allowed to cool. A top view of the canisters in a typical turntable arrangement is shown in Figure 3.3. The capability to model this arrangernent is called a multiple-grid or body-fitted coordinate system. The L4 version of TEMPEST has neither capability.

\subsubsection{Grid Boundaries (Glass/Air Interface)}

The glass-pouring problem requires that the moving boundary of the glass surface be tracked as it rises in the canister. During the pour, hot glass streams down the middle of the canister and impacts the surface of the glass. From there it both spreads along the surface and penetrates the molten glass below the surface. The degree to which the glass penetrates or spreads along the surface is controlled by the initial momentum of the glass stream and the local viscosity, which is highly temperature-dependent. Below the glass surface, molten glass convects and slowly congeals. Above the glass surface, air convects heat away from the glass and canister and out the top.

During the pour, the actual glass surface moves, resulting in a moving boundary problem. To handle a range of glass-pouring problems, a code would need to handle an arbitrary pour scenario that includes stopping and starting. TEMPEST does have a flexible time-dependent table feature (user-supplied at input), but not a moving boundary capability. 


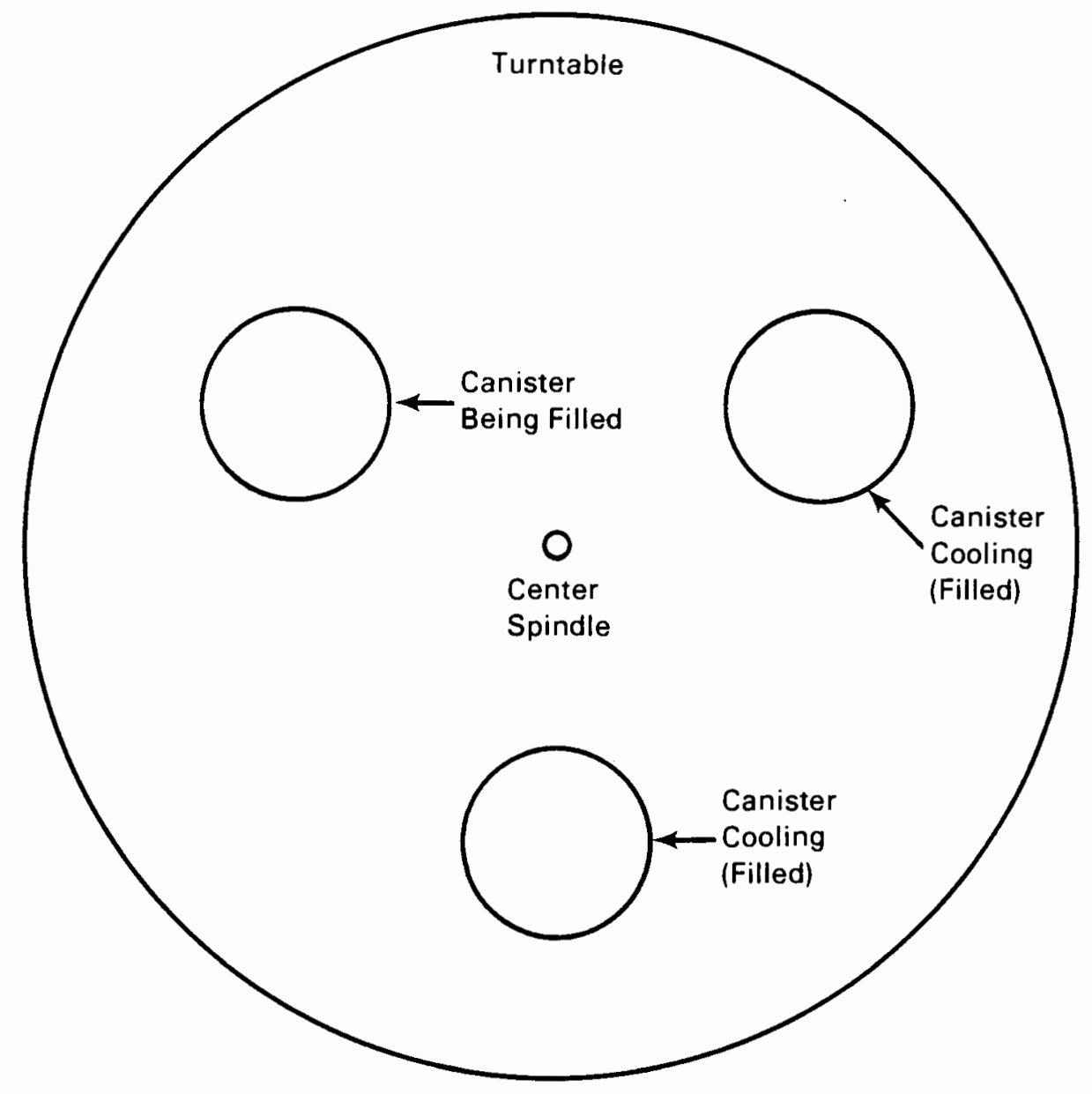

FIGURE 3.3. Canister and Turntable Arrangement

\subsection{CODE VERSIONS}

TEMPEST is a living code. The released version, designated L4, is available from the National Energy Software Center, Argonne, Illinois. In addition, several advanced versions are available at PNL for various research problems. These advanced versions are constantly undergoing change as new problems arise that need analysis, but which are not immediately amenable to solution by TEMPEST.

Version $L 4$ of the code was not powerful enough to adequately analyze the glass-pouring and cooldown problem. An experimental version, L4X, was created 
to add the LO and $\mathrm{HI}$ radiation capability described in Section 3.2.1. However, glass convection and a moving boundary capability were not available with the L4X version.

To add glass convection and the moving boundary capability, another version was created, designated $M$. This version incorporated the $L O$ and $H I$ radiation capability of $L 4 X$, but in a very restrictive, nongeneral way. Version $M$ was created quickly, to assess the increase in accuracy that could be obtained by simulating convecting glass and the moving glass/air interface. This TEMPEST version crudely tracked the glass interface, but allowed no convection of air above the glass surface. It was designed to handle both batch- and continuous-fill scenarios.

The results of the simulations with Versions $L 4 X$ and $M$, coupled with the importance of accurate glass thermal history predictions, led to initial development of a better version that would address all of the problems discussed in Section 3.2. This version is currently designated N29. Version N29 is still under development and was not used to rerun the predictions.

Version $L 4 X$ of the code was used exclusively for the batch-fill scenarios. Version $M$ was used for canisters modeled with a continuous (time-varying) pour. The turntable simulant, in which a canister was irisulated asymmetrically around its circumference to simulate the nonconcentric geometry of a turntable, was also run with version L4X. 


\subsection{EXPERIMENTAL DATA COLLECTION}

The data against which TEMPEST-generated predictions were compared were collected during two experiments with the pilot-scale ceramic melter (PSCM) at PNL. The melter, described in Chikalla and Powell (1982), is a source of molten, nonradioactive glass at about $1150^{\circ} \mathrm{C}$. This chapter provides a description of the equipment and methodology used to generate the data.

\subsection{CANISTER DESCRIPTION}

Five canisters of three different designs were used in the two PSCM experiments. The canister design features are compared in Table 4.1. Three canisters had 12-in. nominal diameters; the other two were $13 \mathrm{in.}$ and $24 \mathrm{in}$. in diameter. All canisters were made of $304 \mathrm{~L}$ stainless steel. Canister height varied from $45.4 \mathrm{in}$. to $85.4 \mathrm{in.}$. The bottoms of the 12-in.-diameter canisters were flat except for a 0.5-in. lip and a 3.5-in.-diameter by 1.6-in.-high cylindrical bulge in their centers (see Figure 4.1). The bottom of the 13-in.-diameter canister was slightly rounded and supported by four bars located at $90^{\circ}$ intervals beneath the canister. The 24-in.-diameter canister's bottom was dished up $1.06 \mathrm{in}$. in the center, in a reversed flange design. The radial variation of this design is shown in Table 4.2 .

The inside surfaces of the 13-in.-diameter canister were lined with 1/8-in.-thick Fiberfrax(a) paper and a graphite mold release compound. Half of the bottom and a $180^{\circ}$ arc of the side were lined with Fiberfrax; the remainder of the canister was coated with graphite mold release agent. This was done to compare the effects of Fiberfrax, which minimizes both shear and compressive stresses, to the mold release compound, which reduces only the shear stresses at the wall. This canister was insulated with the same total amount of combined internal and external insulation in both the graphite and the Fiberfrax sides, to keep radial temperature differences the same for both the

(a) Fiberfrax is a ceramic paper manufactured by Carborundum Resistant Materials Co., Insulation Division, Niagara Falls, New York. 
TABLE 4.1. Canister Information

\begin{tabular}{|c|c|c|c|c|c|}
\hline \multirow[b]{2}{*}{ Design Features } & \multicolumn{5}{|c|}{ Cianister } \\
\hline & $12 \mathrm{LI}$ & $12 \mathrm{HI}$ & 12TTS & 13 & 24 \\
\hline PSCM run & 20 & 20 & 20 & 21 & 21 \\
\hline Height, in. & 45.4 & 45.4 & 45.4 & 56.0 & 85.0 \\
\hline Outside diameter, in. & 11.75 & 11.75 & 11.75 & 12.75 & 24.0 \\
\hline Inside diameter, in. & 11.12 & 11.12 & 11.12 & 12.25 & 23.5 \\
\hline Wall thickness, in. & 0.31 & 0.31 & 0.31 & 0.25 & 0.25 \\
\hline Liner & & & & & \\
\hline Material & $\mathrm{FF}(\mathrm{a})$ & $\mathrm{FF}$ & $\mathrm{FF}$ & $F F \& g r^{(b)}$ & $\begin{array}{l}\text { Dura }{ }^{(c)} \\
\& F F\end{array}$ \\
\hline Thickness, in. & $1 / 8$ & $1 / 8$ & $1 / 8$ & $1 / 8^{(b)}$ & $\begin{array}{l}1 / 4 \text { sides } \\
1 / 2 \text { bot }\end{array}$ \\
\hline External insulation & & & & & \\
\hline Material & Dura & Dura & Dura & $\begin{array}{l}\text { Dura \& } \\
\text { FF(d) }\end{array}$ & None \\
\hline Thickness, in. & $1 / 4$ & 3 & -- & $\begin{array}{l}1 / 4 \& \\
3 / 8(d)\end{array}$ & -- \\
\hline Bottom design & bulge & bulge & bulge & rounded & dished \\
\hline
\end{tabular}

(a) Fiberfrax ceramic paper type $970 \mathrm{~J}$ (12 1b/cu. ft. density).

(b) A $180^{\circ}$ arc and half of the bottom of this canister were lined with $1 / 8 \mathrm{in}$. of Fiberfrax; the remainder of the canister was coated with a graphite. mold release compound (Dylon Grade AE Mold Release Agent, Dylon Industries).

(c) Durablanket (8 1b/cu. ft. density).

(d) A $180^{\circ}$ arc and half of the canister bottom were externally insulated with $1 / 8$ in. of Fiberfrax and $1 / 4$ in. of Durablanket (graphite side, see (b)); the remainder of the canister was externally insulated with only $1 / 4 \mathrm{in}$. of Durablanket.

graphite- and Fiberfrax-lined regions. Thus, in addition to the $1 / 4 \mathrm{in}$. of Durablanket ${ }^{(a)}$ placed over the entire surface, $1 / \varepsilon \mathrm{in}$. of Fiberfrax paper was used on the outside of the graphite-coated region. The other canisters were covered with 0 in. to 3 in. of Durablanket insulation (Table 4.1).

(a) Durablanket is a ceramic fiber blanket. It is manufactured by Carbonumdum Resistant Materials Co., Insulation Division. 


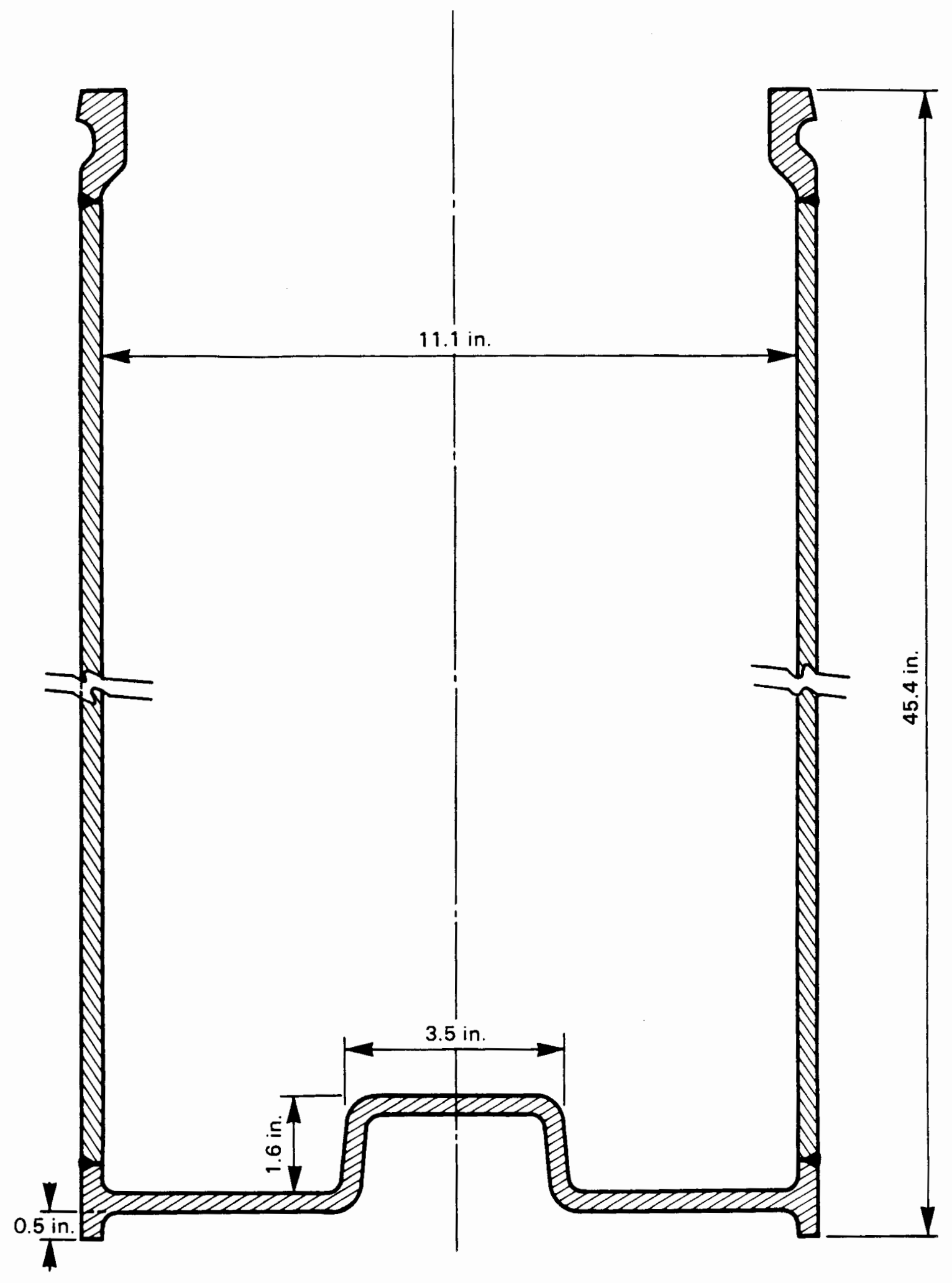

FIGURE 4.1. Cross Section of 12-in.-Diameter Canisters

$$
4.3
$$


TABLE 4.2. Measured Distances from the Bottom of the Reverse Flanged 24-in.-Diameter Canister

\begin{tabular}{cc}
$\begin{array}{c}\text { Distance from } \\
\text { Center, in. }\end{array}$ & $\begin{array}{c}\text { Distance Above } \\
\text { Outside Edge, in. }\end{array}$ \\
\hline 0 & 1.06 \\
1.5 & 0.89 \\
3.0 & 0.63 \\
4.5 & 0.50 \\
6.0 & 0.38 \\
7.5 & 0.25 \\
9.0 & 0.13 \\
10.5 & 0.06
\end{tabular}

The filling arrangement used for the 13-in.-diameter canister is shown in Figure 4.2. The PSCM-to-canister adapter was inserted about 6 in. into the canister. An air seal to prevent unwanted air from entering the PSCM was formed by inserting a 4-in.-wide strip of Durablanket into the annulus. This type of seal was used in an attempt to minimize vertical forces between the adapter and the canister; this allowed for accurate weight readings to be obtained by the load cell.

The arrangement shown in Figure 4.2 is identical to that used for two of the three 12-in.-diameter canisters (12LI and 12HI--see Table 4.1), except that the PSCM-to-canister adapter was placed about 2 in. above the canister. An air seal was formed by wrapping Durablanket around the upper portion of the canister and the lower portion of the adaptor and securing it with a roll of sheet metal held in place by hose clamps.

\subsection{TURNTABLE SIMULANT}

The radioactive liquid-fed ceramic melter (RLFCM) at PNL is equipped with a turntable that can hold up to three canisters at one time. A computer model is needed to compute the heat transfer within such turntables. To determine the ability of the TEMPEST code to compute the heat transfer within nonconcentric, multi-barrier geometries, the third 12-in. canister (canister 12TTS--see Table 4.1) was filled while within a turntable sirulant (TTS). The purpose of 


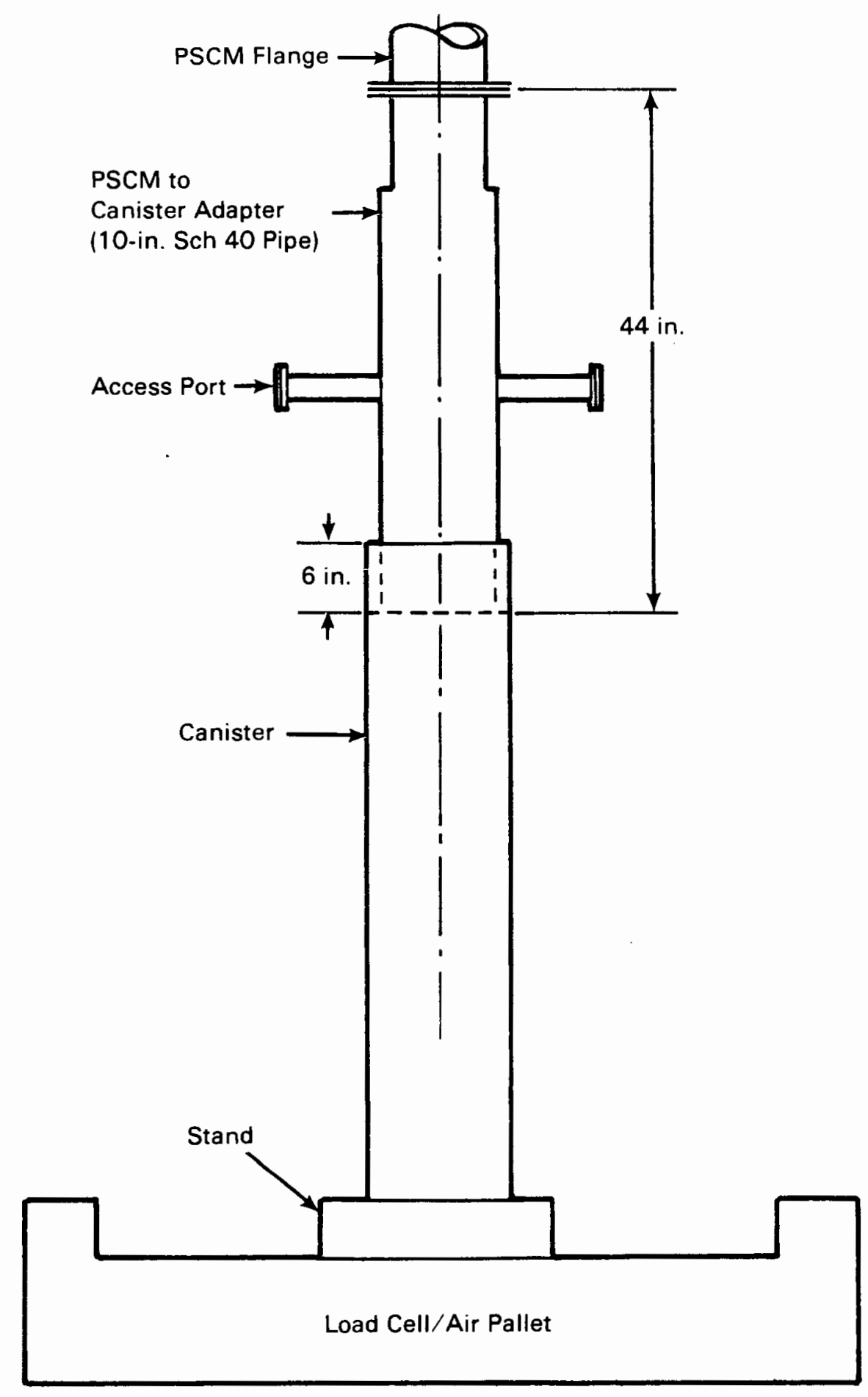

FIGURE 4.2. Canister Placement Under Melter for 13-in.-Diameter Canister 
the TTS was to mimic, although not duplicate, the heat transfer resistances found in the RLFCM turntable at PNL. The TTS consisted of three concentric shells located off-center in a 46.5-in.-diameter shell (Figure 4.3). In order of increasing distance from the canister, these shells are referred to as the overpack, the liner, the thimble, and the turntable. The shells have outside diameters of $14 \mathrm{in.,} 18 \mathrm{in.,} 24 \mathrm{in}$., and $46 \mathrm{in.,}$ respectively. All shell surfaces within the thimble were concentric; however, the thimble shell was positioned off-center in the turntable shell such that its point of closest approach to the turntable was 1 in.

The tops of the thimble and liner were $1.5 \mathrm{in}$. below the top of the TTS she11. The tops of the canister and the overpack were 5.25 in. below the top of the liner. The canister was held 1 in. above the bottom of the overpack by crossbars. Concentricity of the canister in the overpack was ensured by four 1-in. bars, located at $90^{\circ}$ intervals, that ran vertically the length of the canister. These vertical bars limited air flow between the quadrants formed by the bars.

The overpack was also held within the liner by crossbars that permitted essentially free flow of air between the large cavity under the overpack and the annulus around the canister. Approximately 2 in. of Durablanket were placed at the top between the liner and the thimble, to prevent air flow from this annulus to the remainder of the TTS.

The 24-in.-diameter canister was also filled while in the TTS, to permit a measure of the amount of material volatilized from the glass. However, all inside apparatus, i.e., the overpack, liner, and thimble, were removed, and the canister was placed at the center of the 46-in.-diameter shell.

The lid of the TTS was bolted to the PSCM flange. A water seal was used to minimize vertical forces between the TTS lid and the remainder of the TTS. The TTS, in turn, rested upon a load cell; the weight of the glass that was added was determined by the indicated changes in weight. 


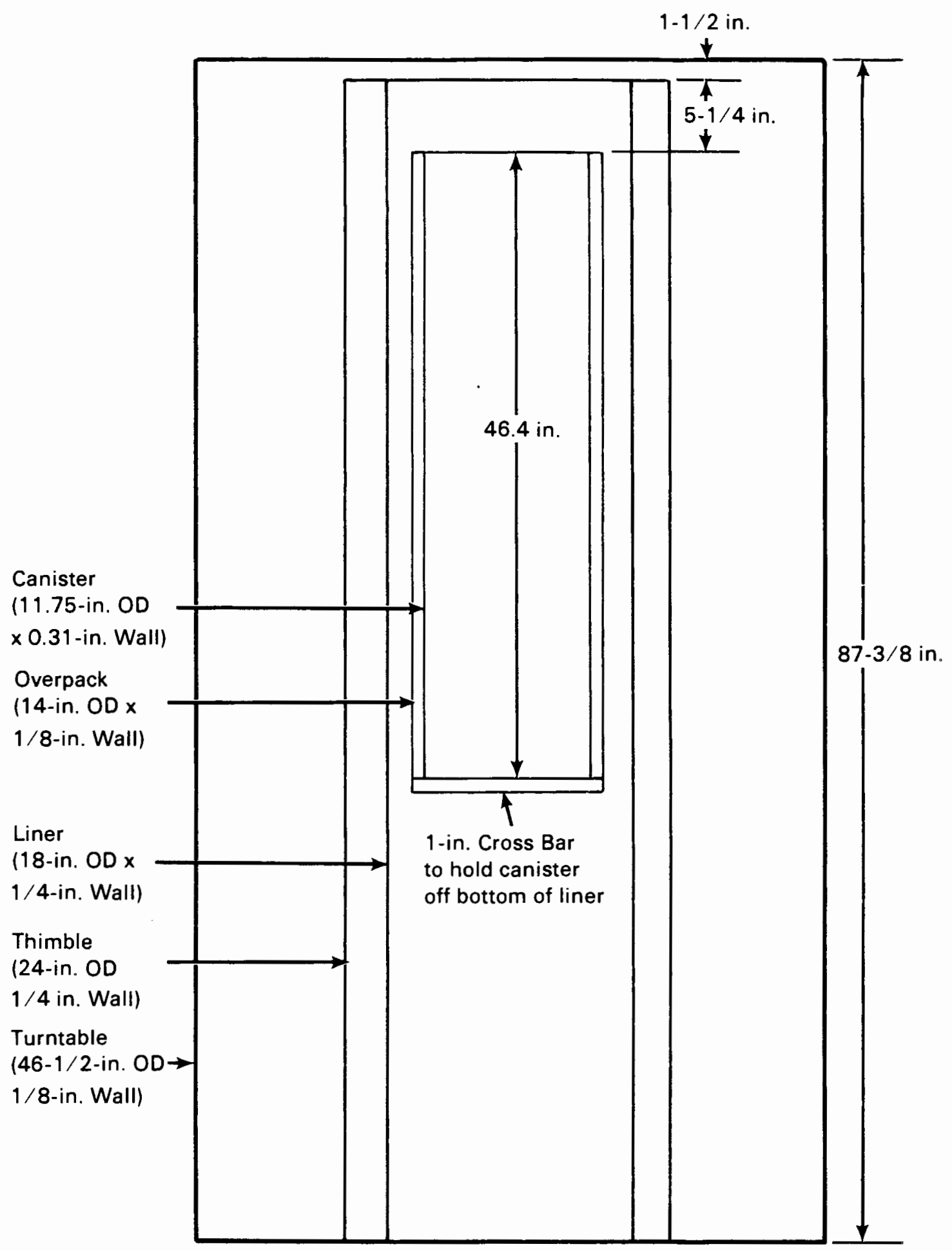

FIGURE 4.3. Turntable Simulant Model Configuration 


\subsection{THERMOCOUPLE LOCATIONS}

Stainless-steel sheathed type $K$ thermocouples, $1 / 16$ in. and $1 / 8$ in. in diameter, were used to measure canister temperatures, glass temperatures and temperatures within the TTS. The thermocouple outputs were fed into a datalogger and recorded on paper and magnetic tape. The data were manipulated by digital computers.

Calibration checks at $300^{\circ} \mathrm{C}, 600^{\circ} \mathrm{C}$, and $900^{\circ} \mathrm{C}$ on a representative sample $(57 \%)$ of the thermocouples gave a maximum error of $7^{\circ} \mathrm{C}$. Computations made with the TEMPEST code also yielded thermocouple conduction errors ranging from $-0.8^{\circ} \mathrm{C}$ to $-22.7^{\circ} \mathrm{C}$ (see Tables 4.3 and 4.4 ). These errors depended upon glass temperature, thermocouple diameter, and depth of immersion.

Thermocouples were placed on the outside surfaces of all five canisters. These externally-mounted thermocouples were placed in contact for 4 in. horizontally along the wall and were coated with $1 / 8$ in. of Ceramobond 571 (a) cement to improve the thermal contact between the thermocouple junction and the wall of the canister. In addition, thermocouples were located within all but canister 12TTS. The thermocouple locations in the canister glass were selected to give data on the radial temperature distributions within the canister; thermocouples were located at vertical positions to give information on thermal conditions as a function of distance from the glass/air interfaces.

Figures 4.4 and 4.5 give the 30 thermocouple locations for canisters $12 \mathrm{LI}$ and $12 \mathrm{HI}$. As shown, one thermocouple was located $5 \mathrm{in}$. from the edge on the bottom of each canister; additional internal thermocouples were emplaced at eight axial locations. Internal thermocouples placed 1, 2, and 4-1/4 in. from the inside wall were located at all levels per Figure 4.5, except for level 7 , which had only a 4-1/4-in. thermocouple.

Thermocouples were not placed in the center of the canisters, to minimize interactions with the glass stream. Nevertheless, radial migrations during glass pouring caused by a deteriorated pour tip resulted in some glass

(a) Ceramobond is a ceramic cementing agent manufactured by Aremco Products, Ossining, New York. 
TABLE 4.3. TEMPEST-Determined Thermocouple Conduction Factors for Canisters with 1/4-in. Durablanket Insulation

\begin{tabular}{cccccc}
$\begin{array}{c}\text { Thermocouple } \\
\text { Diameter, } \\
\text { in. }\end{array}$ & $\begin{array}{c}\text { Thermocouple } \\
\text { Distance from } \\
\text { Canister Inside } \\
\text { Wall, in. }\end{array}$ & & \multicolumn{2}{c}{$\begin{array}{c}\text { Conduction Error at } \\
\text { Temperature Within TTS, }{ }^{\circ} \mathrm{C}\end{array}$} \\
\cline { 1 - 2 } $1 / 16$ & 1 & $\frac{-4.1(\mathrm{a})}{300^{\circ} \mathrm{C}}$ & $\frac{600^{\circ} \mathrm{C}}{-6.3}$ & $\frac{1100^{\circ} \mathrm{C}}{-19.8}$ \\
$1 / 8$ & 2 & & -5.4 & -8.1 & -22.7 \\
$1 / 8$ & 4.25 & -4.0 & -7.3 & -11.0
\end{tabular}

(a) A negative sign signifies that the thermocouple is giving a low value.

TABLE 4.4. TEMPEST Determined Thermocouple Conduction Factors for Canisters with 3-in. Durablanket Insulation

\begin{tabular}{ccccc}
$\begin{array}{c}\text { Thermocouple } \\
\text { Diameter, } \\
\text { in. }\end{array}$ & $\begin{array}{c}\text { Thermocouple } \\
\text { Distance from } \\
\text { Canister Inside } \\
\text { Wall, in. }\end{array}$ & & \multicolumn{2}{c}{$\begin{array}{c}\text { Conduction Error at } \\
\text { Temperature Within TTS, }{ }^{\circ} \mathrm{C}\end{array}$} \\
\cline { 2 - 3 } $1 / 16$ & 1 & $\frac{-0.9(\mathrm{a})}{300^{\circ} \mathrm{C}}$ & $\frac{600^{\circ} \mathrm{C}}{-1.6}$ & $\frac{1100^{\circ} \mathrm{C}}{-5.0}$ \\
$1 / 8$ & 2 & -1.2 & -2.3 & -5.0 \\
$1 / 8$ & 4.25 & -0.8 & -1.9 & -3.0
\end{tabular}

(a) A negative sign signifies that the thermocouple is giving a low value.

splattering on the thermocouples located 2 in. and 4-1/4 in. from the canister wall. However, the diameter and support structure for thermocouples (see Figure 4.5) were selected so that the thermocouples could remain their positions in the canister.

The 30 thermocouple locations for the 13-in.-diameter canister are given in Table 4.5. Six levels were used; five thermocouples were located at each level as follows:

- on the outside surface of the canister (1/16-in. diameter)

- on the inside surface of the Fiberfrax liner (1/16-in. diameter)

- 1 in. from the canister inside wall (1/16-in. diameter) 


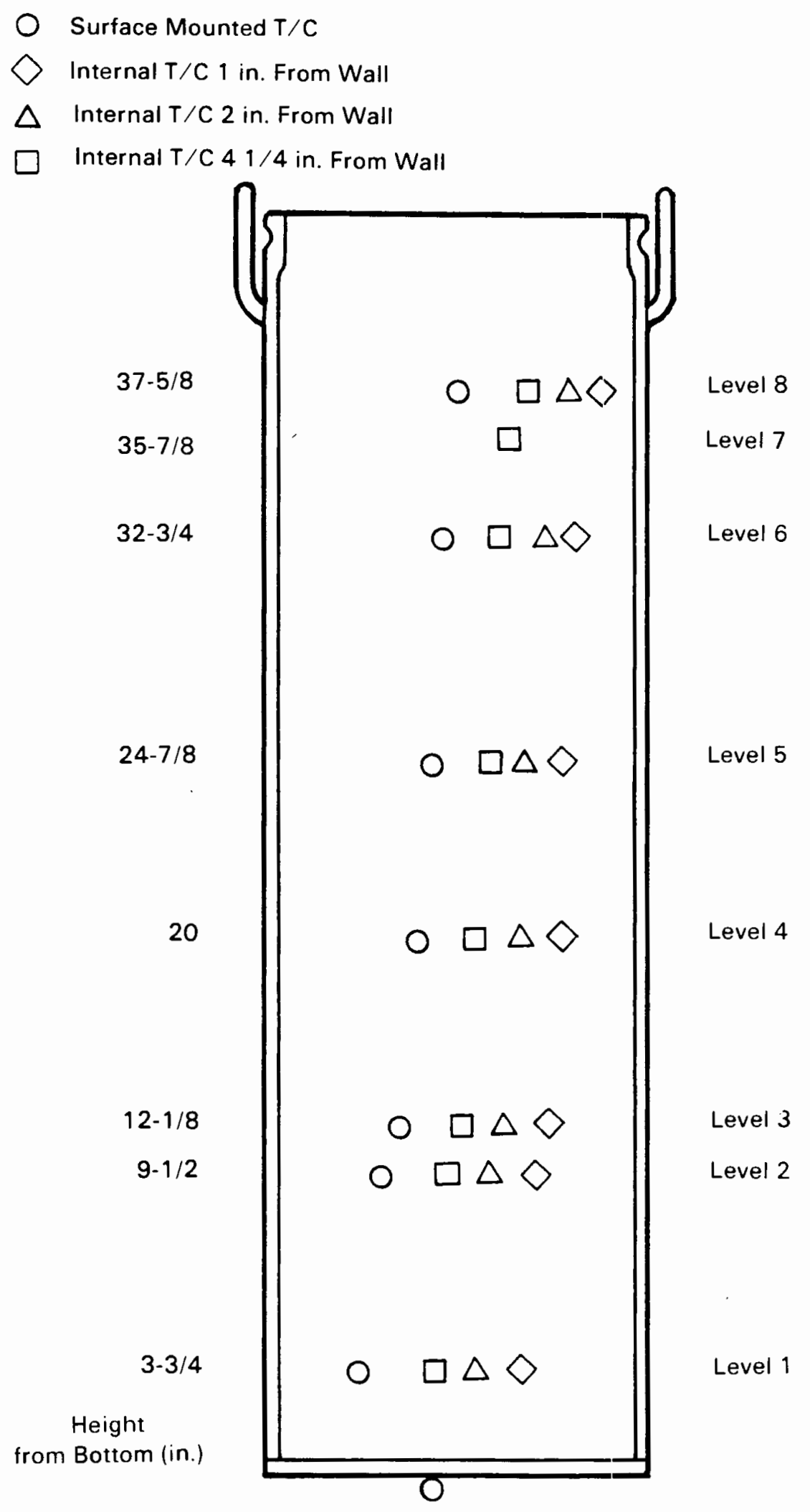

FIGURE 4.4. Thermocouple Locations for Canisters $12 \mathrm{LI}$ and $12 \mathrm{HI}$ 


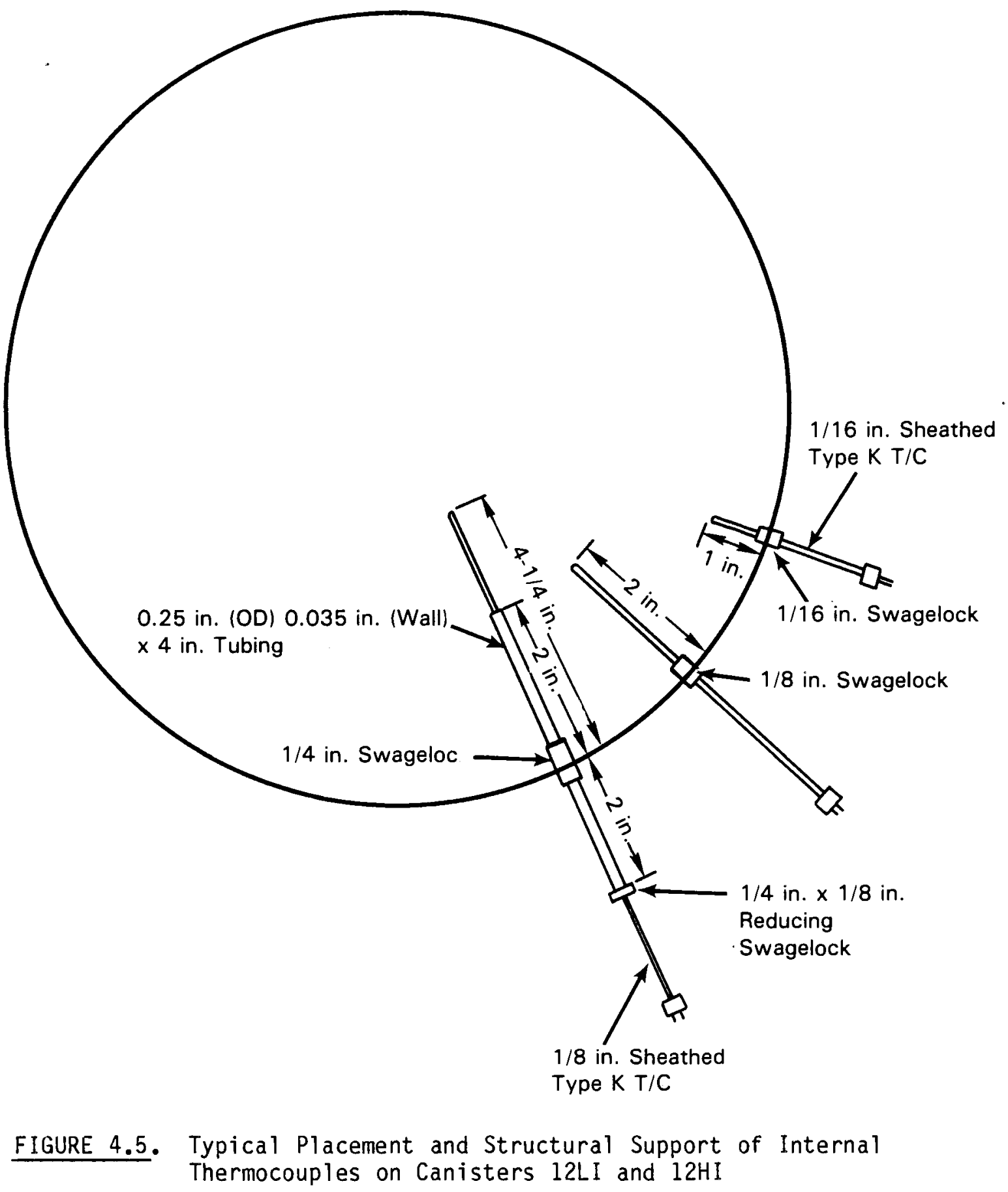


TABLE 4.5. Axial Thermocouple Locations for the 13-in.-Diameter Canister

\begin{tabular}{cc} 
Level & $\begin{array}{c}\text { Distance from } \\
\text { Outside Bottom of } \\
\text { Canister, in. }\end{array}$ \\
\hline 1 & 3.5 \\
2 & 13.3 \\
3 & 21.2 \\
4 & 26.1 \\
5 & 34.0 \\
6 & 38.4
\end{tabular}

TABLE 4.6. Axial Thermocouple Locations for the 24-in.-Diameter Canister

\begin{tabular}{cc} 
Level & $\begin{array}{c}\text { Distance from } \\
\text { Outside Bottoin of } \\
\text { Canister, in. }\end{array}$ \\
\cline { 2 - 2 } 1 & 2.25 \\
2 & 5.25 \\
3 & 14.25 \\
4 & 21.75 \\
5 & 29.25 \\
6 & 36.75 \\
7 & 44.25 \\
8 & 53.25 \\
9 & 62.25 \\
10 & 65.25
\end{tabular}

- 2 in. from the canister inside wall (1/8-in. diameter)

- 4-1/4 in. from the canister inside wall (1/8-in. diameter).

The thermocouple locations for the 24-in.-diameter canister are given in Table 4.6. Five thermocouples were located at each of ten levels. The thermocouple locations were: 
- on the outside surface of the canister (1/16-in. diameter)

- on the inside surface of the 1/4-in.-thick Fiberfrax Iiner (1/16-in. diameter)

- $2.5 \mathrm{in.}$ from the canister inside wall (1/16-in. diameter)

- 5 in. from the canister inside wall (1/8-in. diameter)

- 10 in. from the canister inside wall (1/8-in. diameter).

The innermost three thermocouples were supported similarly to those shown in Figure 4.5 , except that:

- The 2.5-in. thermocouples were supported by a 1/8-in.-diameter tube extending 2 in. from the wall.

- The 5-in. thermocouples were supported by a 1/4-in.-diameter tube extending $2.5 \mathrm{in}$. from the wall.

- The 10-in. thermocouples were supported by a 1/4-in.-diameter tube extending 8 in. from the wall.

The primary purpose of the experiment in which canister 12TTS was filled while in the TTS was to determine the heat transfer behavior external to the canister. Because of this, and because of the space limitations arising from the small clearance involved, thermocouples were not placed inside this canister. Instead, details on the three-dimensional surface temperature profiles in the TTS were emphasized. Thermocouples were placed at 3 circumferential and 20 axial locations on the canister. The circumferential locations corresponded to the side closest to the outer TTS wall, farthest from the outer TTS wall, and midway $\left(90^{\circ}\right)$ between these two radial positions. Additional thermocouples were placed 1) at adjacent radial and axial locations on the overpack, liner, thimble, and turntable walls at the above-mentioned 20 levels, and 2) at additional axial levels above and below the canister.

\subsection{CANISTER FILLING METHODS}

Two methods were used to fill the canisters with molten glass: continuous filling and batch filling. Batch filling is necessary when the glass production rate from the melter is too slow to adequately fill a canister 
continuously. If the fill rate is too slow, voids may be formed because the glass cools too quickly to flow to the outside edge of the canister. Also, the glass may pillar in the canister, necessitating canister removal before filling is complete. The three 12-in.-diameter canisters from the PSCM-20 experiment were filled in three batch pours of about $53 \mathrm{~kg}$ each; the 24-in.-diameter canister used in the PSCM-21 experiment was filled in 33 batches ranging from about $10 \mathrm{~kg}$ to $60 \mathrm{~kg}$ each, as part of a study of the effect of batch size on product quality, e.g., cracking and voids. The 1.3-in.-diameter canister from PSCM-21 was filled continuously at a nominal rate of $0.8 \mathrm{~kg} / \mathrm{min}$, for a total glass mass of $207 \mathrm{~kg}$ over $260 \mathrm{~min}$.

\subsection{GLASS MEASUREMENTS}

Information required for TEMPEST validation included the amount of glass and the location of the glass surface after each glass pour. Three methods were used to obtain this information:

- weight measurements

- direct measurements of the surface by lowering a weight (sinker) to the surface

- observation of thermocouple response, to infer when surface coverage occurred.

Interactions between the canister and the PSCM-to-canister adapter significantly reduced the usefulness of the weight measurements. In addition, procedural difficulties resulted in some loss of glass height data taken by use of the sinker. Thermocouple response, combined with sinker measurements, proved to be most useful in determining glass height during the filling sequence.

The glass surface in the canister is not perfectly flat, either during filling or after cooling. It is not uncommon for a cold filled and cooled canister to develop a sinkhole up to a few inches in diameter and depth at the center of the surface. In addition, glass beads and cylinders of perhaps $1 / 2 \mathrm{in}$. in diameter may be found on the surface. These are formed when the glass pour stream is nearly finished and has therefore cooled significantly. 
Significant irregularities in the hot surface as the glass pours onto it have been observed during other PSCM experiments. One such irregularity is lobing, where the glass moves out from the center in lobes, first covering one sector, then another. These irregularities are minimized at the nominal $2-\mathrm{kg} / \mathrm{min}$ pour rates used during batch pours, but could be significant at the $0.8-\mathrm{kg} / \mathrm{min}$ average pour rate for the 13-in.-diameter canister.

A reasonable value for accuracy of the measured glass heights is about $1 \mathrm{in}$. during the pours and about $1 / 2 \mathrm{in}$. for the final height, because the latter could be checked after the canister had cooled. Times of coverage are probably accurate to $6 \mathrm{~min}$ or better.

The glass heights as a function of elapsed time from start of fill for canisters 12LI, 12HI, and the 13-in.-diameter canister are given in Tables 4.7, 4.8 , and 4.9 , respectively. The long time between the first and second pours of canister $12 \mathrm{HI}$ resulted from a melter experiment in which the pour was interrupted for a day to simulate an LFCM process upset. The data for for 24-in.-diameter canister are presented in a somewhat different format in Table 4.10 because the TEMPEST simulation treated this case as a continuous fill of varying filling rate, even though this canister was batch-filled. This approach significantly reduced the input modeling effort.

\section{TABLE 4.7. Glass Height for Canister 12L I}

\begin{tabular}{|c|c|c|c|c|}
\hline Pour & Number & $\frac{\text { Elapsed }}{\text { Start }}$ & $\frac{\text { Time, min }}{\text { Finish }}$ & $\begin{array}{c}\text { Final Glass Height } \\
\text { Measured from Outside } \\
\text { Bottom of Canister, in. }\end{array}$ \\
\hline & 1 & 0 & 23 & 12.9 \\
\hline & 2 & 304 & 360 & 25.7 \\
\hline & 3 & 714 & 763 & 39.5 \\
\hline
\end{tabular}


TABLE 4.8. Glass Height for Canister 12H I

\begin{tabular}{|c|c|c|c|c|}
\hline Pour & Number & $\frac{\text { Elapsed }}{\text { Start }}$ & $\frac{\text { Time, min }}{\text { Finish }}$ & $\begin{array}{l}\text { Final Glass Height } \\
\text { Measured from Outside } \\
\text { Bottom of Canister, in. }\end{array}$ \\
\hline & 1 & 0 & 27 & 13.1 \\
\hline & 2 & 1758 & 1797 & 27.0 \\
\hline & 3 & 2037 & 2089 & 38.5 \\
\hline
\end{tabular}

TABLE 4.9. Glass Height for the 13-in.-Diameter Canister

Final Glass Height

\begin{tabular}{cc} 
Elapsed Time, min & $\begin{array}{c}\text { Measured from Outside } \\
\text { Bottom of Canister, in. }\end{array}$ \\
\cline { 2 - 2 } 26 & 3.5 \\
86 & 13.3 \\
155 & 21.2 \\
170 & 26.1 \\
224 & 34.0 \\
254 & 38.4 \\
263 & 40.1
\end{tabular}


TABLE 4.10. Glass Height for the 24-in. Diameter Canister

\begin{tabular}{|c|c|c|c|}
\hline Pour Number & $\frac{\text { Elapsed }}{\text { Start }}$ & $\frac{\text { Time, min }}{\text { Finish }}$ & $\begin{array}{l}\text { Final Glass Height } \\
\text { Measured from Outside } \\
\text { Bottom of Canister, in. }\end{array}$ \\
\hline 1 & 0 & 24 & 4.3 \\
\hline 2 & 365 & 393 & 6.2 \\
\hline 3 & 1314 & 1345 & 10.6 \\
\hline 4 & 1539 & 1551 & 12.1 \\
\hline 5 & 1649 & 1663 & 13.5 \\
\hline 6 & 1788 & 1798 & 15.3 \\
\hline 7 & 1942 & 1949 & 16.6 \\
\hline 8 & 2034 & 2052 & 17.7 \\
\hline 9 & 2177 & 2196 & 19.2 \\
\hline 10 & 2286 & 2333 & 22.2 \\
\hline 11 & 2886 & 2929 & 26.5 \\
\hline 12 & 3261 & 3270 & 27.4 \\
\hline 13 & 3360 & 3368 & 28.5 \\
\hline 14 & 3492 & 3501 & 30.5 \\
\hline 15 & 3745 & 3761 & 33.1 \\
\hline 16 & 3951 & 3960 & 34.3 \\
\hline 17 & 4026 & 4034 & 35.4 \\
\hline 18 & 4167 & 4174 & 36.3 \\
\hline 19 & 3645 & 3661 & 36.9 \\
\hline 20 & 3851 & 3860 & 38.1 \\
\hline 21 & 3926 & 3934 & 39.3 \\
\hline 22 & 4067 & 4074 & 41.3 \\
\hline 23 & 4160 & 4168 & 42.9 \\
\hline 24 & 4292 & 4300 & 45.5 \\
\hline
\end{tabular}


* 


\subsection{TEMPEST INPUT MODELS AND ASSUMPTIONS}

This chapter begins with a discussion of the considerations taken into account in developing the TEMPEST input models for this study. Next, each of the models developed to predict and compare results is described. Last, the most important assumptions underlying each model's development are discussed.

\subsection{MODEL DEVELOPMENT CONS IDERATIONS}

Five different glass pouring and filling scenarios were simulated: the 12LI and 12HI canisters, the 13-in. and 24-in.-diameter canisters, and the 12-in.-diameter TTS canister. The 12LI and 12HI models were batch-pour cases, while the 13-in.-diameter canister model simulated a continuous pour. The 24-in.-diameter canister was filled in 33 separate batch pours, which were modeled with the continuous-fill version of TEMPEST (Version M). The TTS canister was subjected to a batch-pour scenario.

The number of cells used to model a given canister depends primarily on whether the canister is to be modeled with the batch-fill model (Version L4X) or the continuous-fill model (Version M) of TEMPEST. The continuous-fill model required uniform axial cells and allowed only 10 cells in the radial direction for the glass-filling region. The batch-fill model had no restrictions on the number and dimensions of the radial and axial cells in the glass.

The production of time history plots with TEMPEST is accomplished by dumping the temperature of user-selected cells to an auxiliary post-processing file each time step. These user-selected cells are called monitor cells, and up to 16 cells can be selected on any run.

When the TEMPEST input is designed, care must be taken to arrange for the center of a cell to come as close as possible to the actual spatial location of the thermocouples in each cell. In addition, cells representing the response of thermocouples should not be too large, because the temperature calculated by TEMPEST is actualiy the average temperature in a cell. For stability reasons, variations in axial and radial cell dimensioning should increase and decrease as gradually as possible. 
The meshes designed to handle the batch-filling problems have another restriction. A batch pour is simulated by instantaneously converting cells that used to be air into cells that are glass. This is done by stopping the code, changing the input, and doing a restart. Because the batch-pour version of the code ( $L 4 X)$ does not allow for partially filled cells, certain axial dimensions must be chosen to precisely match the amount of glass in an individual pour.

Although TEMPEST is a three-dimensional code, all of the models described in this chapter were for two-dimensional meshes. Except for the TTS case, any variation in the circumferential direction was insufficient to justify a full three-dimensional simulation. However, a major objective of the TTS simulation was to see how accurately a two-dimensional model would work.

\subsection{INPUT MODELS}

The TEMPEST models used to simulate the scenarios are described in this section.

\section{$5.2 .1 \quad 12 \mathrm{LI}$ and $12 \mathrm{HI}$ Canisters}

Figures 5.1 and 5.2 show the TEMPEST noding used for the 12 I canisters. Modeling was performed using the batch-fill Version L4X of TEMPEST. In this version, the glass is modeled as a solid, without accounting for any glass convection during its molten state. Figure 5.1 shows the TEMPEST mesh with glass height after the first batch pour. Cells above the glass surface are noncomputational. Figure 5.2 shows the same mesh with the glass height after the second and the third (final) pour. Again, cells above the glass surface are noncomputational.

The 16 monitor cell locations for each modeled canister were determined on the basis of the number of axial levels and locations of thermocouples in each experimentally modeled canister. The batch-fill modeled canisters each had eight thermocouple levels; locations of the 16 monitor cells used for canisters $12 \mathrm{HI}$ and $12 \mathrm{LI}$ are listed in Table 5.1. 


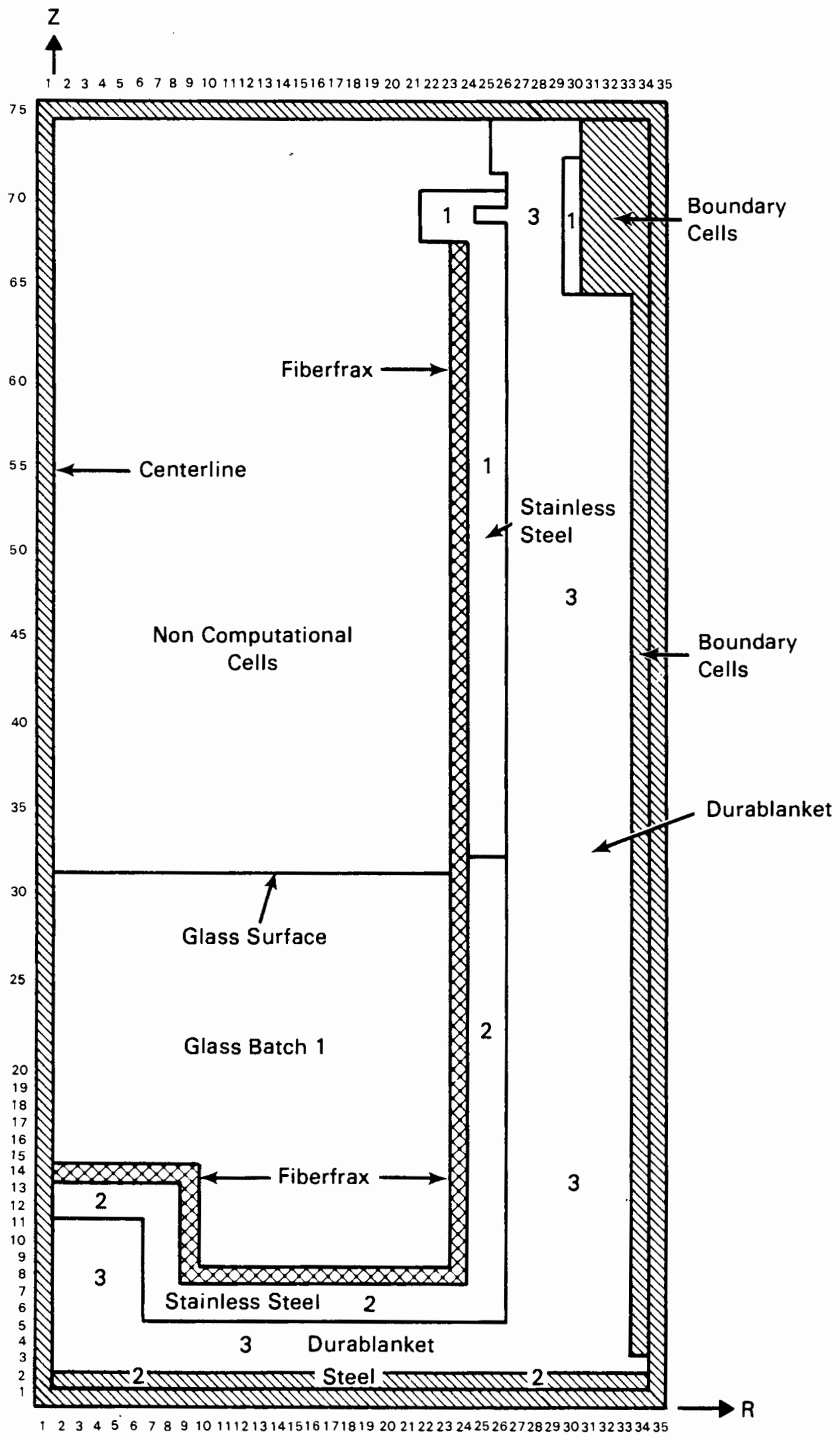

FIGURE 5.1. TEMPEST Mesh for Canisters 12LI and 12HI After First Glass Batch Pour 


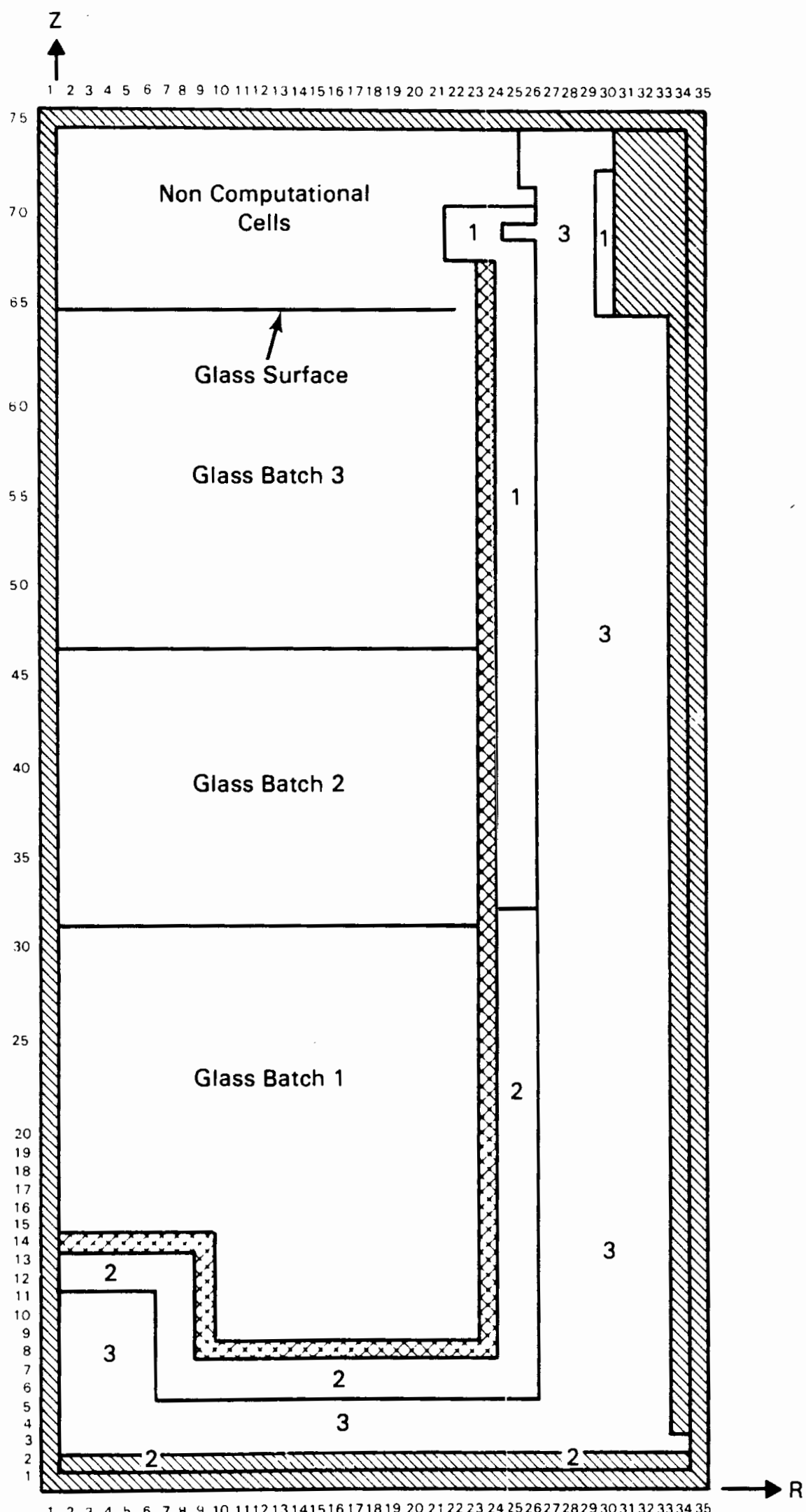

FIGURE 5.2. TEMPEST Mesh for Canisters 12LI and 12HI After Final (Third) Glass Batch Pour 
TABLE 5.1. Monitor Cell Locations for Canisters $12 \mathrm{LI}$ and $12 \mathrm{HI}$

\begin{tabular}{clr} 
Axial Level & & \multicolumn{2}{c}{$\begin{array}{l}\text { Radial Positions Monitored } \\
\text { (in from the inside wall) }\end{array}$} \\
\cline { 3 - 4 } 2 & $4.25 \mathrm{in.}$ & $1 \mathrm{in}$. \\
3 & $4.25 \mathrm{in.}$ & $1 \mathrm{in}$. \\
4 & $4.25 \mathrm{in.}$ & $1 \mathrm{in}$. \\
5 & $4.25 \mathrm{in.} 2 \mathrm{in.}$ & $1 \mathrm{in}$. \\
6 & $4.25 \mathrm{in.}$ & $1 \mathrm{in}$. \\
7 & $4.25 \mathrm{in.}$ & $1 \mathrm{in}$. \\
8 & $4.25 \mathrm{in.}$ & \\
$4.25 \mathrm{in.}$ &
\end{tabular}

\subsubsection{3-in.-Diameter Canister}

Figure 5.3 shows the TEMPEST noding for the 13-in.-diameter canister. Note that this model uses the continuous-fill Version M of TEMPEST. This version accounts for convecting glass (with the inviscid approximation described earlier) but does not allow convection of air above the glass surface.

For the 13-in.-diameter canister, there were six axial thermocouples levels, each containing four internal thermocouples (4.25 in., 2 in., 1 in. and $1 / 8$ in. from the canister wall). Because of the constant axial dimension required for the continuous-fill model, it was not possible to match the monitor cells with the location of the thermocouples as closely as for the batchfill case, and no attempt was made to vary the cell dimension around the area of the thermocouple to minimize the volume of a monitor cell. Locations of the 16 monitor cells for the 13-in.-diameter canister are listed in Table 5.2.

\subsubsection{4-in.-Diameter Canister}

The noding for the 24-in.-diameter canister is very similar to the mesh for the 13-in. canister shown in Figure 5.3. However, in this model, there were 10 axial levels containing four thermocouples per level ( 10 in., 5 in., $2.5 \mathrm{in}$. and $0.25 \mathrm{in}$. from the canister wall). This canister, although filled with 33 batch pours, was also modeled with the continuous-pour Version $M$ of 


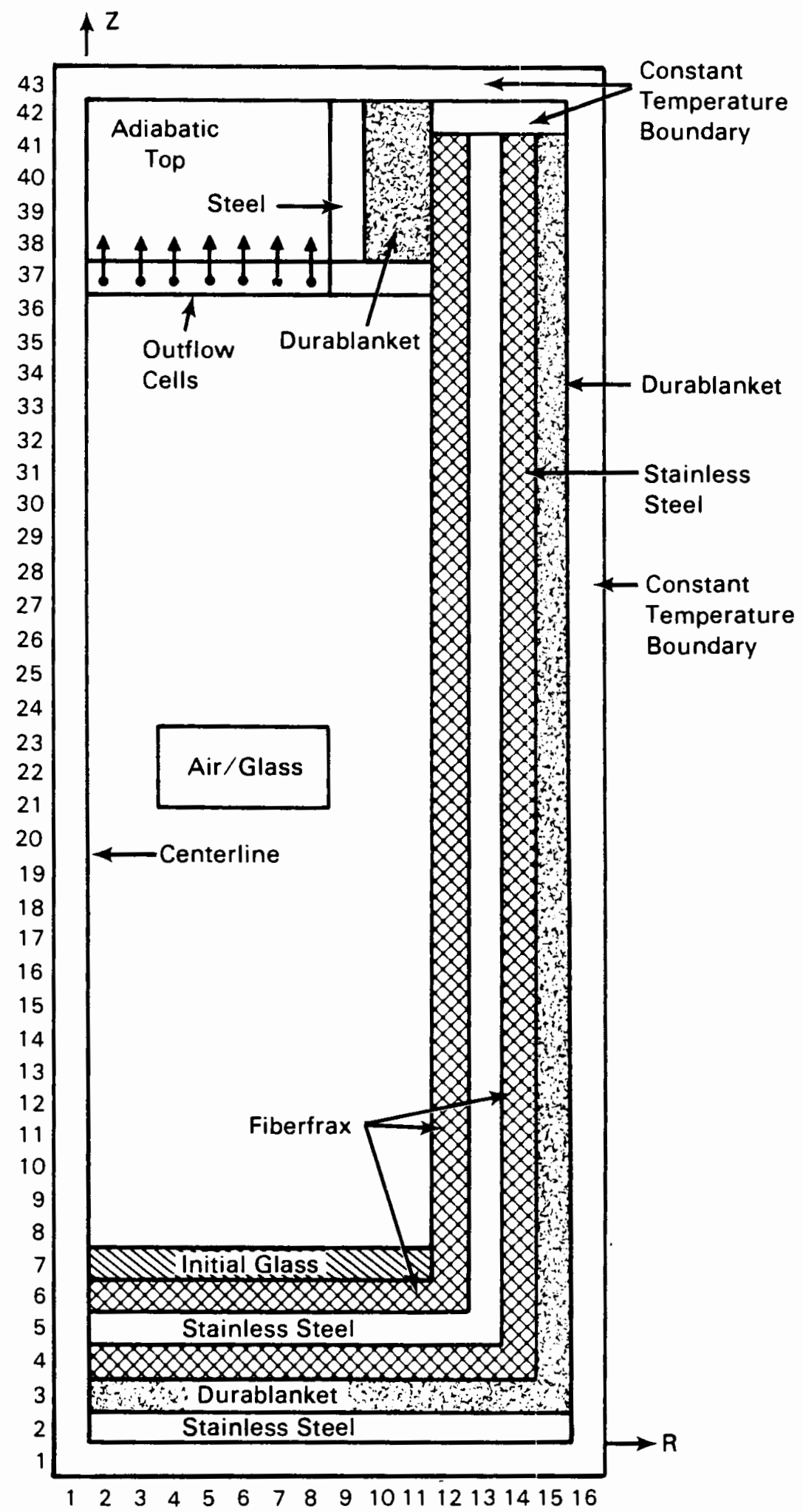

FIGURE 5.3. TEMPEST Mesh for Continuous-Fill Modeling of the 13-in-Diameter Canister 
TABLE 5.2. Monitor Cell Locations for the 13-in.-Diameter Canister

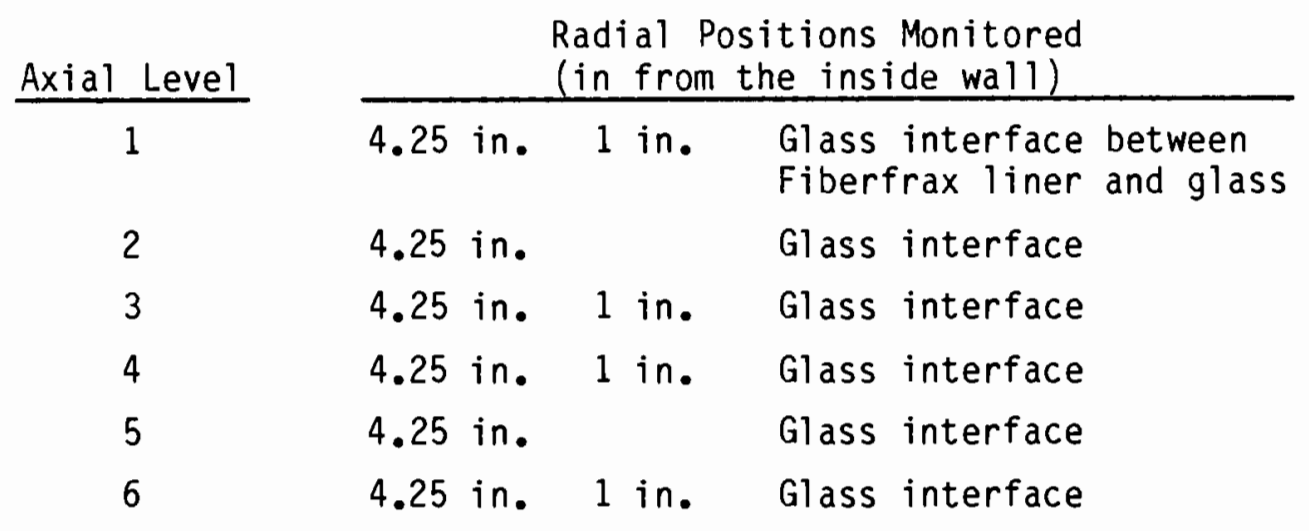

TEMPEST. In this model the cells above the glass surface are noncomputational. Locations of the 16 monitor cells for the 24-in.-diameter canister are listed in Table 5.3.

TABLE 5.3. Monitor Cell Locations for the 24-in.-Diameter Canisters

\begin{tabular}{|c|c|c|}
\hline Axial Level & \multicolumn{2}{|c|}{$\begin{array}{l}\text { Radial Positions Monitored } \\
\text { (in from the inside wall) }\end{array}$} \\
\hline 1 & $10 \mathrm{in.}$ & $\begin{array}{l}\text { Glass interface between } \\
\text { Fiberfrax liner and glass }\end{array}$ \\
\hline 2 & $10 \mathrm{in.}$ & \\
\hline 3 & $10 \mathrm{in.}$ & Glass interface \\
\hline 4 & $10 \mathrm{in.}$ & \\
\hline 5 & $10 \mathrm{in.}$ & Glass interface \\
\hline 6 & $10 \mathrm{in.}$ & Glass interface \\
\hline 7 & $10 \mathrm{in.}$ & \\
\hline 8 & $10 \mathrm{in.}$ & Glass interface \\
\hline 9 & $10 \mathrm{in.}$ & \\
\hline 10 & $10 \mathrm{in.}$ & Glass interface \\
\hline
\end{tabular}




\subsection{UNDERLYING ASSUMPTIONS}

TEMPEST is a flexible computer code, allowing the user to simulate many different situations. However, as with all computer codes, any simulation of an actual engineering system does involve some approximations. The most important assumptions used in developing the TEMPEST models for canister filling and cooling are discussed in this section.

\section{3 .1 Geometry}

The major assumptions related to problem geonetry are described in the following paragraphs.

When the two 12-in.- and the one 13-in.-diameter canisters were under the melter, they were positioned beneath a 4-ft spooljiece that was insulated with 3 in. of Durablanket insulation to prevent any significant heat transfer. However, the spoolpiece had no thermocouple monitoring. To model these three canisters, it was decided to ignore the spoolpiece and treat the area above the modeled canister as adiabatic. The spoolpiece was omitted from the canister models for two reasons: 1) the significant increase in total cells required to accurately handle the spoolpiece and canister, and 2) the uncertainty with respect to actual spoolpiece temperatures.

While under the melter, the canisters sat on a large metal canister stand that was spaced to allow convective and radiative heat transfer underneath. To model this area, it was assumed that while the carlister is under a melter it would rest upon a 1/4-in. piece of metal. The metal, having a free convection and radiation coefficient, would then act as a thermal connection to the environment. All three canisters would also be separated from the metal piece by a 1/2-in. Durablanket insulation layer. However, the 12-in.-diameter canisters had a lip and a large inverted bump on the bottom (see Figure 4.1). Likewise, the feet on the 13-in.-diameter canister held the canister above the stand. Rather than simulate a dead air space, the gap was assumed to be filled with Durablanket insulation. Any radiation in this gap was ignored.

When these canisters were moved out from under the melter, they were placed upon a layer of Durablanket insulation on the floor. A canister lid and/or layer of Durablanket insulation was then placed on the canister top. To 
model this change in node dimensions, a restart of the canister simulation at its change-out time was required. In the restart condition, a canister lid and a layer of Durablanket insulation at room temperature was placed on top of the canister, and axial heat transfer was allowed above the canister's top surface. On the bottom of the model, Durablanket insulation at room temperature was placed between the canister and the 1/4-in. metal shell, and direct conductive heat transfer from the canister to the floor at ambient temperature was used (no convective or radiative heat transfer). On the two 12-in.-diameter canisters, room temperature insulation was also used to fill the canister gap. These changes were assumed to occur instantaneously upon change-out, without changing the previously generated temperatures in the canister. The 12-in.-diameter canisters also had a connecting metal band (holding the canister to the spoolpiece) removed during the change-out restart.

The batch-fill model assumed that air cells (above the current glass surface) change instantaneously into glass cells with the next batch pour. Because the model did not contain a method for changing cell and material types during the computer simulation, a restart of the transient simulation was required for modeling each batch. The restart input file contains the information about changed cell and material types for the section of newly poured glass. In addition, a new initial temperature for the just-added glass volume was required. A disadvantage of the batch-fill model is that it allows only one type of material in each cell (no partially filled cells), and it requires a separate restart for each batch pour. This is a significant inconvenience if the number of batch pours is large.

The continuous-fill model uses a time-dependent boundary table to handle the mass and energy addition of a batch pour or a continuous pour. Theoretically, any arbitrary function can be simulated, including a function that intermittently goes to zero. (Thus, a batch-fill scenario can be simulated.) As a result, Version $M$ of this TEMPEST does not require a restart for every new pour or change in the average fill rate. A restart is required only when a change in environment occurs (e.g., when the canister is moved from under the melter. Filling input for the 13-in.-diameter canister is generated as a series of step-function average fill rates, with glass levels determined by 
thermocouple response. Filling input for the 24-in.-diameter canister is set up as a series of step functions, alternating between the average fill rate of each batch and no filling.

The 24-in.-diameter canister noding differs from the other canister noding descriptions in that it is not externally insulated and is placed in a 48-in.diameter turntable simulant she11. The change in emissivity over time on the canister and shell surfaces is uncertain, and the enclosure radiation between the canister and turntable shells cannot be accurately modeled. A timedependent model was used for the wall temperature of the canisters to fix the heat transfer driving force out of the canister. This time-dependent canister wall temperature was determined by digitizing experimental temperatures taken at ten levels on the 24-in.-diameter. Because of these time-dependent temperatures, no radiation or convection coefficients are required on the canister wal1. Adiabatic heat transfer was assumed above the canister, and only conduction heat transfer was assumed out of the bottom of the canister. No restart condition upon canister change-out was required. One additional feature of the 24-in.-diameter canister was the presence of a bowed, inverted bottom. To model the bowed bottom using TEMPEST, an average height of the bow was determined and used as an insulation-filled gap between the canister and turntable shel1.

\subsubsection{Glass Properties}

An important part of the comparison between actual temperature profiles and TEMPEST predictions was to determine any significant variation in glass properties as a function of temperature; such variations could affect the TEMPEST predictions. Currently, data on the density, specific heat, and thermal conductivity variations of nuclear waste glass with temperature have been tabulated for SRL-411 glass only. To calculate the thermal properties of another waste glass, properties of a different simulated glass from PSCM-20 were determined at temperatures up to $800^{\circ} \mathrm{C}$. A comparison between the PSCM-20 and the old SRL 411 glass properties is shown in Table 5.4.

As shown, certain assumptions were made to extrapolate the measured PSCM20 values over the full range of the SRL 411 table. The extended density values above $600^{\circ} \mathrm{C}$ should be quite accurate, as the SRL values have a thermal 
TABLE 5.4. Comparison of SRL 411 and PSCM-20 Glass Properties

\begin{tabular}{|c|c|c|c|c|c|c|}
\hline $\begin{array}{c}\text { Temperature, } \\
{ }^{\circ} \mathrm{C} \\
\end{array}$ & $\frac{\text { Density, }}{\text { SRL 411 }}$ & $\frac{\mathrm{kg} / \mathrm{m}^{3}}{\mathrm{PSCM}-20}$ & $\begin{array}{r}\begin{array}{r}\text { Spec } \\
\text { Heat, }\end{array} \\
\text { SRL } 411 \\
\end{array}$ & $\begin{array}{l}\text { fic } \\
/ \mathrm{kg}-\mathrm{K} \\
\mathrm{PSCM}-20 \\
\end{array}$ & $\begin{array}{r}\text { Thermal } \\
\text { tivity } \\
\text { SRL 411 } \\
\end{array}$ & $\begin{array}{l}\text { Conduc- } \\
\frac{W / m-K}{} \\
\text { PSCM-20 }\end{array}$ \\
\hline 22 & 2610 & 2801 & 920 & $696^{(a)}$ & 1.05 & $0.813^{(a)}$ \\
\hline 100 & 2603 & 2794 & 1000 & 757 & 1.11 & $0.858^{(a)}$ \\
\hline 200 & 2598 & 2785 & 1100 & 892 & 1.16 & 0.921 \\
\hline 300 & 2590 & 2776 & 1180 & 983 & 1.16 & 1.021 \\
\hline 400 & 2575 & 2767 & 1270 & 1060 & 1.22 & 1.095 \\
\hline 500 & 2555 & 2757 & 1910 & 1180 & 1.63 & 1.144 \\
\hline 600 & 2531 & 2718 & 1820 & 1710 & 1.17 & 1.006 \\
\hline 700 & 2501 & $2678^{(b)}$ & 1520 & $1710^{(c)}$ & 1.05 & 0.864 \\
\hline 800 & 2458 & $2638^{(b)}$ & 1500 & $1710^{(c)}$ & 1.20 & 0.842 \\
\hline 900 & 2405 & 2599 (b) & 1610 & $1710^{(c)}$ & 1.48 & $0.994^{(a)}$ \\
\hline 1000 & 2352 & $2561^{(b)}$ & 1730 & $1710^{(c)}$ & 1.83 & $1.153^{(a)}$ \\
\hline 1100 & 2321 & $2523^{(b)}$ & 1880 & $1710^{(c)}$ & 2.23 & $1.288^{(a)}$ \\
\hline 1200 & 2310 & $2487^{(b)}$ & 2020 & $1710^{(c)}$ & 2.62 & 1.399 (a) \\
\hline
\end{tabular}

(a) Extrapolated or projected using SRL-411 values.

(b) Assumes the same thermal expansion at all temperature $>506^{\circ} \mathrm{C}$.

(c) Assumes constant specific heat above $600^{\circ} \mathrm{C}(1710 \mathrm{~J} / \mathrm{kg}-\mathrm{K})$.

expansion coefficient similar to that of the PSCM-20 glass at these temperatures. The assumed specific heat values are based on a number of curves of glass specific heat versus temperature, which have shown a constant specific heat for glass above $650^{\circ} \mathrm{C}$. Although possibly inaccurate, the inaccuracy is offset at these temperatures if the thermal diffusivity values $(k / \rho C p)$ are accurate. All other iterated values are determined by projecting the property slopes from SRL $411 \mathrm{glass}$ over the PSCM-20 glass. This is an area where significant potential for error exists and is a possible cause for TEMPEST deviations from experimental values.

A comparison of the thermal properties shows notable variances, particularly with regard to the thermal conductivity and specific heat properties. However, the effect on thermal diffusivity values is negligible except at temperatures above $500^{\circ} \mathrm{C}$ where the measured PSCM-20 properties become 
suspect. Although better property measurements, particularly in the higher temperatures, would be desirable, it can be assumed that the thermal property variations in glasses above $500^{\circ} \mathrm{C}$ do not significantly affect steady-state heat transfer.

Because the new measured glass properties were from PSCM-20, it was decided to use these measured and assumed values for canister $12 \mathrm{HI}$ and $12 \mathrm{LI}$, which were modeled with the batch-fill version of TEMPEST (L4X). With the 13and 24-in.-diameter canisters from PSCM-21, however, it was felt that PSCM-21 glass would resemble SRL 411 glass more closely than PSCM-20 glass. Therefore, glass properties used in the continuous-fill model consisted mostly of SRL 411 properties. Densities were increased by a factor of 1.034 to account for the increased PSCM-21 glass density at room temperature $\left(2700 \mathrm{~kg} / \mathrm{m}^{3}\right)$.

A glass emissivity of 0.8 was measured for the SRL $411 \mathrm{glass.} \mathrm{No} \mathrm{mention}$ was made of the effect of temperature on glass emissivity. However, it was felt that the 0.8 emissivity would be sufficiently accurate for use with TEMPEST's crude glass surface radiation model. If development proceeds on a better radiation heat transfer model, it would be wise to measure glass emissivity as a function of temperature.

\subsubsection{Insulation Properties}

Temperature-dependent thermal conductivity data for Durablanket and Fiberfrax and emissivity data for Fiberfrax (970-j) were taken from vendor information. However, the temperature dependency of the insulation's specific heat and density is considered proprietary information by the manufacturer. Therefore, a few assumptions had to be made.

For uncompressed insulation, the $8-1 b / f t 3$ bulk density for Durablanket and $10-1 \mathrm{~b} / \mathrm{ft}^{3}$ bulk density for Fiberfrax are fractions of each material's specific gravity. It was assumed that any thermal expansion of the insulation material would serve only to increase or decrease the fraction of the material's specific gravity without changing bulk volume. This assumption justifies the use of a constant bulk density versus temperature for the two insulations.

The assumptions used to derive a temperature-dependent specific heat for the two insulation materials were iterative and more approximate. Both 
insulations are composed of $\sim 50 \% \mathrm{SiO}_{2}$ and $\sim 50 \% \mathrm{Al}_{2} \mathrm{O}_{3}$. Temperature-dependent specific heat tables for the two nonmetallic materials were found, and an average specific heat at each temperature point was determined. The new average specific heat table was used for the two insulation values.

An additional consideration brought about in determining insulation properties is the compression of insulation in the canister by the glass fill. The primary compression is caused by the hydrostatic pressure forces of the glass. However, the insulation compression can be influenced also by thermal expansion differences between the canister wall and the glass. Average calculations of insulation compression on the canister floor and walls, based on determined compression thicknesses, resulted in the average insulation thickness given in Table 5.5 (wall thicknesses are averages). The insulation dimensions shown in Table 5.5 were used in the TEMPEST simulations.

The insulation manufacturer had no information on the effect of compression on insulation thermal conductivity. For this study, no change was assumed. For new bulk density values, the percentage of compression was added to 1.00 and multiplied by the uncompressed bulk density. Specific heat was assumed not to change with compression since specific heat is dependent on material weight alone.

Vendor information provided a constant value of 0.9 for the Durablanket insulation emissivity. Although this may rise with increasing temperature, it was assumed constant for this study because the highest temperature seen by the radiating Durablanket surface is relatively low.

\subsubsection{Stainless Steel Properties}

Thermal properties of $304 \mathrm{~L}$ stainless steel versus temperature are well documented (JANAF 1986). The primary concern with stainless steel is the influence of temperature on oxidation rate and the influence of oxidation rate on canister shell emissivity. More information is needed in this area. Stainless steel emissivity data are necessary for only the 24-in.-diameter canister simulation, because the radiation heat transfer from all other canister surfaces was controlled by the emissivity of the Durablanket. 


\section{TABLE 5.5. Canister Insulation Thickness}

A. 12- and 13-in.-Diameter Canister Insulation Thicknesses

\begin{tabular}{|c|c|c|}
\hline Dimension & Uncompressed & Compressed \\
\hline Bottom bump (12 in.) & $0.125-i n$. & $0.1045-i n$. \\
\hline Bump wall (12 in.) & 0.125 -in. & $0.1035-i n$. \\
\hline Canister bottom & $0.125-i n$. & $0.1035-i n$. \\
\hline Canister wall & $0.125-i n$. & $\begin{array}{l}0.106-i n . \text { for } 12 \mathrm{HI} \\
0.121-i n \text {. for } 12 \mathrm{LI}\end{array}$ \\
\hline
\end{tabular}

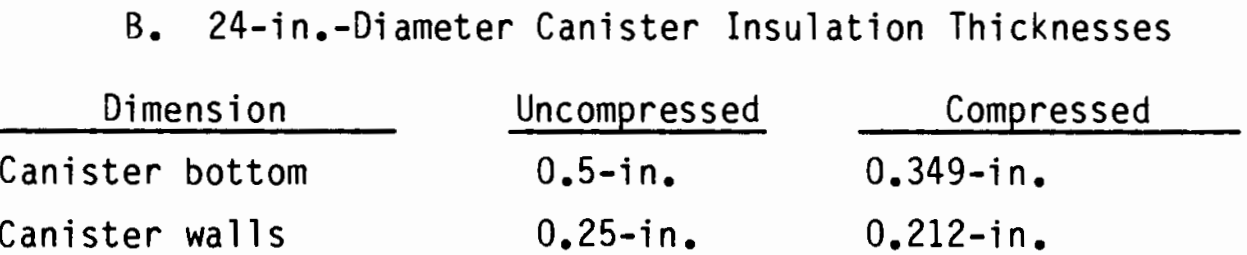

\subsubsection{Initial Glass Temperatures}

Initial glass temperatures for the continuous-fill canisters were estimated at $1075^{\circ} \mathrm{C}$. This estimate was based on observed pouring temperatures for the 13-in.-diameter canister. No effort was made to estimate glass temperatures more accurately because there were not enough temperatures or levels being recorded in each can.

Temperatures for the batch-fill modeled canisters were determined as follows:

- If the experimental temperatures were recorded every 2 minutes, the initial glass temperature used for a particular pour was an average of the hottest temperature (usually centerline) recorded at each axial level covered during the pour.

- If the experimental temperatures were recorded every 6 minutes, the initial glass temperature used for a particular pour was the hottest temperature recorded during a pour.

Table 5.6 is a summary of the initial glass temperatures used for modeling canisters $12 \mathrm{LI}$ and $12 \mathrm{HI}$. 
TABLE 5.6. Initial Glass Temperatures Used for Canistera 12LI and 12HI During Batch-Fill Modeling

$\begin{array}{ccc}\text { Pour Number } & \frac{12 \mathrm{LI}}{1056^{\circ} \mathrm{C}} & \frac{12 \mathrm{HI}}{1115^{\circ} \mathrm{C}} \\ 1 & 1050^{\circ} \mathrm{C} & 1028^{\circ} \mathrm{C} \\ 3 & 1060^{\circ} \mathrm{C} & 919.9^{\circ} \mathrm{C}\end{array}$

The pour temperatures used are within $50^{\circ} \mathrm{C}$ of $1075^{\circ} \mathrm{C}$, with the exception of the last pour temperature of canister 12HI. This low temperature was caused by the loss of a face heater in the glass overflow section of the melter during pouring. It was determined as the average of the hottest recorded temperatures for three axial levels in the glass pour. 


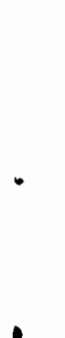

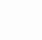




\subsection{COMPARISON OF TEMPEST PREDICTIONS WITH EXPERIMENTAL OBSERVATIONS}

In this chapter, temperature predictions generated with the TEMPEST input models are compared to canister temperature measurements obtained during actual filling of canisters by the PSCM. The TEMPEST-predicted heat transfer behavior of the turntable-filled canister is also compared with actual observations.

\subsection{CANISTER INTERNAL TEMPERATURES}

Canisters 12LI, 12HI, and the 24-in.-diameter canister were filled with batch pours, but the 13-in.-diameter canister was filled in a continuous pour. Canisters $12 \mathrm{LI}$ and $12 \mathrm{HI}$ were filled in three pours; the 24-in.-diameter canister was filled in 33 pours. Canisters $12 \mathrm{HI}$ and $12 \mathrm{LI}$ were modeled using the batch-fill version of TEMPEST (L4X); the 13-in.- and 24-in.-diameter canisters were modeled using the continuous-fill version of TEMPEST (M). The continuous-fill version was selected for the 24-in.-diameter canister because modeling the 33 batch pours using the batch-fill version would have required too much staff time.

\subsubsection{TEMPEST Batch-Fill Model}

Two radiation models were used to compute the radiation heat transfer from the glass surface to the Fiberfrax liner in the canister. The first used the temperature of the Fiberfrax in contact with the glass surface as the sink temperature. (a) Because the actual sink temperatures are less than the computed sink temperature, the rate of heat transfer from the glass surface is underpredicted. Because this would result in a high-temperature prediction, this model is referred to here as the high-temperature model. Using the second radiation model, the temperatures of the Fiberfrax in contact with the glass and the Fiberfrax at the top of the canister were averaged for use as the sink temperature. This estimate of sink temperature is probably lower than the mean sink temperature; therefore, the radiant flux for this model is probably

(a) Average sink temperature refers to the temperature that would result in the same radiation to the glass surface from the portion of the canister and melter above the glass as which existed during the pour. 
overpredicted. Consequently, the predicted glass temperatures should be low. Hence, this model is referred to as the low-temperature model.

Canister $12 \mathrm{HI}$

Canister $12 \mathrm{HI}$ was insulated externally with 3 in. of Durablanket insulation and was filled with an "interrupted" three-batch pour. After one-third of the canister was filled in one batch, the canister was removed from under the PSCM for 1 day. The first pour was 13.1 in. deep. The canister was then placed back under the PSCM, where the second and third pours were made $29.5 \mathrm{~h}$ and $33.95 \mathrm{~h}$ after the start of the first pour.

Comparisons between the TEMPEST predictions using the high-temperature radiation model and the observed time/temperature histories are given for the eight axial thermocouple levels in canister $12 \mathrm{HI}$ in Figures 6.1 through 6.7. Because this canister was heavily insulated, the radial temperature differences are small during most of the cooldown phase.

The onset of the heating wave from the second pour can be seen in Figures 6.1 through 6.3. Note how the wave reaches the highest axial thermocouple level covered by the first pour very close to the time when the pour started (Figure 6.3), but does not cause a noticeable change in the downward slope of either the predicted or observed temperatures for the other two axial thermocouple levels (Figures 6.1 and 6.2) until 30 and $31 \mathrm{~h}(0.5$ and $1.5 \mathrm{~h}$ after the pour). As expected, the temperature rise caused by heating from the second pour decreases with distance between the axial thermocouple level and the top of the first pour.

The TEMPEST predictions shown in Figures 6.1 through 6.3 have the following characteristics:

- They are in reasonable agreement with experimental results.

- The predicted cooldown for the first 8 to $10 \mathrm{~h}$ is too slow. (a)

- Agreement of TEMPEST predictions with experimental results improves during the remainder of the $29.5 \mathrm{~h}$ prior to the second fill.

(a) As will be discussed later, this is not true for the top batch surfaces. 


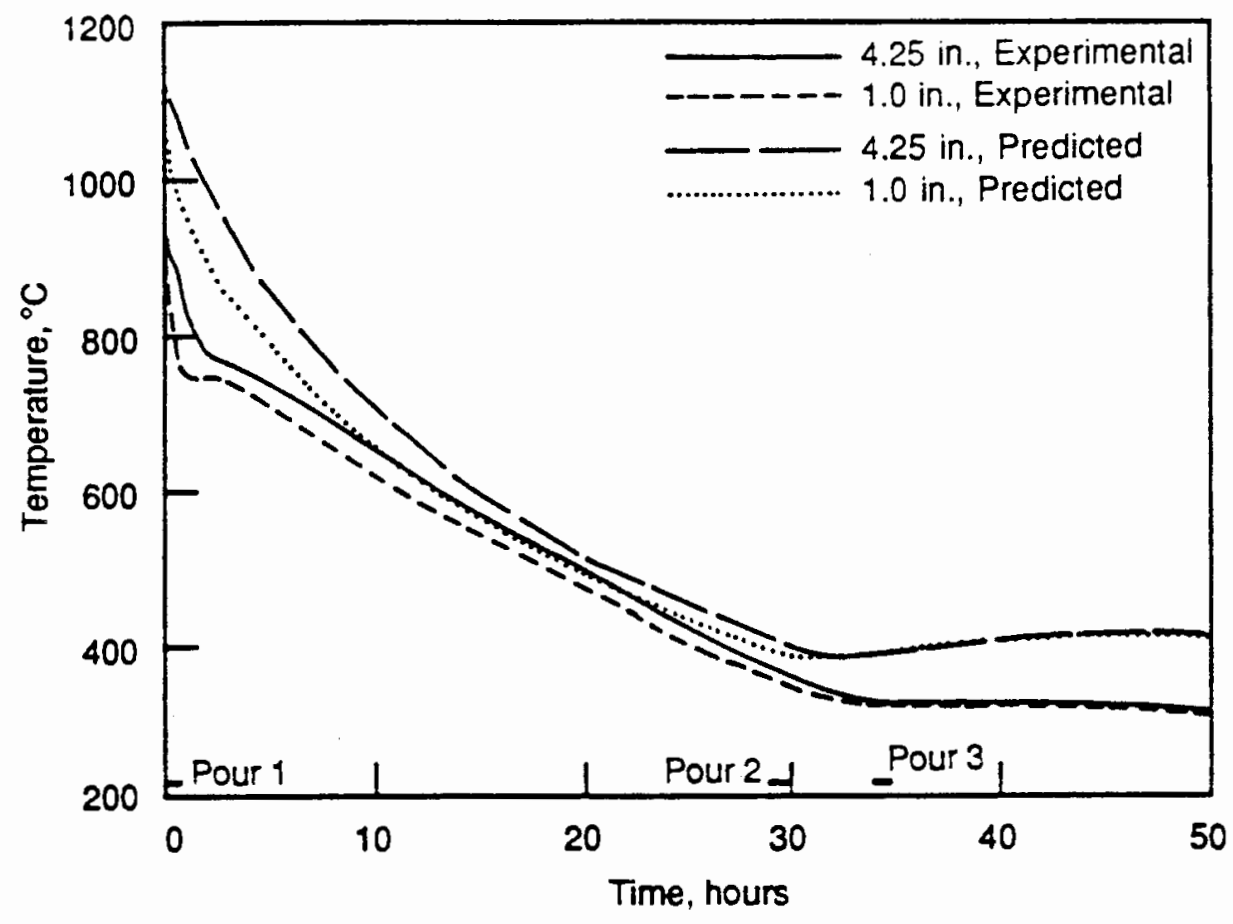

FIGURE 6.1. TEMPEST Predictions and Experimental Temperatures Measured in Canister $12 \mathrm{HI}$ at Axial Level 3.75 in. from Canister Bottom

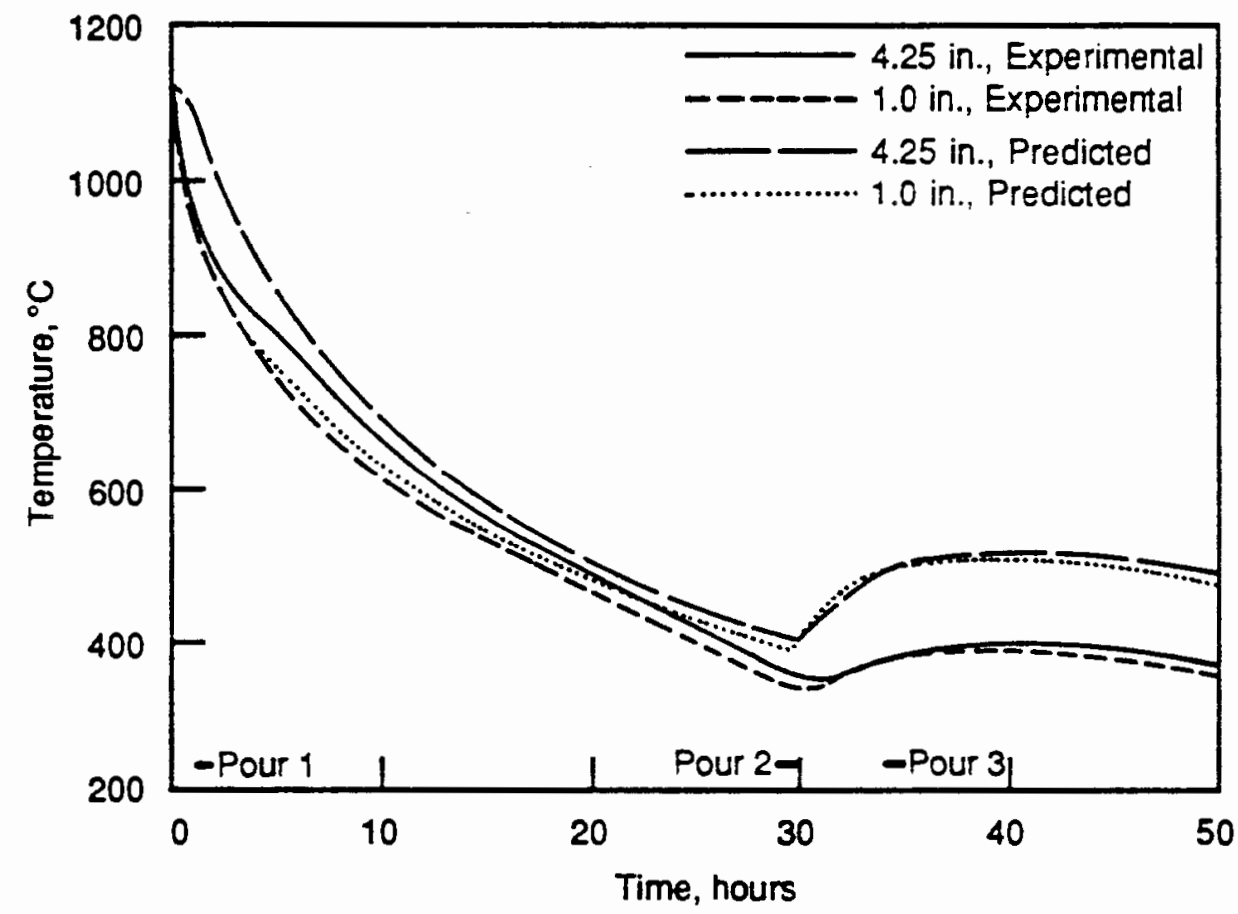

FIGURE 6.2. TEMPEST Predictions and Experimental Temperatures Measured in Canister $12 \mathrm{HI}$ at Axial Level $9.5 \mathrm{in}$. from Canister Bottom 


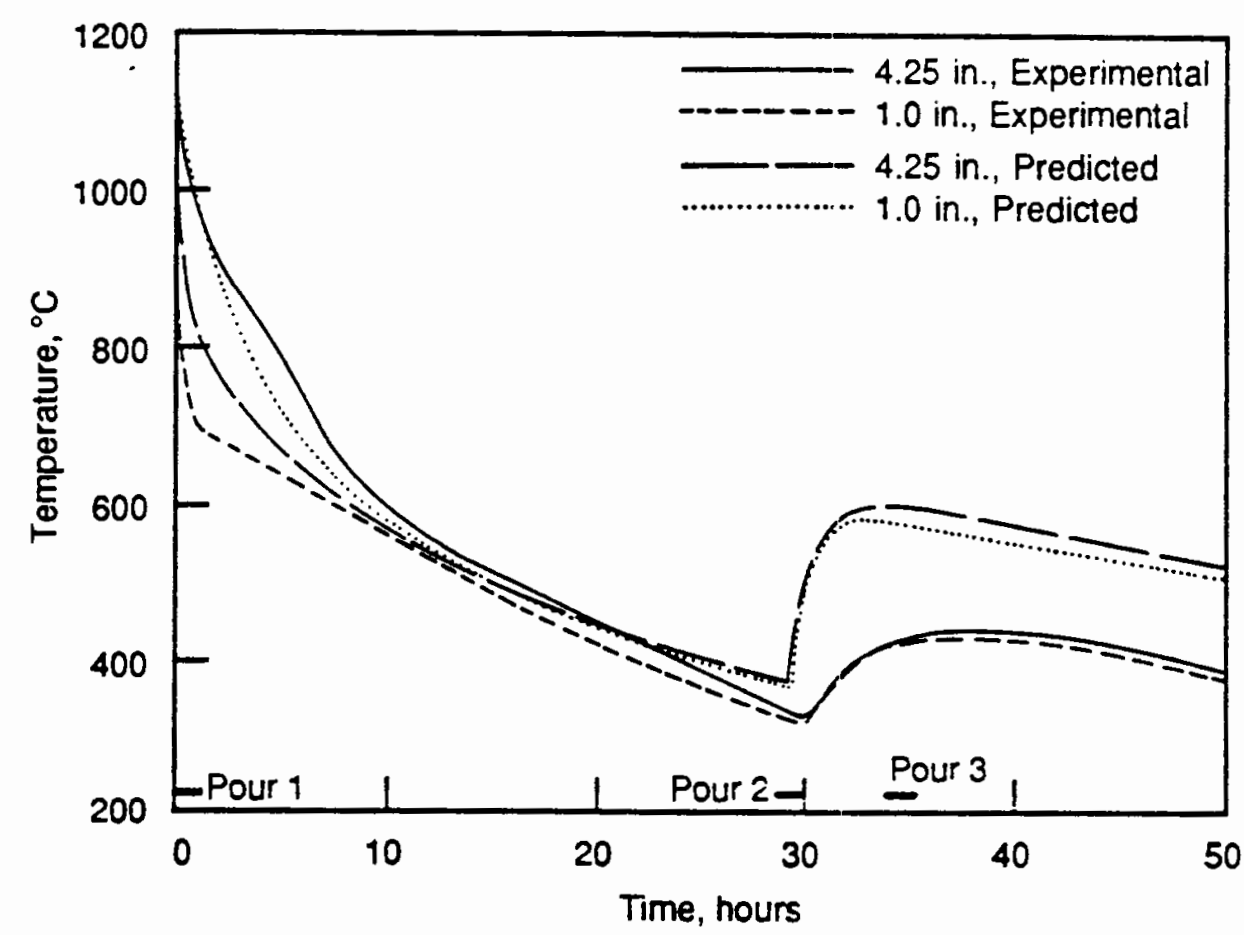

FIGURE 6.3. TEMPEST Predictions and Experimental Temperatures Measured in Canister 12HI at Axial Level 12.125 in. from Canister Bottom

- TEMPEST predicts a considerably greater increase in temperature by reheating from the second pour at the second and third thermocouple levels (Figures 6.2 and 6.3) and a somewhat greater reheat at the first thermocouple level than that observed (Figure 6.1).

Figures 6.4 and 6.5 show the results for the two axial thermocouple levels (20 in. and 24.875 in.) covered during the second pour. The top of the second pour was at $27 \mathrm{in}$., so these levels were 7.0 and $2.25 \mathrm{in}$. below the surface of the glass at the completion of the pour. The first of these levels (Figure 6.4) again showed that TEMPEST underpredicts the rate at which the temperature falls immediately after the pour ends. The near parallel behavior between the predicted and experimental results after $35 \mathrm{~h}$ makes it appear that almost perfect agreement would be obtained if TEMPEST were to predict the initial cooldown rapidly enough. This is not true, however, because the TEMPEST predictions should show a steeper slope because the predicted temperatures and, hence, heat transfer driving forces, are higher. Although it underpredicts the rate of cooldown just after the pour, TEMPEST appears to accurately predict the 


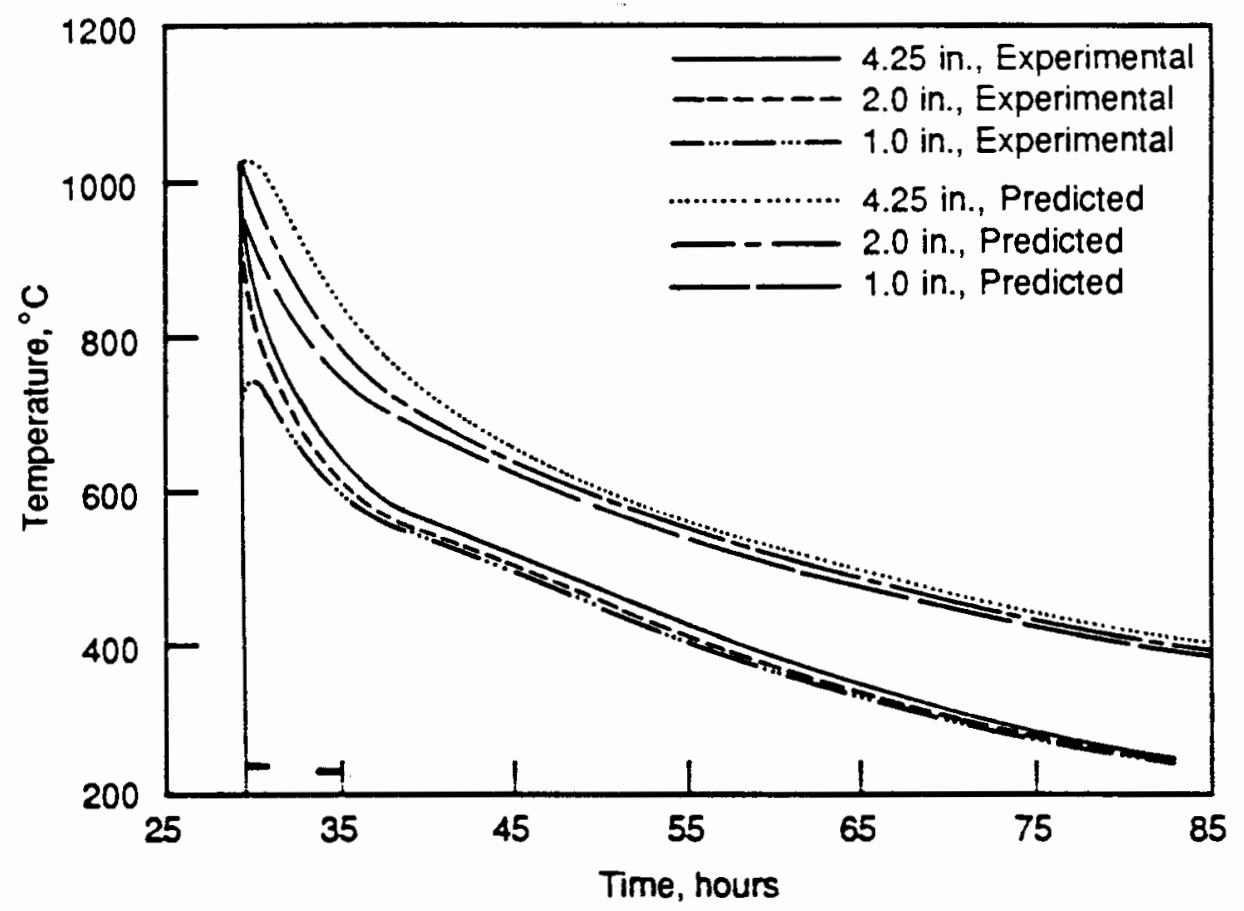

FIGURE 6.4. TEMPEST Predictions and Experimental Temperatures Measured in Canister 12HI at Axial Level 20.0 in. from Canister Bottom

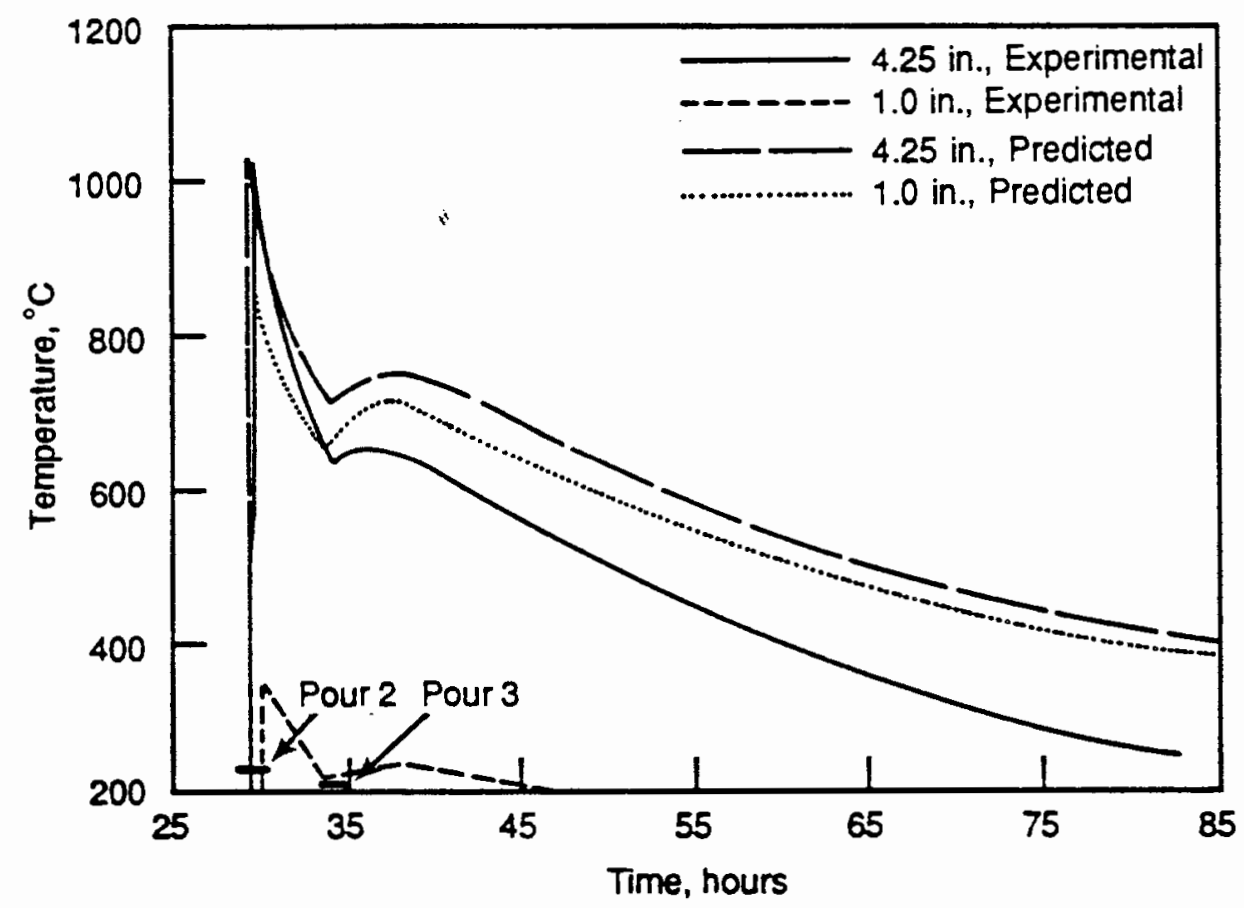

FIGURE 6.5. TEMPEST Predictions and Experimental Temperatures Measured in Canister $12 \mathrm{HI}$ at Axial Level 24.875 in. from Canister Bottom 
timing and the magnitude of reheat in Figure 6.5 for the 4-1/4-in. position. Thermocouple malfunction at the $1-i n$. thermocouple located at the 25-in. level caused the very low reading shown in Figure 6.5 .

Figures 6.6 and 6.7 show the results for the three axial thermocouple levels (32.75 in., $35.875 \mathrm{in.,}$ and $37.625 \mathrm{in.)}$ covered during the final pour. The results for the 37.6-in. thermocouple level are similar to those found during the second pour. Compared to experimental profiles, TEMPEST predicts a much slower cooldown rate early in the transient and a slightly slower cooling rate in the latter stages (evidence by the lower time-temperature slope although the predicted temperature is higher). The final glass level was estimated at $38.5 \mathrm{in}$. Note that the 4.25-in. thermocouple on the 37.6-in. level was cooler than the 4.25-in. thermocouple on the level below (Figure 6.7); this is due to the heat transfer from the top of the glass.

For the two thermocouples at the 37.6-in. level, TEMPEST predicts an anomaly in the time/temperature history at about $43 \mathrm{~h}$. At this time, the negative slope of the temperature curves increase sudden $1 y$, then returns to a more typical value. This is probably due to an inaccurate measurement of the time at which canister $12 \mathrm{HI}$ was removed from under the melter.

Comparisons of the observed and predicted glass temperatures for the eight $4.25 \mathrm{in}$. thermocouples are illustrated in Figures 6.8 through 6.15 . The observed glass temperatures were compared with the predicted glass temperatures from both the high and low radiation heat transfer models. As mentioned above, use of these two models would be expected to bound the radiant heat transfer from the surface. The low-temperature model does indeed predict lower glass temperatures. However, the temperatures predicted by the two models differ by less than $55^{\circ} \mathrm{C}$ over the entire cooling period, except

- during the cooldown from the first pour, at axial thermocouple levels 2 (9.5 in.) and 3 (12.1 in.) (See Figures 6.9 and 6.10)

- at level 5 (24.9 in.), for a short time before and after the final pour (see Figure 6.12) - Although the final pour caused a heat-up peak, the high and low radiation model predictions increased until the final pour. Thereafter, the differences decreased rather 


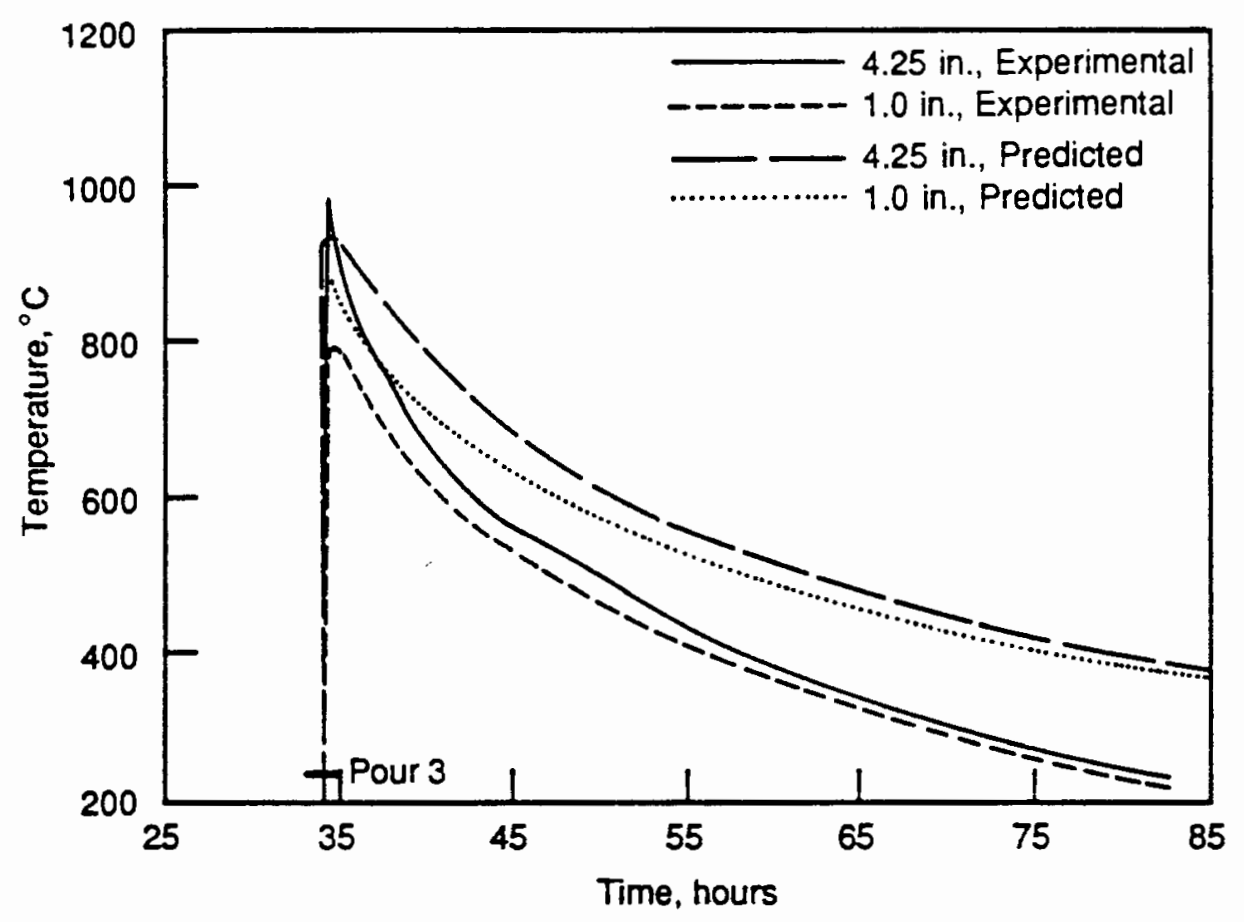

FIGURE 6.6. TEMPEST Predictions and Experimental Temperatures Measured in Canister 12HI at Axial Level 32.75 in. from Canister Bottom

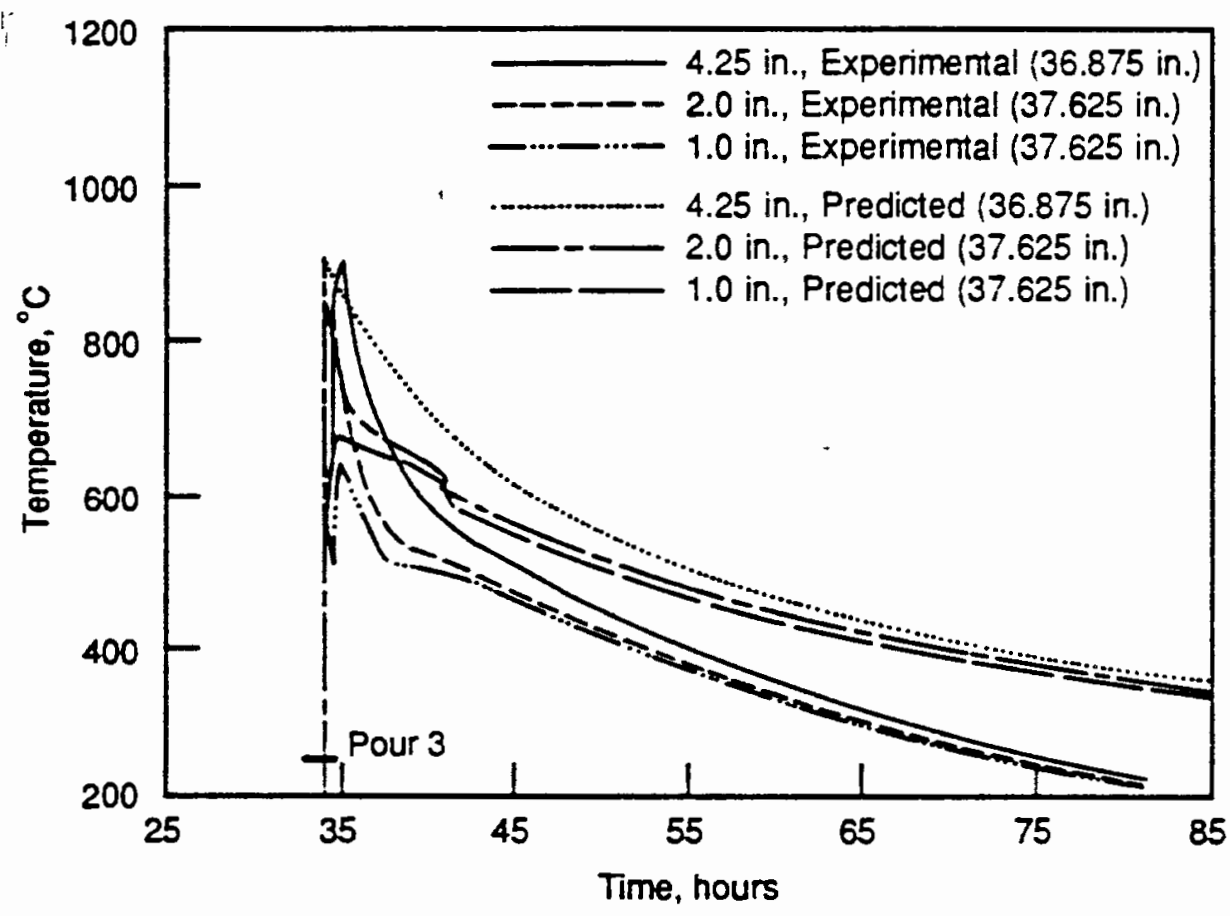

FIGURE 6.7. TEMPEST Predictions and Experimental Temperatures Measured in Canister $12 \mathrm{HI}$ at Axial Levels 37.625 and 35.875 in. from Canister Bottom 


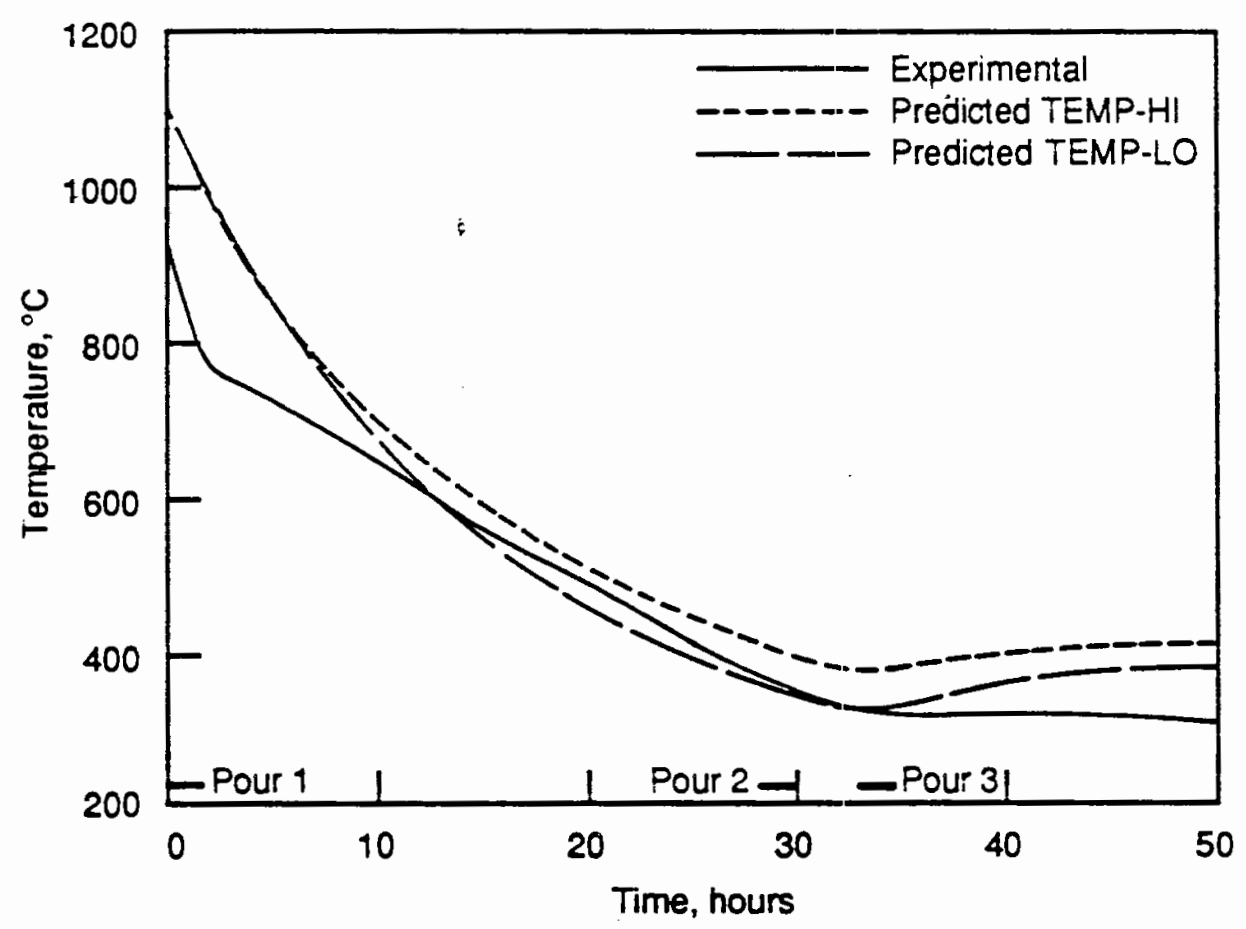

FIGURE 6.8. TEMPEST High- and Low-Temperature Radiation Model Predictions and Experimental Temperatures Measured in Canister $12 \mathrm{HI}$ at Axial Level 3.75 in. from Canister Bottom

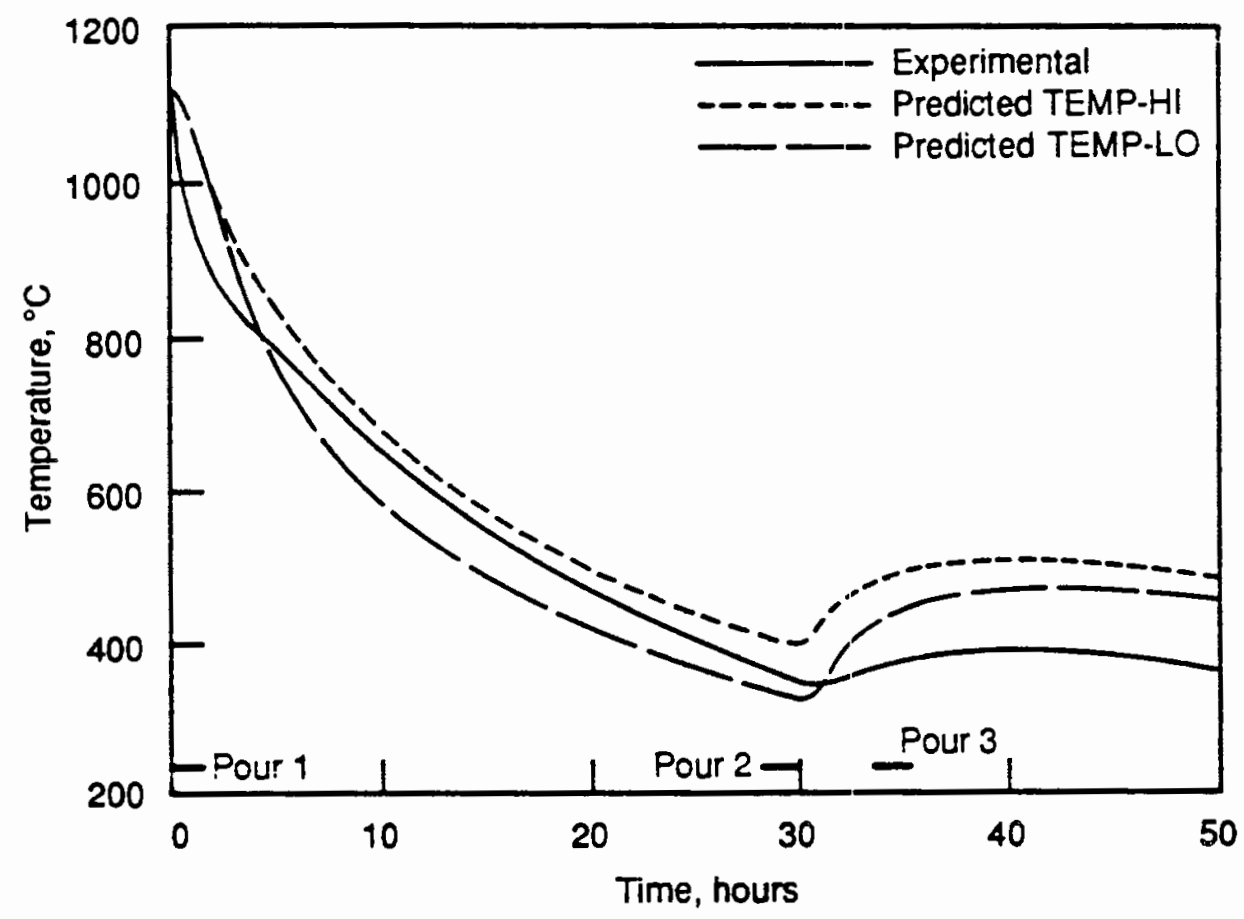

FIGURE 6.9. TEMPEST High- and Low-Temperature Racliation Model Predictions and Experimental Temperatures Measured ir Canister $12 \mathrm{HI}$ at Axial Level $9.5 \mathrm{in}$. from Canister Bottom 


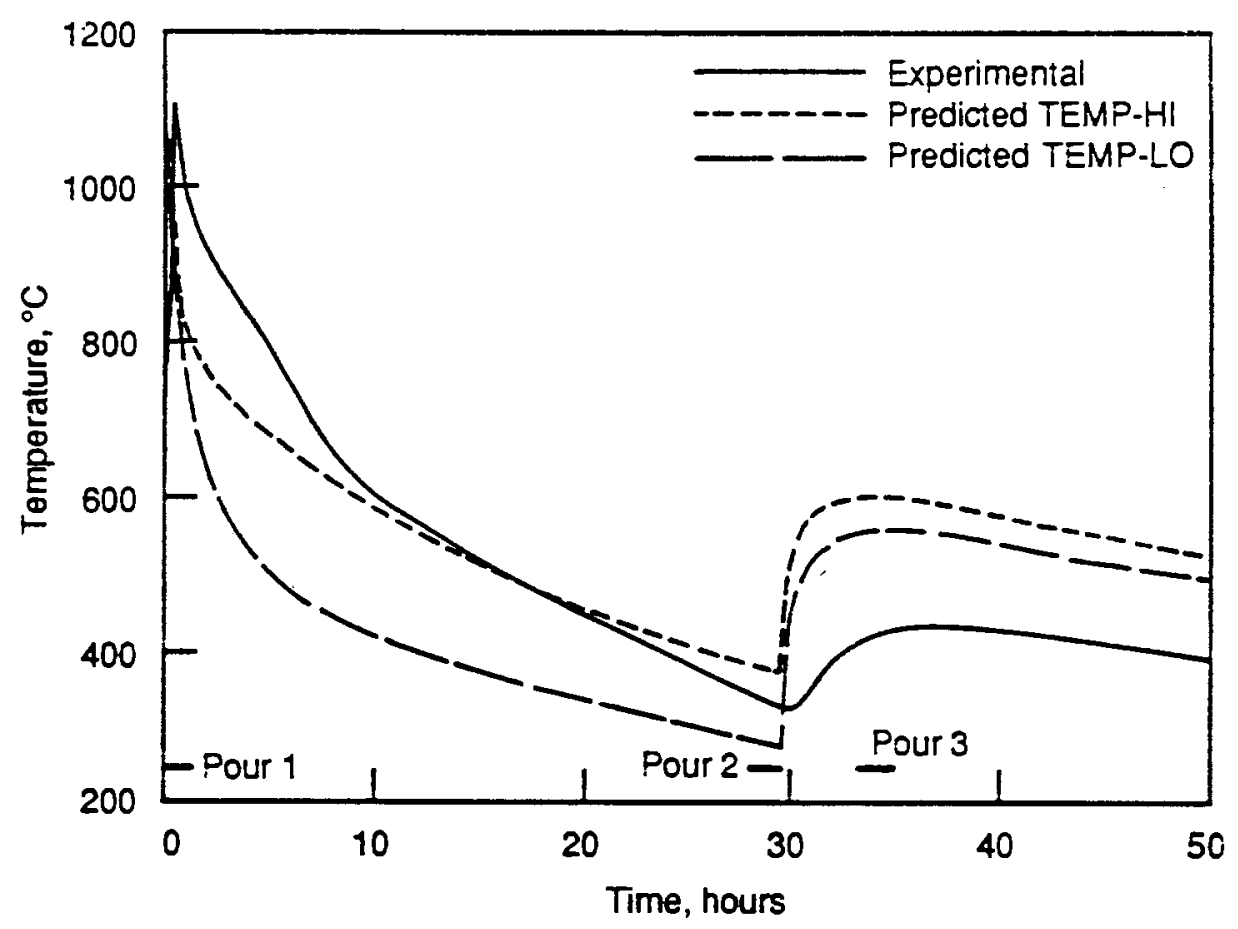

FIGURE 6.10. TEMPEST High- and Low-Temperature Radiation Model Predictions and Experimental Temperatures Measured in Canister $12 \mathrm{HI}$ at Axial Level 12.125 in. from Canister Bottom

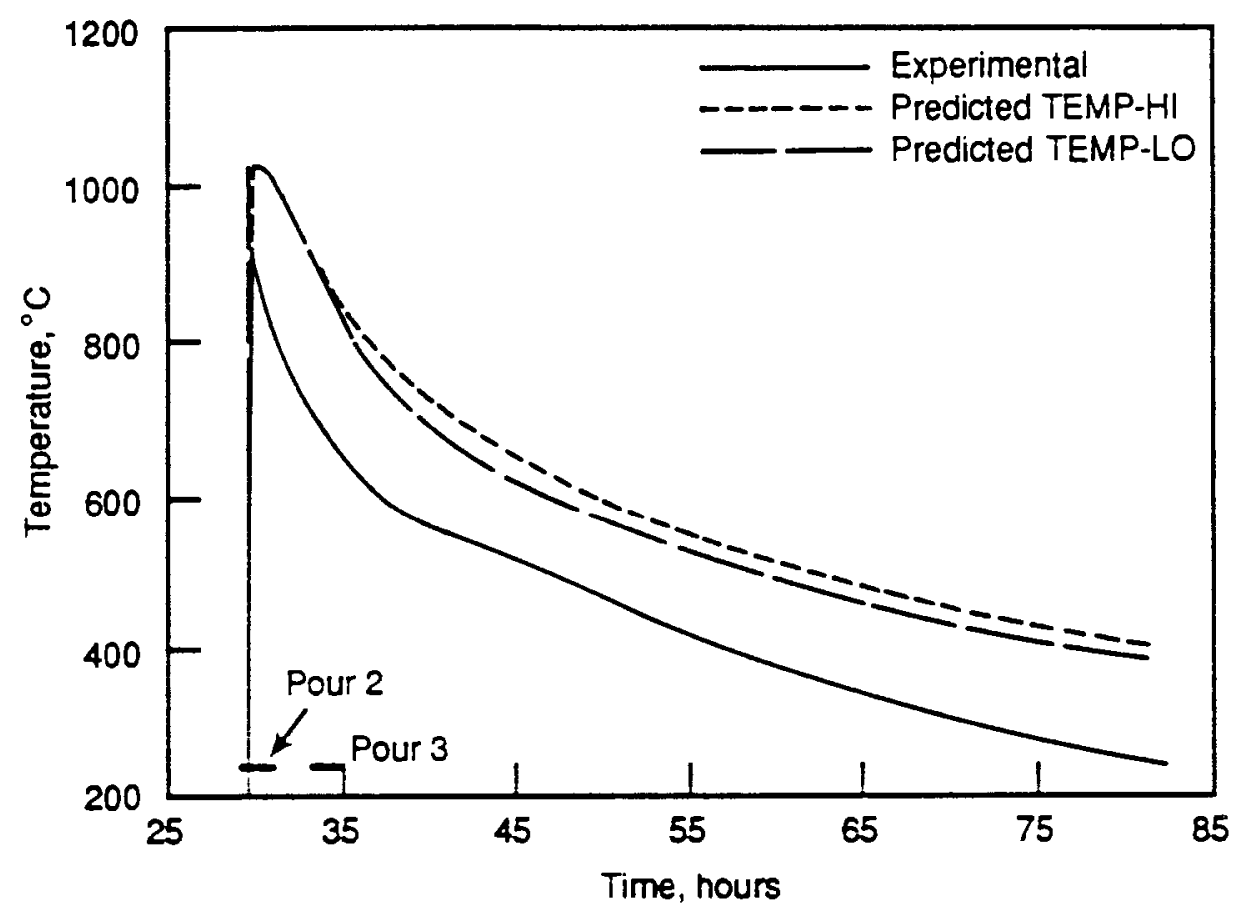

FIGURE 6.11. TEMPEST High- and Low-Temperature Radiation Model Predictions and Experimental Temperatures Measured in Canister $12 \mathrm{HI}$ at Axial Level 20.0 in. from Canister Bottom (Second Pour) 


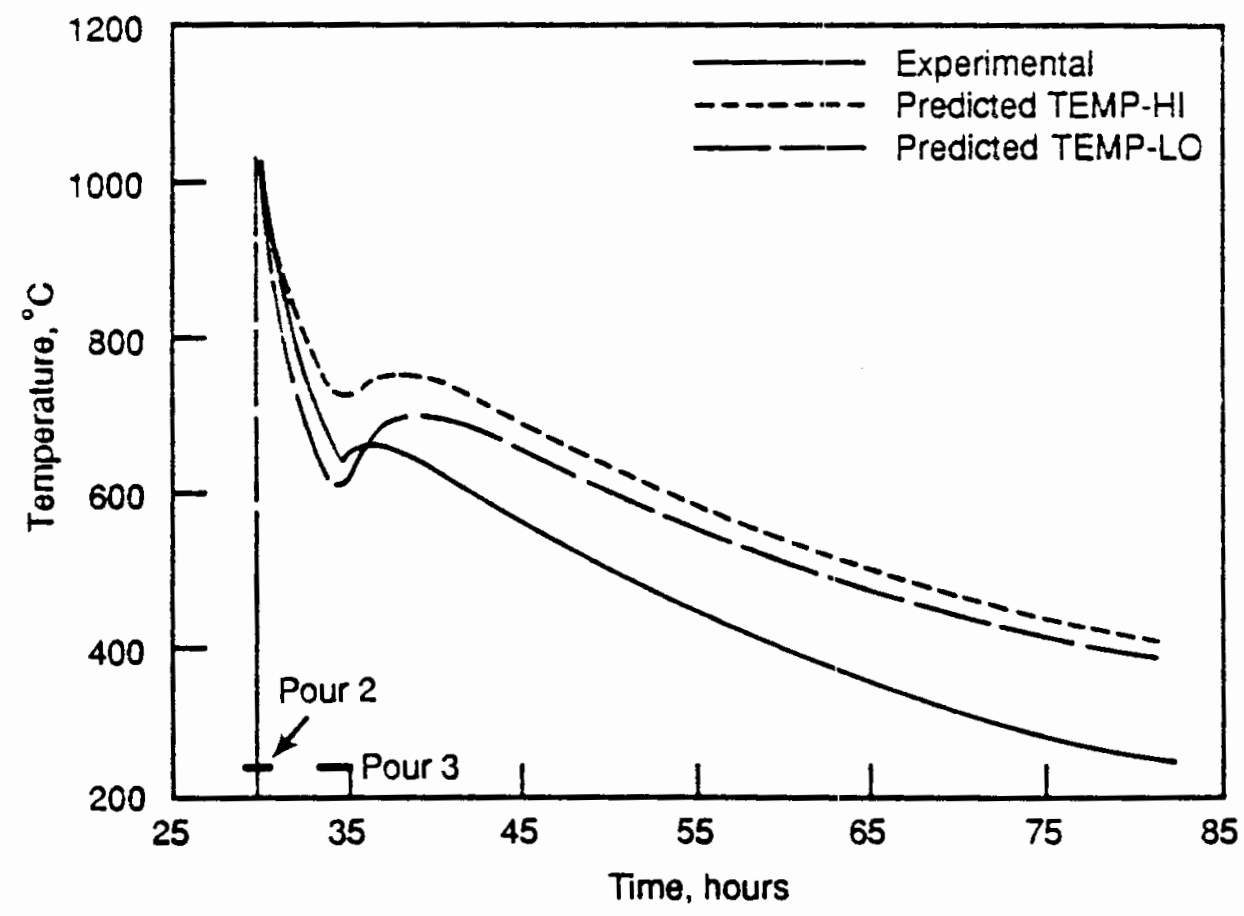

FIGURE 6.12. TEMPEST High- and Low-Temperature Radiation Model Predictions and Experimental Temperatures Measured in Canister $12 \mathrm{HI}$ at Axial Level 24.875 in. from Canister Bottom

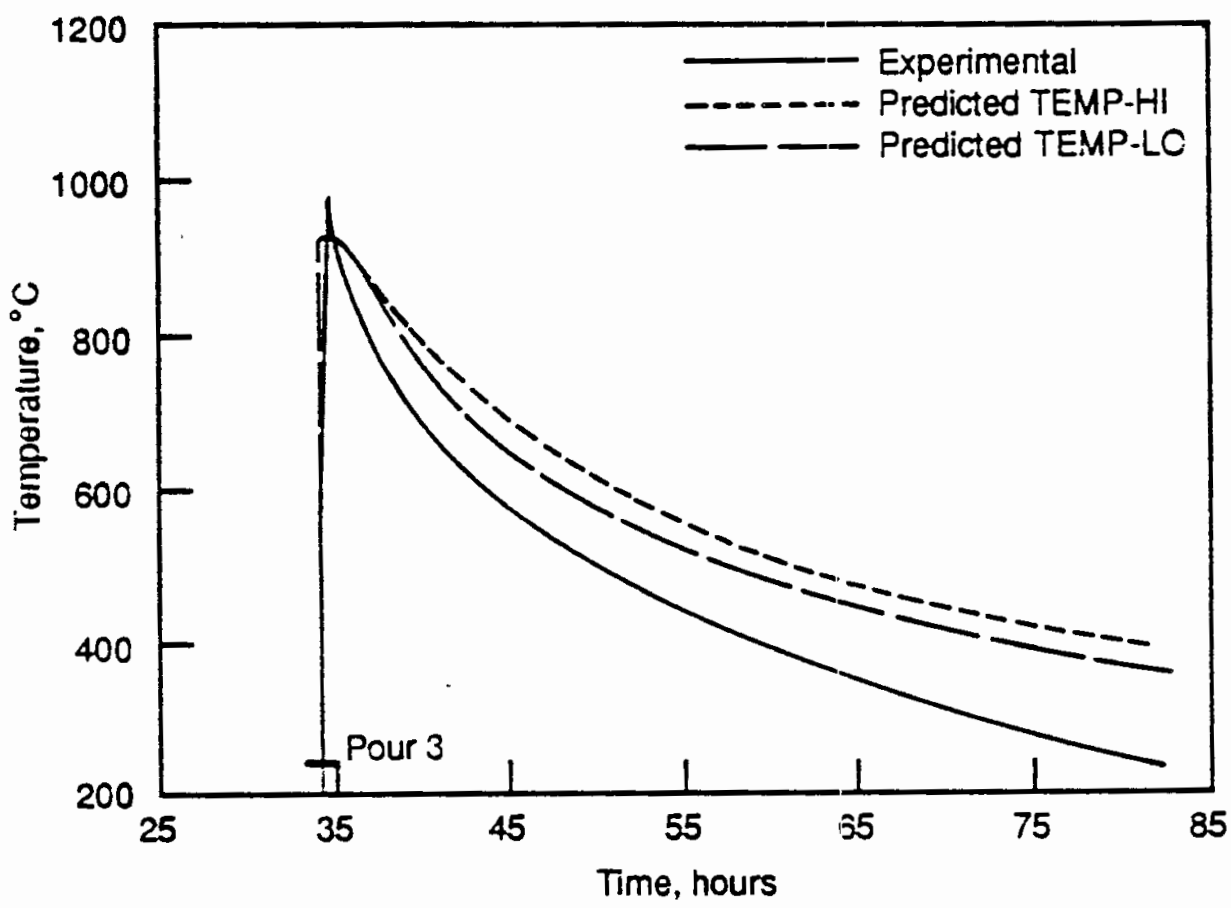

FIGURE 6.13. TEMPEST High- and Low-Temperature Radiation Model Predictions and Experimental Temperatures Measured in Canister $12 \mathrm{HI}$ at Axial Level 32.75 in. from Canister Bottom 


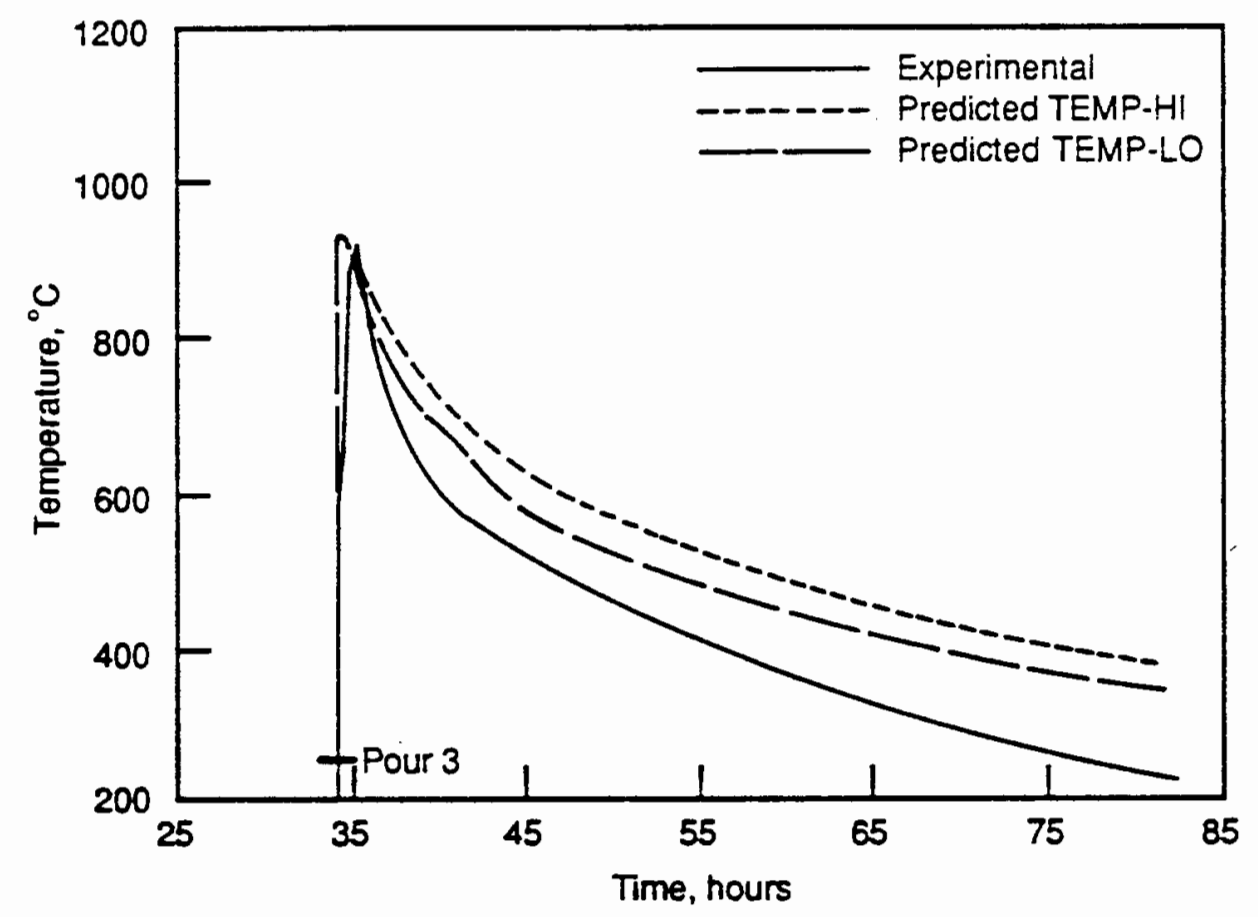

FIGURE 6.14. TEMPEST High- and Low-Temperature Radiation Model Predictions and Experimental Temperatures Measured in Canister $12 \mathrm{HI}$ at Axial Level 35.875 in. from Canister Bottom

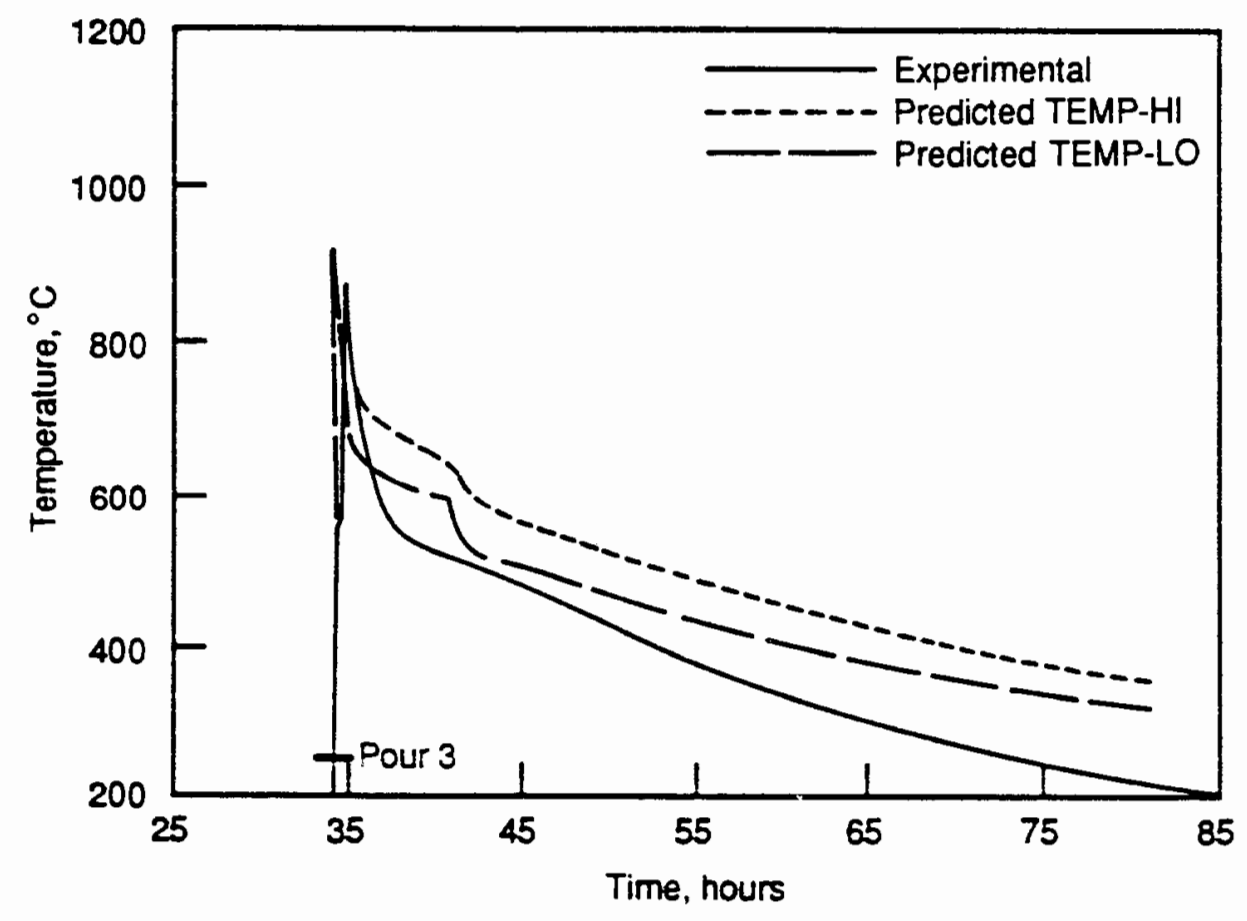

FIGURE 6.15. TEMPEST High- and Low-Temperature Radiation Model Predictions and Experimental Temperatures Measured in Canister 12HI at Axial Level 37.625 in. from Canister Bottom 
rapidly. This suggests that an error in glass height measurement might explain the large difference in the predictions of the high and low radiation models.

Note that level 3 is 1 in. from the top of pour 1 and level 5 is only 2.2 in. from the top of pour 2. In each case, a greater than $50^{\circ} \mathrm{C}$ difference occurs between the two models. Because the levels of the first and second pours were known to within an accuracy of only 1 in., it is possible that these large differences between the two radiation models were partially caused by an error in assumed glass level for TEMPEST. For example, if level 3 was only $0.5 \mathrm{in}$. from the glass surface, the effects of the heat loss from the surface by radiation (as opposed to heat loss through the walls) would be significantly greater than if $1 \mathrm{in}$. of glass covered the thermocouple. Thus, errors in glass height could well be the explanation for these large differences in results obtained from the two radiation models.

However, for the most part, the differences between the two radiation models were small enough that they did not change the general picture. For canister $12 \mathrm{HI}$, TEMPEST underpredicts the rate of cooldown immediately after a pour and, to a lesser extent, it underpredicts the rate of cooldown thereafter.

Canister 12LI

Canister $12 \mathrm{LI}$ was covered with $1 / 4 \mathrm{in}$. of Durablanket insulation. This canister was filled in three pours; the second and third batches of glass were poured 5.1 to $6.0 \mathrm{~h}$ and 11.9 to $12.7 \mathrm{~h}$, after initiation of the first pour. Glass interfaces between the three pours were at $12.9 \mathrm{in.,} 25.7 \mathrm{in.,}$ and $39.5 \mathrm{in.}$ Because the canister has less insulation, the radial temperature differences were larger and the cooling rates greater than those of canister $12 \mathrm{HI}$.

Comparisons between the temperatures predicted by TEMPEST using the hightemperature radiation model and the temperatures observed at the eight axial thermocouple levels are presented in Figures 6.16 through 6.22. Unlike canister $12 \mathrm{HI}$, the onset of heating from the second pour could not be detected at the first thermocouple level (3.75 in. as shown in Figure 6.16), although the amount of glass added during the first pour was nearly the same for both 


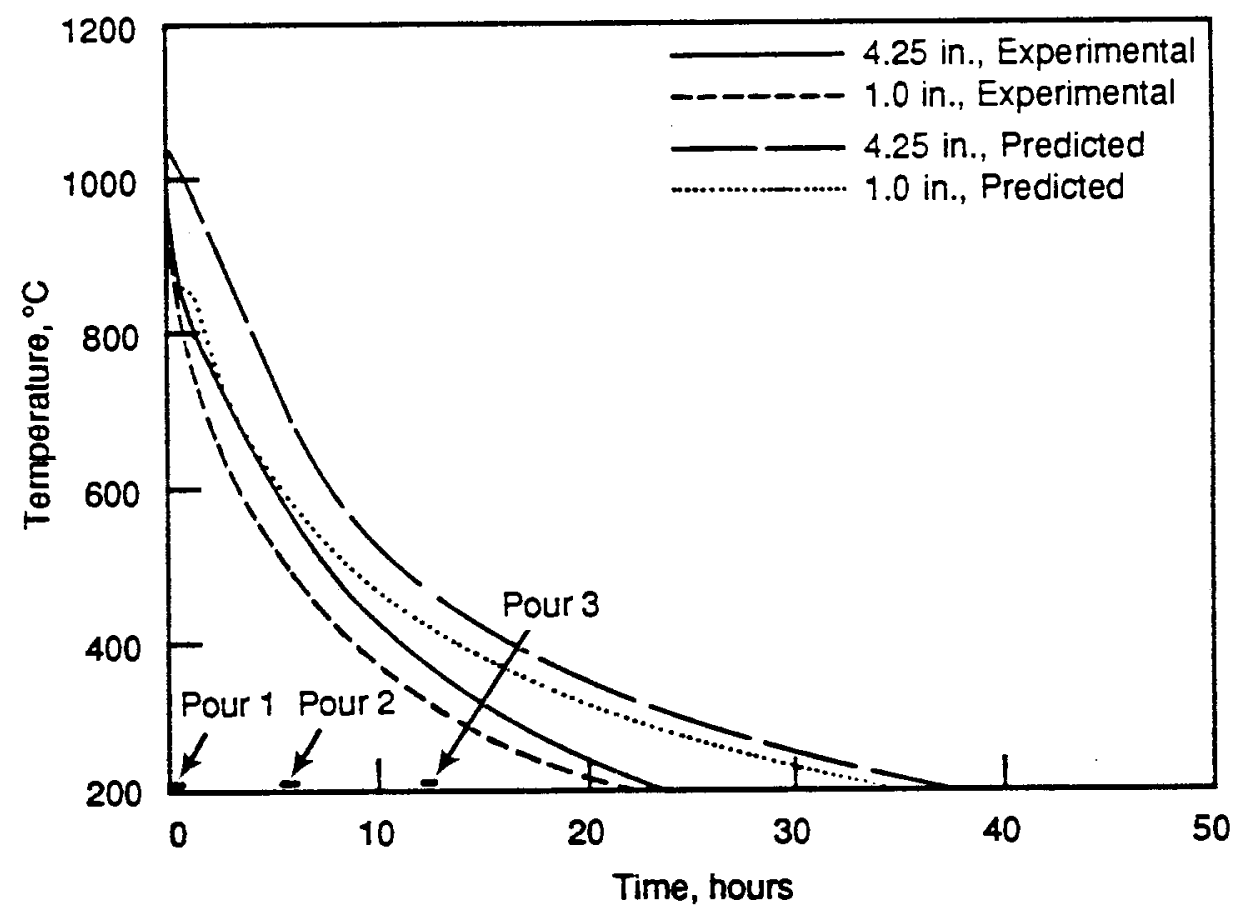

FIGURE 6.16. TEMPEST Predictions and Experimental Temperatures Measured in Canister 12LI at Axial Level 3.75 in. from Canister Bottom

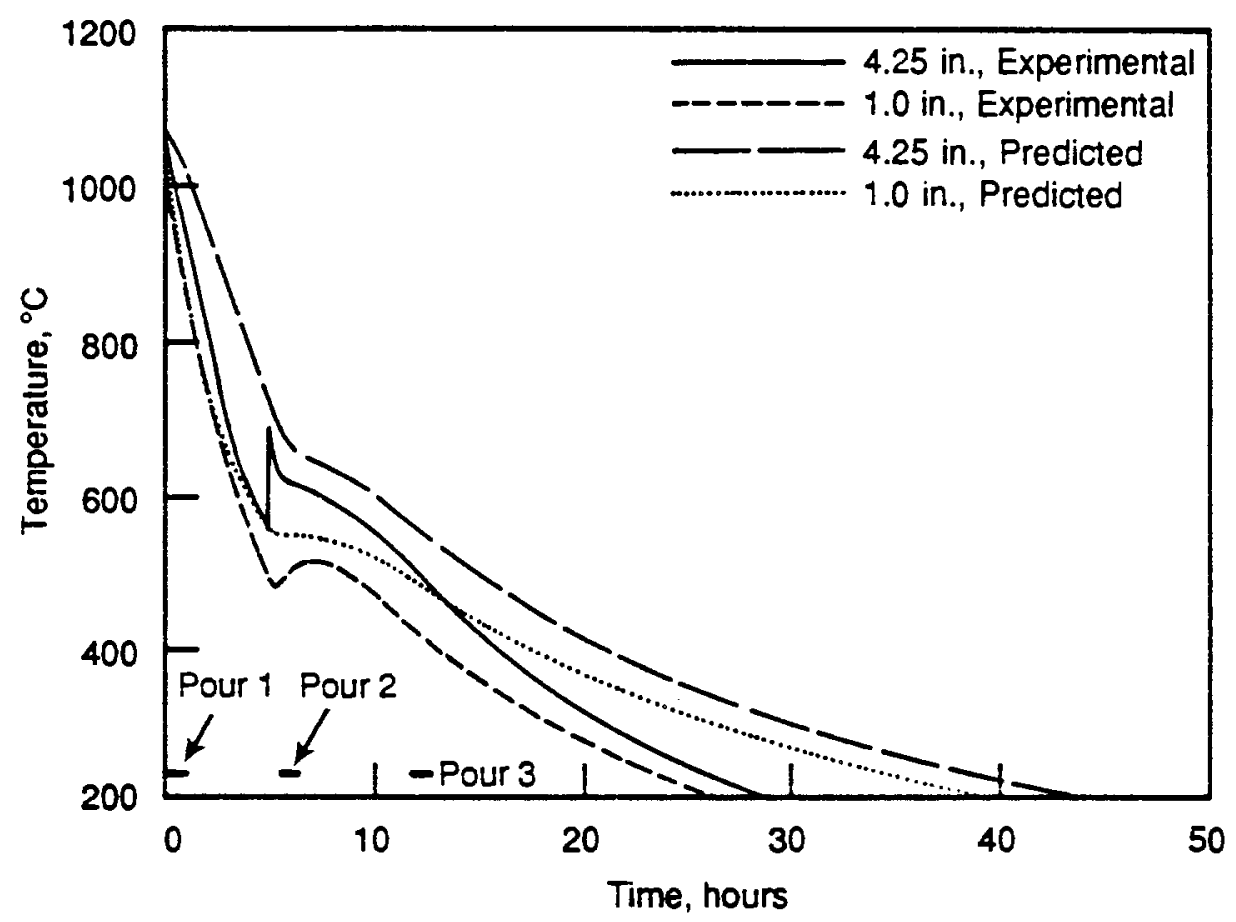

FIGURE 6.17. TEMPEST Predictions and Experimental Temperatures Measured in Canister 12LI at Axial Level 9.50 in. from Canister Bottom 


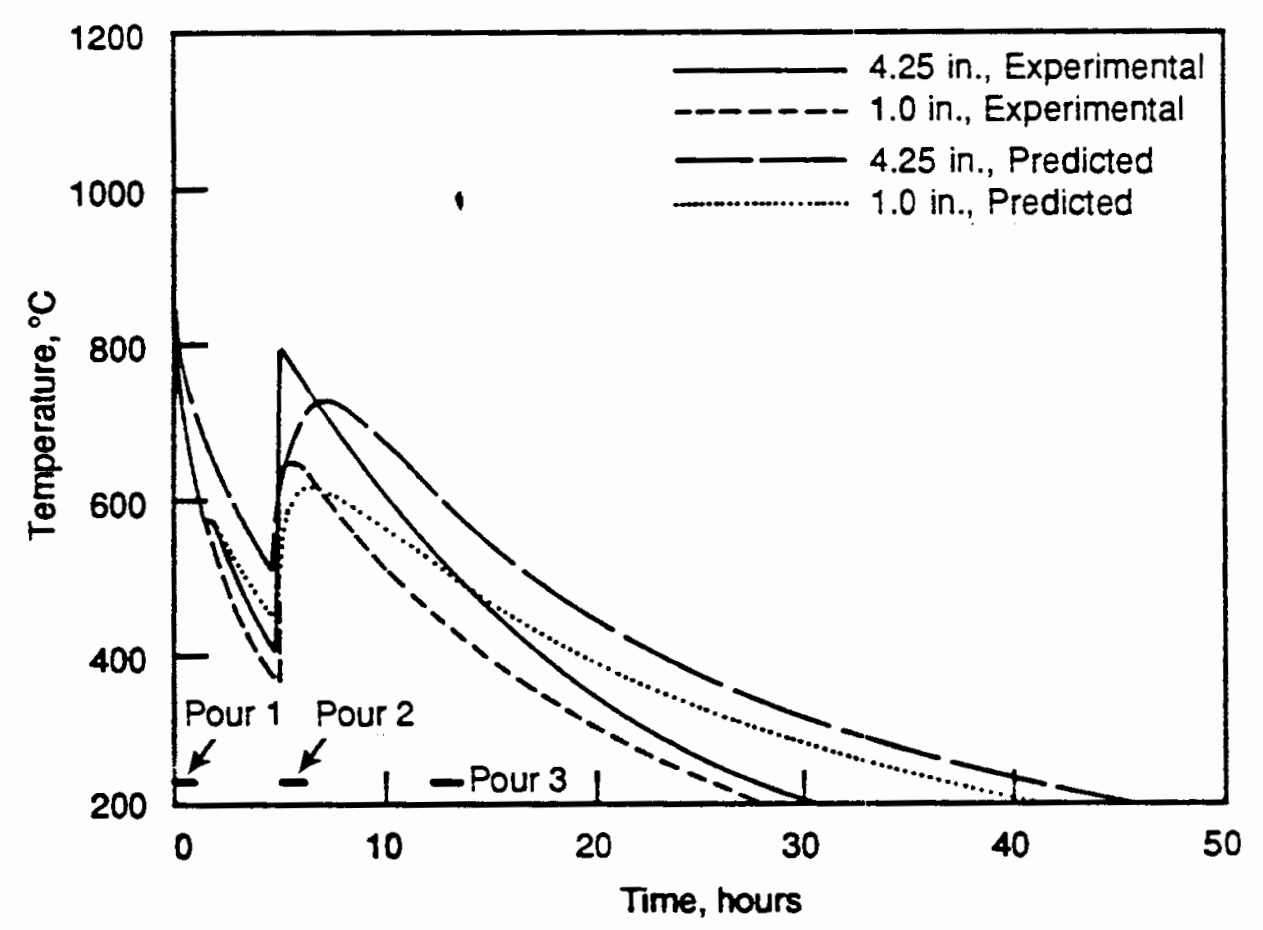

FIGURE 6.18. TEMPEST Predictions and Experimental Temperatures Measured in Canister 12LI at Axial Level 12.175 in. from Canister Bottom

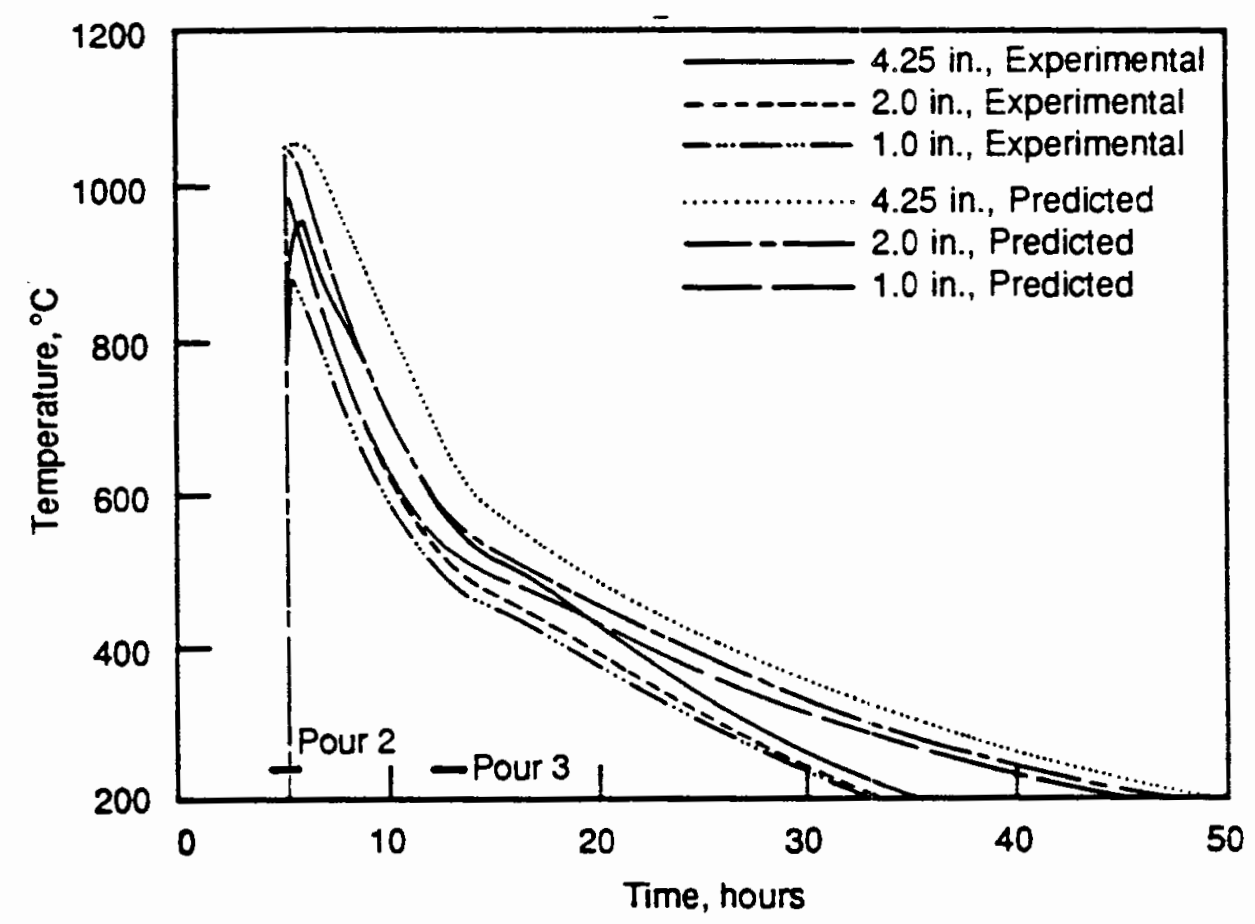

FIGURE 6.19. TEMPEST Predictions and Experimental Temperatures Measured in Canister 12LI at Axial Level 20.0 in. from Canister Bottom 


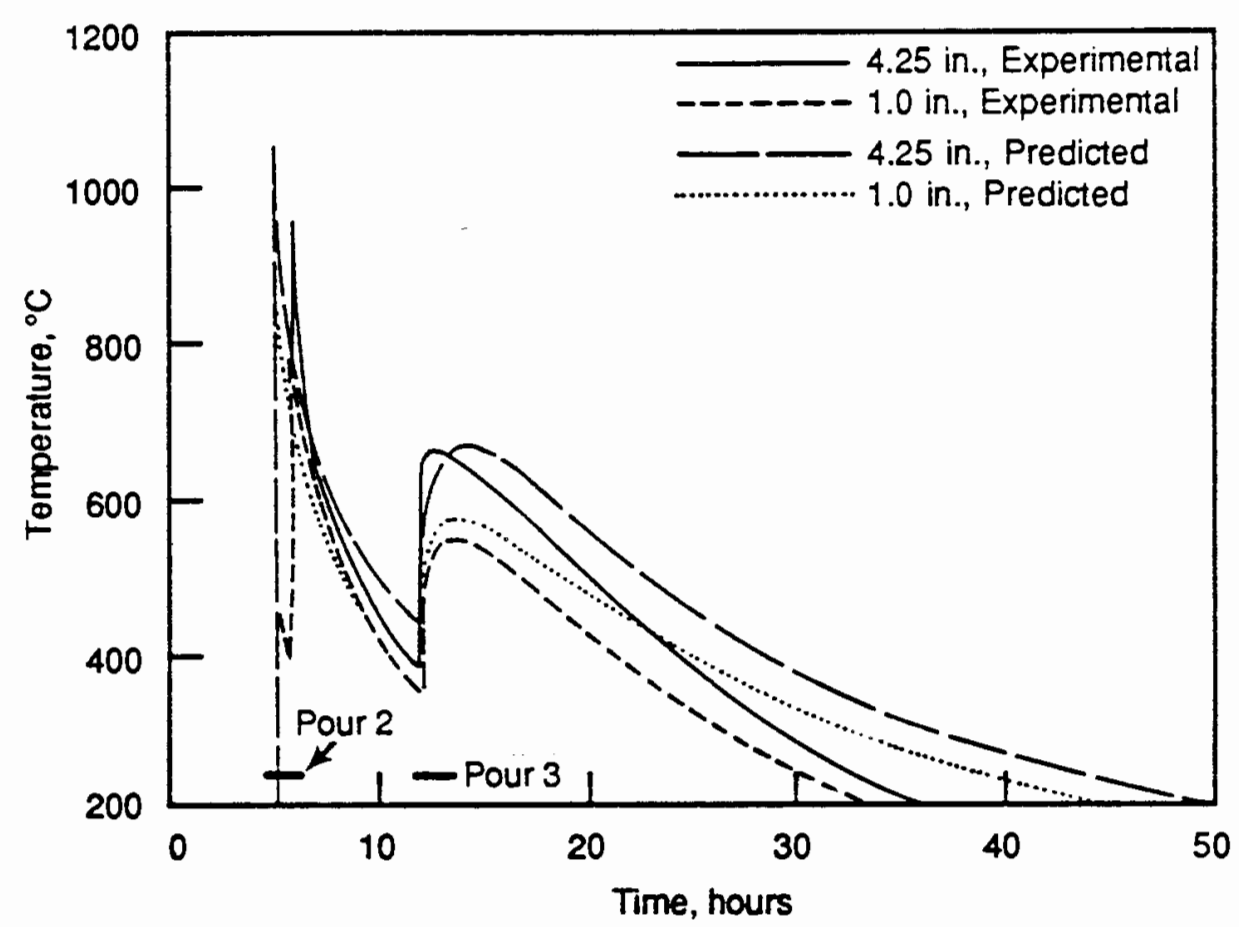

FIGURE 6.20. TEMPEST Predictions and Experimental Temperatures Measured in Canister 12LI at Axial Level 24.875 in. from Canister Bottom

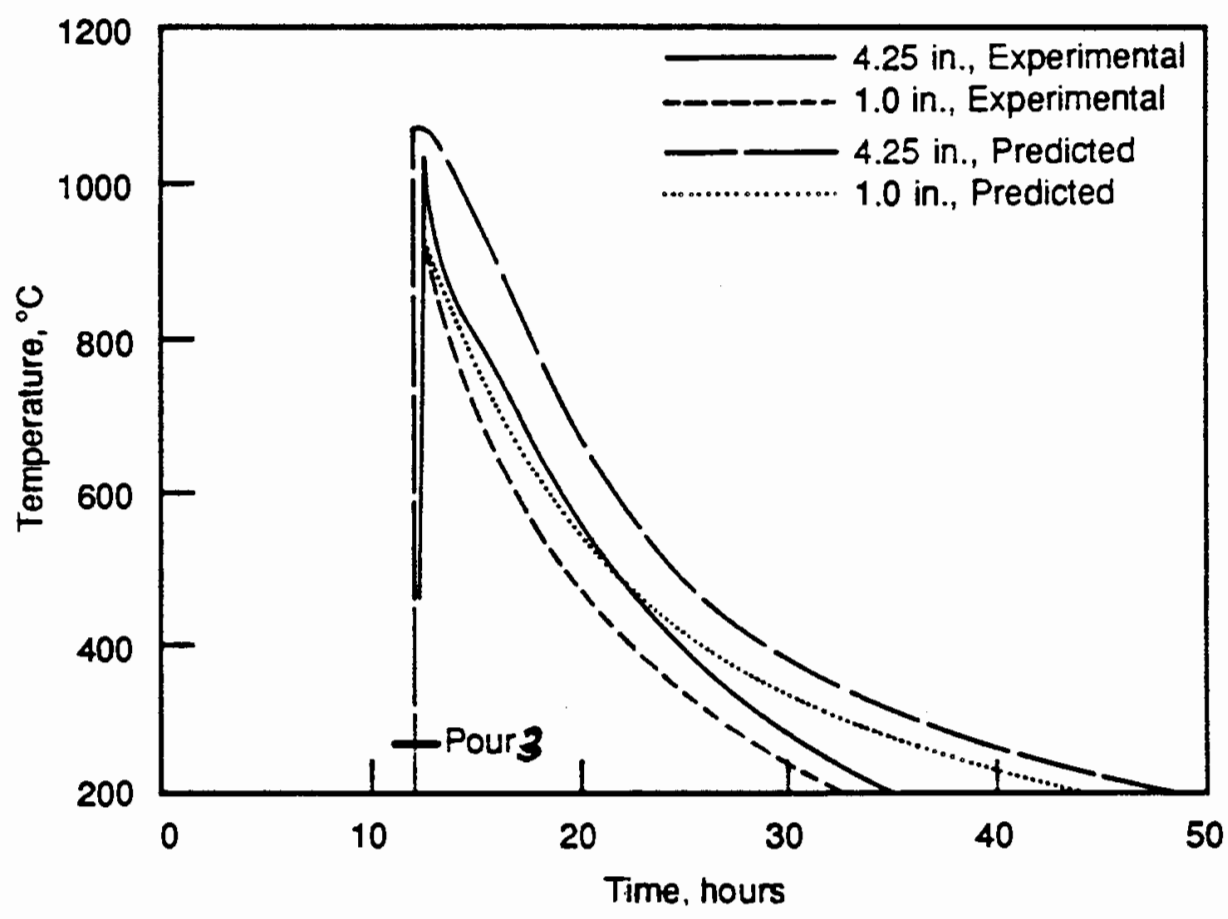

FIGURE 6.21. TEMPEST Predictions and Experimental Temperatures Measured in Canister 12LI at Axial Level 32.75 in. from Canister Bottom 


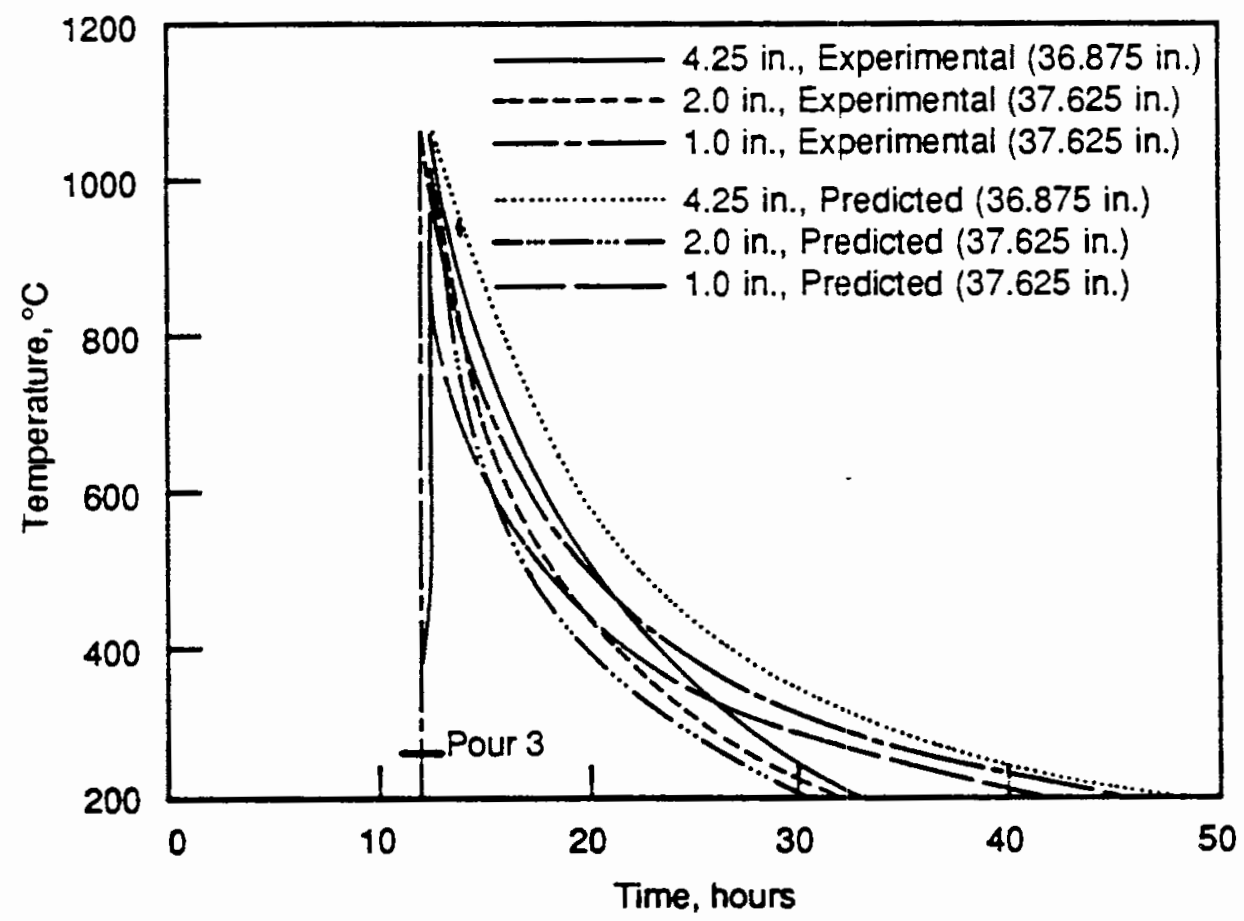

FIGURE 6.22. TEMPEST Predictions and Experimental Temperatures Measured in Canister 12LI at Axial Levels 35.875 and 37.625 in. from Canister Bottom

canisters. However, significant reheating occurred from the second pour at the second and third axial thermocouple levels, as shown in Figures 6.17 and 6.18 . As in the case of 12HI, the TEMPEST-predicted cooldown immediately after the first pour was too slow. However, instead of an improvement in agreement as time progressed after the first pour, the difference between the observed and predicted temperatures increased, despite the greater thermal driving force caused by the higher temperatures.

It is also interesting to note that TEMPEST predicted a less steep reheat at the second and third axial thermocouple levels of canister $12 \mathrm{LI}$ than that observed (Figures 6.17 and 6.18).

Figures 6.19 and 6.20 show the results for the two axial thermocouple levels covered during the second pour. The high temperatures predicted by TEMPEST for thermocouple level 4 (Figure 6.19) during the period immediately after the pour appear to be caused by TEMPEST using a higher initial glass temperature. However, consistent with the first four, the predicted cooling 
rate beyond $12 \mathrm{~h}$ was lower than that observed in the experiment. The observed and predicted points of inflection caused by reheating from the third pour appear similar (Figure 6.19).

The fifth axial thermocouple level is 24.9 in. from the bottom of the canister, which is only $0.6 \mathrm{in}$. from the top of the second pour. Careful analyses of the raw data clearly show that the fifth axial thermocouple level for canister 12LI was covered during the pour. However, glass levels cannot be predicted to better than about an inch. Significant axial temperature gradients exist near the surface because of the large radiant flux there. The agreement between experimental and predicted values (Figure 6.20) is very good, considering the uncertainties. The reheat pulse was reasonably modeled. However, the predicted long-term cooling rate was slower than that observed.

Figures 6.21 and 6.22 present the predicted and observed results for the three axial thermocouple levels covered during the third glass pour in canister 12LI. The TEMPEST predictions immediately after the fill were lower than the observed temperatures instead of being too high. However, as with canister $12 \mathrm{HI}$, the predicted long-term cooling rates were too low. Note that TEMPEST correctly predicts that the temperature of the uppermost axial thermocouple level, which is only $1.9 \mathrm{in}$. from the surface, is lower than that on the next lowest axial thermocouple level at the same radial position, which is located 3.7 in. from the surface, because of axial cooling affects.

Figure 6.23 presents the predicted and observed axial temperature profiles at the 4.25-in. radial location for canister $12 \mathrm{LI}$. The figure is composed of three sections. The uppermost section gives the TEMPEST predictions (solid line) for the glass in the canister after the first pour. The middle and bottom sections present the TEMPEST predictions for the glass after the second and final (third) pours, respectively. In all cases, the experimental data are plotted as points and the predictions are plotted as curves. The curves are plotted with time as the parameter. The times were selected to give values immediately after a pour was finished, roughly midway between two pours, and immediately before the next pour. 


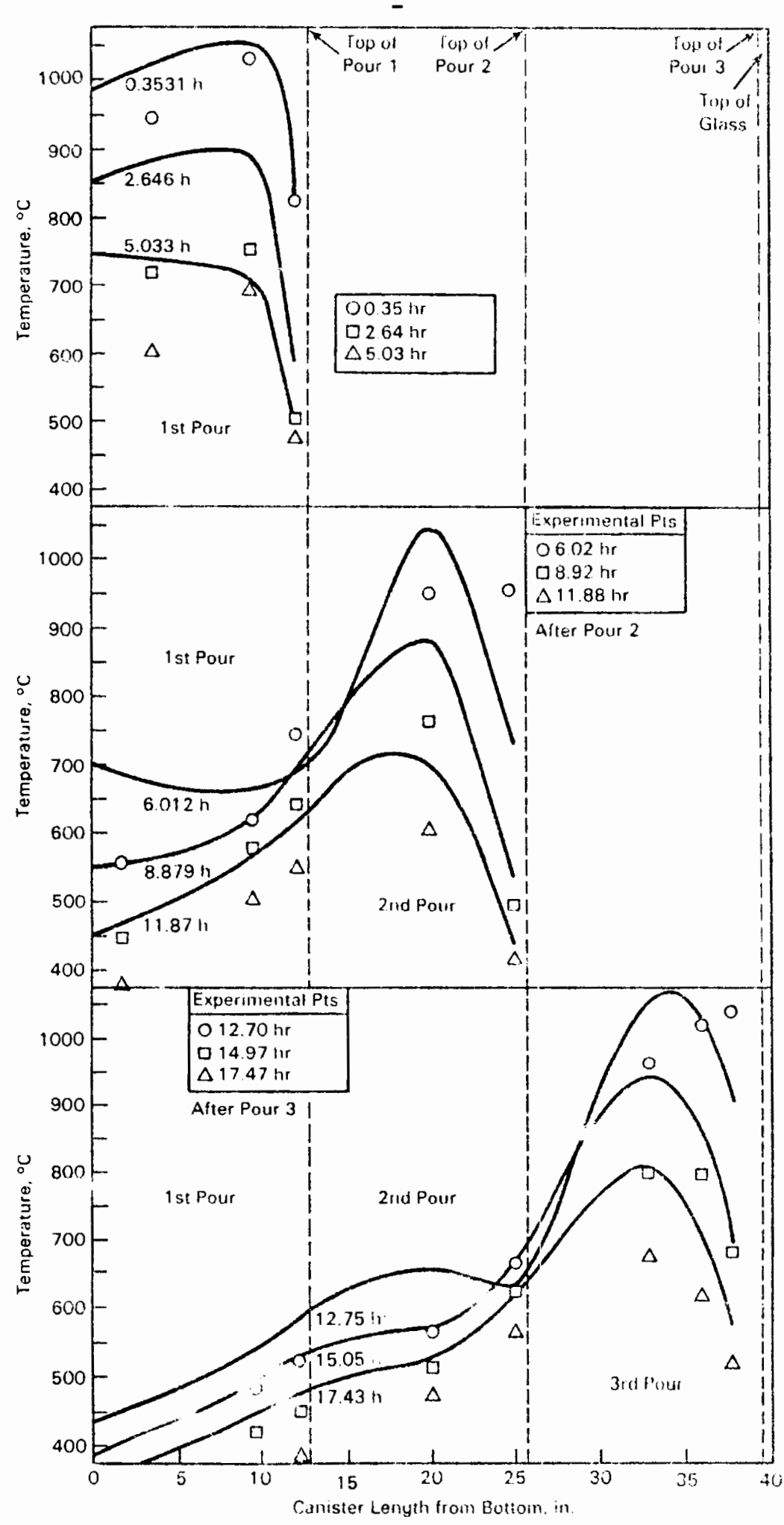

FIGURE 6.23. Axial Profiles for Canister 12LI 
In most cases, the TEMPEST predictions were higher than the observed temperatures. A few exceptions occurred at pour interfaces immediately after a pour. For example, note that the data point at $12.125 \mathrm{in}$. at $6.012 \mathrm{~h}$ lies above the TEMPEST prediction line. Note also that the agreement between the experimental points and the TEMPEST predictions was relatively accurate at the glass/air interface for times far removed from the end of the pour.

The predicted axial temperatures near the bottom of the canister, and the predicted shape of the axial profile immediately after the second and third pours $(6.012 \mathrm{~h}$ and $12.7 \mathrm{~h})$ did not agree closely with the experimental data. The high predicted temperatures at the bottom of the canister are probably due to the assumption made in the TEMPEST batch-fill model, that the glass for each pour is instantaneously placed in the canister. It is also possible that the high predictions for the temperatures at the bottom of the canister may be caused by larger than expected heat transfer out of the bottom of the canister. However, instead of instantaneously filling each canister with glass, the three batch pours required $0.25 \mathrm{~h}, 0.93 \mathrm{~h}$ and $0.82 \mathrm{~h}$, respectively. During these periods, hot, new glass was continuously added to the glass surface, thereby keeping the surface temperature high. The batch model, however, postulates that a hot cylinder of glass, roughly $13 \mathrm{in.} \mathrm{high,} \mathrm{is} \mathrm{instantaneously} \mathrm{added} \mathrm{to}$ the canister. This entire cylinder begins to cool at the start of the pour from both ends. Thus, the batch-fill model:

- overpredicts the temperature at the bottom of the batch immediately after a pour because it underestimates the heat loss from radiation that occurred at this position during the initial stage of the pour

- underpredicts the temperature at the top of the batch because the model starts cooling the top of the pour at the beginning of the pour, where, in reality, the top of the pour consists of fresh, hot glass placed there at the end of the pour.

The cooling of each batch of glass will result in predicted temperature profiles that peak in the center of each pour; this is seen in all three cases. The predicted temperature profiles for the top of the first batch immediately after pouring $(0.35 \mathrm{~h})$ were reasonably accurate, because the pour was relatively short. However, the TEMPEST predictions for the second and 
third pours were much lower than the actual temperature profiles. This is because of the long periods for pours 2 and $3(0.93 \mathrm{~h}$ and $0.82 \mathrm{~h}$, respectively). The inaccuracies involved in batch-pouring simulations are the primary reason why work was begun on an improved version of TEMPEST, as described in Section 3.3.

Figures 6.24 through 6.26 present comparisons of the observed and predicted temperatures for three axial thermocouple levels at the 4.25-in. radial position. Both the high-temperature and low-temperature radiation models are included in each figure. As mentioned above, use of these two models was expected to bound the radiant heat transfer from the surface if all other aspects of the modeling were accurate. Although the low-temperature model does indeed predict lower glass temperatures, the effect is very small for six of the eight levels. The remaining two levels showed a slightly increased sensitivity to the model used (Figures 6.25 and 6.26). Thus, except for a few relatively short times at two axial levels, the predicted temperatures remained above the observed results in a manner entirely consistent with the hightemperature case.

The reduced temperature sensitivity of the high- and low-radiation heattransfer models is probably caused by the much higher rate of heat losses from the canister surface. These higher heat losses are caused by the thinner layer of external insulation. As a result, radiation heat transfer from the glass surface is much less important than for the 3-in. insulated canister $(12 \mathrm{HI})$. The two exceptions, Figures 6.25 and 6.26 , were for thermocouple locations near the top of the pours. Because the effect of radiation cooling is largest at these positions, it is not surprising that larger differences are found.

\subsubsection{TEMPEST Cont inuous-Fill Model}

As mentioned earlier, the continuous-fill model, TEMPEST Version $M$, was used to model canisters 13 and 24. Although the latter could have been modeled using the batch-fill version, the large number of batches (33) made the continuous-fill model a better choice because it eliminated the considerable manual labor associated with each restart. 


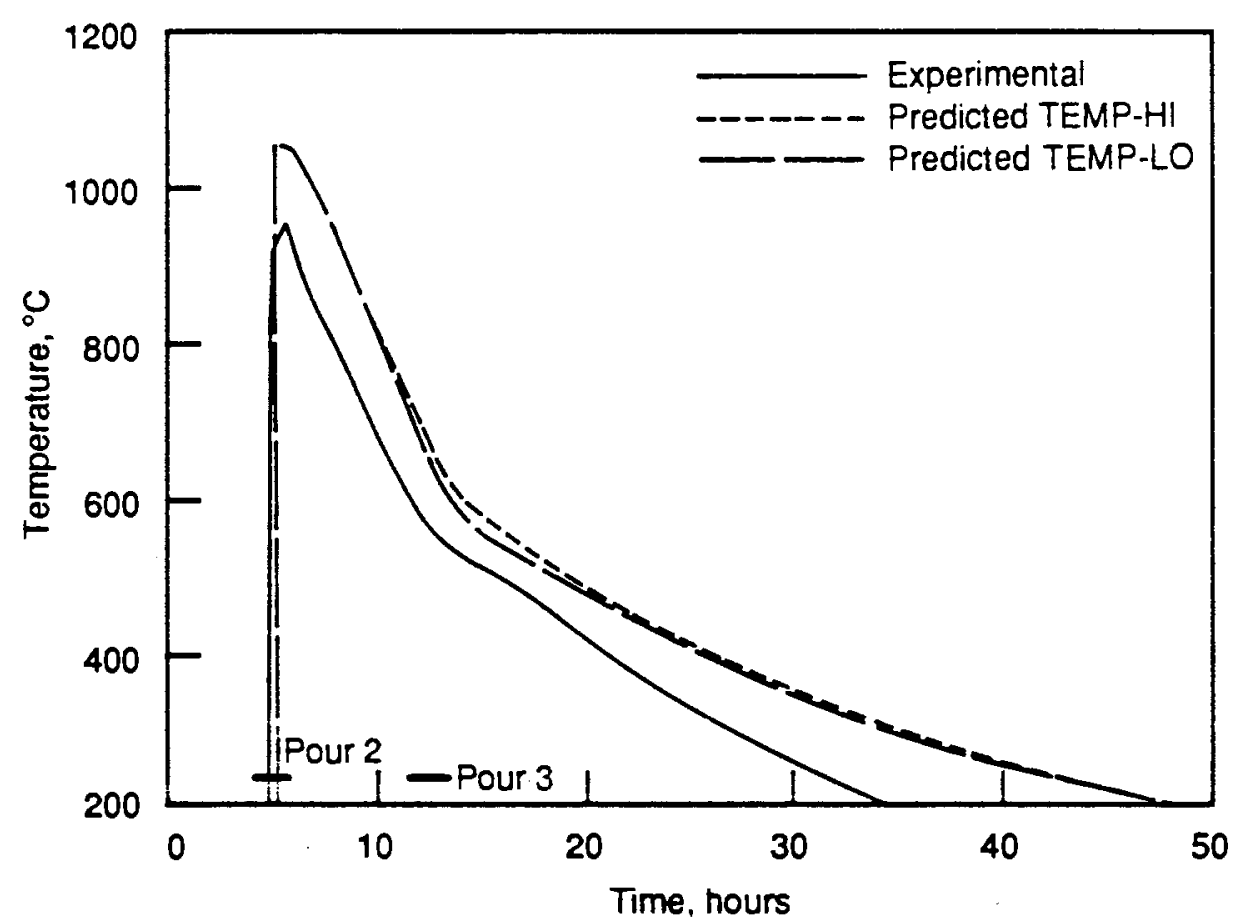

FIGURE 6.24. TEMPEST High- and Low-Temperature Radiation Model Predictions and Experimental Temperatures Measured in Canister 12LI at Axial Level 12.175 in. from Canister Bottom

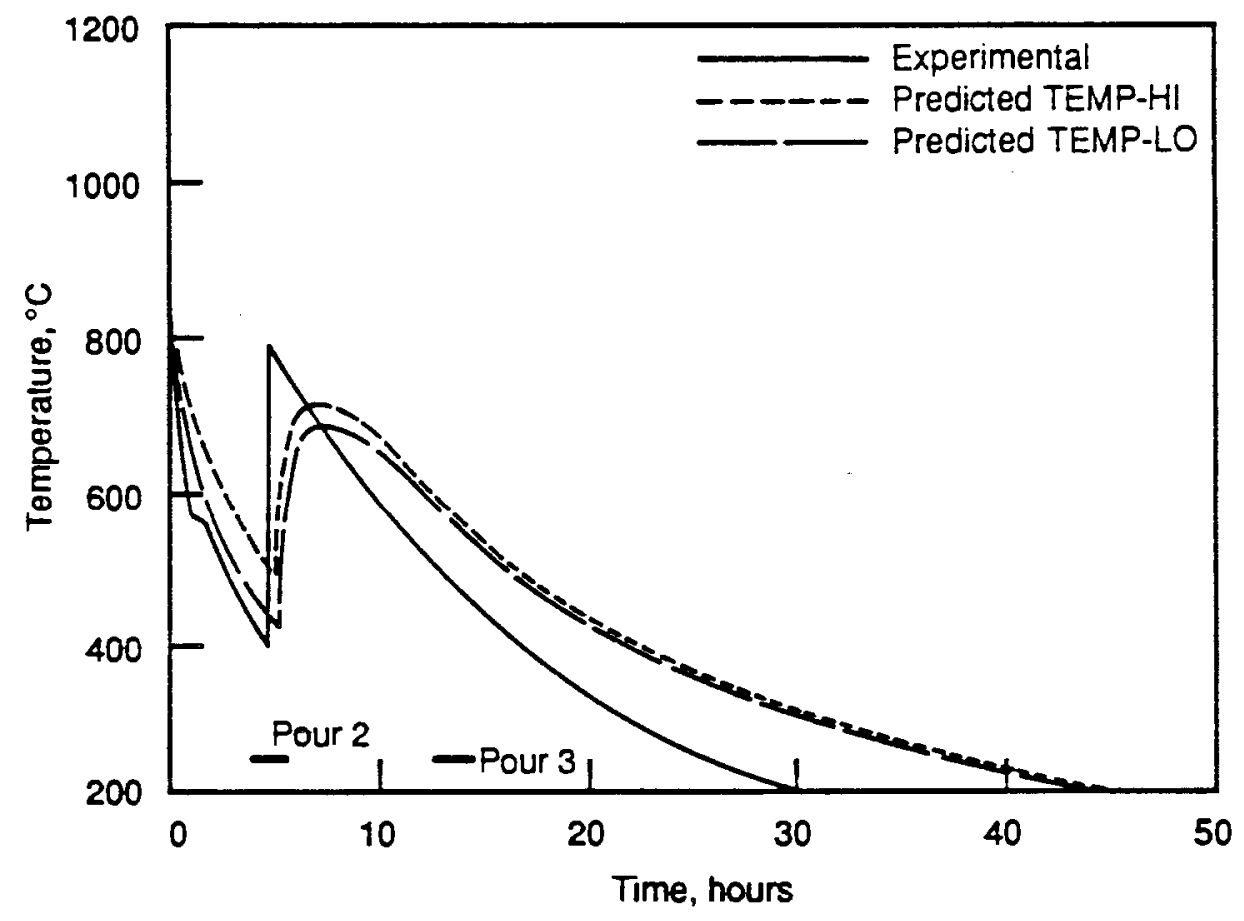

FIGURE 6.25. TEMPEST High- and Low-Temperature Radiation Model Predictions and Experimental Temperatures Measured in Canister $12 \mathrm{LI}$ at Axial Level $20 \mathrm{in.}$. from Canister Bottom 


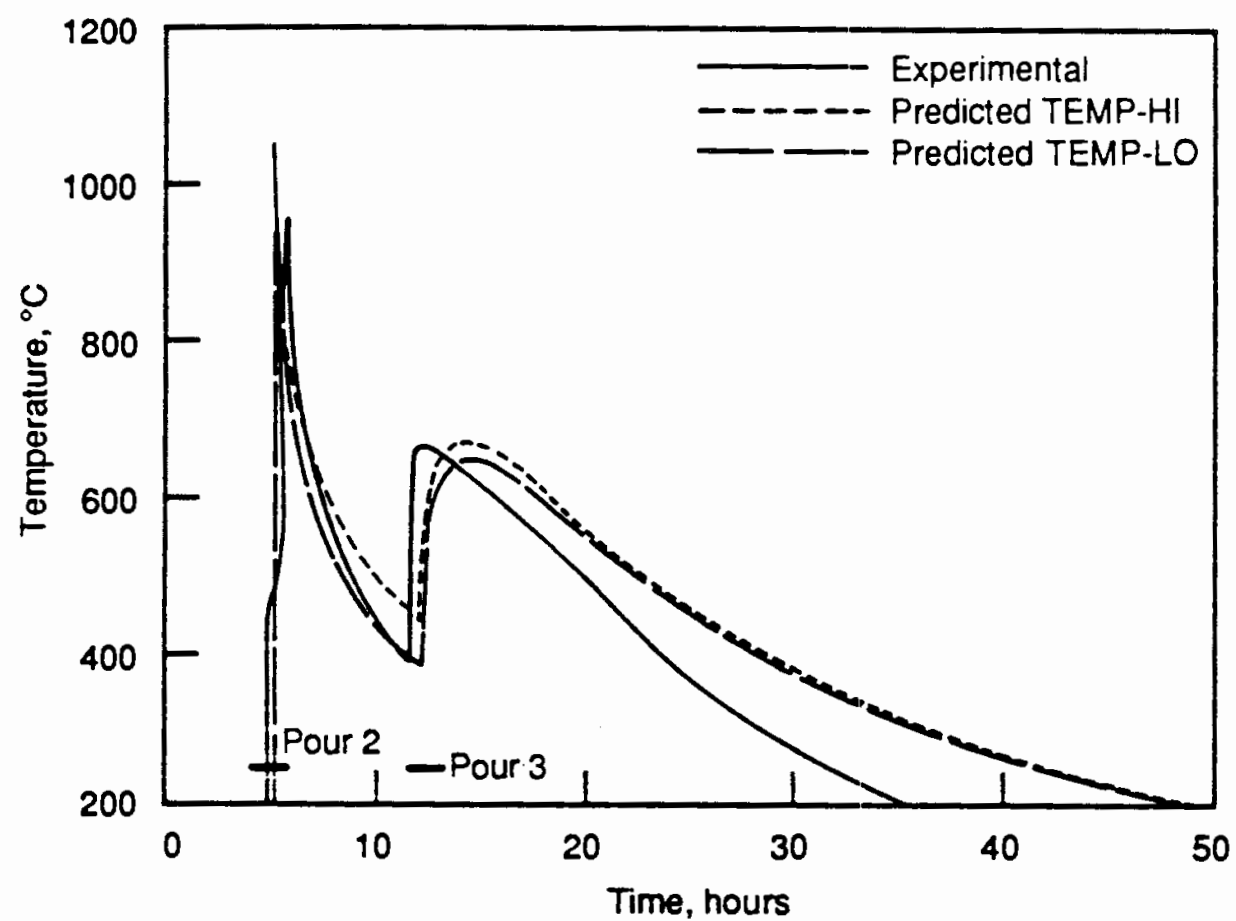

FIGURE 6.26. TEMPEST High- and Low-Temperature Radiation Model Predictions and Experimental Temperatures Measured in Canister 12LI at Axial Level $24.875 \mathrm{in.}$ from Canister Bottom

\section{3-in.-Diameter Canister}

The TEMPEST model for the 13-in.-diameter canister was insulated with $1 / 8$ in. of Fiberfrax on the inside and $1 / 4 \mathrm{in}$. of Durablanket on the outside (see Table 4.1). This is slightly different from the actual canister geometry. The canister was filled using a continuous pouring procedure. The fill rate used was an average value assuming constant fill rates between thermocouple levels during the 263-min period required to fill the canister (see Table 4.10). Figures 6.27 through 6.32 compare the TEMPEST predictions to the observed temperatures for the six thermocouple levels.

The long-term cooling behavior is similar to that found with the batch pours. However, with one exception TEMPEST also predicts a slower cooling rate than that observed after the initial transient (the thermocouple at the glass/Fiberfrax interface; see Figure 6.32). This difference results in the predicted temperatures of each position eventually exceeding the observed temperatures. 


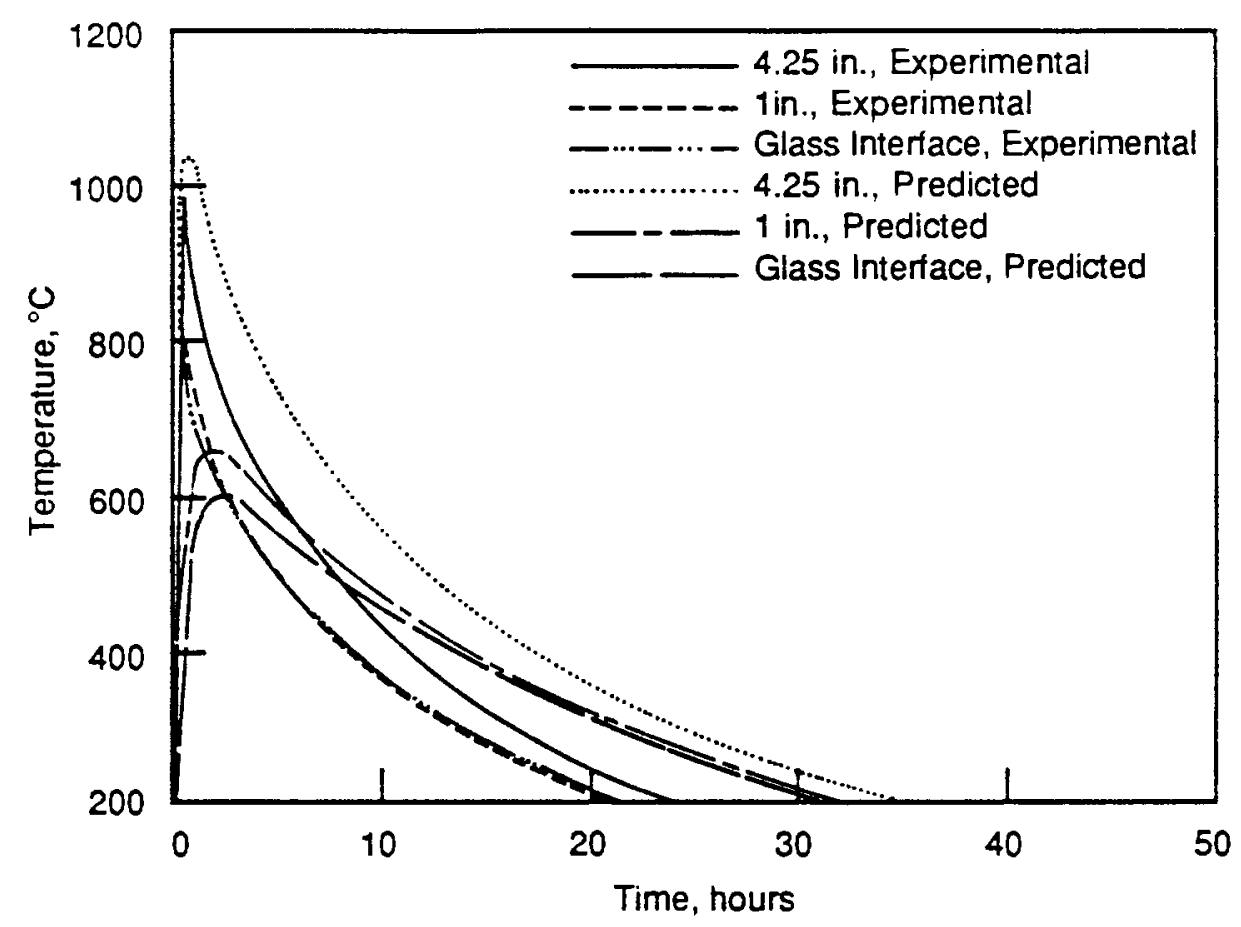

FIGURE 6.27. TEMPEST Predictions and Experimental Temperatures for the 13-in.-Diameter Canister at Axial Level 3.5 in. from Canister Bottom

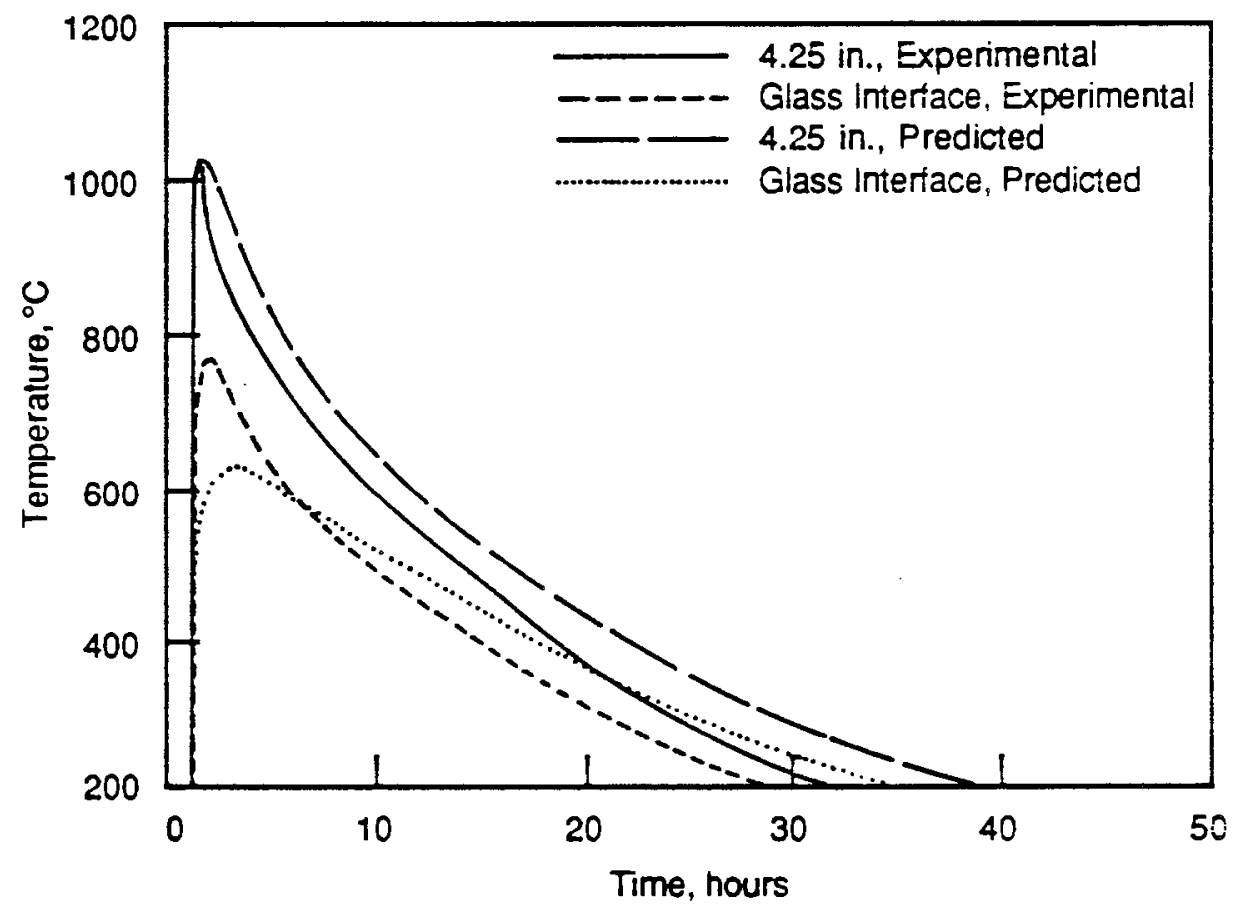

FIGURE 6.28. TEMPEST Predictions and Experimental Temperatures for the 13-in.-Diameter Canister at Axial Level 13.3 in. from Canister Bottom 


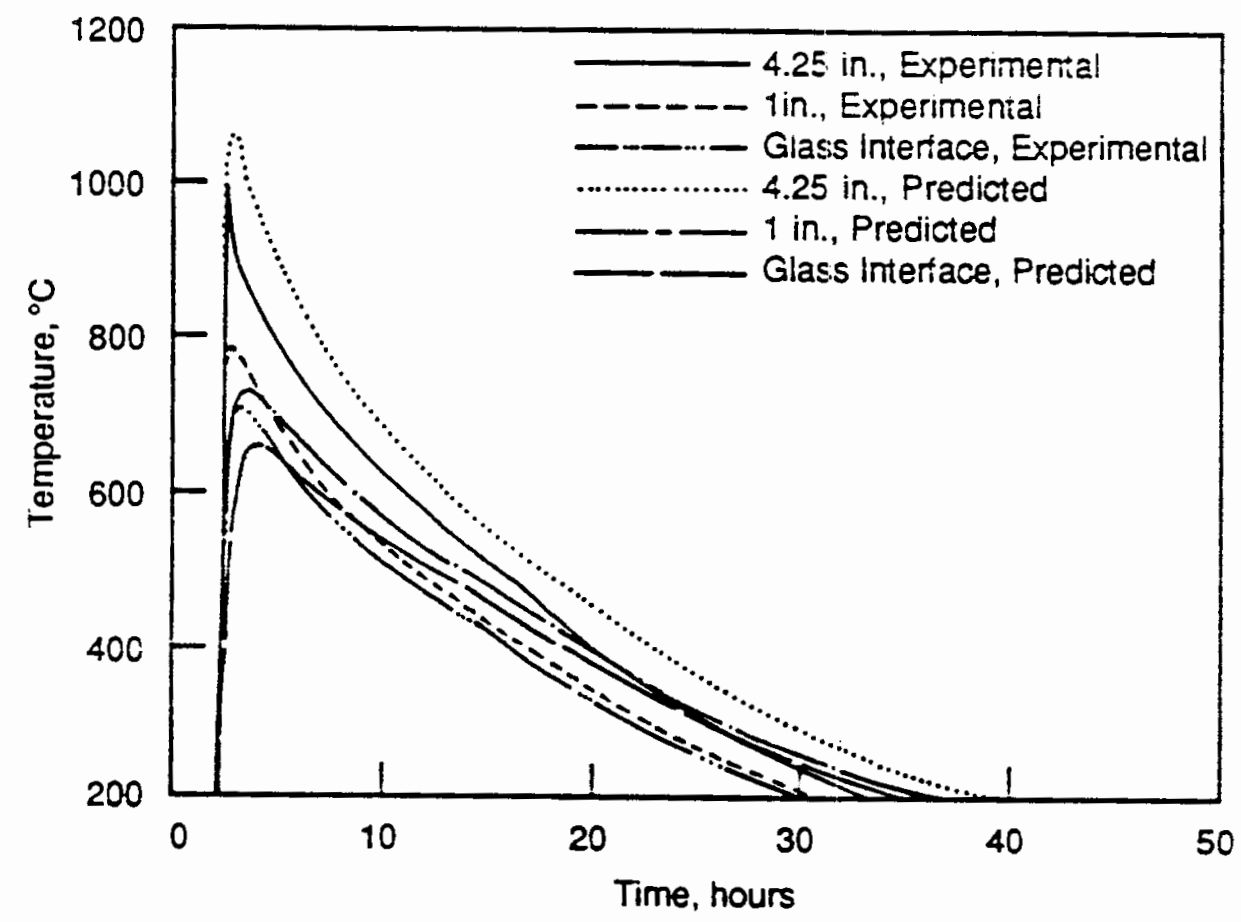

FIGURE 6.29. TEMPEST Predictions and Experimental Temperatures for the 13-in.-Diameter Canister at Axial Level 21.1 in. from Canister Bottom

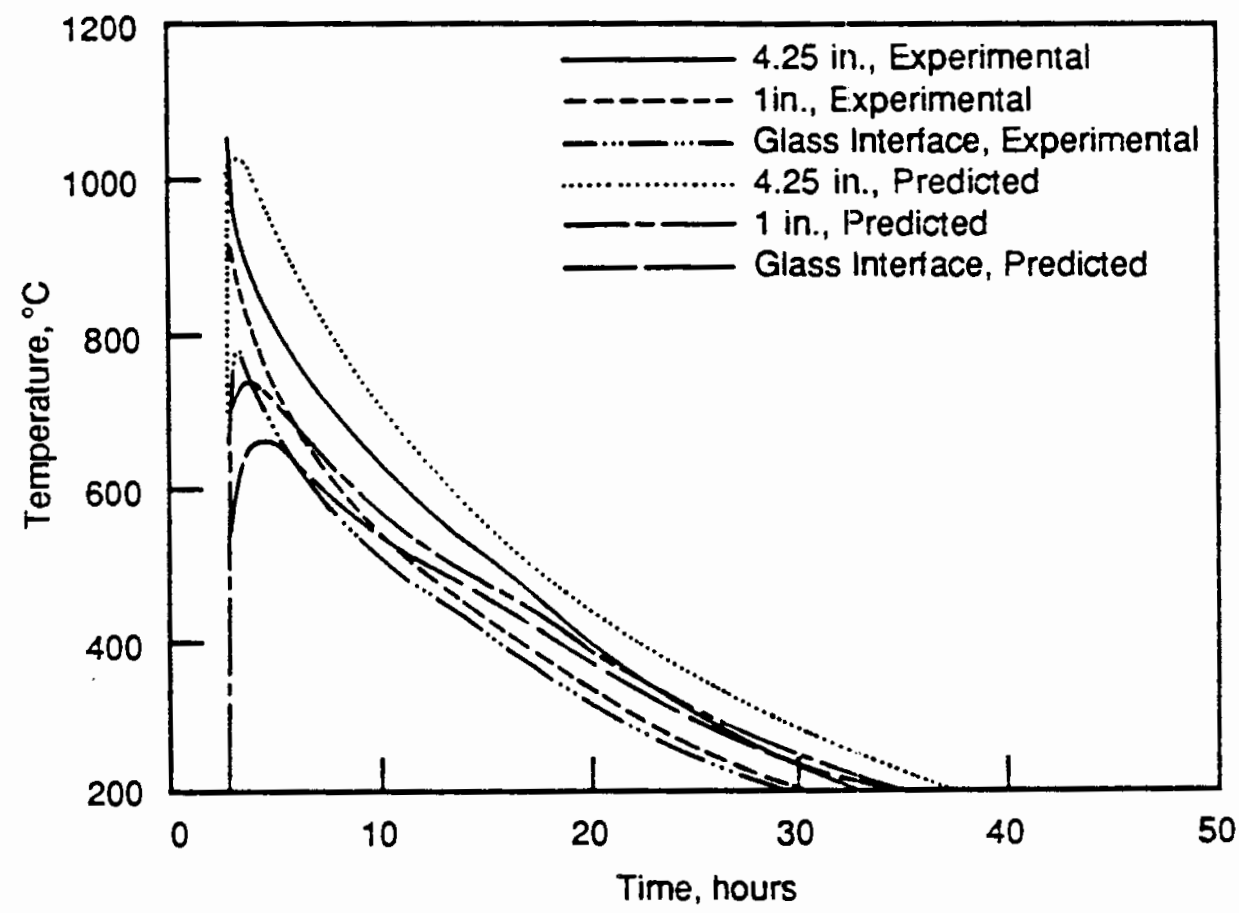

FIGURE 6.30. TEMPEST Predictions and Experimental Temperatures for the 13-in.-Diameter Canister at Axial Level 26.1 in. from Canister Bottom 


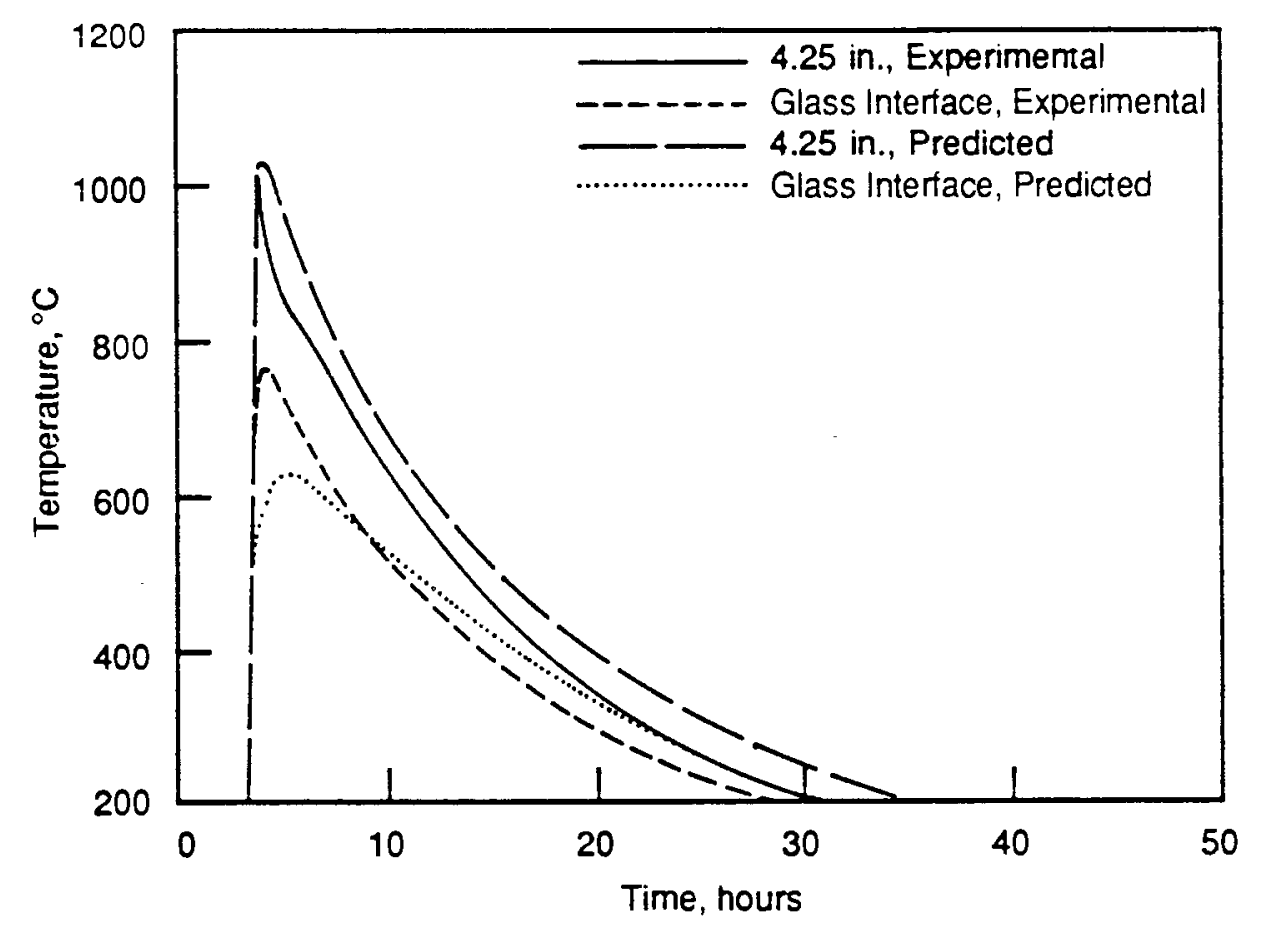

FIGURE 6.31. TEMPEST Predictions and Experimental Temperatures for the 13-in.-Diameter Canister at Axial Level 38.4 in. from Canister Bottom

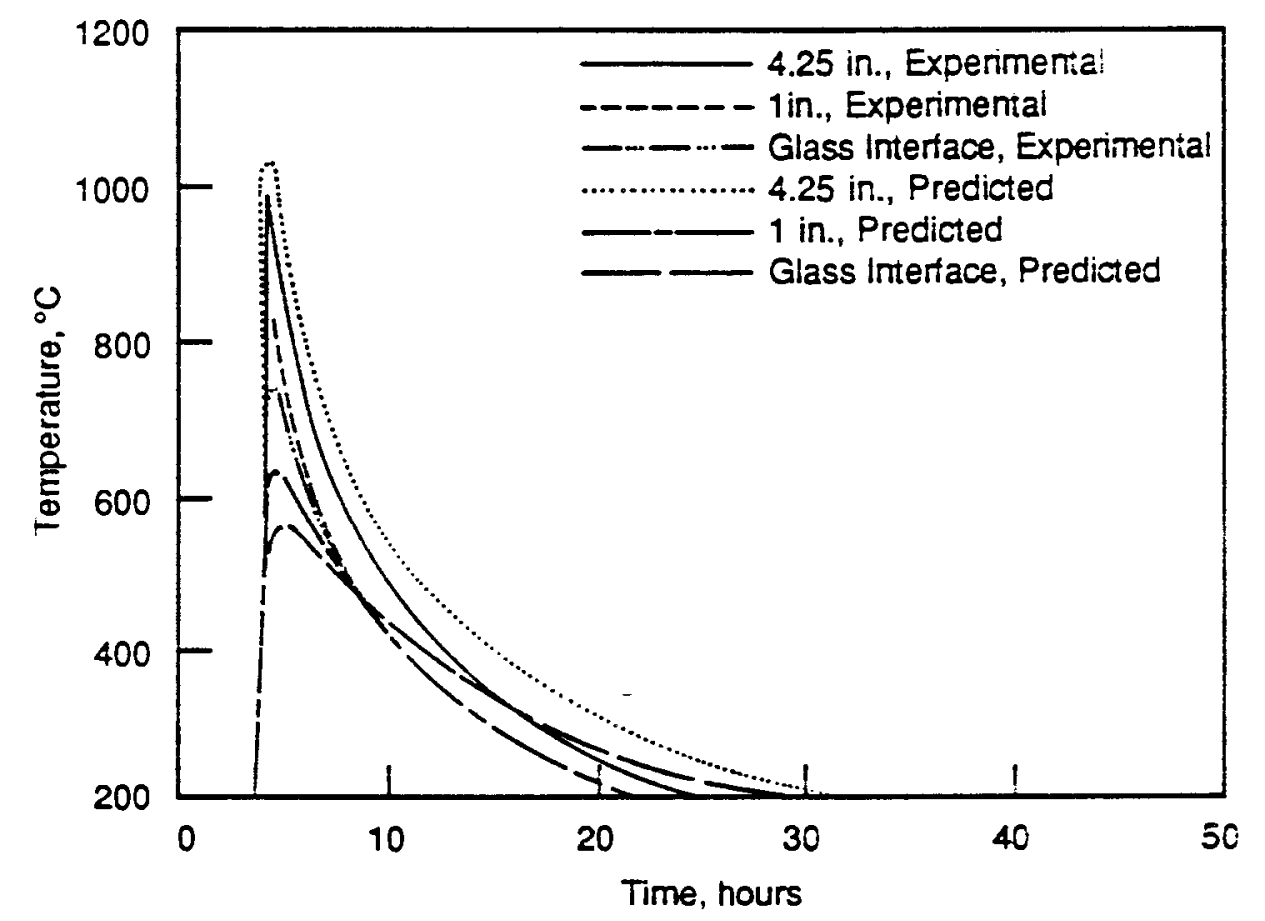

FIGURE 6.32. TEMPEST Predictions and Experimental Temperatures for the 13-in.-Diameter Canister at Axial Level 34.0 in. from Canister Bottom 
The cooling behavior that follows the covering of an axial thermocouple level with glass is more complicated. The temperatures of the glass used by TEMPEST were taken from the experimentally observed maximum peak temperature at each level. Thus, the peak temperatures were expected to agree reasonably well at the 4.25-in. radial position. This was generally found to be the case. However, the predicted peaks occurred 15 min later than the observed peaks. Given a mean rate of glass surface rise of $0.15 \mathrm{in.} / \mathrm{min}$ ( $40.1 \mathrm{in}$. of glass poured in $263 \mathrm{~min}$ ), this $15-\mathrm{min}$ delay is equivalent to $2.25 \mathrm{in}$. of glass, which is significantly larger than the estimated glass level accuracy of 1 in. The 15 min delay is probably due to the cell dimensioning restrictions, which caused the axial dimension of each cell in the glass filling region to be uniform. The TEMPEST predictions at the 4.25-in. radial position also show a somewhat lower rate of cooling than that observed; however, the agreement is much better than that observed with the batch-fill TEMPEST version used with canisters $12 \mathrm{LI}$ and $12 \mathrm{HI}$.

TEMPEST predictions of the maximum temperature for the period immediately following glass coverage of the 1 -in. radial thernocouples occur 30 to 90 min later than observed, with the exception of the uppermost level, which was only 15 min later (see Figure 6.32). In addition, the predicted peak temperatures range from $50^{\circ} \mathrm{C}$ to $400^{\circ} \mathrm{C}$ lower than those observed. This is probably caused by the inviscid convection assumption of the continuous-fill model, which neglects increases in viscosity of the glass as it cools. This results in cooled glass beneath the TEMPEST glass surface cell being forced out to the wall.

TEMPEST predictions for the transient following coverage of the thermocouples at the glass/Fiberfrax interface were usually 30 min to $3 \mathrm{~h}$ late. The predicted peak temperatures were also $50^{\circ} \mathrm{C}$ to $400^{\circ} \mathrm{C}$ lower than those observed.

24-in.-Diameter Canister

The 33 batch pours for the 24-in.-diameter canister proved to be too difficult to model with the continuous-fill model of TEMPEST. This was caused by the code's inability to handle continuous flow over the wide range of batch pour rates encountered. As a result, the temperatures from the canister modeling could not be compared to the actual glass temperatures in the canister. 


\subsection{TURNTABLE SIMULANT EXPER IMENT}

The experiment in which canister 12TTS was filled in the turntable simulant was conducted for three reasons:

- to determine the effects of the asymmetrical thimble structure on circumferential temperature gradients at the canister surface

- to determine the correctness of the assumed emissivities and radiant heat transfer modeling simplifications used in the TEMPEST simulation

- to determine the correctness of assumed contact coefficients simulating convective heat transfer in the TEMPEST simulation. Results addressing each of these points are summarized below.

The need to examine the effects of asymmetrical emplacement of the thimble in a turntable is due to the requirement by the TEMPEST code for axial symmetry with cylindrical geometries. Symmetrical modeling of the unsymmetrical turntable geometry will give accurate results only if the circumferential temperature gradients at all axial levels are negligible.

To better examine these potential gradients, an extensive threedimensional circumferential array of thermocouples was placed on the surfaces of each canister or turntable shell. The circumferential temperature gradients at various axial levels of the canister were analyzed to determine the existence of these gradients over time. In general, $40^{\circ} \mathrm{C}$ circumferential temperature gradients occurred on the canister shell immediately after each batch fill. However, this gradient decreased to less than $10^{\circ} \mathrm{C}$ after the next glass batch was added to the canister. Furthermore, the significant portion of the circumferential gradient occurred over less than $25 \%$ of the turntable shell. At a canister temperature around $400^{\circ} \mathrm{C}$, the effect of the circumferential gradients on the average temperature at that level is a reduction of approximately 1 to $5^{\circ} \mathrm{C}$. On the basis of these observations, it can be assumed that cylindrical modeling of the RLFCM turntable via the TEMPEST code, ignoring circumferential temperature gradients, is an acceptable approximation from a heat transfer perspective.

The other reason for the turntable simulant evaluation stems from the inability of the TEMPEST code to exactly model transient convective and 
radiative heat transfer concurrently. To estimate the actual convective and radiative heat transfer with TEMPEST, a solid, nonconvecting form of an "infinitely conductive" material, with density and specific heat properties equivalent to air, was used. Radiant heat transfer, along with contact coefficients determined to simulate gap convection, were then placed between each metal shell and the "infinitely conductive" material to simulate the heat transfer between shells. The effectiveness of this simplification was evaluated.

A steady-state computer simulation of the turntable simulant was made by TEMPEST. The experimentally obtained canister shell temperature profile was taken from a point in time where the cooling rate of the canister had slowed and the glass at the hottest point on the glass/Fiberflax interface was just beginning to harden. This condition was chosen because it was at a temperature in the primary range of interest at a time when the rate of change in temperature was low enough to make a reasonable approximation possible. The axial canister temperature profiles that were input into TEMPEST varied from $234^{\circ} \mathrm{C}$ at the top of the canister wall, to $411^{\circ} \mathrm{C}$ at canister mid-1evel, to $272^{\circ} \mathrm{C}$ at the canister bottom. Emissivities of 0.7 for the canister surface and 0.5 for all other shells were used. The emissivity values were based on values given for appropriate stainless-steel oxidation levels and were estimated to be the highest possible emissivities, based on the maximum experimental temperatures of each of these shells. The emissivities used should result in faster cooling rates and larger radial temperature gradients than would actually exist. The contact coefficients used to simulate convective heat transfer were determined using steady-state convective heat transfer analyses.

One assumption required for comparing steady-state analysis with transient cooling profiles is the presence of insignificant lag time in temperature response between shells. A comparison of the metal shell temperatures over time shows a "lag time" of approximately $3 \mathrm{~h}$ between a batch fill in the canister and the complete temperature response of the turntable shell. However, much of this lag time occurs primarily in the outer shells where the temperature variation over time is slow. Observation of the transient cooling and reheating profiles of the metal shells shows a maximum expected error of $25^{\circ} \mathrm{C}$ at each metal shell, if a steady-state analysis at this point in time is used. 
Due to the modeling simplification required by TEMPEST, the computed axial temperature gradients on metal shells in the turntable simulant were 50 to $200 \%$ greater than the actual profiles observed in the run. To better examine our assumptions, the average temperatures of the experimental and TEMPEST-simulated cooldowns were computed for each metal shell. The difference in average temperatures between adjacent shells were then determined, and comparison was made between the experimental and computed temperatures. The results of this comparison, shown in Table 6.1, indicate reasonably good agreement between the experimentally-derived and the TEMPEST-predicted temperatures. The only discrepancies occur in the region between the canister shell and overpack and the region between the turntable wall and ambient. Attempts to improve these discrepancies are discussed below.

Improved convective heat transfer calculations were performed based on experimental shell temperatures; these calculations resulted in variations of less than $8 \%$ in the total amount of heat transfer. To examine the effect of

TABLE 6.1. Comparison of Computer-Predicted Temperature Drops with Experimental Results Between Shells of the PSCM Turntable Simulant

\begin{tabular}{|c|c|c|c|}
\hline \multirow[b]{2}{*}{$\begin{array}{l}\text { Gap Location } \\
\text { Canister wall } \\
\text { to overpack }\end{array}$} & \multicolumn{3}{|c|}{ Average Temperature Drops } \\
\hline & $\frac{\text { Experimental }}{70^{\circ} \mathrm{C}}$ & $\frac{\text { Computer Pred. (a) }}{48^{\circ} \mathrm{C}}$ & $\begin{array}{l}\text { Lowered }(b) \\
\frac{\text { Emissivities }}{52^{\circ} \mathrm{C}}\end{array}$ \\
\hline $\begin{array}{l}\text { Overpack to } \\
\text { seal liner }\end{array}$ & $80^{\circ} \mathrm{C}$ & $75^{\circ} \mathrm{C}$ & $79^{\circ} \mathrm{C}$ \\
\hline $\begin{array}{l}\text { Seal liner } \\
\text { to thimble }\end{array}$ & $64^{\circ} \mathrm{C}$ & $72^{\circ} \mathrm{C}$ & $76^{\circ} \mathrm{C}$ \\
\hline $\begin{array}{l}\text { Thimble to } \\
\text { turntable wall }\end{array}$ & $64^{\circ} \mathrm{C}$ & $67^{\circ} \mathrm{C}$ & $61^{\circ} \mathrm{C}$ \\
\hline $\begin{array}{l}\text { Turntable wa } 1 \\
\text { to ambient } \\
\text { c })^{1}\end{array}$ & $19^{\circ} \mathrm{C}$ & $35^{\circ} \mathrm{C}$ & $28^{\circ} \mathrm{C}$ \\
\hline
\end{tabular}
(a) Canister emissivity 0.7 ; other shell emissivities 0.5 .
(b) Canister emissivity 0.5 ; other shell emissivities 0.4 .
(c) Ambient air temperature $=22^{\circ} \mathrm{C}$. 
improved convective heat transfer, along with variations in emissivity, another steady-state calculation was made with improved convective heat transfer coefficients, a canister emissivity of 0.5 , and all cther shell emissivities of 0.4 (see Table 6.1, Column 3). The results of this simulation are similar to the higher emissivity simulation, with noticeable improvements. This suggests a flatter emissivity profile than expected. However, discrepancies still occur in the temperature shell'a axial distribution. These findings indicate that emissivities are not the only reason for these discrepancies. Other modeling concerns that may affect the comparison of the computer simulations with experimental results are:

- thermocouple error in the experimental results

- limitations and inaccuracies in the radiant/convective heat transfer modeling required by the code

- limitations in the use of steady-state analysis to predict transient cooling temperatures between shells.

In summary, the use of a turntable simulant demonstrated that the TEMPEST code can effectively simulate the heat transfer resistance caused by emplacement of a canister in the RLFCM turntable. Although some discrepancies exist, the agreement is close enough to give a reasonably accurate prediction of the radioactive canister's cooling rates and temperature profiles. 


\subsection{DISCUSSION}

Four main topics are covered in this chapter. The results obtained with the TEMPEST batch-fill model are discussed in Section 7.1. In Section 7.2, the TEMPEST continuous-fill model results are explained. Next, the implications from the turntable simulant results are presented in Section 7.3. The chapter concludes with Section 7.4, which provides a general discussion of problems

encountered in using the code, opportunities for using the code, suggested code development activities, and potential input model and associated model activities.

\subsection{TEMPEST BATCH-FILL MODEL RESULTS}

When used to model the batch-fill experiments, the TEMPEST code did a reasonable job of predicting temperatures. The maximum deviations from experimental results $\left(100\right.$ to $\left.250^{\circ} \mathrm{C}\right)$ occurred during the initial cooldown transient. Thereafter, the TEMPEST predictions were generally within $125^{\circ} \mathrm{C}$ of the observed temperatures. These latter deviations would be smaller if it were not for the code's failure to model the initial cooldown effect (see Figure 6.4, for example). Two factors account for most of the deviations:

- a large underprediction of the cooling rates for the 8 to $10 \mathrm{~h}$ immediately after pouring

- a less pronounced underprediction of the cooling rates for times longer than $10 \mathrm{~h}$ after pouring.

Possible reasons for the existence of these factors include:

- changes in conductive heat transfer that are caused by glass fracturing

- inaccurate modeling of radiant heat transfer from the glass surface

- errors implicit in the assumption that the entire batch of glass added during a pour is instantaneously dumped into the canister

- the assumption that only conductive heat transfer occurs in the glass 
- errors in the code-required input for physical properties of glass at high temperature

- an overestimation of the insulation properties of Fiberfrax and/or Durablanket.

Each of these reasons is discussed below.

Significant glass cracking with concurrent formation of gaps could conceivably decrease the effective thermal conductivity of glass. However, this explanation does not seem plausible for canisters $12 \mathrm{HI}$ or 12LI, for three reasons. First, for a given temperature at the 4.25-in. thermocouple (chosen because it is closest to the center), the radial temperature differences between the 4.25-in, and 1-in. thermocouple are very close to the observed temperature differences. Second, the temperature differences within the glass are far smaller than they are between the glass surface (whether on the bottom, sides, or top) and the ambient temperature. Even if cracking had increased these gradients to twice that of crack-free glass, the effect on temperature drop would have been far smaller than the deviations between TEMPEST and the observed results. Third, a decrease in actual thermal conductivity of glass would serve only to decrease experimental cooling rates, not increase them as observed. Therefore, we conclude that glass cracking is not a significant cause for the observed deviations.

As discussed in Chapters 3 and 5, TEMPEST is incapable of modeling radiation and convection heat transfer concurrently in an exact manner. This undoubtedly leads to errors in predicted temperatures. However, for the canister filling conditions encountered in this study, the radiation model used appears to cause relatively minor errors. This is evidenced by the small differences in the predicted temperatures when using the high-temperature and the low-temperature radiation models (see Figures 6.8 through 6.15 and 6.24 through 6.32). Note that the differences in the predictions made by these two models are far smaller than the differences between the predictions of the models and the observed results. An improved radiation model should be developed to ensure that this potential source of error does not become significant for other TEMPEST applications to LFCM heat transfer calculations. 
The errors associated with assuming that the entire amount of glass poured during a batch is instantly placed in the canister is the probable cause of much of the slow cooldown prediction by TEMPEST immediately following a pour. If this source of error were to be eliminated, the agreement between the TEMPEST predictions and the experimental results would be dramatically improved. Evidence supporting this hypothesis is found in the consistently superior predictions obtained using TEMPEST Version M (the continuous pour model) in the 13-in.-diameter canister. This is discussed in more detail in Section 7.2 .

To understand the cause for the errors implicit in the batch version, it helps to consider the fill process. Batch filling gets its name because it is discontinuous. The LFCM is allowed to fill; the canister is then filled at a substantially faster rate than would be possible under continuous filling because the latter is limited by the glass production rate. However, the duration of the fill, which ranged from 23 to 54 min for canisters $12 \mathrm{HI}$ and 12LI, is still long enough to permit significant heat transfer. The batch fill version partially accounts for this by adding the filling time to the cooling time between pours so that total cooling time remains the same. However, the batch-fill version does not accurately model the temperature of the glass surface during the filling process. In reality, a stream of glass approximately $1 / 6$ in. in diameter strikes the glass surface; the point of impact meanders about the center of the canister as a result of wetting and Coanda effects at the pour spout of the LFCM. This glass stream partially submerges itself in the glass. Pressure gradients set up from the momentum of this stream, buoyancy effects due to convection, and gravity effects due to the glass impacting near the center cause the glass surface to move upward, maintaining itself level perhaps to within an inch or so. This source of new, hot glass keeps the surface at an elevated temperature that is determined by the rate at which heat is added from the new glass and lost by radiation and convection from the glass surface.

In the TEMPEST batch pour model, the entire pour (about 13 in. for canisters $12 \mathrm{HI}$ and $12 \mathrm{LI}$ ) enters the canister instantly. This glass is cooled at the top, bottom, and sides. At the top, the glass surface is cooled by 
radiation and convection as described above. However, the modeled surface temperature at the top of the canister will fall much more rapidly than the actual temperature because the surface is not be:ng renewed with new, hot glass. The lower surface temperatures will cause a much lower heat transfer rate from the top of the glass (because radiation, the dominant heat transfer mechanism soon after a pour, is proportional to temperature to the fourth power). This lower heat transfer rate probably accounts for much of the early post-cooldown deviation.

The assumption of solely conductive heat transfer in the glass may account for some of the remaining deviation in early post-cooldown temperatures. The batch-fill model assumes that the glass is a solid, that is, no convective heat transfer within the glass is assumed, so only conduction is computed. Examination of the experimental data shows isothermal regions near the glass surface. These regions are at least 2 in. deep by $4 \mathrm{in}$. across, which indicates extremely high rates of heat transfer. The TEMPEST simulations show significant temperature gradients in the same region, hence lower heat transfer. clearly, a more accurate modeling of the region inmediately below the surface would improve the accuracy of the TEMPEST predictions.

One possible explanation for this apparently extremely high rate of heat transfer is that the glass in these regions $\left(\sim 1000^{\circ} \mathrm{C}\right)$ may be sufficiently fluid that a combination of convective cells, combined with stirring caused by the impacting glass stream, increases heat transfer far above that predicted by conduction. Another possibility is that the values of high temperature thermal diffusivity used by canister $12 \mathrm{HI}$ and $12 \mathrm{LI}$ are in error. The technique used to measure glass thermal diffusivity is well accepted for solids; its applicability to molten glass needs to be verified, however.

Finally, there is a significant underprediction of cooling rate for long periods after each batch pour. This underprediction is manifested by the lower rates of cooling exhibited by TEMPEST later in the cooling process see figures $6.4,6.6,6.16,6.17$, and 6.20). The underprediction occurs even though the predicted glass temperatures are higher than measured, which should cause a higher cooling rate. The most likely explanation for the difference is that the actual thermal conductivities for Fiberfrax and/or Durablanket insulation 
are higher than that used for the TEMPEST simulations. Several reasons support this explanation. First, the TEMPEST predictions all err in the same direction for the later portions of the cooldown process. Second, and perhaps more convincing, TEMPEST exhibits this deviation for the case of canister $12 \mathrm{HI}$. Canister $12 \mathrm{HI}$ was insulated with $1 / 8 \mathrm{in}$. of Fiberfrax internally and $3 \mathrm{in}$. of Durablanket externally. Therefore, the limiting thermal resistance should be the Durablanket. Examination of Figures 6.1 through 6.7 shows that the 4.25 -in. radial temperatures at $50 \mathrm{~h}$ range from $420^{\circ} \mathrm{C}$ at the bottom to $630^{\circ} \mathrm{C}$ at level 5 and back down to $525^{\circ} \mathrm{C}$ at level 8 . The temperature differences between the 4.25-in. and 1-in. thermocouples in the glass are quite small at $50 \mathrm{~h}$, however, ranging from 0 to $50^{\circ} \mathrm{C}$. Temperatures at the $1-i n$. thermocouple locations at $50 \mathrm{~h}$ range from 400 to $600^{\circ} \mathrm{C}$. Unless there is an extremely large temperature drop in the center 1 in. of glass, well over $80 \%$ of the temperature drop, hence thermal resistance, is in the Fiberfrax and the Durablanket, of which the latter provides by far the greater resistance.

Observations show that the predicted time/temperature slope at $50 \mathrm{~h}$ is either equal to or slightly greater than that of the observed results, even though the predicted temperatures are about $100^{\circ} \mathrm{C}$ higher. This $100^{\circ} \mathrm{C}$ higher temperature translates into approximately $25 \%$ greater temperature driving force to the ambient. Thus, it is tentatively concluded that the effective thermal conductivity of the Durablanket/Fiberfrax insulation was about $25 \%$ higher than that used in the TEMPEST input.

Further analyses, which would include using the thermocouple data collected at the surface of the canister, could determine if some unforseen heat transfer resistances exist inside the Durablanket. If no such resistances are found, the problem is probably due to the thermal conductivity values given for Durablanket; the heat transfer calculation for canister $12 \mathrm{HI}$ after $50 \mathrm{~h}$ is a simple conduction problem well within the verified capabilities of TEMPEST.

\subsection{TEMPEST CONTINUOUS-FILL MODEL RESULTS}

The TEMPEST continuous-fill version was used to model the 13-in.-diameter canister. The long-range cooling behavior predicted for the canister is similar to that found with the batch-fill model results described above. The 
most likely explanation is the same: a $25 \%$ underprediction of the insulating values of Durablanket (and/or possibly Fiberfrax).

Canister 12LI and the 13-in.-diameter canister are similar in the amount of insulation and in size. In spite of these similarities, it is difficult to make direct comparisons between their cooldown rates because the 13-in.-diameter canister was filled in only $4 \mathrm{~h}$, whereas canister $12 \mathrm{LI}$ was filled in three pours over a 12.7-h period. However, spot checks made at similar thermocouple levels consistently showed much better agreement between the predicted temperatures and the observed temperatures for the 13-in.-diameter canister. Except for the lowest thermocouple level, where the deviation was similar $\left(125^{\circ} \mathrm{C}\right.$ for canister $12 \mathrm{LI}$ compared with $110^{\circ} \mathrm{C}$ for the $13-i n .-d i a m e t e r$ canister), deviations for the 13-in.-diameter canister were about half those of canister 12LI. This is probably the result of better predictions of the transient by the continuousfill model, which accounts for the replenishment of the surface layer with hot glass (Section 7.1). In short, over most of the cooldown, the TEMPEST predicted temperatures that were within $50^{\circ} \mathrm{C}$ of those observed for most of the thermocouple locations in the 13-in.-diameter canister.

However, significant differences in short-term predictions of the temperature gradients occurred as a function of radial position. TEMPEST was late in predicting the peak temperatures. This error increased with increasing thermocouple distance from the canister center, reaching $3 \mathrm{~h}$ at the canister wall. TEMPEST also predicted peak temperatures that were too low. Again, this error increased with distance from the center, with errors reaching $400^{\circ} \mathrm{C}$ at the glass/wall interface. This deviation is consistent with the position taken in Section 7.1: TEMPEST appears to grossly underpredict the rate of heat transfer near the glass surface, either because of the use of inaccurate thermal properties, or because mixing, convection, or some other phenomenon is greatly increasing heat transfer above that predicted by conduction alone. Another potential reason is the large axial cell dimensions in the glass filling region.

It should be noted that the advanced $N 29$ version of TEMPEST is designed to rectify these deficiencies. In this version, the glass/air interface will be 
tracked more exactly and the mesh will be rezoned at each time step. Furthermore, the user will be allowed to specify how many and what size cells he wishes to use to resolve the front. This option will allow automatic and dynamic mesh refinement at the interface, precisely the location of maximum temperature gradients and highest temperatures. Thus, the radiation model will automatically be improved by resolving the high temperature gradients at the glass surface rather than smearing them over too large a cell.

\subsection{IMPLICATIONS OF THE TURNTABLE SIMULANT RESULTS}

Generalized results of the turntable simulant analysis show that the primary modeling problems stem from insufficient knowledge of how stainlesssteel emissivity changes over time with temperature and from the inability of the TEMPEST code to simultaneously model radiation and convection between the steel shells. Again, completion of the $N 29$ version of TEMPEST should partially rectify this problem. Although the results show a circumferential temperature gradient on the canister shell caused by asymmetrical emplacement in the turntable simulant, the gradient is only $40^{\circ} \mathrm{C}$ or less and is, therefore, of secondary concern. A discussion of the two main areas follows.

The way in which the canister and turntable shells change their surface emissivity as a function of temperature and time becomes increasingly important at higher canister surface temperatures. Currently, there is insufficient information on how fast canister emissivity changes, and what the maximum emissivity is for various shell temperatures. Arrowsmith et al. (1977) have studied spectral emissivity in the infrared region (16 to $27 \mu \mathrm{m}$ ) at temperatures up to $600^{\circ} \mathrm{C}$. Their studies demonstrate no appreciable oxide formation and thus no significant change in emissivity for Hastelloy C-276 tubing exposed to air for $16 \mathrm{~h}$ at $500^{\circ} \mathrm{C}$, or $1 \mathrm{~h}$ at $600^{\circ} \mathrm{C}$. The emissivity for unoxidized Hastelloy tubing is shown to be around 0.25 . Other information, however, shows the actual canister emissivity rising above 0.5 at 500 and $600^{\circ} \mathrm{C}$, causing over a $100 \%$ increase in radiant heat transfer. More detailed descriptions on $304 \mathrm{~L}$ stainless steel emissivity and its variation over temperature would be desirable. 
As described in Section 3.0, radiation between canister shells is modeled by placing in the gap a material that is highly conductive radially and adiabatic axially. This method allows the surface temperature of the canister shells to radiate to each other. A combined radiant and convective heat transfer coefficient is then placed between the shell and material to attempt to simulate heat transfer across the gap. However, this simplification does not handle axial heat transfer, particularly convection and all but direct radiation, across the gaps. This inadequacy is evidenced by the modeled axial temperature profiles along each shell. The profiles show high temperature at the bottom, top, and middle of each canister shel1, and low temperatures in between. The high temperature in the middle of the shell occurs near the same level as the hottest glass temperatures, and the high temperatures at the top and bottom of the canister are caused by conduction from the inner and outer shells. This pattern is entirely different from that of the profiles generated in the actual experiments. Temperatures in the actual experiments tend to be hotter in the upper half of the shell and cool off without further temperature increase on the ends. Because of the significant difference between experimental and modeled temperature profiles, two-dimensional heat driving force on the shells of the turntable simulant is being generated to incorrectly model heat transfer off the canister. Code development of the $\mathrm{N} 29$ version to more correctly model radiant and convective heat transfer across shell gaps would greatly improve future turntable simulant analyses. A heat transfer measurement during the turntable simulant analysis would also help.

\subsection{TEMPEST CODE DEVELOPMENT CONSIDERATIONS}

The amount of time spent learning and understanding the TEMPEST code, revising it to fit the canister input models, and running the computer simulation was quite extensive. This is because the code is currently not written to handle canister filling and heat transfer modeling. Development of a user-friendly code and manual for heat transfer modeling of canister filling and cooldown would be highly desirable, particularly for the continuous-fill version of the TEMPEST code, which currently has no documentation describing the way it handles a canister fill. Without this development, it is expected 
that modeling of heat transfer in glass-filled canisters will continue to be tedious and lengthy, minimizing the value of the modeling effort.

In general, the code seems to perform reasonably well when modeling cooling of a canister outside of any turntable environment. It is suspected that experimental uncertainties contributed to some of the difference between the observed and predicted results. Improvements in experimental data recording relating to glass pour temperatures, pour level measurements, and canister surface emissivities (with respect to time and temperature) would be highly desirable. More accurate knowledge of temperature-dependent heat transfer properties for the various materials used in and around the glass-filled canister would also be desirable. Some ideas for improving the experimental data base are listed below:

- During canister filling and cooldown, surface emissivities at various positions on the canister should be recorded over time. An attempt to find a way to determine the temperature of the glass pour stream along with the pour rate during each fill should also be made. This could be accomplished by more frequent recordings of the poured glass temperatures during filling and by using improved methods of determining the glass level after each pour.

- An experiment should be performed to determine the change in emissivity for $304 \mathrm{~L}$ stainless steel as a function of temperature from 100 to $1100^{\circ} \mathrm{C}$. This table could then be input to TEMPEST to model a continually changing surface emissivity on the canister wall.

- The convective heat transfer of viscous glasses at temperatures above $900^{\circ} \mathrm{C}$ should be determined. A table of temperature and viscosity versus convective heat transfer could then be developed and input into TEMPEST for more accurate modeling of heat transfer above $900^{\circ} \mathrm{C}$. As stated in Section 3.0, the TEMPEST code was not written for canister heat transfer analysis during glass filling and cooldown. To attempt to model these canisters, the $L 4$ version of the code was revised to handle radiation and heat transfer during filling while trying to decrease the computer time required for each simulation. The two revised versions ( $L 4 X$ and $M$ ) performed 
well considering possible inaccuracies in the input data base. However, development of these code versions represents only a small portion of the code development effort needed to accurately model heat transfer.

Continuous-Fill Modeling - The continuous-fill version of TEMPEST predicts glass temperatures better than the batch-fill version. This conclusion implies that future development efforts should use the continuous-fill model, even in batch-filled canisters. However, the continuous-fill (M) version of the code is currently hardwired to handle only certain sizes of canisters, and no documentation exists for changing the input. In addition, the method for inputting time-dependent glass pours and initial glass temperatures requires much preliminary determination. Development money should instead be spent to finish the $\mathrm{N} 29$ version of the TEMPEST code. In the $\mathrm{N} 29$ version, fill rates and glass temperatures are input instead of the percentage fill rate in the radial center node and the volumetric amount of sensible heat in the glass (automatically calculated in the $\mathrm{N} 29$ version). In addition, the $\mathrm{N} 29$ version allows arbitrary, user-selected radial and axial cell sizes throughout the entire mesh, including the glass-filling area. This flexibility allows more exact monitoring of the thermocouple locations. Therefore, completion of the N29 version of TEMPEST would provide the continuous-fill modeling capability desired.

Radiation - Analysis of the 12- and 13-in.-diameter canisters shows that the current models in TEMPEST for computing radiation from the glass surface are a reasonable first try at modeling radiation. However, improved radiation heat transfer models, coupled with improvements in the computation of convective heat transfer across shells, should be developed. These improvements are particularly crucial when attempting to model large-gap radiation between steel shells in a turntable environment. The improvements would also improve the accuracy of the heat transfer calculation for the rising glass surface during a pour. Improved radiation modeling would allow for use of the improved convection capabilities designed for the N29 version of TEMPEST.

Slow Transient Convection Analysis - In both the batch-fill (L4X) and continuous-fill (M) versions of the code, the momentum equation was entirely. explicit, mandating very small time steps for fluids like glass with large 
viscosities. Thus, the $L 4 X$ and $M$ versions were not able to adequately model the glass convection in the canister. For the models run with the $L 4 X$ version (canisters $12 \mathrm{LI}$ and $12 \mathrm{HI}$ ), the glass was assumed to be a conducting-only medium. For the models run with the $M$ version of the code, the glass was assumed to be inviscid. The $\mathrm{N} 29$ version of the code has been entirely rewritten, and the viscous part of the momentum equation is implicit. Thus, large time steps can be taken with the advanced $N 29$ version of the code so that convection can be modeled economically, even for the type of slow transients involved in canister cooldown calculations.

Asymmetrical Cylindrical Analysis - As stated in Chapter 3, the TEMPEST code cannot currently model asymmetrical emplacement of the turntable shells in an LFCM turntable. Model developers for TEMPEST are currently improving the code's ability to handle noncylindrical coordinate systems, which may help the modeling effort for the asymmetrical turntable geometry. However, this development effort may be as long as 2 years away from completion. Because the turntable simulant analysis shows only a small circumferential gradient on the canister due to asymmetrical emplacement, any development effort in this area can be postponed.

Other developmental efforts to improve TEMPEST modeling of canister temperatures include:

- modeling of the heat transfer of the pour stream as it falls into the canister

- modeling the time- or temperature-dependent emissivities from canister shells. 


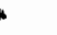

, 


\subsection{QUALITY ASSURANCE AND TRACEABILITY}

The computer code development work was done according to PNL-MA-70, Impact Level II standards. The base version of TEMPEST is designated to the L4 version and has been sent to the National Energy Software Center in Argonne, Illinois. The installation of the implicit viscous diffusion capability resulted in a complete rewrite of the code. Thus, the $\mathrm{N} 29$ version was created to serve as a new base version (designated N29A0) of TEMPEST. It was successfully tested on the standard TEMPEST test problems (Eyler, Trent, and Budden $\left.1983^{[a]}\right)$. An update module (N29B0) was then created to allow implicit viscous diffusion (see Appendix A). These update additions plus the N29AO version were combined to create the $\mathrm{N} 29 \mathrm{~B} 1$ version. The $\mathrm{N} 29 \mathrm{~B} 1$ version served as the starting point for the FY 1987 work. When the front tracker module is finished and added to the existing version, it will be designated as N29B2 (see Appendix B). Traceability and configuration management are accomplished by using the software utility HISTORIAN (see Appendix C).

A11 versions of TEMPEST described in this report were run on the Los Alamos National Laboratory (LANL) Integrated Computer Network (ICN), and stored on their Common file System (CFS). The ICN is composed of various computers; this work was performed in the open partition, which currently comprises one CRAY X-MP and three CRAY-1S machines. All machines run the Cray Time Sharing System (CTSS) operating system. Although the L $4 X$ and $M$ versions of TEMPEST were run on CDC-7600 computers running the Livermore Time Sharing System (LTSS) operating system, TEMPEST is written in FORTRAN and is very portable to any machine with a FORTRAN compiler. The TEMPEST $N 29$ version is running on the LANL CRAY-1S is and on the PNL DEC VAX 11-780 computer running VMS 4.3 .

\footnotetext{
(a) Eyler, L. L., D. S. Trent, and M. J. Budden. 1983. TEMPEST - ThreeDimensional Time-Dependent Computer Program for Hydrothermal Analysis. Volume II: Assessment and Verification Results. Pacific Northwest Laboratory, Richland, Washington.
} 


\subsection{REFERENCES}

Arrowsmith, H. W., and R. P. Allen. 1977. Electrical Decontamination of Strontium Fluoride Storage Capsules. BNWL-2125, Pacific Northwest Laboratory, Richland, Washington.

Chikalla, T. D., and J. A. Powe11. 1982. Nuclear Waste Management Semiannual Progress Report. PNL-4250, Pacific Northwest Laboratory, Richland, Washington.

Eyler, L. L., and D. S. Trent. 1984. Pressurized Thermal Shock: TEMPEST Computer Code Simulation of Thermal Mixing in the Cold Leg and Downcomer of a Pressurized Water Reactor. NUREG/CR-3564, PNL-4909, prepared for the U.S. Nuclear Regulatory Commission by Pacific Northwest Laboratory, Richland, Washington.

JANAF. 1986. JANAF Thermochemical Tables, 3rd Edition, American Chemical Society and American Institute of Physics. (Journal of Physical and Chemical Reference Data Volume 1485, Supplement No. 1.)

Roache, P. J. 1976. Computational Fluid Dynamics. Hermosa Publishers, Albuquerque, New Mexico.

Trent, D. S., L. L. Eyler. 1985. TEMPEST - Code Simulations of Hydrogen Distribution in Reactor Containment Structures. EPRI NP-3955, prepared for the Electric Power Research Institute by Battelle Pacific Northwest Laboratory, Richland, Washington. 

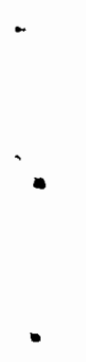

,

.

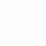

. 
APPENDIX A

IMPLIC IT VISCOUS DIFFUS ION CHANGES TO TEMPEST 


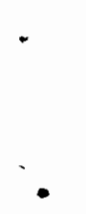

-

.

\author{
列
}

-

"

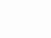

. 


\section{APPENDIX A}

IMPLICIT VISCOUS DIFFUSION CHANGES TO TEMPEST

This appendix contains the HISTORIAN input change file that creates the N29B 1 version of the code from the N29A0 version of TEMPEST. The file is provided to maintain traceability and quality assurance on the $N 29$ versions of TEMPEST when applied to canister simulation. 


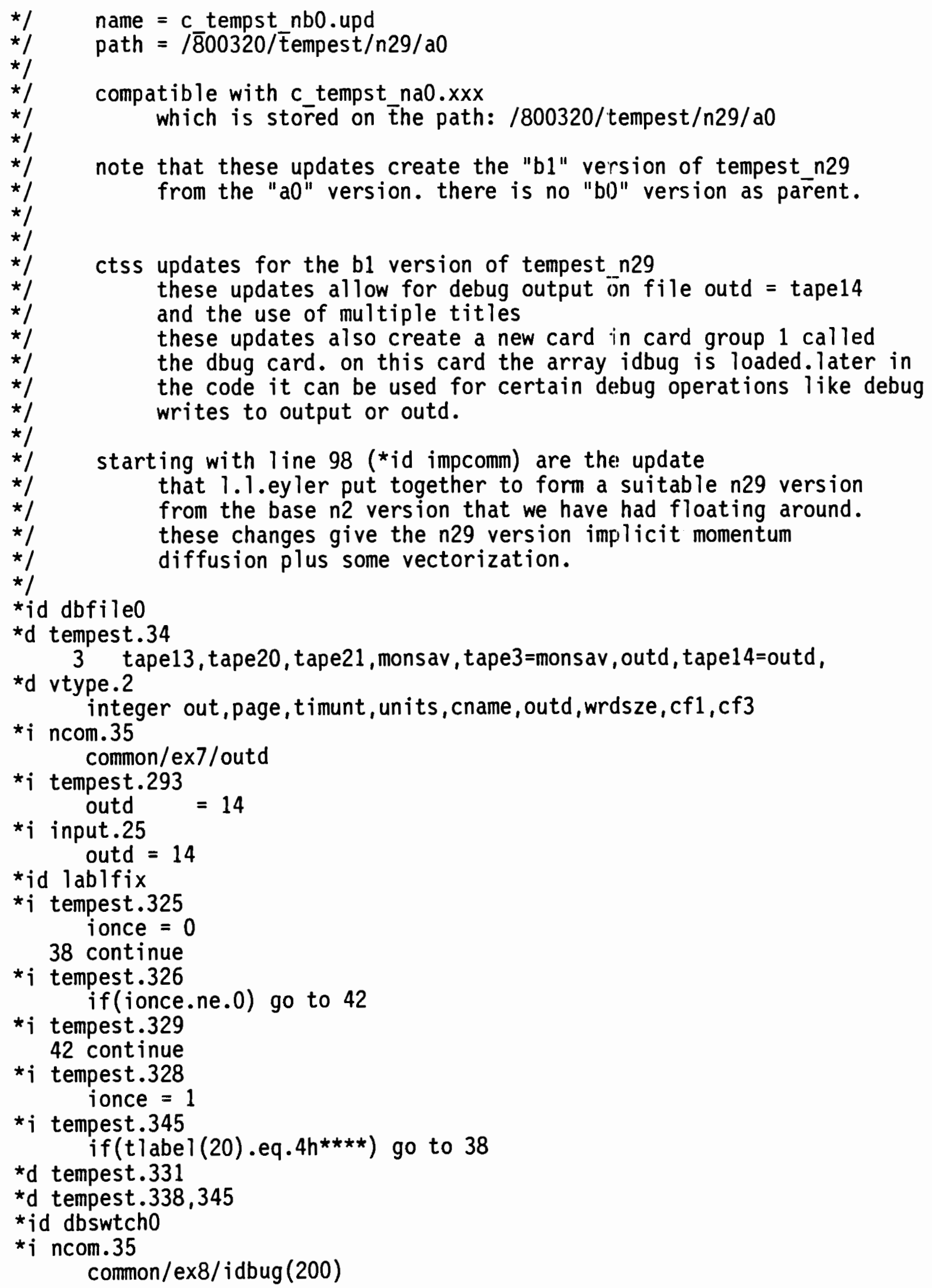


* id dbswtch1

* $i$ tempest.362

if (xcard.eq.4hdbug) go to 170

* $i$ tempest. 497

170 cont inue

$c^{* *}$

$\mathrm{c}^{\star *}$ dbug array card

$c^{\star *}$

igroup $=\operatorname{int}(\operatorname{data}(14))$

if (igroup. 1e.0) igroup $=1$

if (igroup.gt.20) igroup $=20$

istart $=10 *($ igroup -1$)+1$

$1=$ istart -1

do $175 \mathrm{n}=1,10$

$1=1+1$

$\operatorname{idbug}(1)=\operatorname{int}(\operatorname{data}(n))$

175 cont inue

go to 100

*i plabak.51

write (out, 90000)

$n 1=-49$

$i 1=-4$

$i 2=0$

do $2 \mathrm{nn}=1,4$

$i 1=i 1+5$

$i 2=i 2+5$

write(out,90003) i1,i2

$\mathrm{n} 1=\mathrm{n} 1+50$

do $111=1,10$

$i=n 1+11-1$

$j=i+10$

$k=i+20$

$1=i+30$

$m=i+40$

write (out, 90001) $i, i d b u g(i), j, i d b u g(j), k, i d b u g(k), 1, i d b u g(1)$,

$\$ m$, idbug (m)

1 continue

2 continue

write (out, 90002)

90000 format $(/ / /, 5 x, " i d b u g$ array settings" $/ / / /)$

90001 format $(2 x, 2 h i=, i 5,2 x, 6 h i d b u g=, i 5,2 x, 2 h j=, i 5,2 x, 6 h i d b u g=, i 5,2 x$,

$12 \mathrm{hk}=, \mathrm{i} 5,2 \mathrm{x}, 6 \mathrm{hidbug}=, \mathrm{i} 5,2 \mathrm{x}, 2 \mathrm{hi}=, \mathrm{i} 5,2 \mathrm{x}, 6 \mathrm{hidbug}=, \mathrm{i} 5,2 \mathrm{x}, 2 \mathrm{hm}=, \mathrm{i5}, 2 \mathrm{x}$,

2 6hidbug $=$, i5)

90002 format $(/ / /)$

90003 format $(/ /, 2 x$, "idbug array for groups", $2 x, i 3, "$ to ", i3,//)

*id impcomm

* I vmc array needed for moment implicit

${ }^{*} \mathrm{~d}$ comlst. 13

common/imp/vmc (maxarr) , smr (maximp) ,smz (maximp) , smx (maximp) ,

*id impfact

* I redimension

*d facts. 2,16 


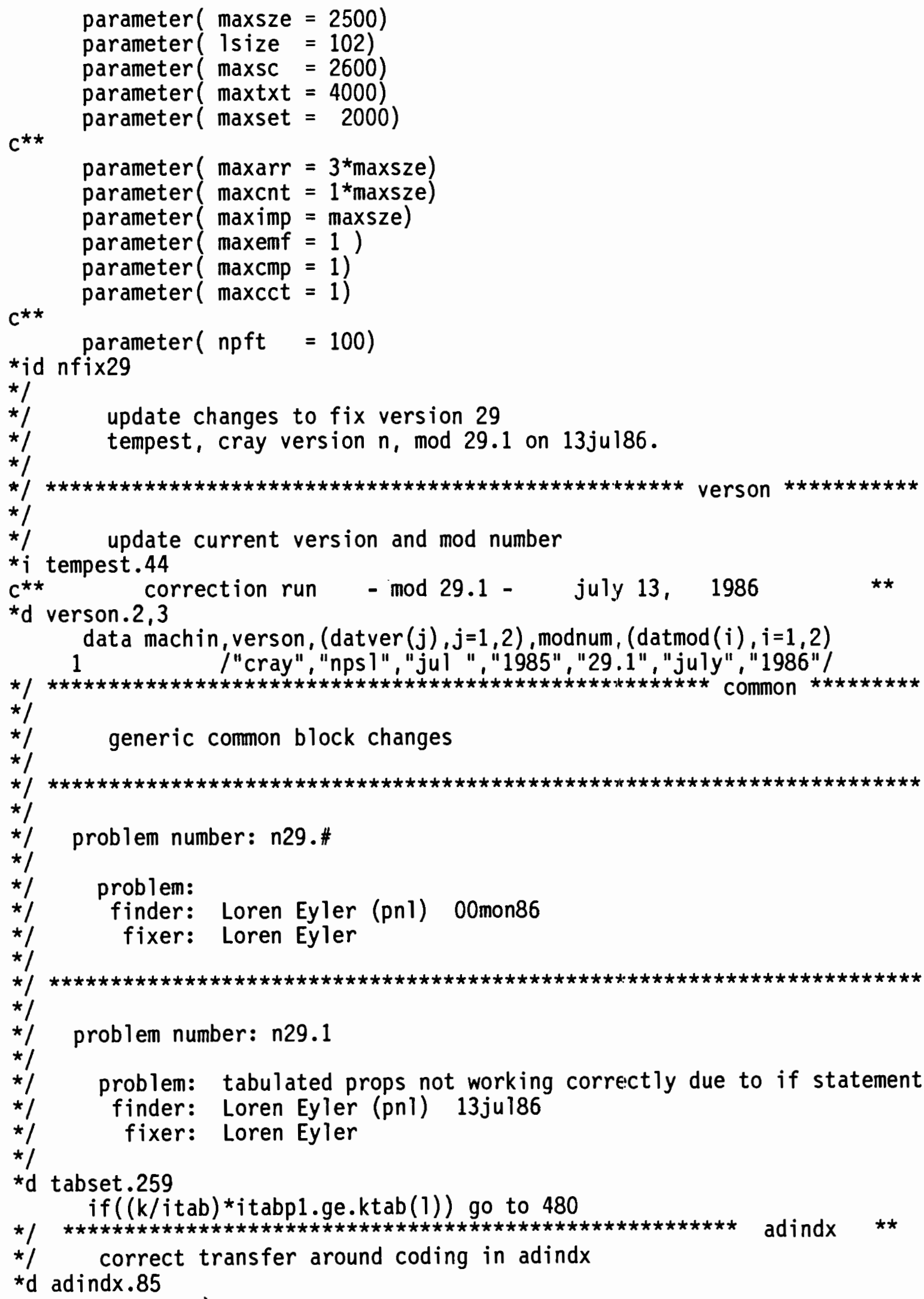




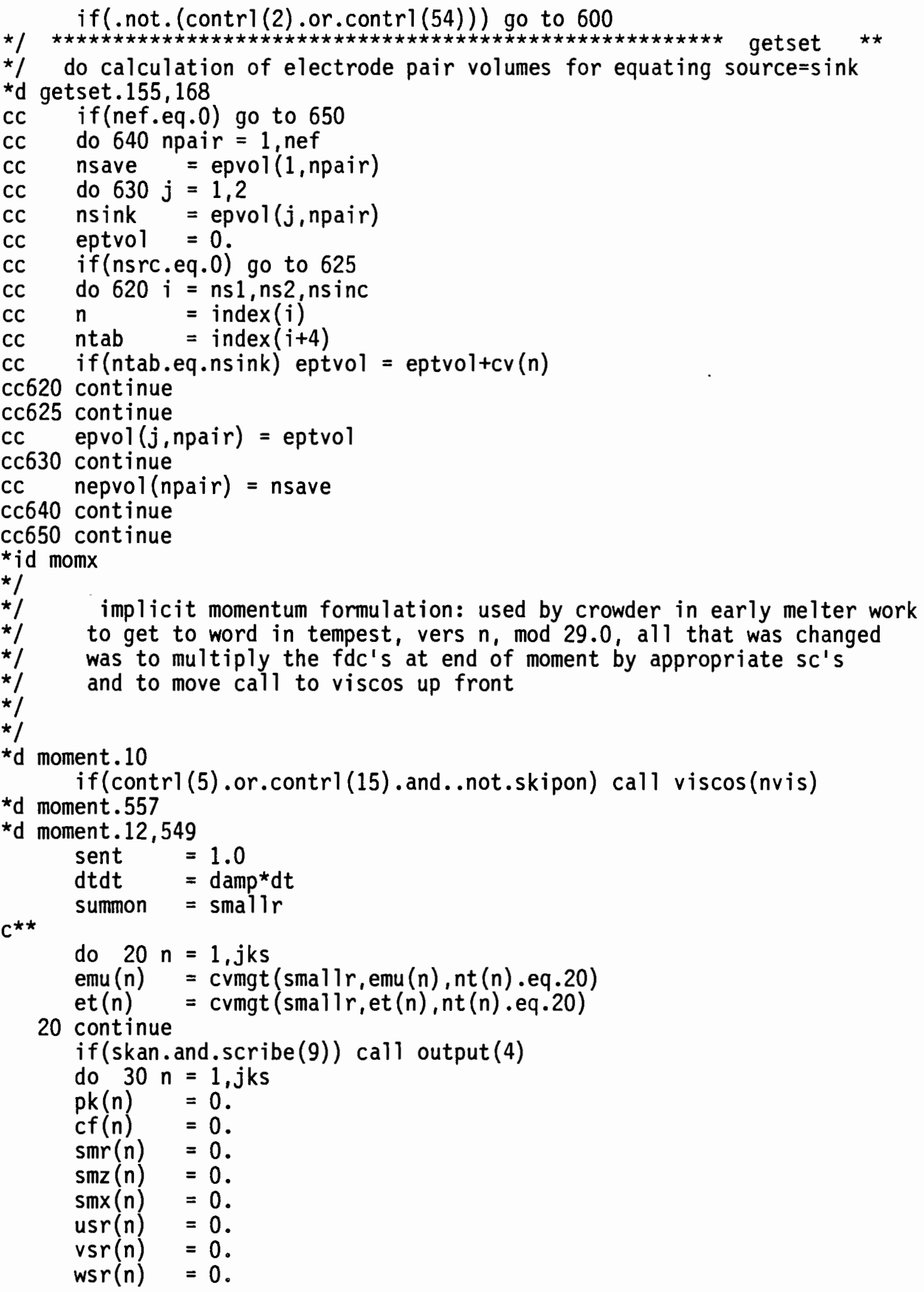




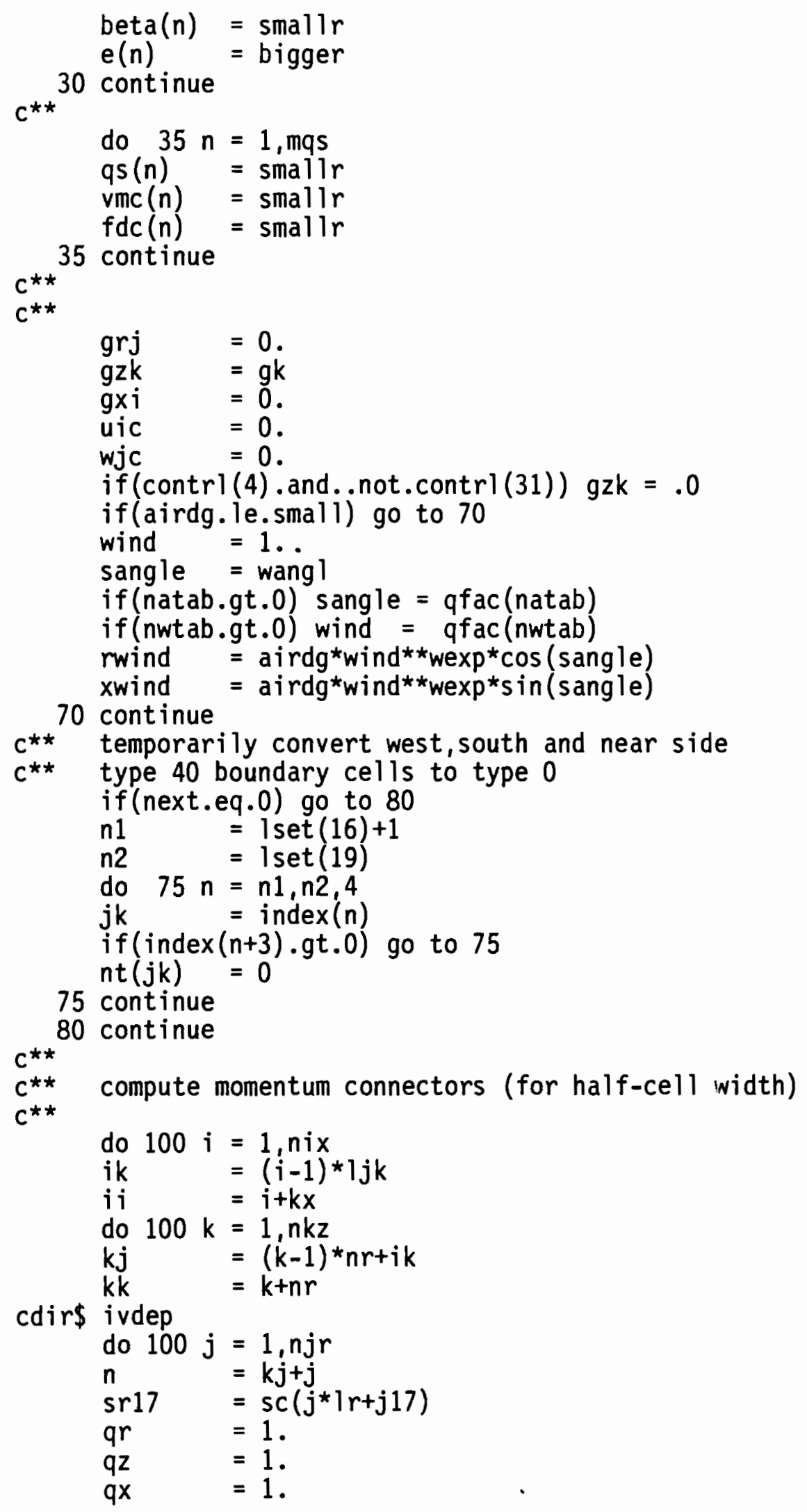




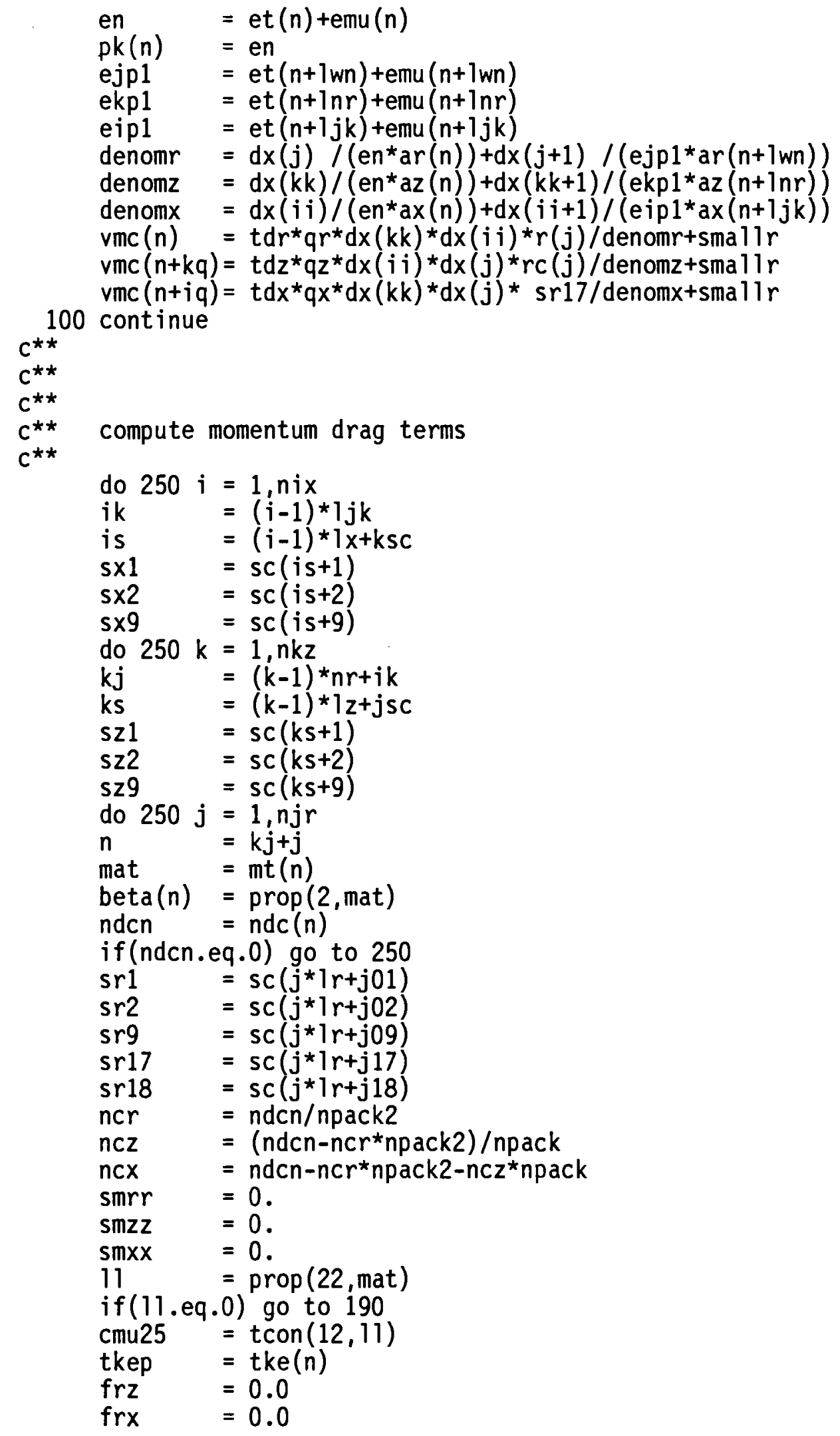




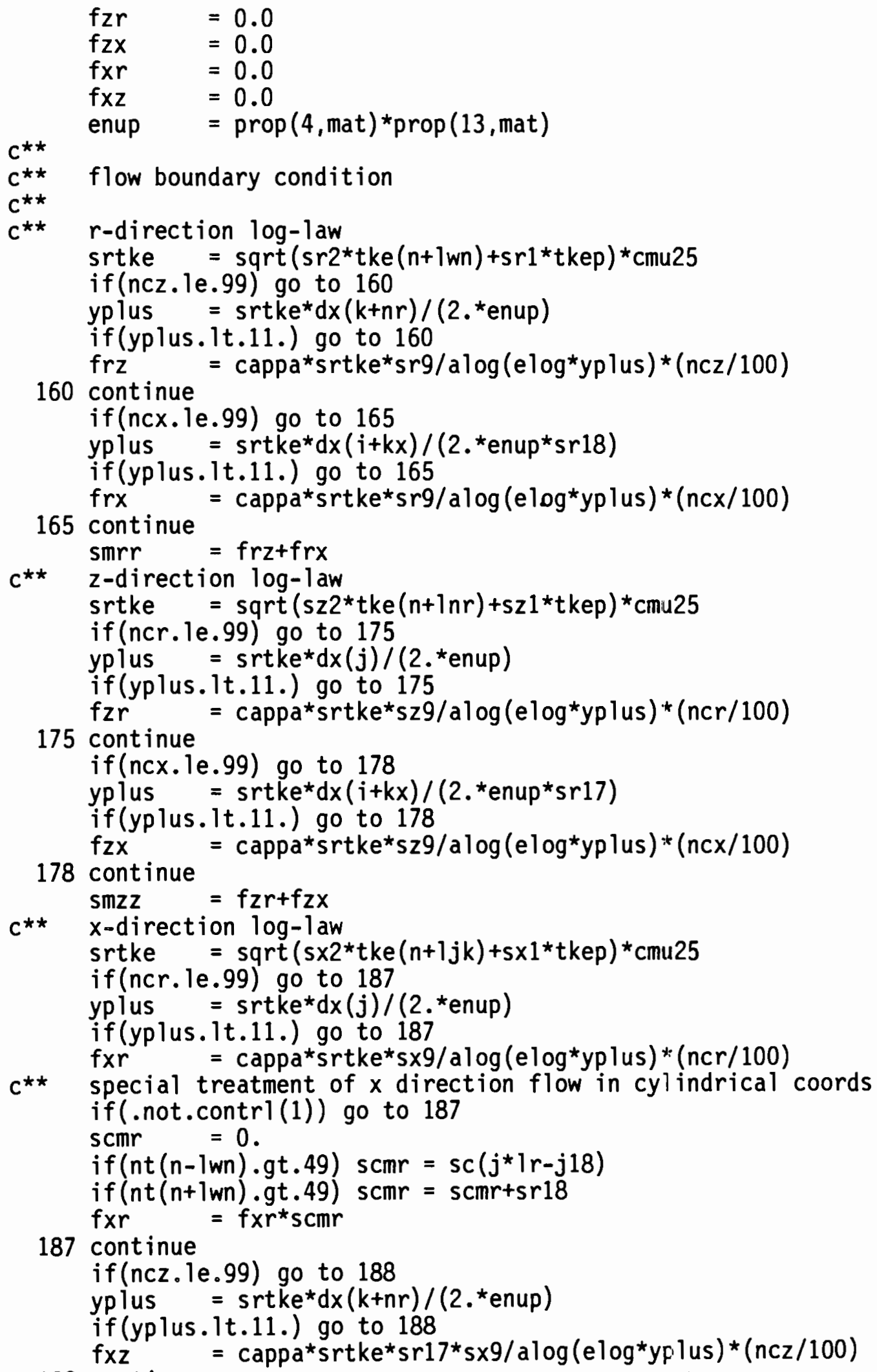


$\operatorname{smxx}=f x r+f x z$

if (ncr.eq.0.or.ncr.ge.99) go to 192

aup $=\operatorname{abs}(u(n))$

factor $=0.5$ *hdc (ncr)

if (ncr. 1t. 49) factor $=$ factor ${ }^{*}$ s 9

if $\left(\operatorname{dex}(n c r)\right.$. ne.2.) factor $=$ factor $^{\star}(\operatorname{aup}+\operatorname{smal1} r) \star \star(\operatorname{dex}(n c r)-2)$.

192 continue

= smrr+factor*aup

if (ncz.eq.0.or.ncz.ge.99) go to 195

$\operatorname{avp}=\operatorname{abs}(v(n))$

factor $=0.5 * h d c(n c z)$

if (ncz.1t.49) factor $=$ factor $*$ sz 9

if $(\operatorname{dex}(n c z) \cdot$ ne.2.) factor $=$ factor $*(\operatorname{avp}+\operatorname{smal} 1 r) \star \star(\operatorname{dex}(n c z)-2)$.

smzz $=$ smzz+factor ${ }^{\star}$ avp

195 continue

if (ncx.eq.0.or.ncx.ge.99) go to 210

awp $=\operatorname{abs}(w(n))$

factor $=0.5^{*}$ hdc (ncx)

if (ncx. 1t.49) factor $=$ factor*sx $9 * s r 17$

if $(\operatorname{dex}(n c x) . n e .2$.$) factor =$ factor $^{\star}(\operatorname{awp}+\operatorname{smal1} r)^{\star \star}(\operatorname{dex}(n c x)-2$.

smxx $=$ smxx+factor*awp

210 continue

$\operatorname{smr}(n)=s m r(n)+s m r r$

$s m z(n)=s m z(n)+s m z z$

$\operatorname{smx}(n)=\operatorname{smx}(n)+\operatorname{smxx}$

250 continue

$c * \star$

$c *$ compute momentum source terms

$c * \star$

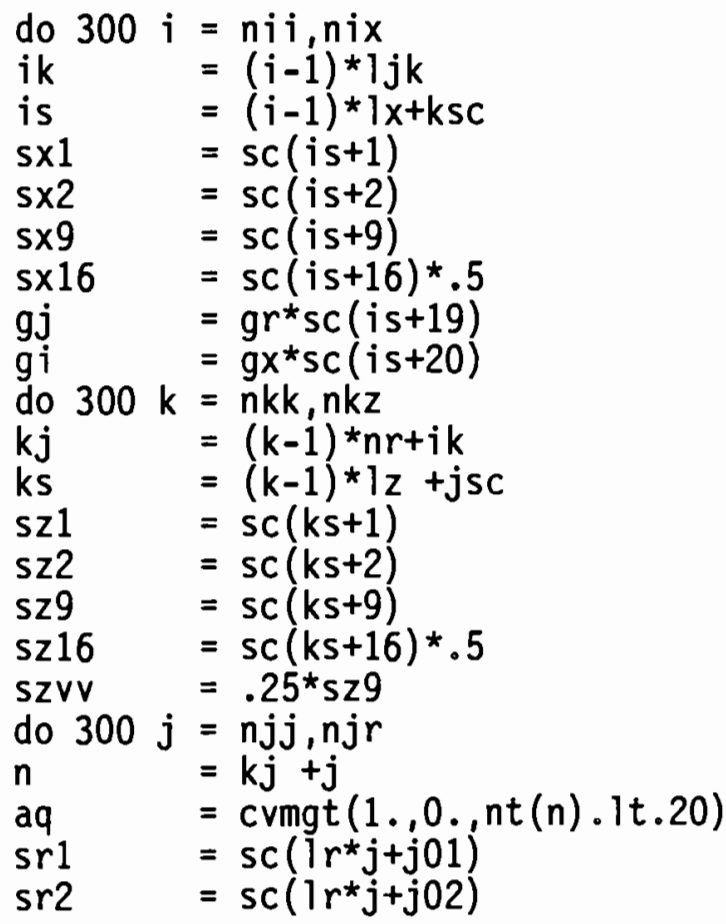




$$
\begin{aligned}
& \operatorname{srg}=s c\left(1 r^{\star} j+j 09\right) \\
& \text { sr16 }=s c\left(1 r^{*} j+j 16\right) * .5 \\
& s r 17=s c\left(1 r^{*} j+j 17\right) \\
& s r 18=s c\left(1 r^{*} j+j 18\right) \\
& s r 19=s c\left(1 r^{*} j+j 19\right) \\
& \text { sXwV }=\text { sr } 17 * s \times 16 \\
& \text { sXwu }=\text { sr18*sX16 } \\
& \text { sruu }=.5 * \operatorname{sr} 9 * \operatorname{sr} 18 \\
& \mathrm{~s} \times w \mathrm{w}=.25 * \mathrm{~s} \times 99^{*} \mathrm{sr} 17 \\
& \mathrm{dp} \quad=\operatorname{rho}(n) \\
& \mathrm{dp} 0 \quad=\operatorname{beta}(n) \\
& \text { denr }=1 . / \mathrm{dp} 0 \\
& \text { sr67 }=\operatorname{sr} 16^{*} \operatorname{sr} 17 \\
& \text { volr }=.5^{\star}(\operatorname{cv}(n)+c v(n+1 w n)) \\
& \text { volz }=.5^{\star}(\operatorname{cv}(n)+c v(n+l n r)) \\
& c^{\star \star} \text { set velocities } \\
& C^{\star \star} \\
& \text { up } \quad=u(n) \\
& \text { ujp1 }=u(n+l w n) \\
& \text { ujm1 }=u(n-1 w n) \\
& \text { uipl }=u(n+1 j k) \\
& \text { uiml }=u(n-1 j k) \\
& \text { ukp1 }=u(n+\ln r) \\
& \text { ukm1 }=u(n-l n r) \\
& \text { ujmip }=u(n+j m i p) \\
& \text { ujmkp }=u(n+j m k p) \\
& v p \quad=v(n) \\
& v j p 1=v(n+7 w n) \\
& v j m 1 \quad=v(n-l w n) \\
& \text { vkp1 }=v(n+\ln r) \\
& \text { vkm1 } \quad=v(n-\ln r) \\
& \text { vipl } \quad=v(n+1 j k) \\
& \text { vim1 } \quad=v(n-l j k) \\
& \text { vjpkm } \quad=v(n+j p k m) \\
& \text { vkmip } \quad=v(n+k m i p) \\
& \text { wp } \quad=w(n) \\
& \text { wjm1 }=w(n-1 w n) \\
& \text { wjp1 } \quad=w(n+1 w n) \\
& \text { wiml } \quad=w(n-1 j k) \\
& \text { wip1 } \quad=w(n+1 j k) \\
& \text { wkm1 } \quad=w(n-\ln r) \\
& \text { wkp1 } 1=w(n+1 n r) \\
& \text { wjpim }=w(n+j p i m) \\
& \text { wkpim }=w(n+k p i m) \\
& \begin{array}{ll}
\text { uap } & =.5^{\star}(\text { up+ujp1) } \\
\text { uam } & =.5^{\star}(\text { up+ujm1) }
\end{array} \\
& \text { ukc }=.5^{\star}\left(s z 2^{*}(u k p 1+u j m k p)+s z 1^{*}(u p+u j m l)\right)
\end{aligned}
$$


uic $\quad=.5^{\star}\left(\mathrm{s} \times 2^{\star}(\right.$ uip $1+u j m i p)+s \times 1 *($ up+ujm1 $\left.)\right)$

vjc $\quad=.5^{\star}\left(s r 2^{\star}(v j p 1+v j p k m)+s r 1 *(v p+v k m 1)\right)$

vic $\quad=.5 *(s \times 2 *(v i p 1+v k m i p)+s \times 1 *(v p+v k m 1))$

wjc $\quad=.5^{\star}(s r 2 *(w j p 1+w j p i m)+s r 1 *(w p+w i m 1))$

wkc $\quad=.5^{\star}(s z 2 *(w k p 1+w k p i m)+s z 1 *(w p+w i m 1))$

compute density averages

rhojpl = cvmgt $(d p, r h o(n+1 w n), n t(n+1 w n) \cdot e q \cdot 20 \cdot o r \cdot n t(n+1 w n) \cdot g t \cdot 49)$

rhokp1 = cvmgt (dp, rho $(n+\ln r), n t(n+\ln r) \cdot e q \cdot 20 \cdot$ or. $n t(n+\ln r) \cdot g t \cdot 49)$

rhoipl = cvmgt (dp, rho(n+1jk),nt(n+1jk).eq.20.or.nt (n+1jk).gt.49)

rhor $=\operatorname{cvmgt}(s r 1 * d p+s r 2 *$ rhojp $1, d p 0$, couple)

rhoz $=\operatorname{cvmgt}\left(s z 1^{*} d p+s z 2^{*}\right.$ rhokpl, dp0, couple)

rhox $=\operatorname{cvmgt}\left(s \times 1{ }^{\star} d p+s \times 2{ }^{*}\right.$ rhoipl, dp0, couple)

$\operatorname{smr}(n)=\operatorname{rhor}^{*} \operatorname{smr}(n)$

$\operatorname{smz}(n)=\operatorname{rhoz}^{\star} \operatorname{smz}(n)$

$\operatorname{smx}(n)=\operatorname{rhox}{ }^{\star} \operatorname{smx}(n)$

$\operatorname{usr}(n)=-s m r(n) * u p$

$\operatorname{vsr}(n)=-\operatorname{smz}(n) * v p$

$w s r(n)=-\operatorname{smx}(n) * w p$

$C^{\star \star}$
$C^{\star \star}$
$C^{\star \star}$

compute advective momentum

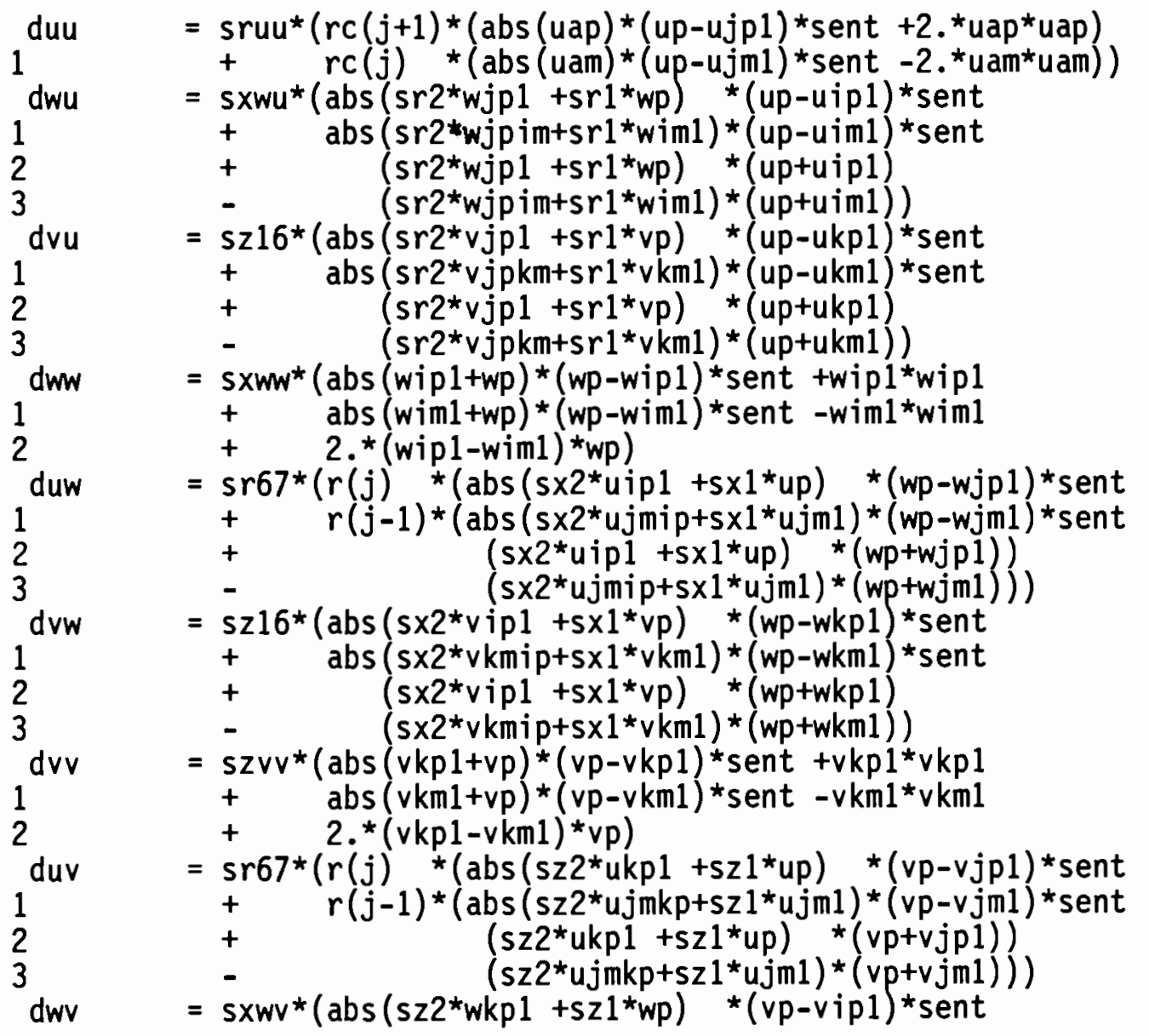




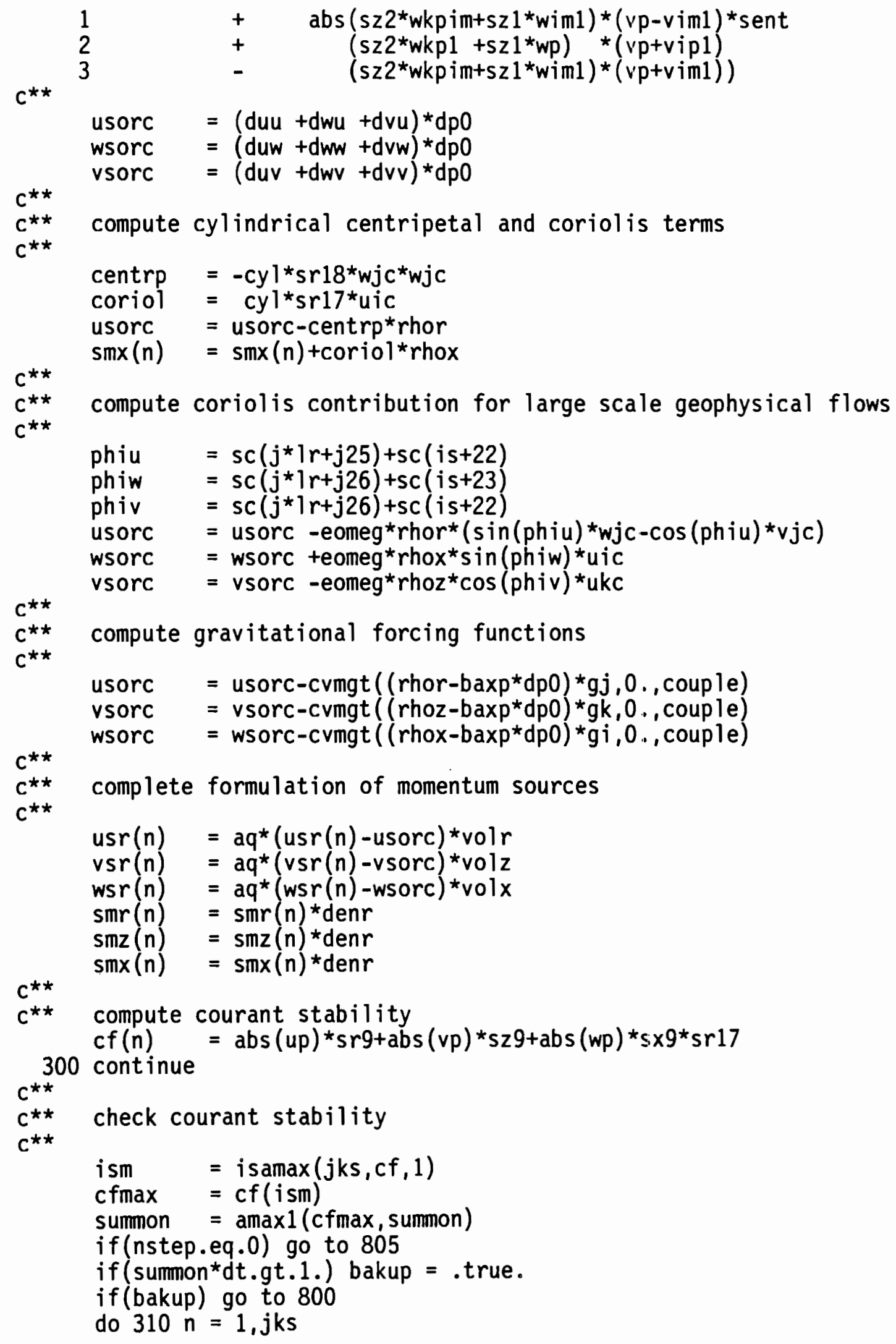




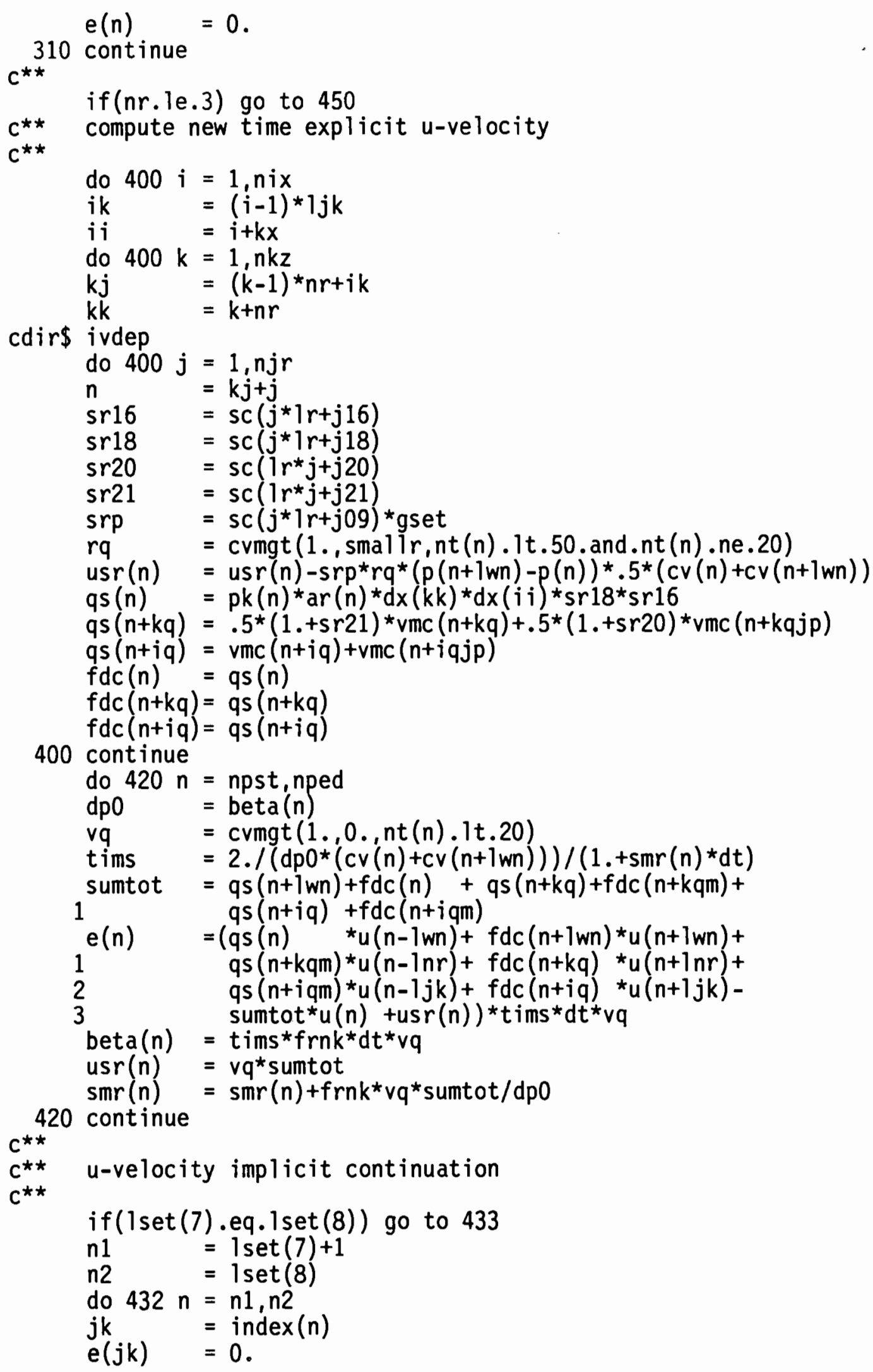




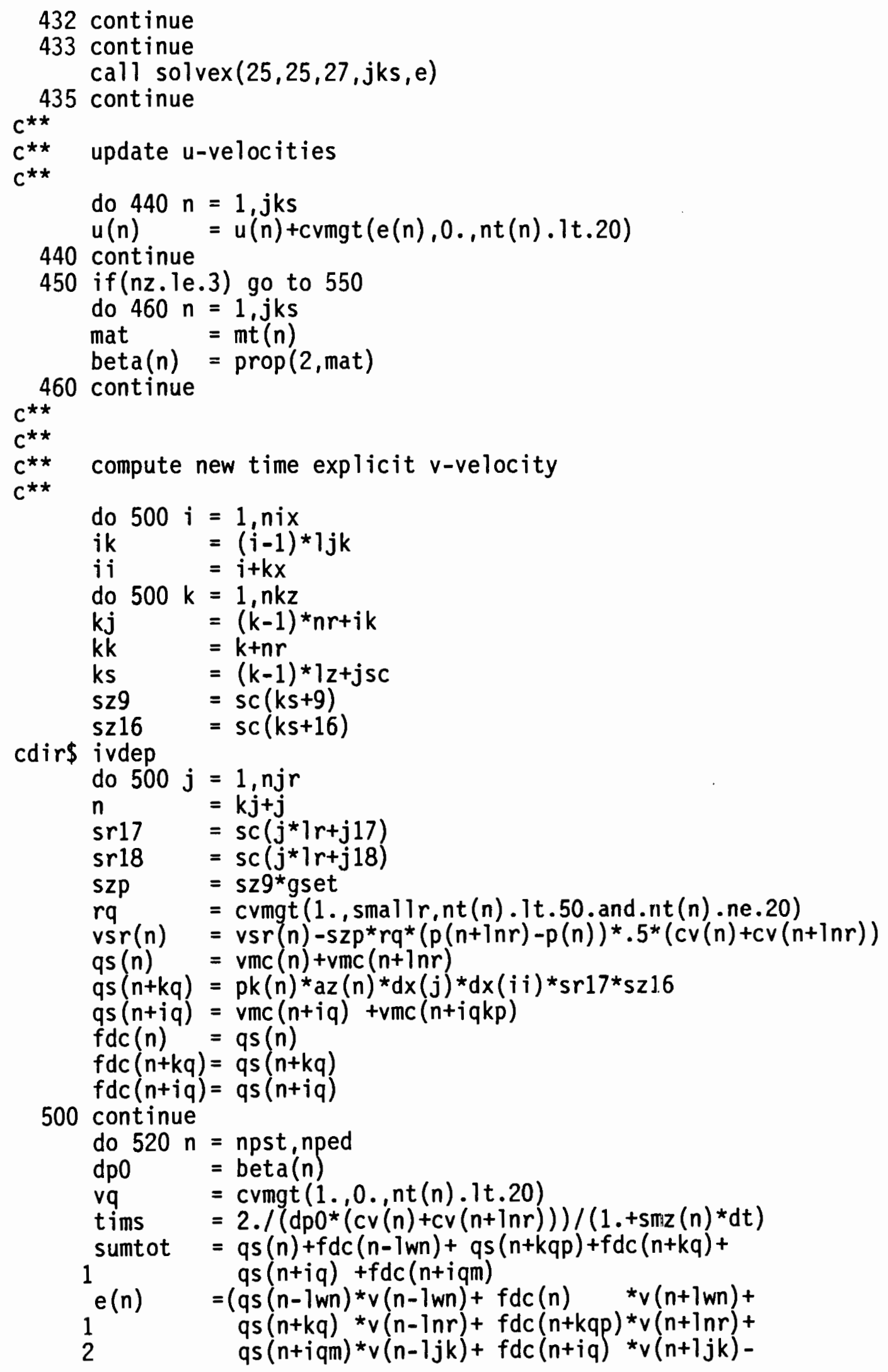




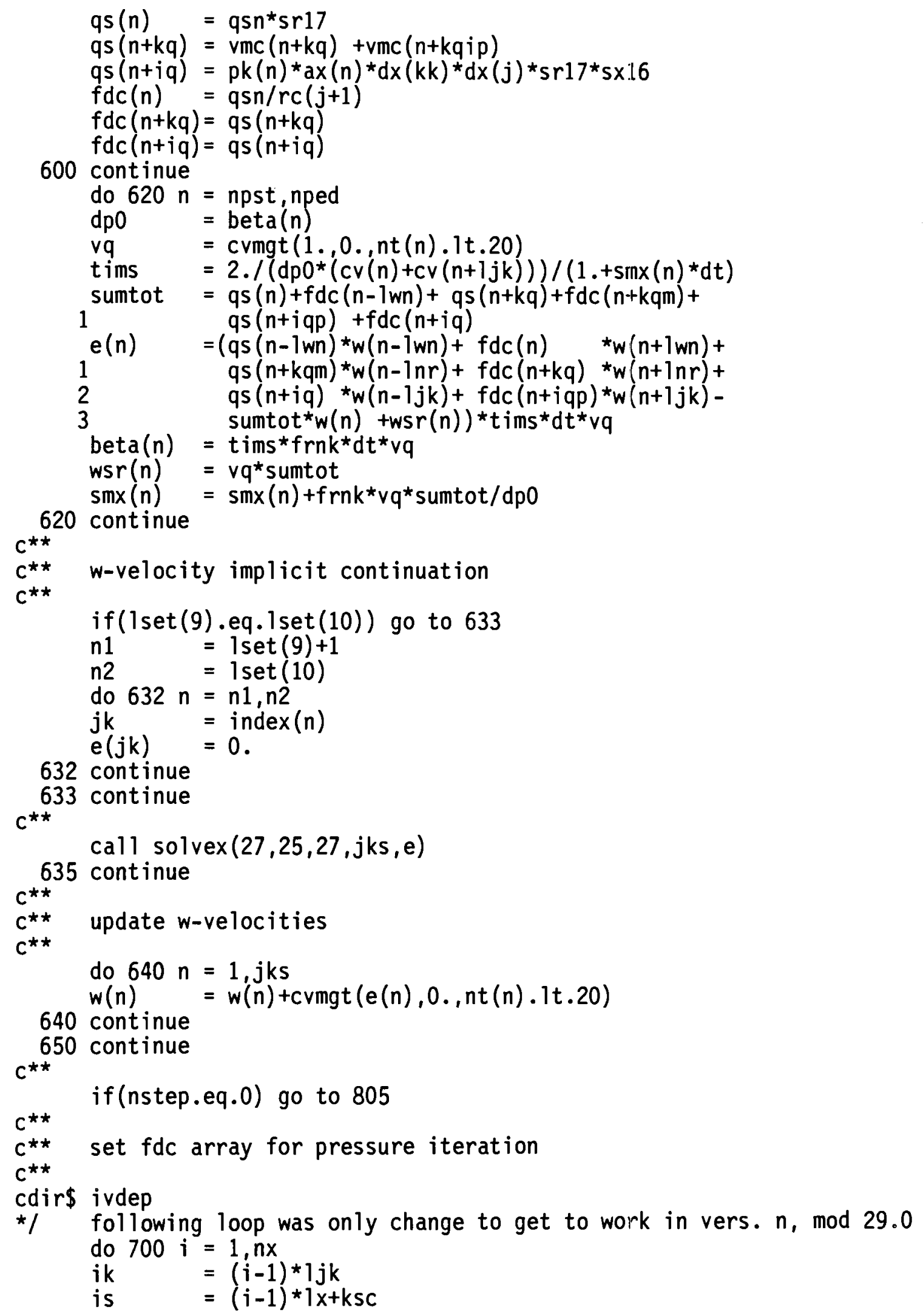




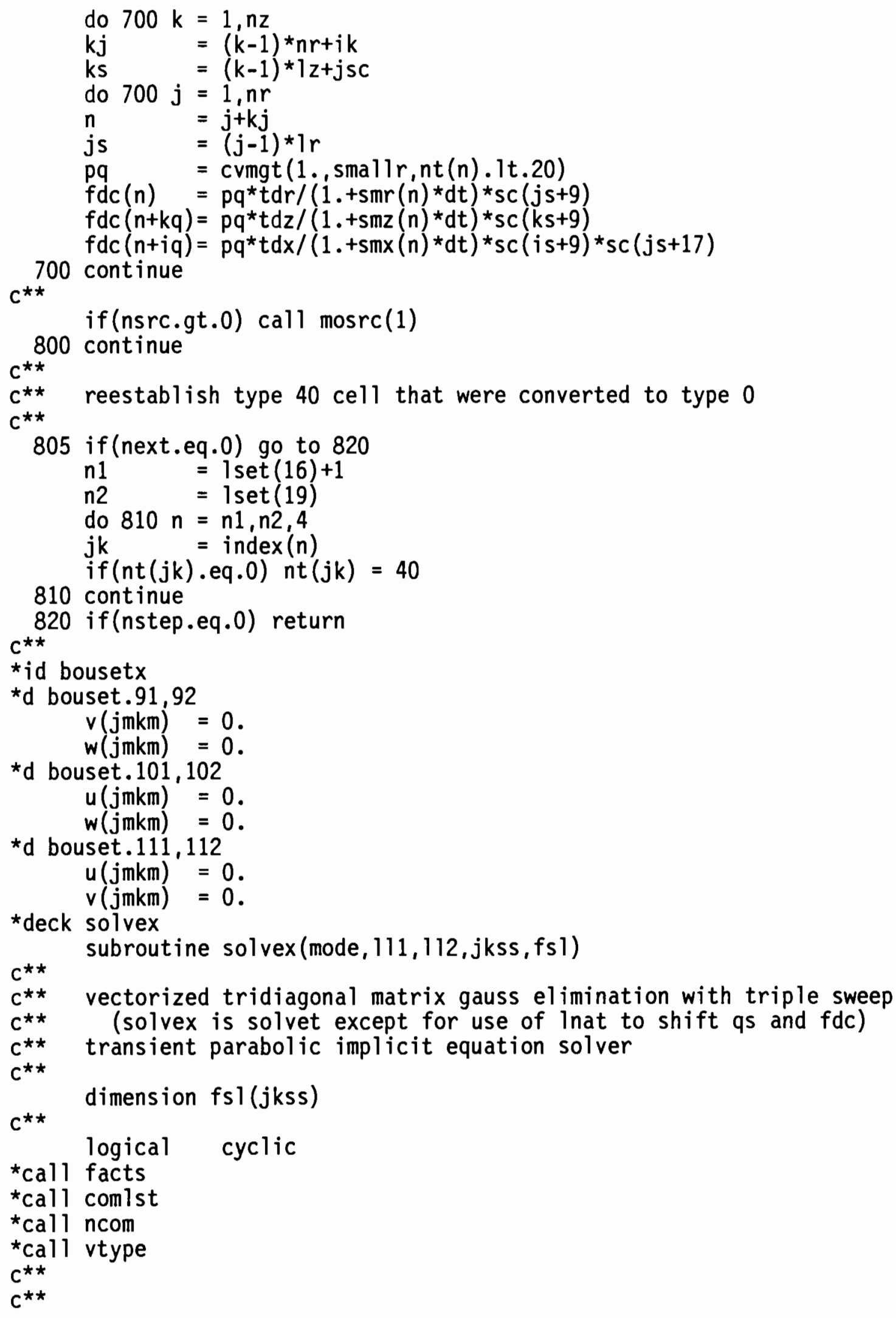




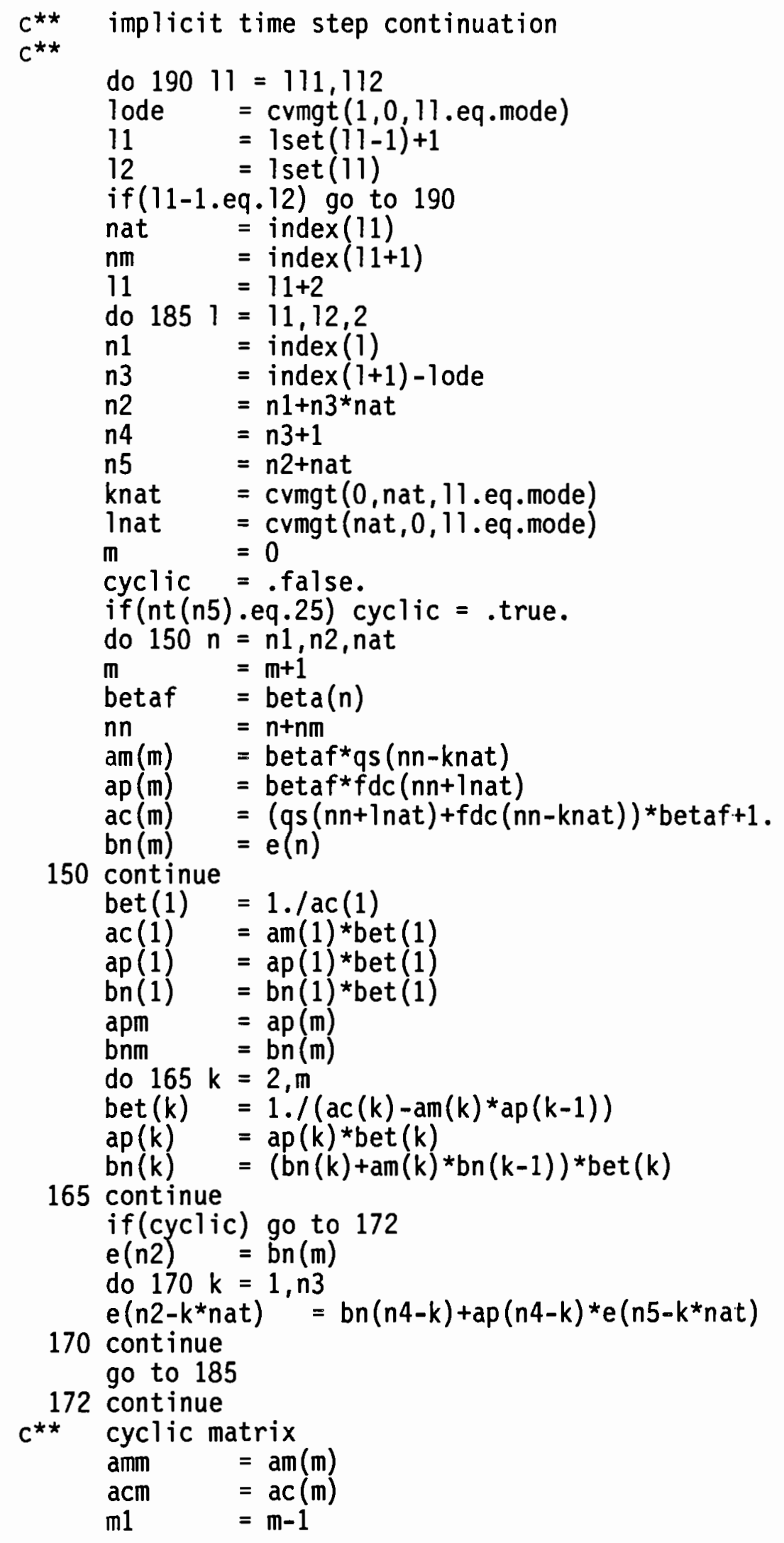




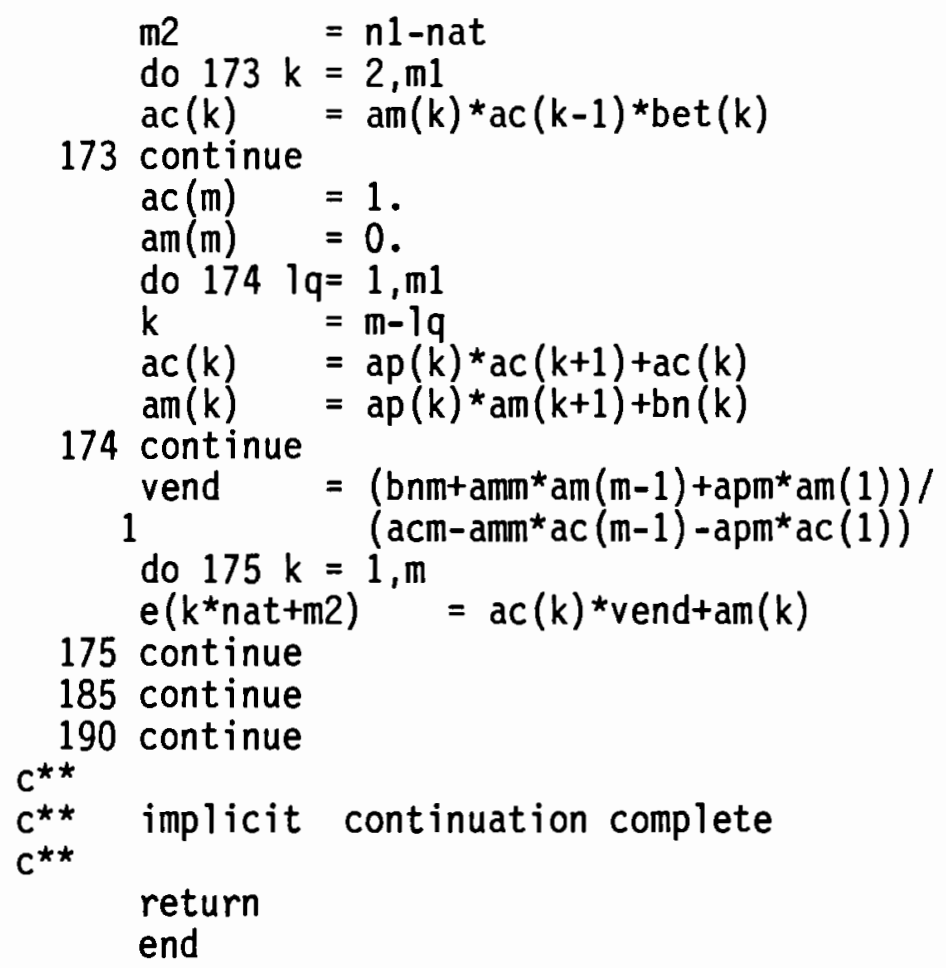




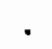

$\checkmark$ 


\section{APPENDIX B}

FRONT TRACKER CHANGES TO TEMPEST 


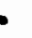




\section{FRONT TRACKER CHANGES TO TEMPEST}

-

This appendix contains the HISTORIAN input change file that creates the N29B2 version of TEMPEST from the N29B1 version. These changes are provided to maintain traceability and quality assurance on the N29B2 version of TEMPEST (the latest version with the front tracker model). Note that this version of TEMPEST is not completed. However, this change file will facilitate the restart of the code development project whenever sufficient funding becomes available. 


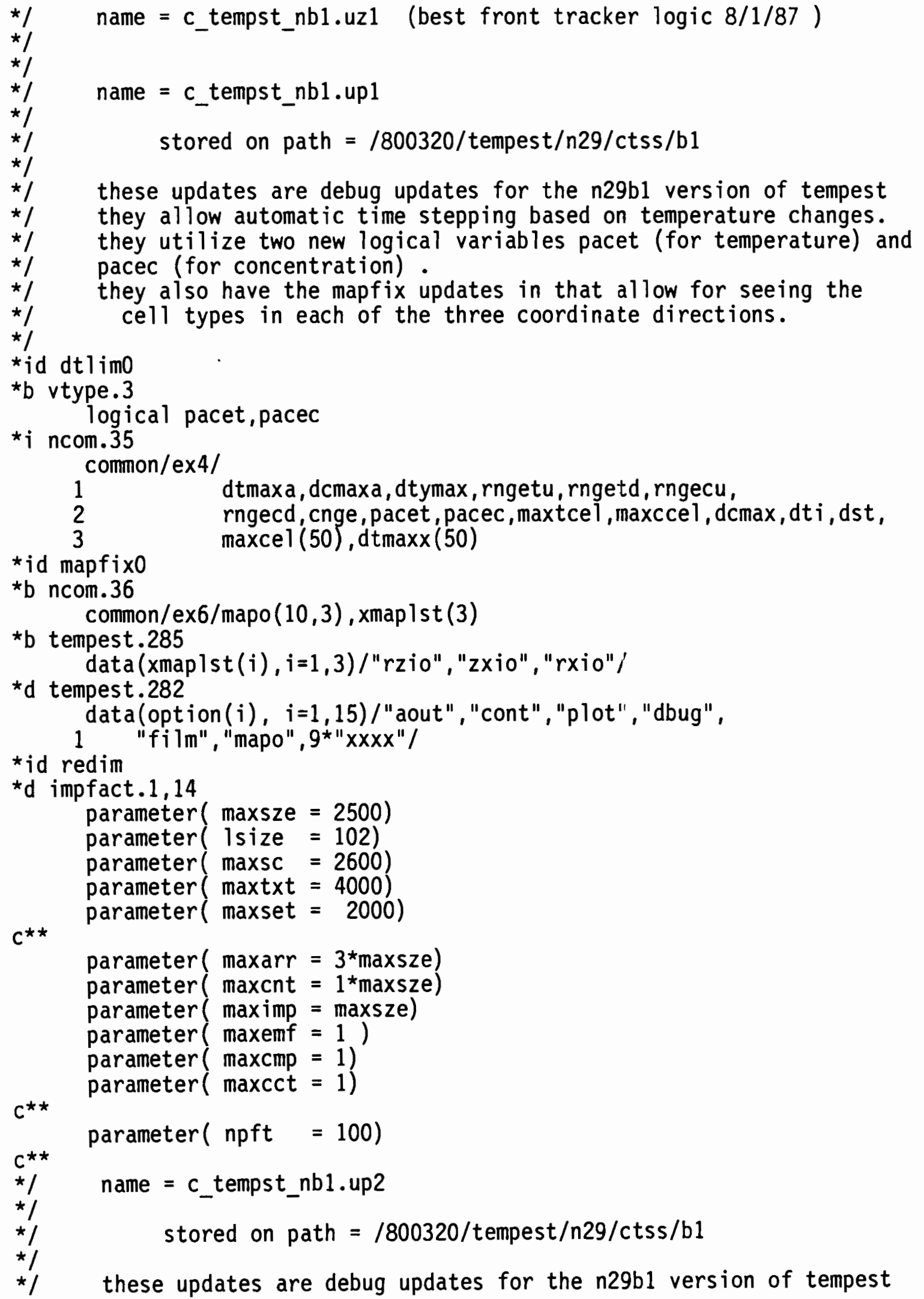


* I they allow automatic time stepping based on temperature changes.

* t they utilize two new logical variables pacet (for temperature) and

* pacec (for concentration).

* they also have the mapfix updates in that allow for seeing the

* cell types in each of the three coordinate directions.

*/

*id mapfix1

$*_{i}$ tempest. 647

if $(x 1$ ist.eq.option(7)) go to 1500

${ }^{*} \mathrm{~d}$ tempest.648

if(xlist.eq." ") go to 400

go to 300

* $i$ tempest.689

1500 continue

if (dat(1).eq."ntyp") go to 1510

if (dat (1).eq."mtyp") go to 1520

if(dat (1).eq."ptyp") go to 1530

if (dat (1).eq."ttyp") go to 1540

if(dat (1).eq."drag") go to 1550

if(dat(1).eq."film") go to 1560

go to 1570

1510 continue

do $1515 \quad 1=2,4$

do $1515 i=1,3$

1515 if $(\operatorname{dat}(1)$.eq.xmaplst $(i))$ mapo $(1, i)=1$

go to 100

1520 continue

do $1525 \quad l=2,4$

do $1525 \quad i=1,3$

1525 if $(\operatorname{dat}(1)$.eq.xmaplst $(i))$ mapo $(2, i)=1$

go to 100

1530 cont inue

do $1535 \quad l=2,4$

do $1535 j=1,3$

1535 if (dat (1).eq.xmaplst (i)) mapo( $3, i)=1$

go to 100

1540 continue

do $1545 \quad l=2,4$

do $1545 i=1,3$

1545 if(dat(1).eq.xmaplst(i)) mapo(4,i)=1 go to 100

1550 continue

do $1555 \quad l=2,4$

do $1555 i=1,3$

1555 if (dat (1).eq.xmaplst(i)) mapo(5,i) $=1$

go to 100

1560 cont inue

do $1565 \quad l=2,4$

do $1565 j=1,3$

1565 if (dat(1).eq.xmaplst $(i))$ mapo $(6, i)=1$ go to 100

1570 continue 


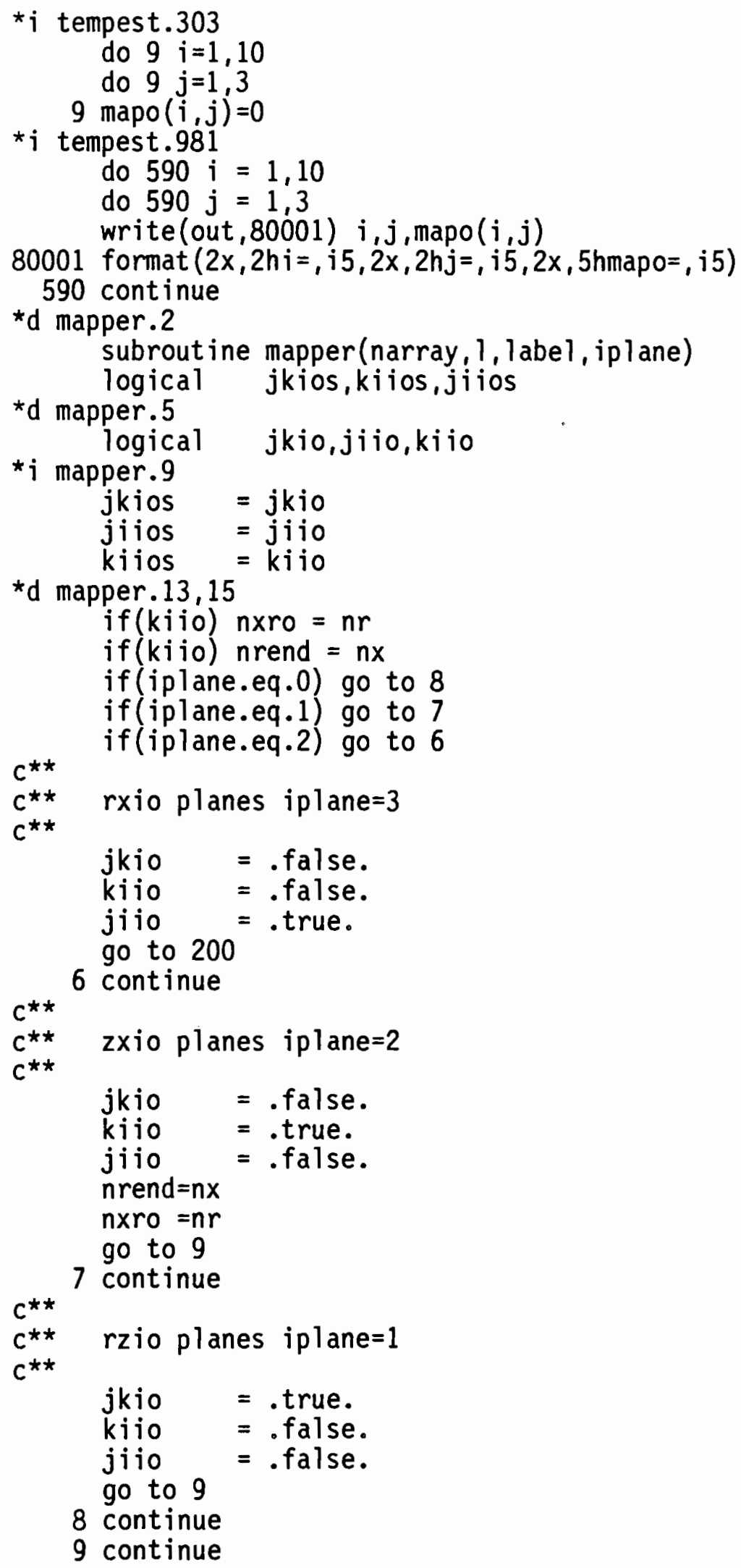


*d mapper. 41

go to 999

* $i$ mapper.61

999 continue

jkio $=$ jkios

jiio $=$ jiios

*d 1cmmap.2

$=\mathrm{kiios}$

subrout ine lcmmap (mode, narray, 1, label, iplane)

* $;$ 1cmmap. 10

jiios $=$ jiio

kiios $=$ kiio

jkios $=$ jkio

if(iplane.eq.0) go to 8

if (iplane.eq.1) go to 7

if (iplane.eq.2) go to 6

$c^{\star \star}$
$c^{\star \star}$
$c^{\star \star}$ rxio planes iplane=3

jiio $=$.true.

kiio $=$.false.

jkio $=$.false.

nrend $=n r$

$n \times z=n z$

$n z x=n x$

go to 9

$c^{\star \star} 6$ continue

$c^{\star \star}$
$c^{\star \star}$ zxio planes iplane $=2$

jiio $=$.false.

kiio $=$.true.

jkio $=$.false.

nrend $=\mathrm{nx}$

$n \times z=n r$

$n z x=n z$

go to 9

7 continue

$c^{\star \star}$ rzio planes iplane $=1$

$c^{\star \star}$

jiio $=$.false.

kiio $=$.false.

jkio $=$.true.

nrend $=n r$

$n \times z=n x$

$n z x=n z$

go to 9

8 continue

*i 1cmmap.61

jiio = jiios 


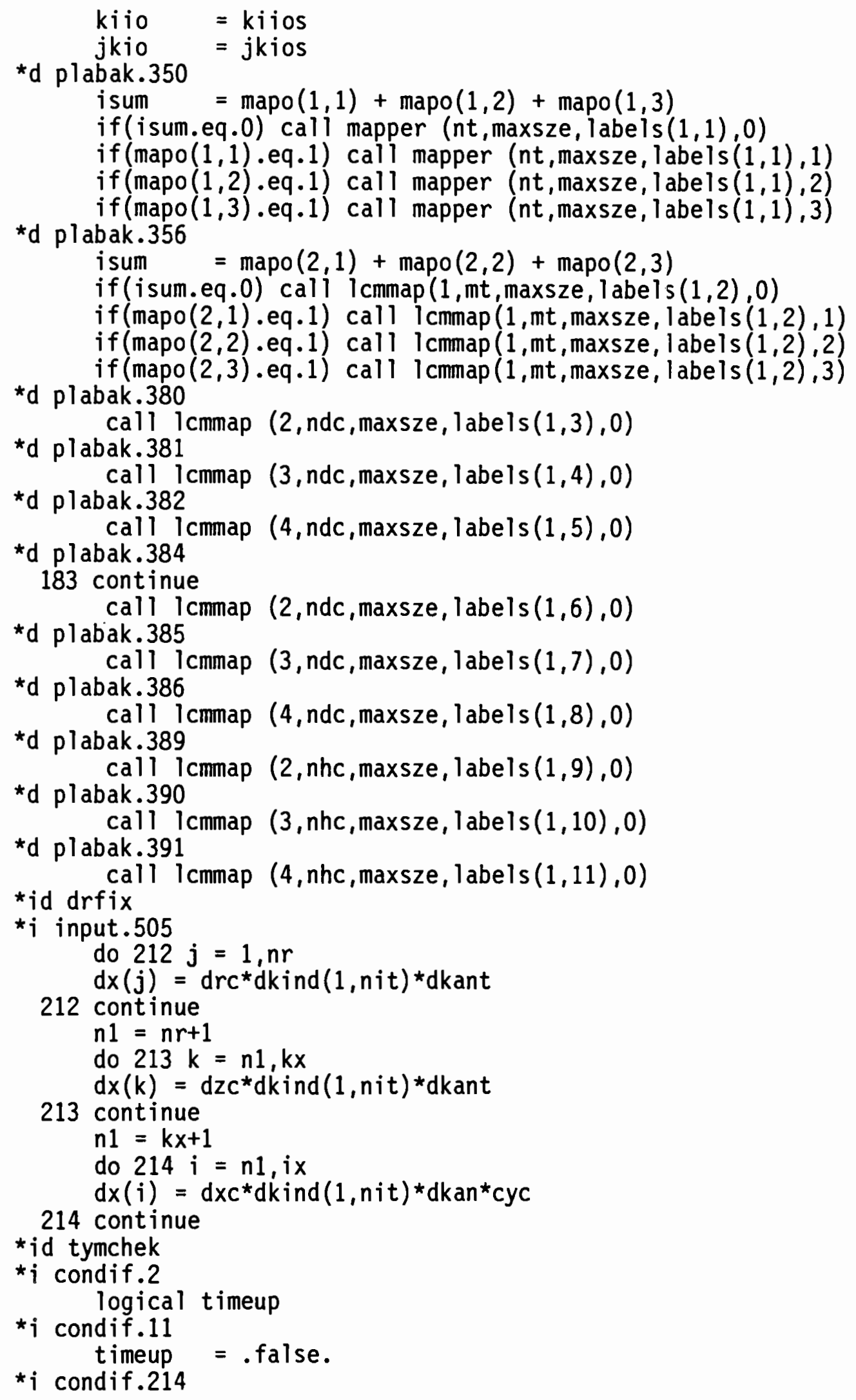

*d plabak.389 call lcmmap $(2$, nhc, maxsze, labels $(1,9), 0)$

*d plabak.390 call lcmmap $(3$, nhc, maxsze, labels $(1,10), 0)$

*d plabak.391

*id drfix call lcmmap $(4$, nhc, maxsze, labels $(1,11), 0)$

*i input.505 do $212 j=1, n r$ $d x(j)=d r c * d k i n d(1, n i t) * d k a n t$

212 cont inue

$n 1=n r+1$

do $213 k=n 1, k x$

$d x(k)=d z c c^{\star} k$ ind $(1, n i t) * d k a n t$

213 continue

$\mathrm{n} 1=\mathrm{kx}+1$

do $214 \mathrm{i}=\mathrm{n1}, \mathrm{ix}$

214 continue

$d x(i)=d x c^{\star} d k$ ind $(1, n i t) * d k a n^{\star} c y c$

*id tymchek

* $i$ condif. 2

$*_{i}$ condif.11

logical timeup

timeup $=$.false.

$* i$ condif.214 


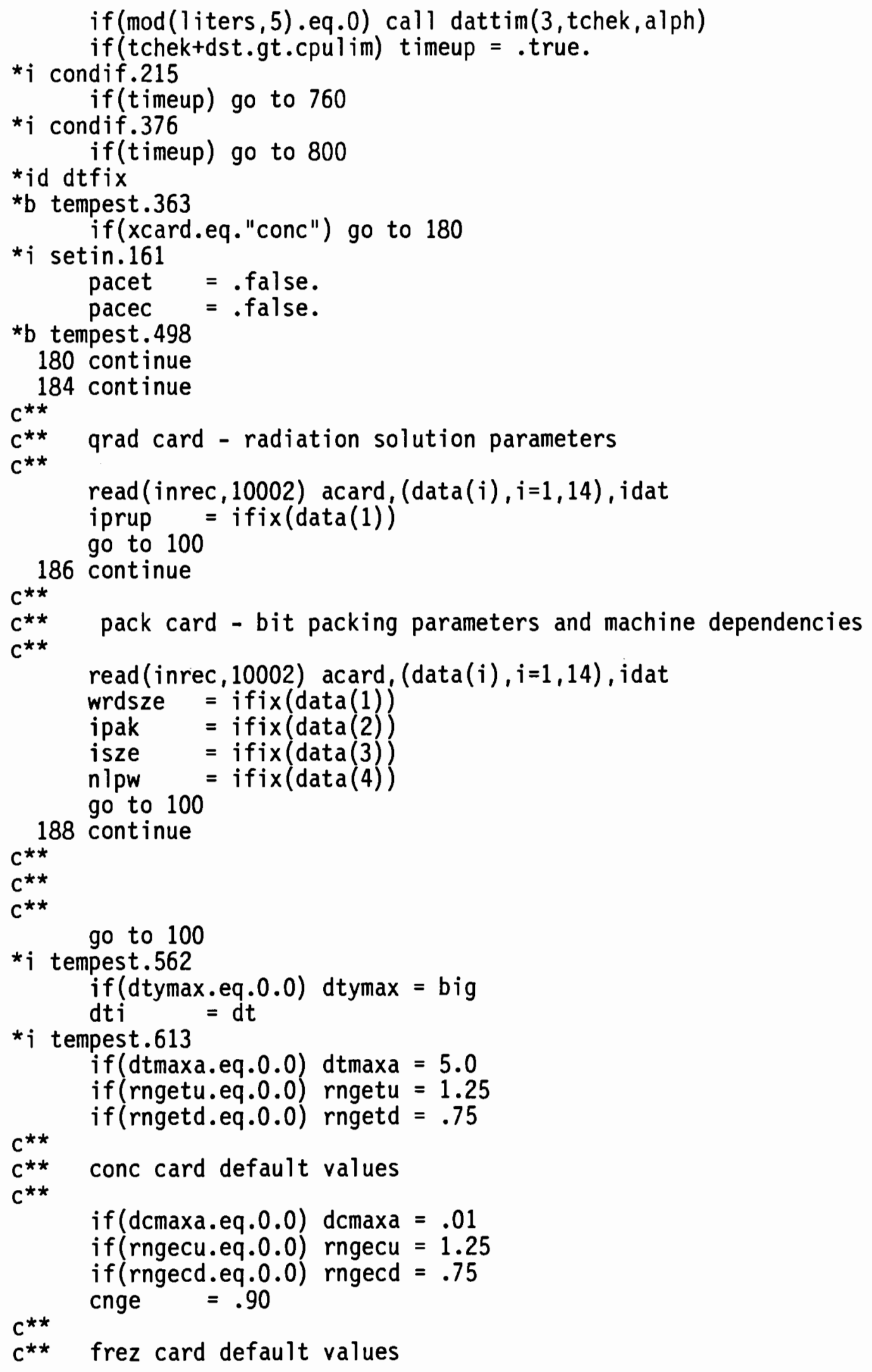




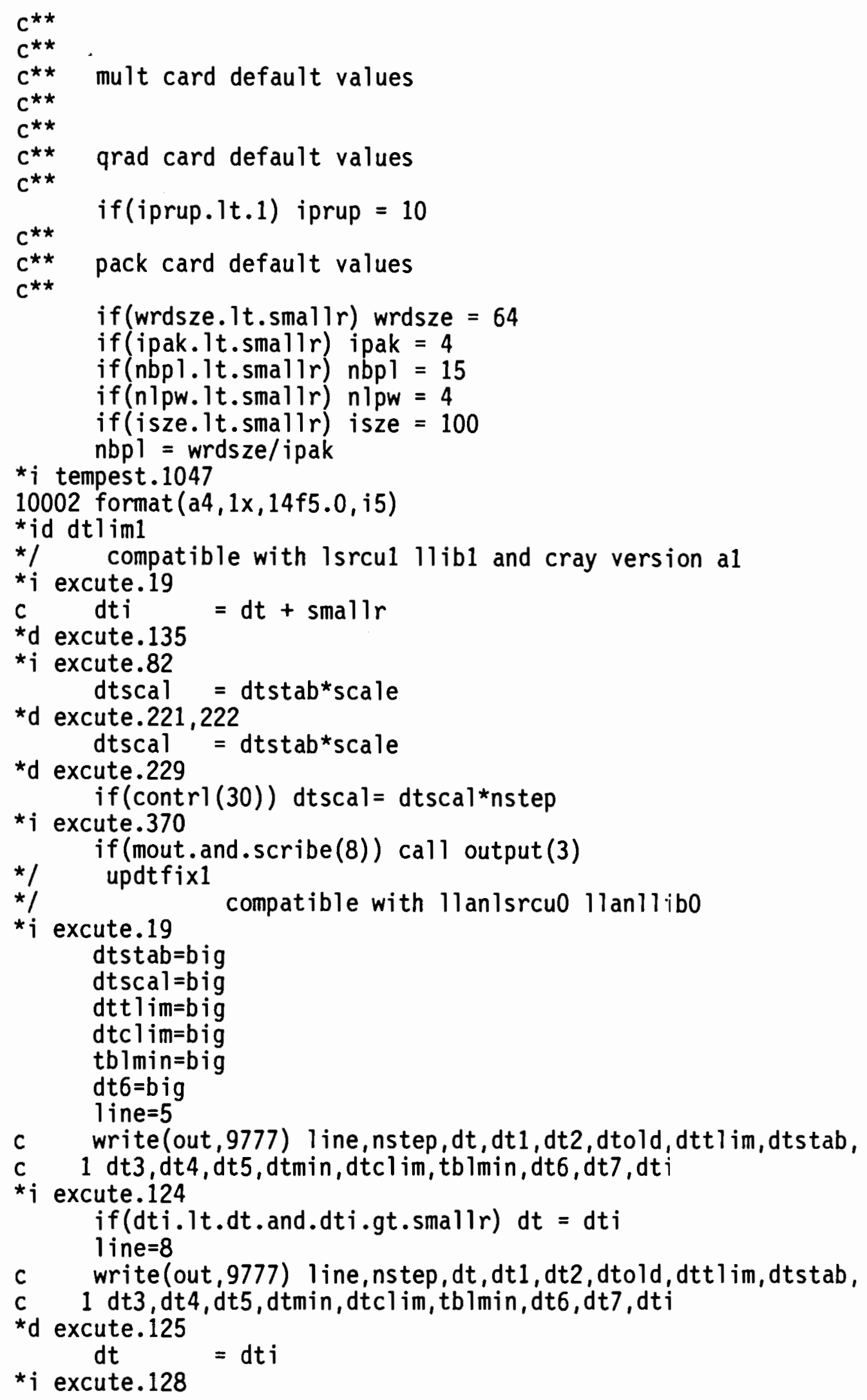




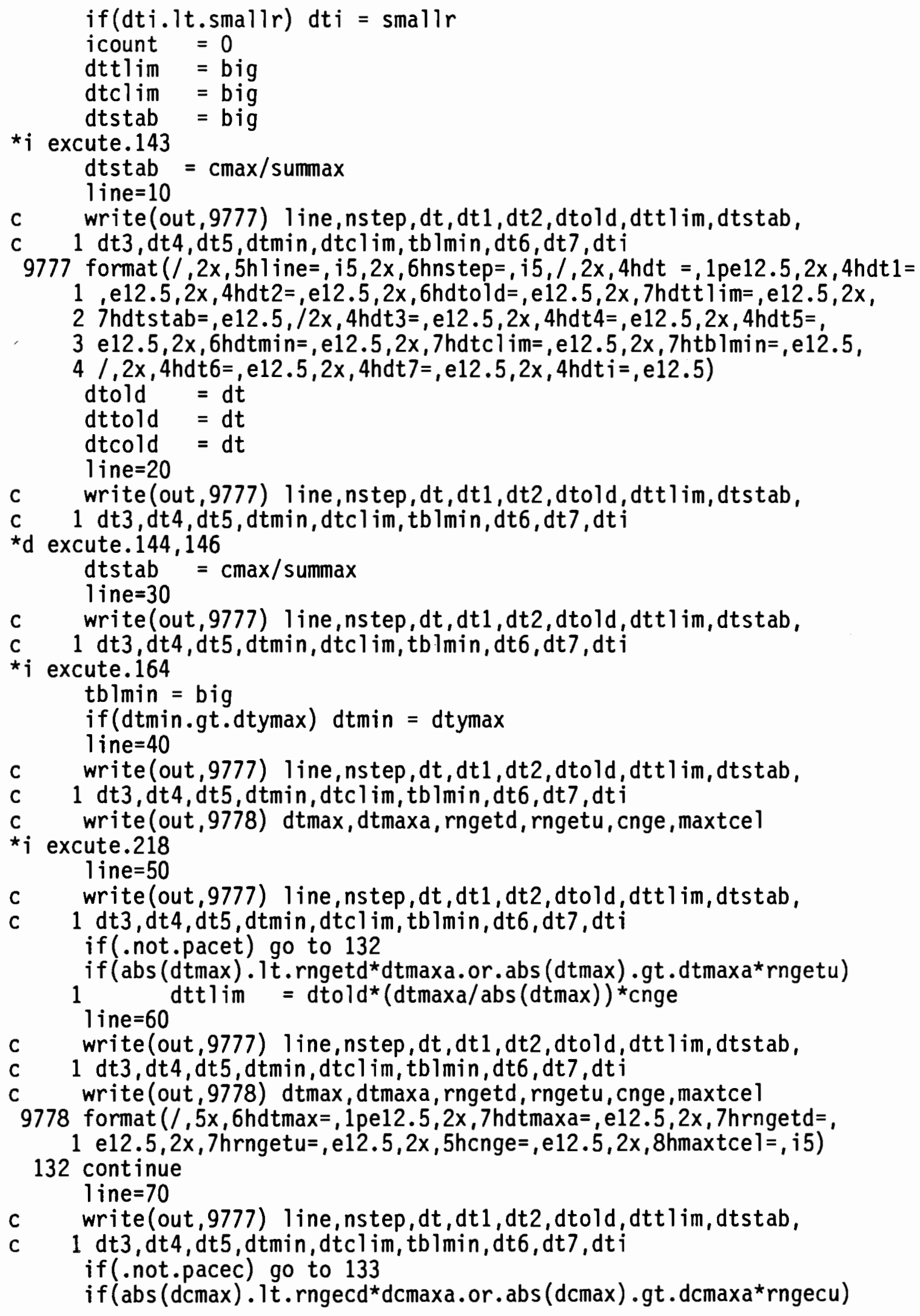




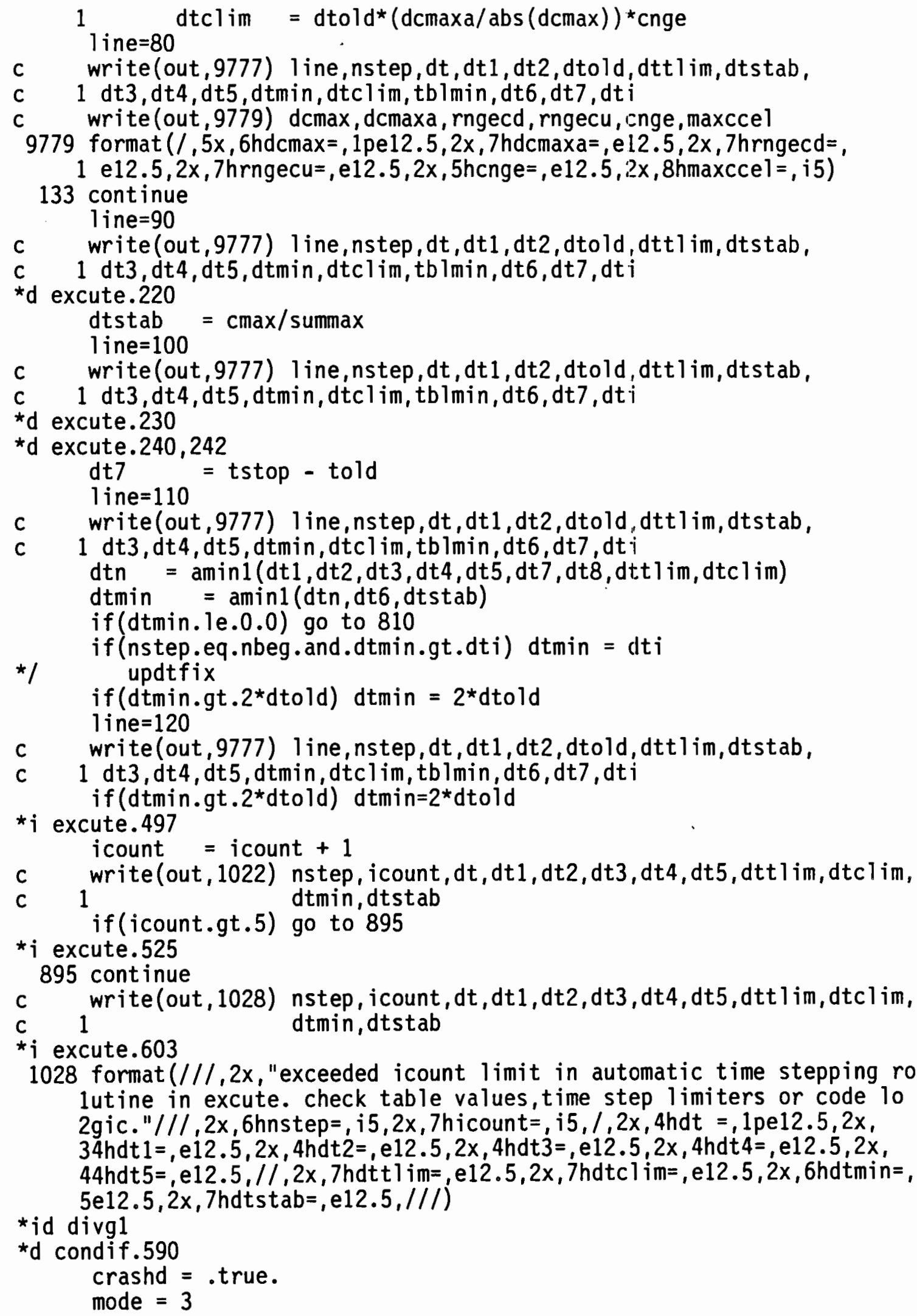


*i patter.214

if(scribe(13)) call patter

$*_{i}$ patter.223

if (crashd) stop

if(crashd.and.mode.eq.3) call exit

*id dtmont1

$*_{i}$ condif. 274

maxtce $]=0$

if (icount.ge.50) icount $=1$

icount $=$ icount +1

$\operatorname{maxcel}($ icount $)=0$

$\mathrm{dtmaxx}($ icount $)=0.0$

*d condif. 280

if $(\operatorname{abs}(e(n))$.le.abs $(\operatorname{dtmax}))$ go to 177

$\mathrm{dtmax}=e(n)$

$\operatorname{maxtce} 1=n$

$d t \operatorname{maxx}($ icount $)=e(n)$

call locati $(n, j c e l, k c e l, i c e l)$

maxcel $(i$ count $)=i c e l+100 * k c e l+10000 * j c e l$

177 continue

* $i$ condif. 307

kount $=$ kount +1

$*_{i}$ condif. 263

if (abs (sdepr). le.abs (dtmaxx(kount))) go to 369

ncel $=\mathrm{n} 2$

$\mathrm{dtmaxx}$ (kount) $=$ sdepr

call locati (ncel, jcel, kcel, icel)

$\operatorname{maxcel}($ kount $)=i c e l+100 * k c e l+10000 * j c e l$

369 continue

*i solvef.70

if(abs(sdepr). le.abs (dtmaxx(kount))) go to 175

ncel $=n 2-k{ }^{*}$ nat

call locati (ncel, jcel, kcel, icel)

$\operatorname{maxcel}($ kount $)=i c e l+100 * \mathrm{kcel}+10000 * j \mathrm{cel}$

$\star_{\mathrm{d}}$ condif.293

$\operatorname{dtmaxx}($ kount $)=$ sdepr

*id bigmon 1

$* 1$

compatible with 1srcu3 and 11 ib3

$\star_{i}$ input. 3

dimension datal(13), ndatal(13)

* $i$ input. 212

do $101 \mathrm{i}=1,10$

101 ndatal $(i)=\operatorname{ndata}(i)$

ndatal $(11)=j \mathrm{~m}$

$\operatorname{ndata1}(12)=\mathrm{km}$

$\operatorname{ndatal}(13)=\mathrm{im}$

* $i$ input. 470

do $201 i=1,10$

$201 \operatorname{data1}(i)=\operatorname{data}(i)$

$\operatorname{data1}(11)=j i$

$\operatorname{data1}(12)=\mathrm{ki}$

$\operatorname{datal}(13)=\mathbf{i}$ 
*d input.394,397

*d input.398,401

*d input.404,415

$$
\begin{aligned}
& m=-2 \\
& \text { do } 152 n=1,4 \\
& 1=4^{\star}(i m-1)+n \\
& m=m+3 \\
& \text { mon }(1)=10 \text { cate (ndatal }(m), \text { ndatal }(m+1), \text { ndatal }(m+2))
\end{aligned}
$$

152 continue

${ }^{*} i$ input. 1286

$c^{\star *}$

$c^{\star *}$ load mint array for monitor output (first and second card only) $c * \star$

850 continue

$$
\begin{aligned}
& m=-2 \\
& \text { do } 855 \quad 1=1,8
\end{aligned}
$$

$\mathrm{n}=\operatorname{mon}(1)$

call locati $(n, j, k, i)$

$m=m+3$

$\operatorname{mint}(m)=j$

$\operatorname{mint}(m+1)=k$

$\operatorname{mint}(m+2)=i$

855 continue

*d input. 416,419

*id llefixl

*d momx.524

is

$=(i-1) * 1 x+k s c$

* id mltgrdo

*b ncom.36

common/gridx/ grdindx(maxgindx), grdcord(maxgcord), ngrid, maxgrid,

*i facts.17 ispgrd, kfrnt, ncpf

parameter $(\operatorname{maxg}$ ind $x=2000)$

* $i$ tempest.60

integer grdtyp

$*_{i} \operatorname{setin} .75$

maxgrid $=64$

ispgrd $=10$

$\star_{i}$ setin.294

$$
\text { ngrid }=0
$$

* $\quad$ name $=$ upzl

$\star 1$

*/ beginning f-tracker/multi-grid updates

$* 1$

$* 1$

*/ compatible with c_tempst_nb1.xxx

*1

*id acbf $x 1$

*d comlst.12

*d comlst.17,18

${ }^{\star} \mathrm{d}$ comlst.3, 9 


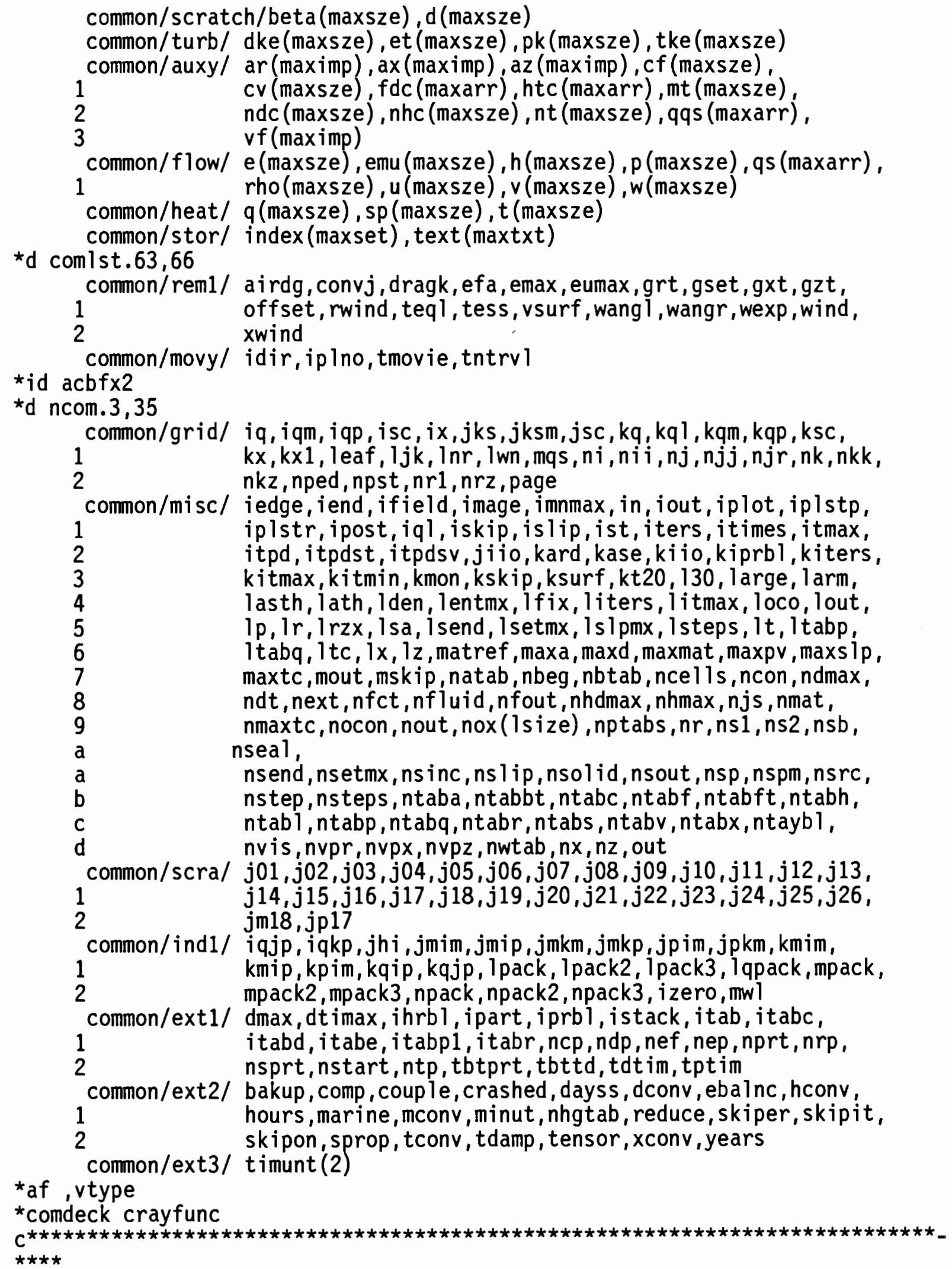




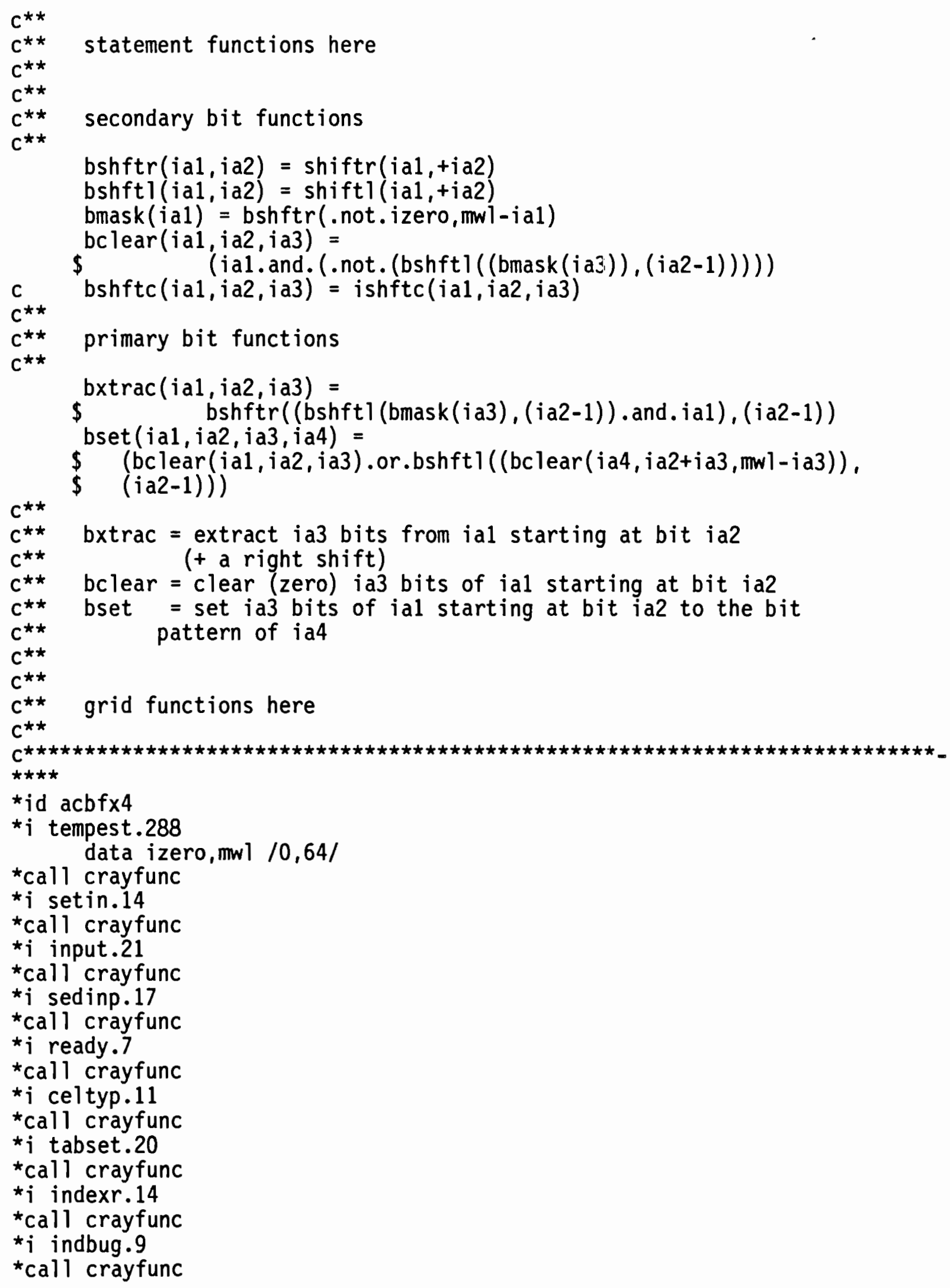


${ }^{*} i$ adindx.7

*call crayfunc

* $\mathrm{j}$ vsindx.7

*call crayfunc

*b balset. 8

*call crayfunc

* i getset. 7

*call crayfunc

*b cgrid.7

*call crayfunc

* $\mathrm{j}$ twix.8

*call crayfunc

*i pinit.7

${ }^{\star}$ call crayfunc

* $i$ tymset. 10

*call crayfunc

*b mosrc. 8

*call crayfunc

*b excute.17

*call crayfunc

*b moment. 7

*call crayfunc

*b momxt.7

*call crayfunc

*b strain.7

*call crayfunc

*b patter. 9

*call crayfunc

*b solvel.15

*call crayfunc

*b balanc. 13

*call crayfunc

*b solvet.14

*call crayfunc

*b solvef.15

*call crayfunc

*i height.9

*call crayfunc

*b condif. 10

*call crayfunc

*b kemod.8

*call crayfunc

*b pkay. 8

*call crayfunc

*b spectr.13

*call crayfunc

*b semble. 7

*call crayfunc

*b cemble. 10

*call crayfunc

*b visset.7

*call crayfunc 


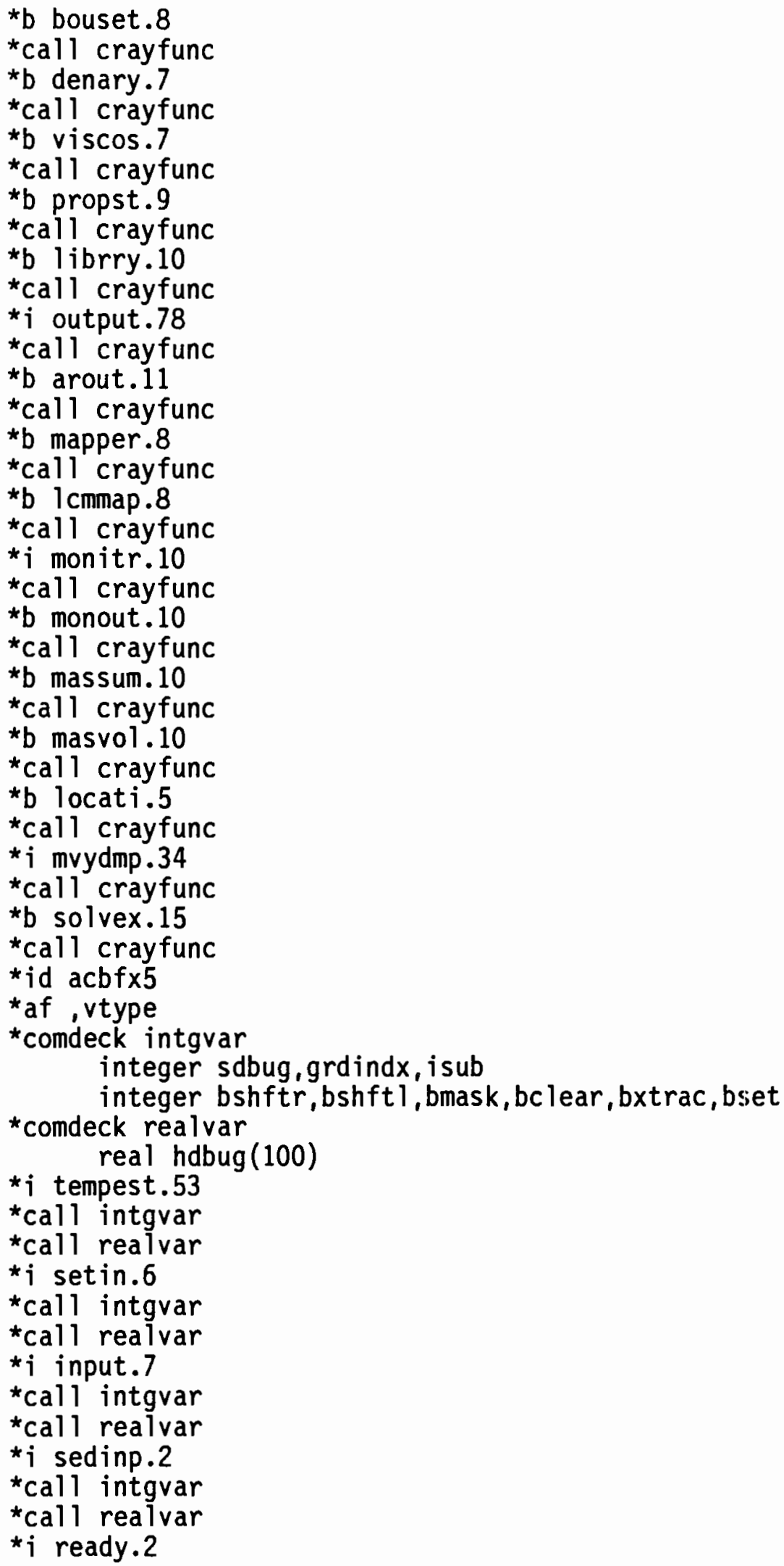


*call intgrar

*call realvar

* $i$ celtyp. 6

*call intgrar

*call realvar

* $i$ tabset.11

*call intgrar

*call realvar

* $i$ indexr. 6

*call intgrar

*call realvar

* $i$ indbug. 4

*call intgrar

*call realvar

* $i$ adindx. 2

*call intgrar

*call realvar

* $i$ vsindx. 2

*call intgrar

*call realvar

* $i$ balset. 2

*call intgrar

*call realvar

* $i$ getset. 2

*call intgrar

*call realvar

* $i$ cgrid.2

*call intgvar

*call realvar

* $i$ twix. 2

*call intgvar

*call realvar

* i plabak. 2

${ }^{*}$ call intgrar

*call realvar

* $i$ pinit. 2

*call intgrar

*call realvar

*i tymset. 2

*call intgrar

*call realvar

*i mosrc. 3

*call intgrar

*call realvar

* $i$ excute. 2

*call intgrar

*call realvar

* $i$ moment. 2

*call intgrar

*call realvar

* $i$ momxt. 2

*call intgrar 
*call realvar

* i strain. 2

*call intgrar

*call realvar

* j patter. 4

*call intgrar

*call realvar

* $i$ solvel. 2

*call intgrar

*call realvar

*i balanc. 2

*call intgrar

*call realvar

${ }^{*} i$ solvet. 2

*call intgvar

*call realvar

* $i$ solvef. 2

*call intgrar

*call realvar

*i efield. 2

*call intgrar

*call realvar

*i height. 2

*call intgvar

*call realvar

* $i$ condif. 2

*call intgrar

*call realvar

* $i$ kemod. 2

*call intgrar

*call realvar

*i pkay. 3

*call intgrar

*call realvar

*i spectr. 5

*call intgrar

*call realvar

* $i$ semble. 2

*call intgrar

*call realvar

* i rebal. 4

*call intgrar

*call realvar

* $\mathrm{j}$ efbal. 6

*call intgrar

*call realvar

*i syclic. 2

*call intguar

*call realvar

* $i$ cemble. 5

*call intgvar

*call realvar 
*i efconn .5

*call intgrar

*call realvar

* j visset.2

*call intgrar

*call realvar

* $i$ xand. 2

*call intgvar

*call realvar

* $i$ xand 2.2

*call intgrar

*call realvar

*i xoffal.2

*call intgrar

*call realvar

* $j$ xoby. 2

*call intgrar

*call realvar

* $i$ xens. 2

*call intgvar

*call realvar

* $j$ xhore. 2

*call intgrar

*call realvar

*i xurf.2

*call intgrar

*call realvar

* $i$ xilt. 2

*call intgrar

*call realvar

*i xlay. 2

*call intgrar

*call realvar

*i xilcla.2

*call intgrar

*call realvar

*i xedhis. 2

*call intgvar

*call realvar

* $i$ bouset. 2

*call intgrar

*call realvar

* i denary. 2

*call intgrar

*call realvar

* $i$ viscos.2

*call intgrar

*call realvar

* $i$ propst. 2

${ }^{*}$ call intguar

*call realvar

*i librry.2 
*call intgrar

*call realvar

*i output. 2

*call intgvar

*call realvar

* i sedout. 2

*call intgrar

*call realvar

* $i$ arout. 3

*call intgrar

*call realvar

* i mapper. 3

*call intguar

*call realvar

* $i$ lcmmap. 3

*call intguar

*call realvar

* i monitr. 2

*call intgrar

*call realvar

*i monout. 5

*call intgrar

*call realvar

* i massum. 5

*call intgvar

*call realvar

*i masvol. 5

*call intgrar

*call realvar

*i locati. 3

*call intgrar

*call realvar

* $\mathrm{i}$ ierror. 2

${ }^{*}$ call intgrar

*call realvar

* $j$ error. 2

*call intgrar

*call realvar

* i banner. 2

*call intgrar

*call realvar

* $i$ dattim. 25

*call intgvar

*call realvar

*i second. 9

*call intgvar

*call realvar

* i mvydmp. 24

*call intgrar

*call realvar

* $i$ solvex. 7

*call intgrar 


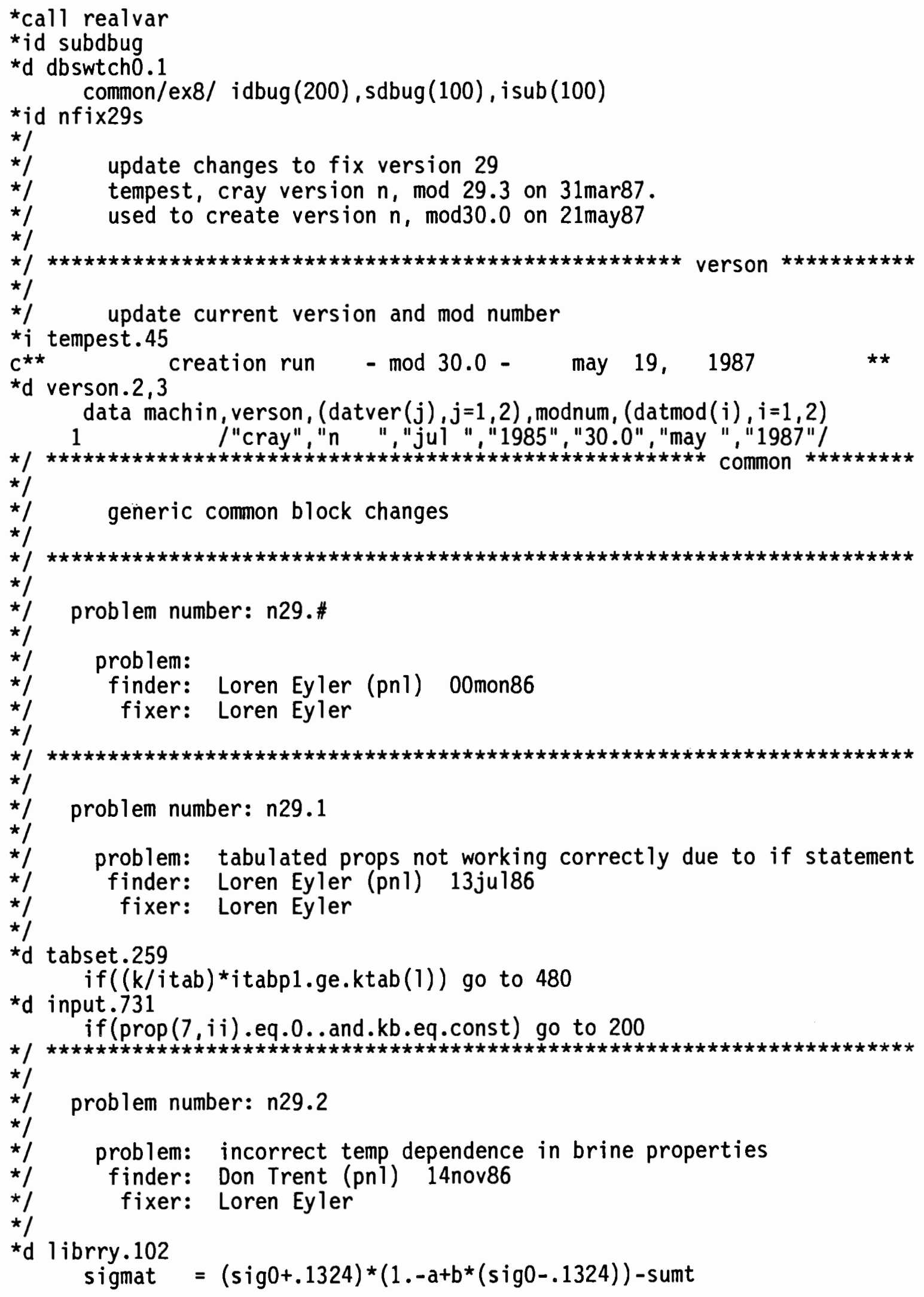


*d denary. 46

sigmat $=(\operatorname{sig} 0+.1324) *(1 .-a+b *(\operatorname{sig} 0-.1324))-$ sumt

*I miscellaneous cleanup

$\star 1$

*d tempest.732

units $(2,31)=$ "mtrs"

${ }^{*} \mathrm{~d}$ indbug. 486

d, 6x, "table" //)

*d balset.3 integer length ( lax), cicle(3)

*d plabak.8 integer unitq1,unitq2

*d plabak.5,6 integer $\quad v d x(3), \operatorname{cdx}(3), \operatorname{wprt}(3)$ integer typr(3), typz(3), typx (3)

$\star d$ monitr.91

$$
\begin{aligned}
& \text { write(out, 1024) mint (1), ksurf, mint (3), } \\
& \text { * } \\
& \text { * } \\
& \text { * }
\end{aligned}
$$

*d monitr.270,271

1 ,t30,"specie $c(", i 2, ")$ - - "2a4,": mass fraction - - cmf",/

*/

2 ,t59,"volume fraction - - cvf"/)

${ }^{*}$ d solvef.74

call cycle $(1, m, 1$ size, am, ac, ap, bn, tend)

$\star_{i}$ ready .204

if (.not. contrl(61)) goto 180

$\star_{i}$ ready. 218 180 continue

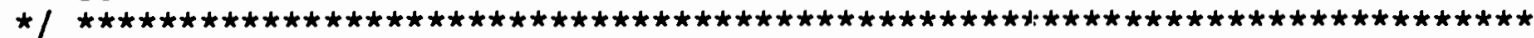

$\star 1$

*/ problem number: n29.3

*

* problem: cyclic solver in subroutine solvet incorrect

* finder: Don Trent (pn1) 27mar87

* f fixer: Don Trent

*1

$\star_{i}$ solvet. 54

$\mathrm{amm} \quad=\mathrm{am}(\mathrm{m})$

$\mathrm{acm} \quad=\mathrm{ac}(\mathrm{m})$

*i solvet. 58

$\mathrm{ac}(\mathrm{k})=\mathrm{am}(\mathrm{k}) * \mathrm{ac}(\mathrm{k}-1) * \operatorname{bet}(\mathrm{k})$

$\star d$ solvet.68,69 


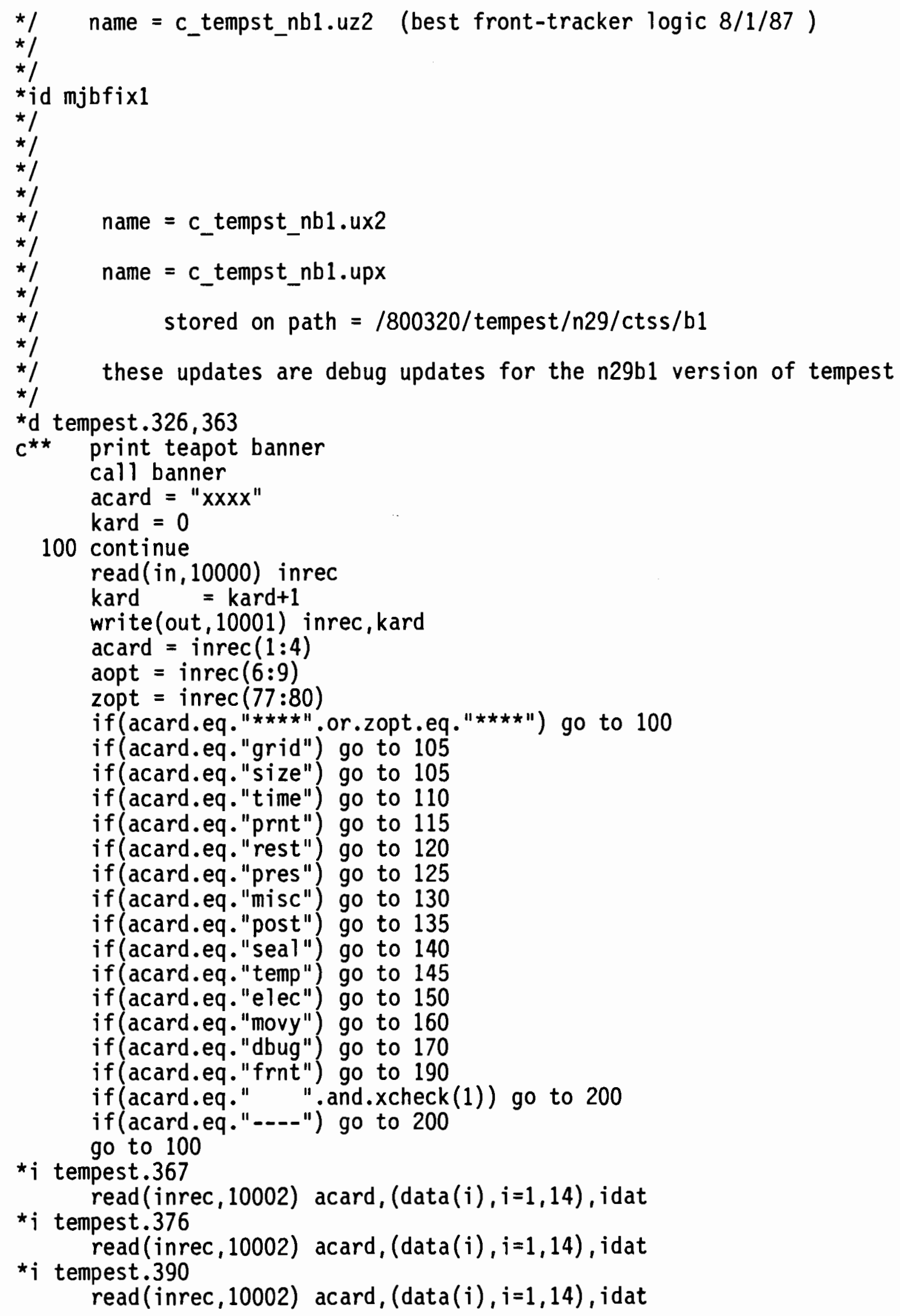

*I these updates are debug updates for the n29b1 version of tempest

$* 1$

$\star d$ tempest. 326,363

$c *$ print teapot banner

call banner

acard $=$ "xxxx"

kard $=0$

100 continue

read (in, 10000) inrec

kard $=k a r d+1$

write(out, 10001) inrec,kard

acard $=$ inrec $(1: 4)$

aopt $=$ inrec $(6: 9)$

zopt $=$ inrec $(77: 80)$

if (acard.eq."

if (acard.eq."grid") go to 105

if (acard.eq."size") go to 105

if (acard.eq."time") go to 110

if (acard.eq."prnt") go to 115

if(acard.eq. "rest") go to 120

if (acard.eq. "pres") go to 125

if (acard.eq."misc") go to 130

if (acard.eq. "post") go to 135

if (acard.eq."seal") go to 140

if (acard.eq."temp") go to 145

if (acard.eq."elec") go to 150

if (acard.eq."movy") go to 160

if (acard.eq."dbug") go to 170

if (acard.eq." frnt") go to 190

if (acard.eq." ".and.xcheck(1)) go to 200

if (acard.eq."----") go to 200

go to 100

$\star_{i}$ tempest. 367

read (inrec, 10002) acard, (data( $i), i=1,14)$, idat

*i tempest. 376

read (inrec, 10002) acard, (data ( $i), i=1,14)$, idat

* $i$ tempest. 390

read(inrec, 10002) acard, (data(i), $i=1,14)$, idat 
*i tempest. 406

read(inrec, 10002) acard,(data(i), $i=1,14)$, idat

* $i$ tempest. 415 read(inrec, 10002) acard,(data(i), $i=1,14)$, idat

*i tempest. 429 read (inrec, 10002) acard, (data(i), $i=1,14)$, idat

* $i$ tempest. 446 read (inrec, 10002) acard,(data( $i), i=1,14)$, idat

*i tempest. 456 read (inrec, 10002) acard, (data(i), $i=1,14)$, idat

* $i$ tempest.468 read(inrec, 10002) acard,(data( $i), i=1,14)$, idat

* $i$ tempest. 477 read(inrec, 10002) acard,(data(i), $i=1,14)$, idat

* $i$ tempest. 490 read (inrec, 10002) acard,(data( $i), i=1,14)$, idat

*b tempest.498

190 continue

$c^{* \star}$

$c *$ front-tracker card

$C^{\star \star}$

read(inrec,10002) acard,(data(i), $i=1,14)$, idat

kfrnt $=$ int (data(1))

ncpf $=$ int (data (2))

$\mathrm{dzu}=\operatorname{int}(\operatorname{data}(3))$

$\mathrm{dzl}=\operatorname{int}(\operatorname{data}(4))$

$n z=n z+2^{\star} n c p f+1$

if (kfrnt.le.0) kfrnt $=99999$

go to 100

$* 1$
$* 1$
$* 1$

* version subroutine

*af , tempest

* deck version

subroutine version

C

c this routine was written primarily to create a banner page for the

c tempst code. it will be used to provide information on the version

$c$ number of tempst currently in use, update information, and applicabl

c documentation. author: cl bartley $4 / 15 / 86$

C

character *1 star,minus

C

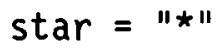

minus $="-"$

C

$$
\text { idat }=6
$$

c

C

c change all writes to unit 9 to idat later

C

write $($ idat , 50) 


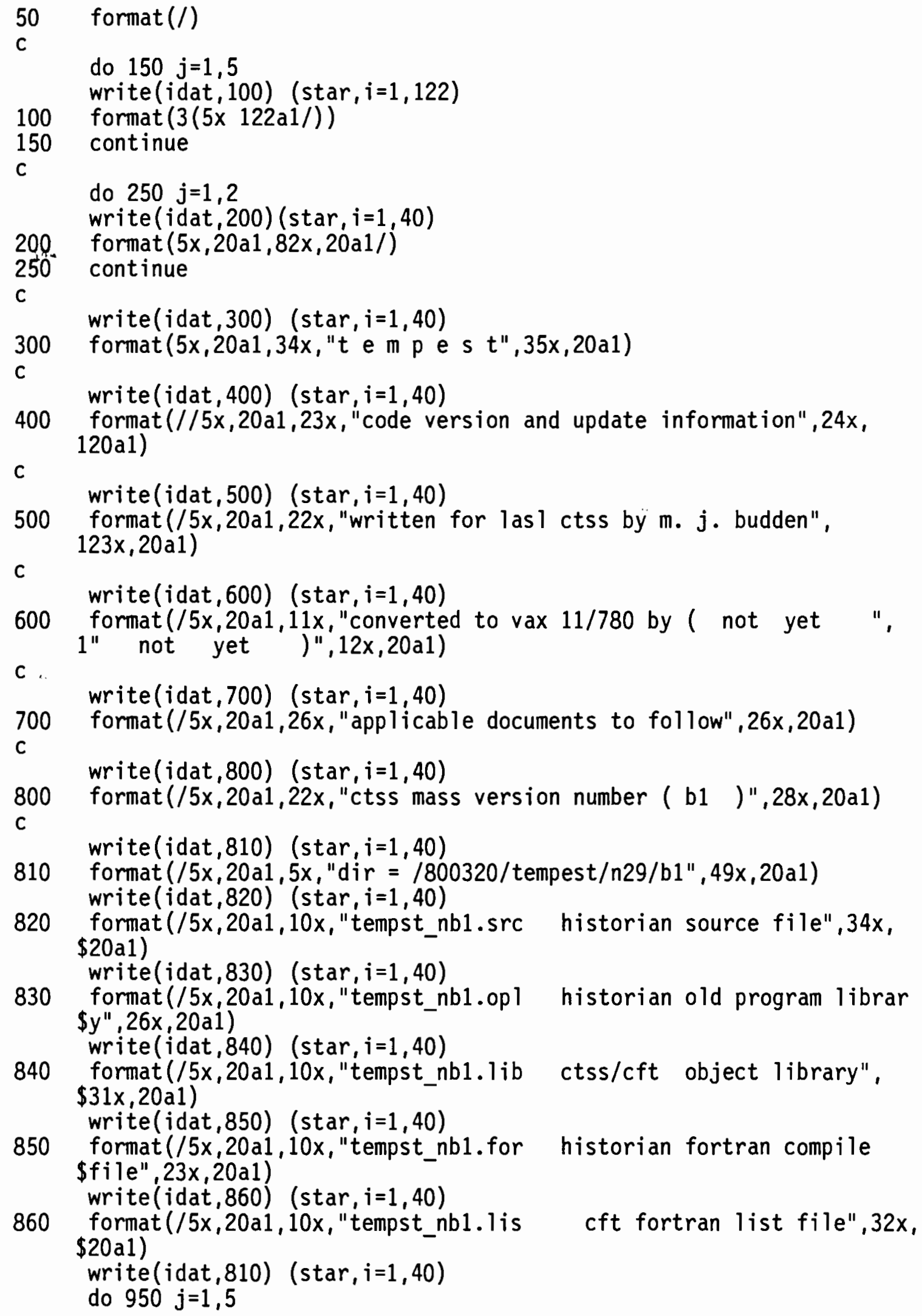




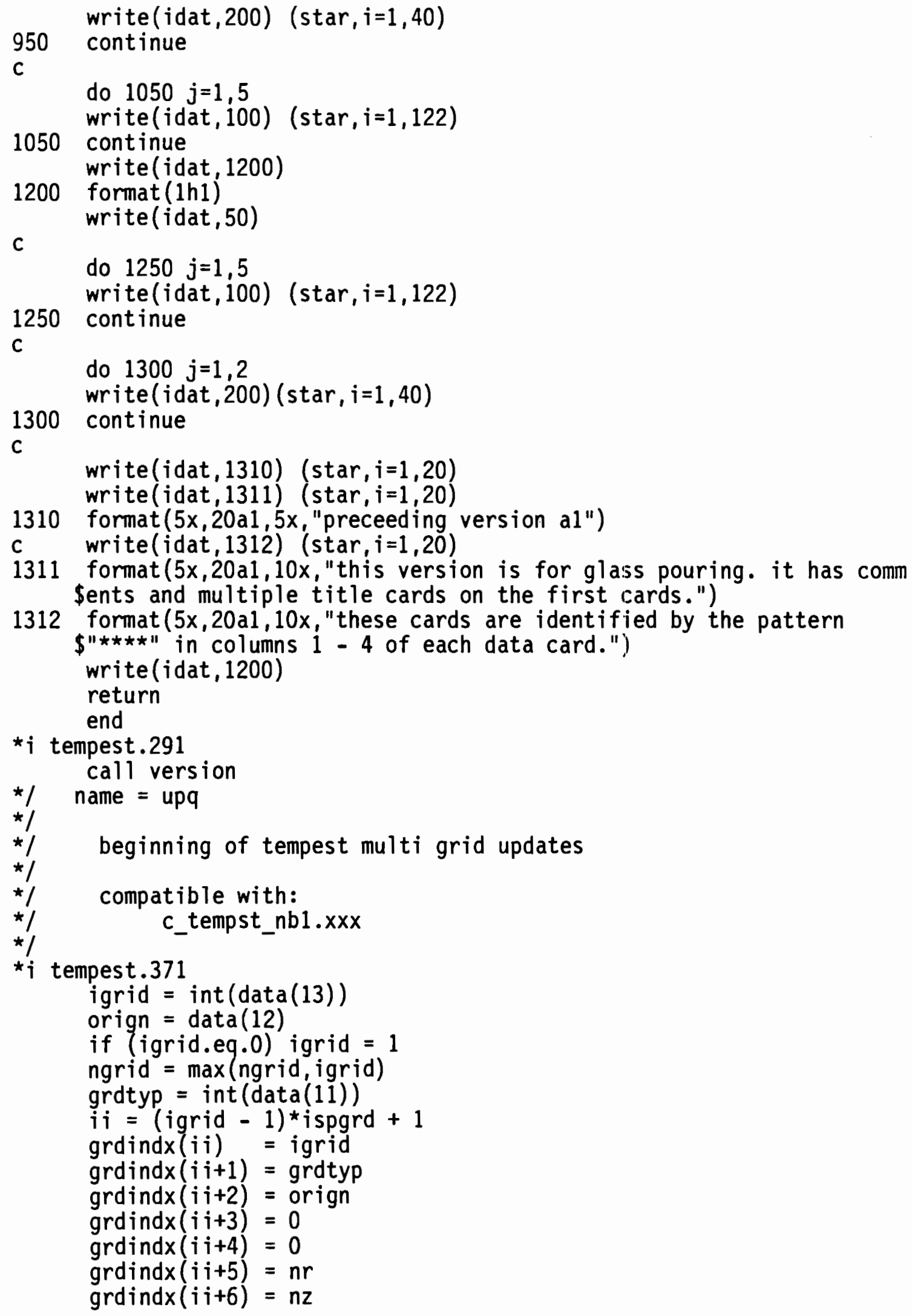




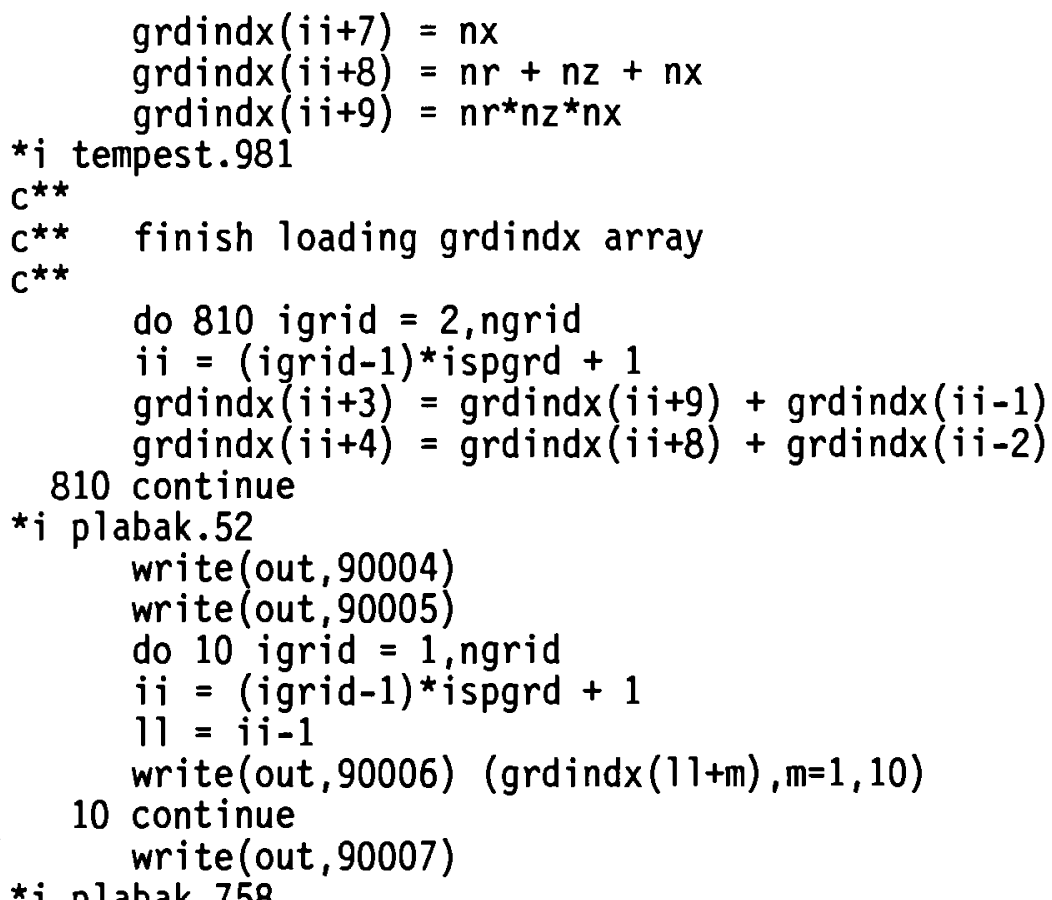

plabak.758

90004 format (///,2x, "print out grdindx array",///)

90005 format (//,2x, "grid \#" ,2x, "grid type",2x, "origen",2x, "offset \#1", $12 x$, "offset \#2",2x, "nr", 2x, "nz",2x, "nx",2x, "nr+nz+nx",2x, $2 \quad " n r * n z * n x ", /)$

90006 format $(2 x, f 5.0,2 x, f 5.0,2 x, 1 p e 12.5,2 x, f 5.0,2 x, f 5.0,2 x, f 5.0$, 90007 format $(/ / /)$

* $\quad$ name $=$ upz2

$\star 1$

*/ beginning f-tracker/multi-grid updates

$\star 1$

$\star 1$

*/ compatible with c_tempst_nb1.xxx

$* 1$

*id mltgrd1

*d tempest.842,926

*d tempest.942,944

*af , tempest

* deck gridi

subroutine gridi(mode, iflag)

*call intgrar

*call realvar

*call facts

*call comlst

*call ncom

*call vtype

*call sedt

*call crayfunc

c**

$c^{\star \star}$ 


$$
\begin{aligned}
& c * \star \\
& \text { if (mode.gt.9.or.mode.1t.1) go to } 9999 \\
& \text { go to }(1000,2000,3000,4000,5000,6000,7000,8000,9000) \text {, mode } \\
& c^{\star \star} \text { set array size and other index parameters } \\
& 1000 \text { continue } \\
& \mathrm{nj}=\mathrm{nr}-1 \\
& \text { nk }=n z-1 \\
& n i=n x-1 \\
& \text { if }(n j . e q .0) n j=1 \\
& \text { if }(n k . e q .0) n k=1 \\
& \text { if }(n i . e q .0) n i=1 \\
& \text { if(ni.le.1) twodim = .true. } \\
& n j r \quad=n j \\
& n k z \quad=n k \\
& \text { nix }=n i \\
& n r z \quad=n r \\
& \text { jsc }=1 r^{\star} n r \\
& \text { ksc } \quad=j s c+1 z^{\star} n z \\
& \text { isc } \quad=k s c+1 x^{\star} n x \\
& \text { jks } \quad=n x^{*} n r^{*} n z \\
& k q \quad=j k s \\
& \mathrm{iq} \quad=j k s * 2 \\
& 1 j k=n r^{*} n z \\
& \text { Iwn }=1 \\
& \ln r \quad=n r \\
& \text { if }(n r . e q .1) \text { lwn }=0 \\
& \text { if }(n z . e q .1) \text { lnr }=0 \\
& \text { if }(n x . e q .1) \quad l j k=0 \\
& \mathrm{kx}=\mathrm{nr}+\mathrm{nz} \\
& \text { ix }=k x+n x \\
& \mathrm{kqm}=\mathrm{kq}-\mathrm{lnr} \\
& k q p=k q+\ln r \\
& i q m=i q-1 j k \\
& i q p=i q+1 j k \\
& \text { jm18 }=j 18-1 r^{\star} 1 w n \\
& \text { jp17 }=j 17+1 r^{\star} 1 w n \\
& k q j p=k q+i w n \\
& k q i p=k q+1 j k \\
& \text { iqjp }=i q+i w n \\
& \text { iqkp }=i q+\ln r \\
& \text { jmip }=1 j k-1 w n \\
& \text { jmkp }=\ln r-\operatorname{lwn} \\
& \text { jpkm }=1 w n-1 n r \\
& \text { kmip }=1 j k-1 n r \\
& \text { jpim = lwn }-1 j k \\
& \mathrm{kpim}=1 \mathrm{nr}-1 \mathrm{jk} \\
& \text { jmkm }=-1 w n-1 n r \\
& \text { jmim }=-1 w n-1 j k \\
& \text { kmim }=-1 n r-1 j k \\
& \text { mqs }=j k s * 3
\end{aligned}
$$




$$
\begin{aligned}
& \text { npst }=1 j k+1 n r+1 w n \\
& k q 1=k q+n p s t \\
& i q l=i q+n p s t \\
& \text { nped } \quad=j k s-n p s t \\
& \mathrm{jksm}=\mathrm{jks}-1 \\
& \text { page } \quad=(63 /(n z+5)) \\
& \text { leaf }=(63 /(n z+2)) \\
& n r 1=n r+1 \\
& k x 1=k x+1 \\
& \text { knox }=\max (n r, n x, n z) \\
& 1 \mathrm{rzx}=\mathrm{knox} \\
& n j \mathrm{j}=2 \\
& \text { nkk } \quad=2 \\
& \text { nii }=2 \\
& \text { if (nr.gt.1) go to } 620 \\
& n r z=n z \\
& n j r=1 \\
& n j j=1 \\
& \text { tdfr }=0 \text {. } \\
& t d r \quad=0 \text {. } \\
& \operatorname{map}(1,1)=0 \\
& \operatorname{map}(1,2)=0 \\
& 620 \text { if (nz.gt.1) go to } 625 \\
& \text { nkz }=1 \\
& \text { nkk }=1 \\
& \operatorname{tdz}=0 \text {. } \\
& \operatorname{tdfz}=0 \text {. } \\
& \operatorname{map}(2,3)=0 \\
& \operatorname{map}(2,4)=0 \\
& \text { nix }=1 \\
& n i j=1 \\
& t d x=0.0 \\
& \operatorname{tdfx}=0 \text {. } \\
& \operatorname{map}(3,5)=0 \\
& \operatorname{map}(3,6)=0 \\
& 630 \text { continue } \\
& n j s=n j j+i n t(c y l) \\
& \text { if (leaf.eq.0) leaf }=1 \\
& \text { if (page.eq.0) page }=1 \\
& \text { go to } 9999
\end{aligned}
$$


*b tempest. 982

write (out, 3001)

write (out, 3002)

do 815 igrid $=1$, ngrid

$i j=($ igrid -1$) * i$ spgrd +1

write (out, 3003) igrid, (grdindx $(i j+1), 1=0,9)$

815 continue

*b tempest.984

call gridi $(1,1)$

*i tempest.1047

3001 format $(/ /, 2 x$, "grid index array",//)

3002 format (2x, "grid \#" 2x, "grid type",2x, "origin",2x,

$\$ \quad$ "offset", $2 x$, "of fset" , $2 x, " n r ", 2 x, " n z ", 2 x, " n x ", 2 x$,

$\$$ "ndelta",2x, "ncells")

3003 format $(2 x, 10(i 5,2 x), 2 x)$

10000 format (a80)

10001 format $(a 80,10 x, i 5)$

10004 format $(a 4,1 x, 14 f 5.0,15)$

10003 format $(a 4,1 x, a 4,1 x, 6(2 x, a 8))$

*/

*/ improved input

$\star 1$

*i tempest. 351

if (xcard.eq."grid") go to 105

$\star_{i}$ input.3

character inrec $\star 80, \mathrm{blank5} 55$

character $* 5$ char5(16)

character $* 4$ acard, aopt, bopt, zopt

*d input.212,214

100 continue

read (in, 10000) inrec

kard $=$ kard +1

if(debug(22)) write(out, 10002) inrec, kard

acard $=$ inrec $(1: 4)$

aopt $=$ inrec $(6: 9)$

bopt $=$ inrec $(11: 15)$

zopt $=$ inrec $(77: 80)$

if (acard.eq."

if (acard.eq."grid") go to 105

backspace in

go to 109

105 continue

read (inrec, 10001) ikard, igkind, igrid

if (igrid.le.ngrid) go to 106

write(out, 90000) igrid,ngrid

bombed $=$.true.

igrid $=$ ngrid

106 continue

109 continue

read (in, 10003) ndata, jm, km, im, kb, kp, 1c, kind, sys

*d input. 470

200 cont inue 


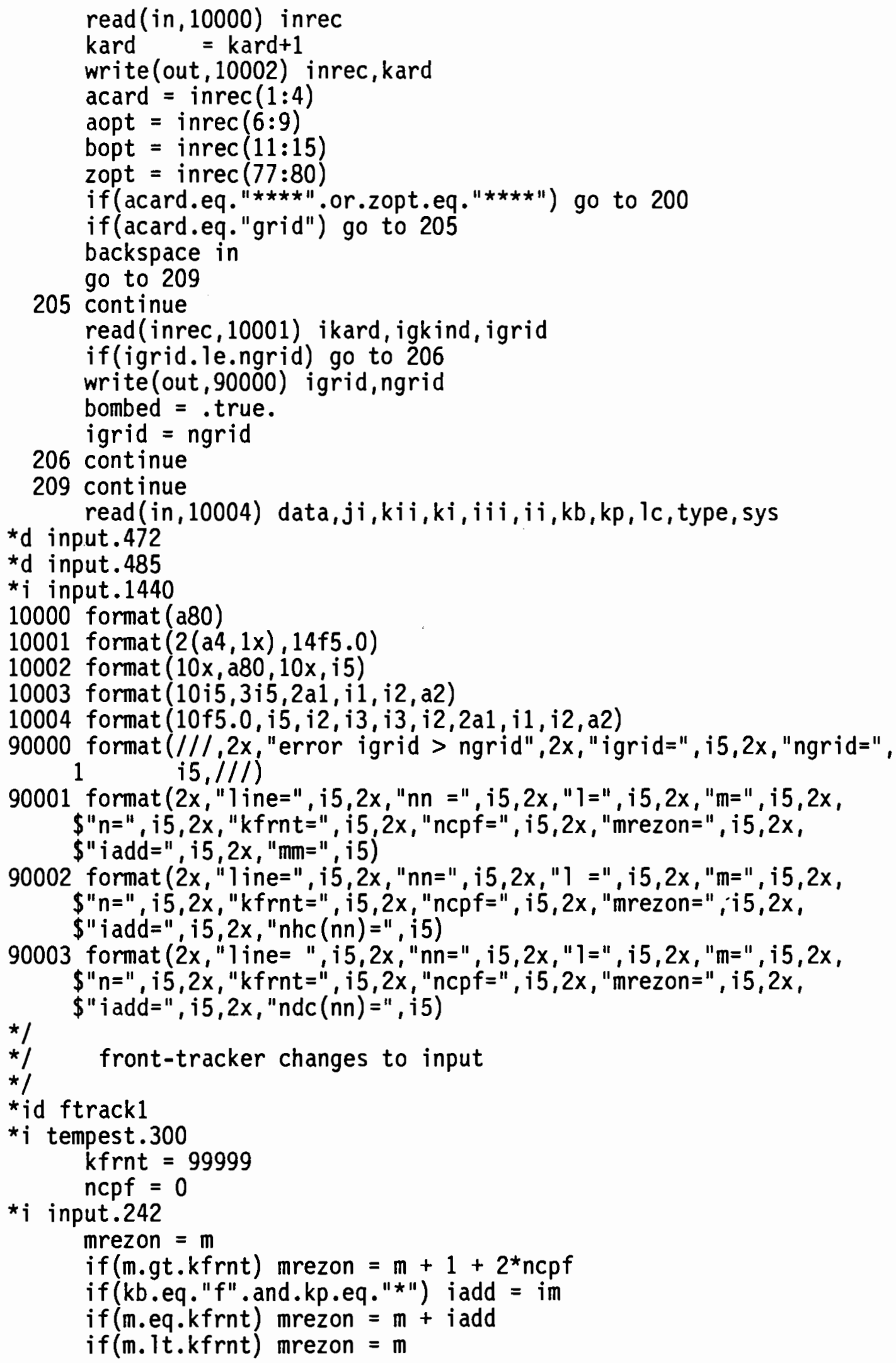




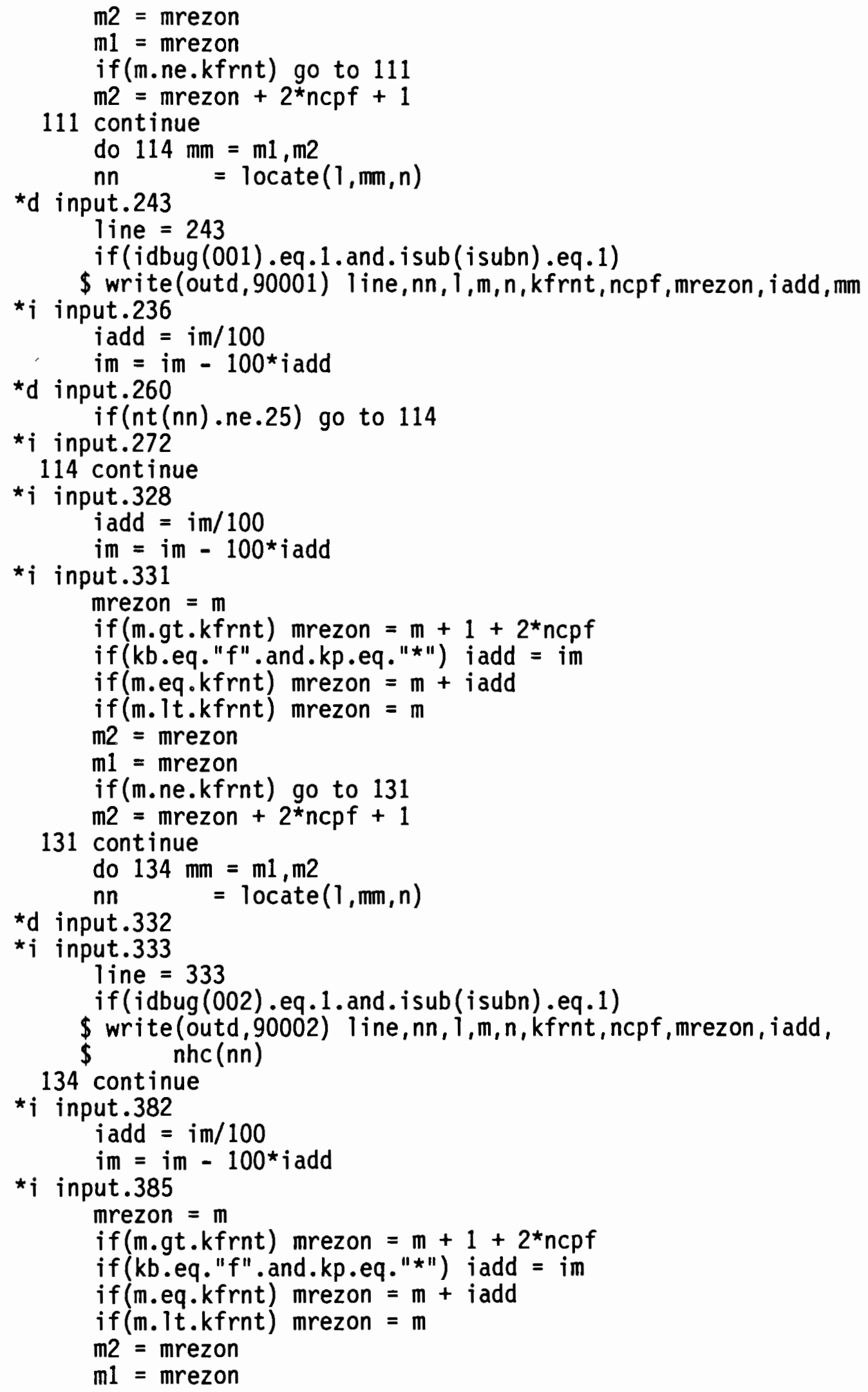




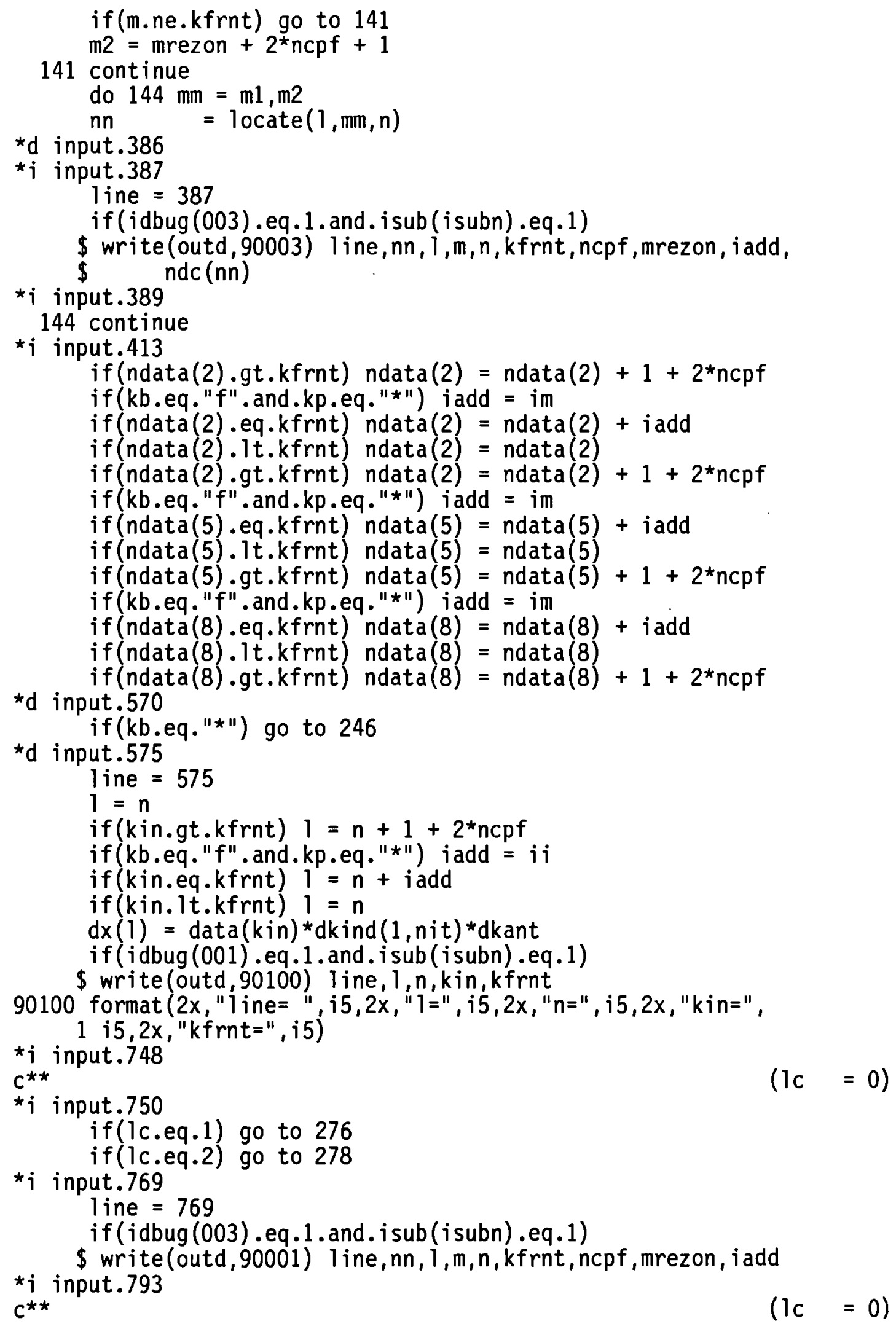




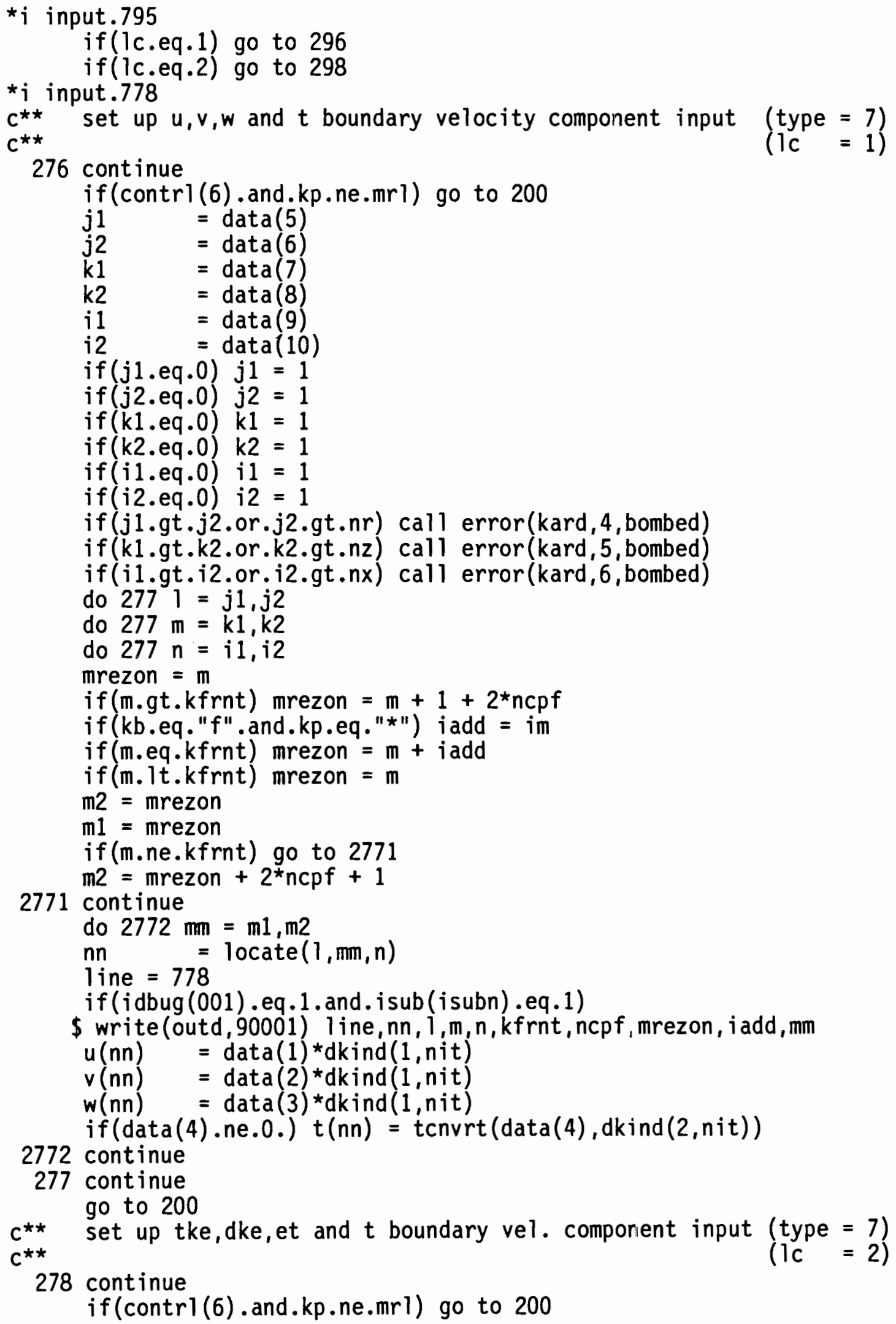




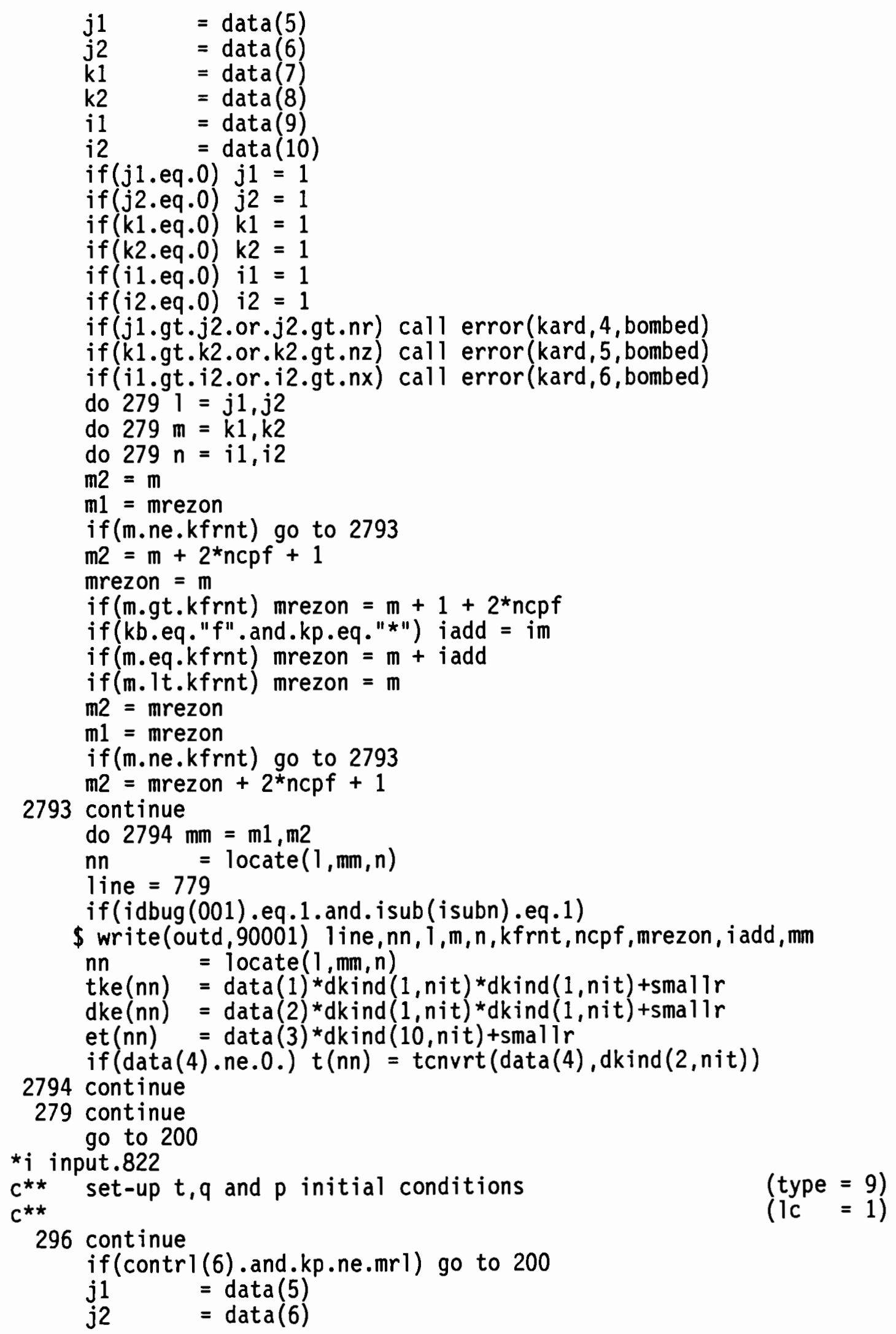




$$
\begin{aligned}
& \mathrm{k} 1=\operatorname{data}(7) \\
& \mathrm{k} 2=\operatorname{data}(8) \\
& \text { i1 }=\operatorname{data}(9) \\
& \text { i2 }=\operatorname{data}(10) \\
& \text { if }(\mathrm{j} 1 \text {.eq.0) } \mathrm{j} 1=1 \\
& \text { if (j2.eq.0) } j 2=1 \\
& \text { if }(k 1 \text {.eq.0) } k 1=1 \\
& \text { if }(k 2 . e q .0) k 2=1 \\
& \text { if }(\text { i1.eq.0) il }=1 \\
& \text { if (i2.eq.0) i2 }=1 \\
& \text { if (j1.gt.j2.or.j2.gt.nr) call error(kard, } 8 \text {, bombed) } \\
& \text { if (k1.gt.k2.or.k2.gt.nz) call error(kard,9 ,bombed) } \\
& \text { if (i1.gt.i2.or.i2.gt.nx) call error(kard, 10, bombed) } \\
& \text { do } 2971=j 1, j 2 \\
& \text { do } 297 \mathrm{~m}=\mathrm{k} 1, \mathrm{k} 2 \\
& \text { do } 297 n=i 1, i 2 \\
& \text { mrezon }=m \\
& \text { if (m.gt.kfrnt) mrezon }=m+1+2 \star n c p f \\
& \text { if (kb.eq. "f". and.kp.eq." } " * \text { ) } \text { iadd }=\text { im } \\
& \text { if }(m . \text { eq.kfrnt }) \text { mrezon }=m+\text { iadd } \\
& \text { if (m.lt.kfrnt) mrezon }=m \\
& \mathrm{~m} 2=\mathrm{mrezon} \\
& \mathrm{m} 1=\mathrm{mrezon} \\
& \text { if(m.ne.kfrnt) go to } 2971 \\
& \mathrm{~m} 2=\text { mrezon }+2^{*} \mathrm{ncpf}+1 \\
& 2971 \text { continue } \\
& \text { do } 2972 \mathrm{~mm}=\mathrm{m} 1, \mathrm{~m} 2 \\
& \mathrm{nn} \quad=\text { locate }(1, \mathrm{~mm}, \mathrm{n}) \\
& \mathrm{nn} \quad=\text { locate }(1, \mathrm{~mm}, \mathrm{n}) \\
& \text { line }=822 \\
& \text { if (idbug (001).eq.1. and.isub (isubn).eq.1) } \\
& \$ \text { write (outd, 90001) line, nn, } 1, m, n, k f r n t, n c p f \text {, mrezon, iadd, mm } \\
& \text { if (data (1).ne.0.) } t(n n)=\operatorname{tcnvrt}(\operatorname{data}(1), \operatorname{dkind}(2, n i t)) \\
& \text { if }(\operatorname{data}(2) \cdot n e .0 .) q(n n)=\operatorname{data}(2) \star d k i n d(8, n i t) /(d k a n t \star \star 3) \\
& 2972 \text { continue } \\
& 297 \text { continue } \\
& \text { go to } 200
\end{aligned}
$$

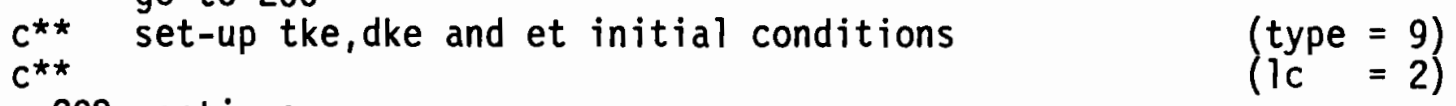

$$
\begin{aligned}
& \text { if (contrl (6). and.kp.ne.mrl) go to } 200 \\
& \text { j1 }=\operatorname{data}(5) \\
& \text { j2 }=\operatorname{data}(6) \\
& \mathrm{k} 1=\operatorname{data}(7) \\
& \text { k2 }=\operatorname{data}(8) \\
& \text { i1 }=\operatorname{data}(9) \\
& 12=\operatorname{data}(10) \\
& \text { if }(j 1 . \text { eq.0) } j 1=1 \\
& \text { if }(j 2 . \text { eq.0) } j 2=1 \\
& \text { if }(k 1 \text {.eq.0) } k 1=1 \\
& \text { if }(k 2 . \text { eq.0) } k 2=1
\end{aligned}
$$




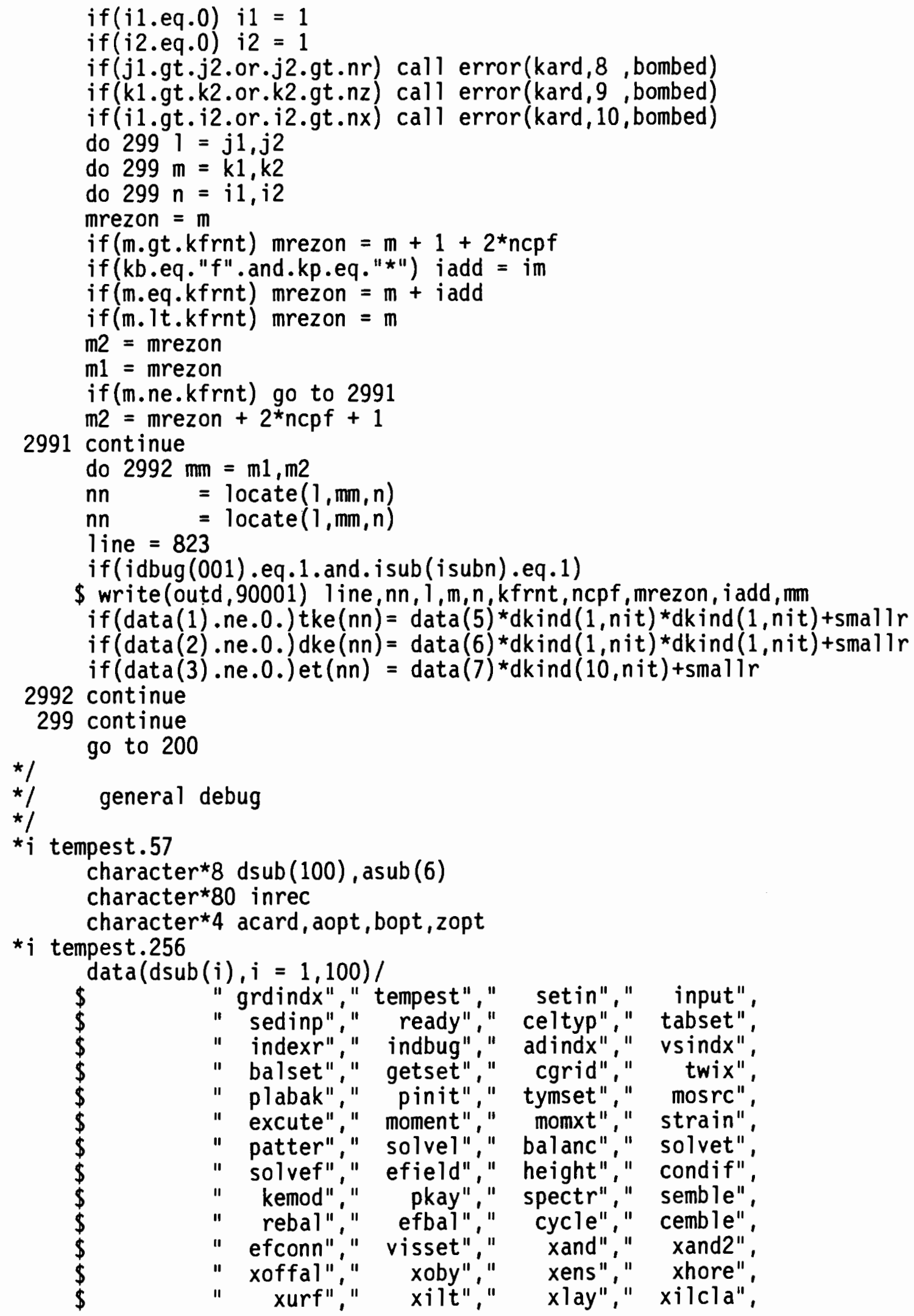




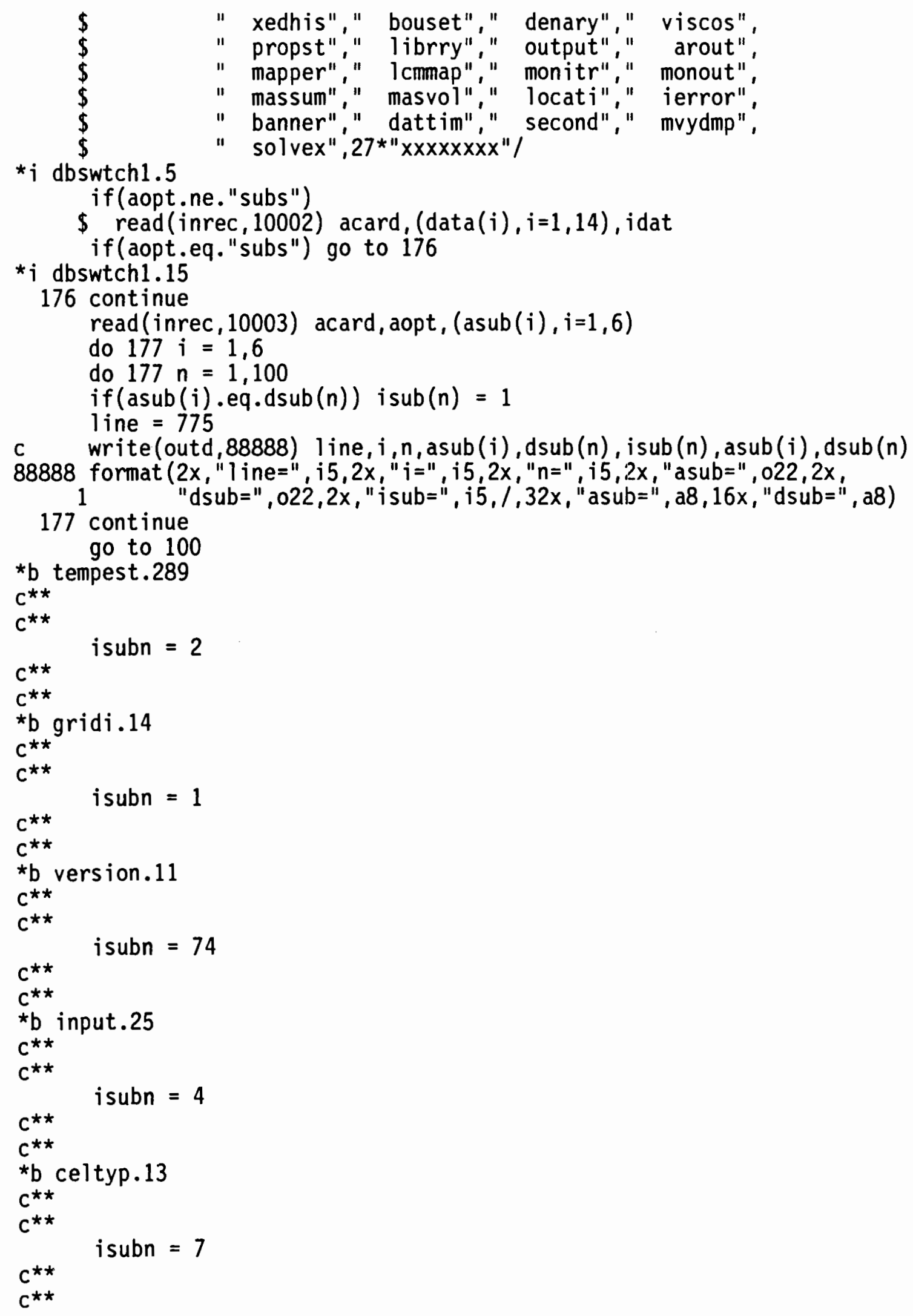




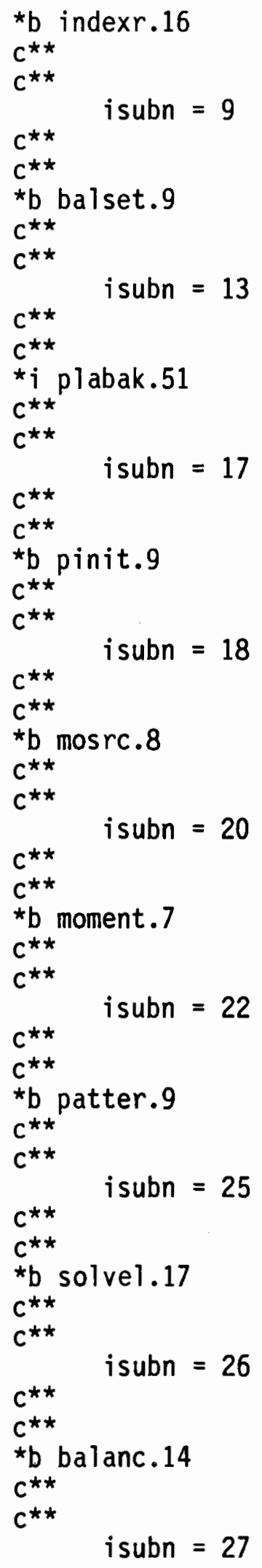




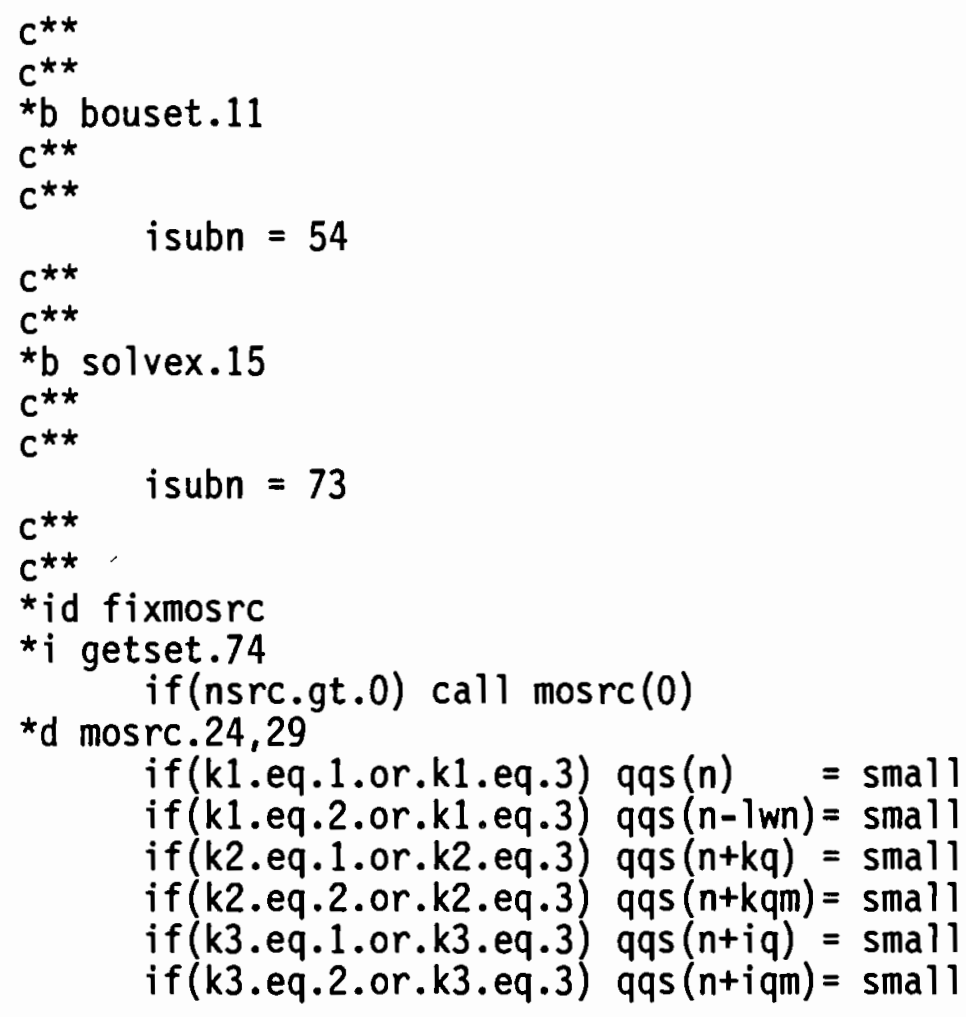


APPENDIX C

HISTORIAN SOFTWARE UTILITY 

APPENDIX C

HISTORIAN SOFTWARE UTILITY

This appendix describes the file-naming convention, the location of stored files, and the function of HISTORIAN (which is used as an automated version tracking mechanism). This is provided to enhance the traceability requirements for code development and to facilitate restart of the project.

The important files are stored on the LANL CFS in a simple tree structure. The base version of TEMPEST for the FY87 work is the N29 version, and the starting point is the AO version of the $\mathrm{N} 29$ version. The CFS storage tree is shown in Figure C.1.

The dotted directories are the ones used for this work. Inside each directory are special files indicating the type of file and the version number. These are:

1. C_TEMPST_NAO.SRC = HISTORIAN Source file

2. C_TEMPST_NAO.OPL = HISTORIAN 01d Program Library

3. C_TEMPST_NAO.LIB = Relocatable Object Library

4. C_TEMPST_NAO.FOR = FORTRAN file, input to compiler

5. C_TEMPST_NAO.LIS = FORTRAN Listing file with cross reference map

6. C_TEMPST_NAO.EXE = Executable version, absolute binary

7. C_TEMPST_NAO.UPD $=$ AO UPdate change file for UPDATE or HISTORIAN

8. C_TEMPST_NBO.UPD = BO Update change file for UPDATE or HISTORIAN

The file-naming convention is very simple and makes use of the 16-character limit for CFS file names. The leading $C$ indicates that these are al1 CRAY versions of the code. The underscores set off the 6-character name of the code (TEMPEST is abbreviated TEMPST), and also delimit the 3-character version designation NAO. Version N29 is implicitly understood because these files are stored in the AO subdirectory of the N29 subdirectory as shown in Figure C.1. Finally, the file type is separated from the rest of the name by a period followed by a 3-character designation. 


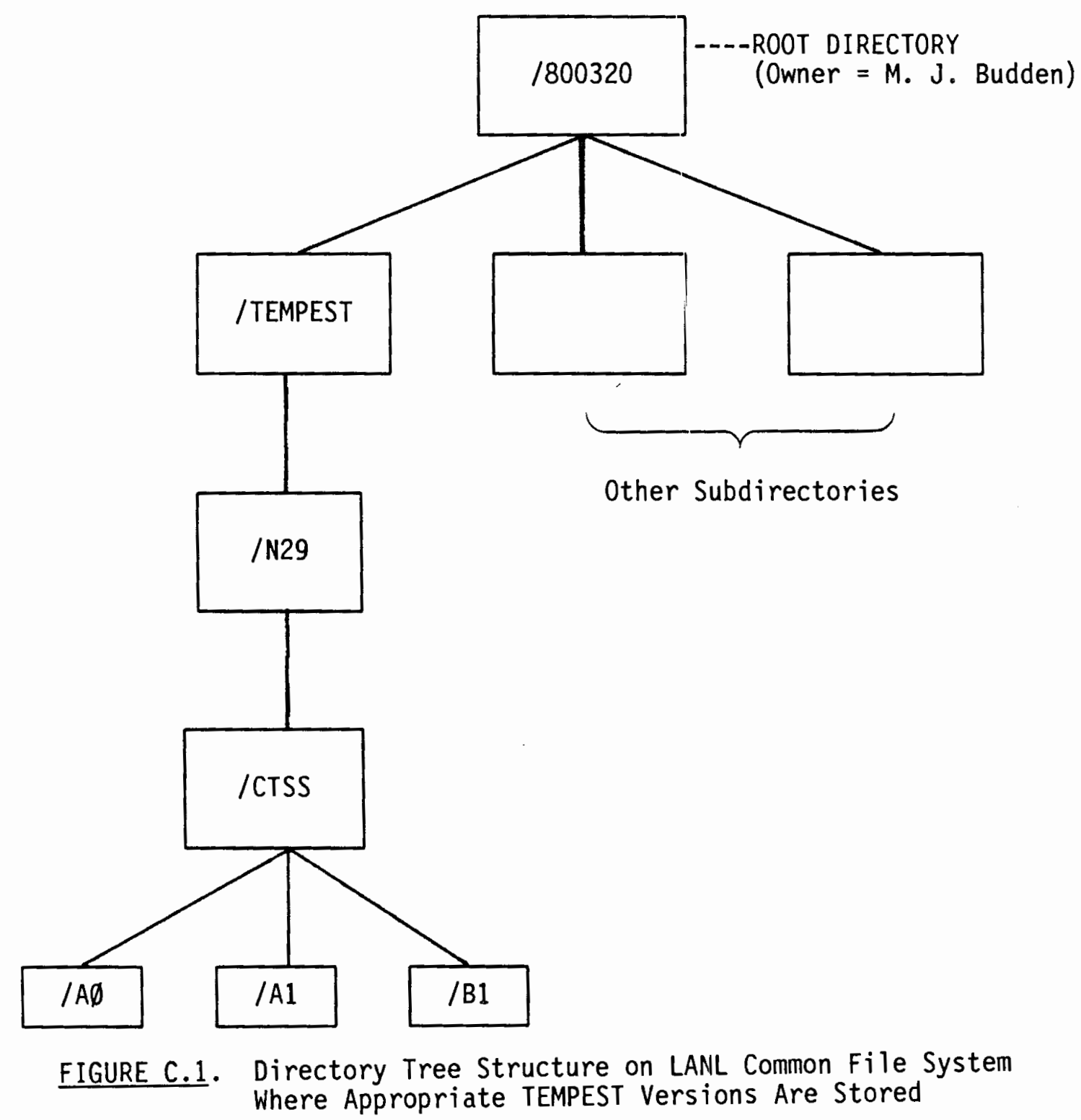

Files $1,2,7$, and 8 above are special files used by HISTORIAN. HISTORIAN fulfills its traceability function by assigning a unique identifier composed of characters and consecutive integers to each line of code. Directives about inserting new code and deleting existing lines can then be made by referring to the unique identifier of each line. One advantage of this version tracking method is that succeeding versions can be maintained by carrying only the change set, which probably would not exceed a few thousand lines of code. This is a big savings when compared to the 30,000-plus lines of code in each version of TEMPEST. The changes from one version to another are also

\section{C.2}


immediately visible, so the user need not search a 30,000-line FORTRAN source program to understand the differences between versions.

To begin to put a new code under configuration management using HISTORIAN, one must first create a HISTORIAN source file. This is file number 1 , with the .SRC extension to indicate the file type. A HISTORIAN source file looks just like an ordinary FORTRAN program except that subroutines and the main program are preceded by *DECK cards to define the HISTORIAN identifiers. Also, COMMON blocks are preceded by *COMDECK directives. The ${ }^{\star}$ COMDECK feature accomplishes what the INCLUDE statement does on some FORTRAN-77 extended compilers. Figure C.2 shows parts of the .SRC file for TEMPEST.

When the .SRC file is used as input to HISTORIAN, a complete FORTRAN file can be, and is usually, one of the outputs from HISTORIAN. This file is ready to go to the compiler as input. Figure C.3 shows parts of the .FOR file that comes out of HISTORIAN. Notice that it looks like an ordinary FORTRAN source file, except that columns 80 through 96 contain the HISTORIAN-generated identification for each line. The FORTRAN compiler disregards all information beyond column 72 on each line.

Figure $C .4$ shows an example .UPD change file. The most often-used directives are:

- *I, which means insert after

- ${ }^{*} B$, which means insert before

- ${ }^{\star} D$, which means delete and insert after.

Note that the ${ }^{*}$ I in columns 1 and 2 is interpreted by HISTORIAN or UPDATE as a comment card and that the *ID card defines the identifier for all subsequent changes.

HISTORIAN provides the traceability function that is important to satisfy requirements in PNL-MA-70. It also provides a convenient framework for a team of programmers to work with, so that changes made by one individual are more easily understood by another individual and less likely to adversely impact his unique efforts. Finally, HISTORIAN provides the continuity necessary for development on a big program. This makes the project somewhat independent of individual staff members and therefore minimizes problems arising from changes in. project staffing. 


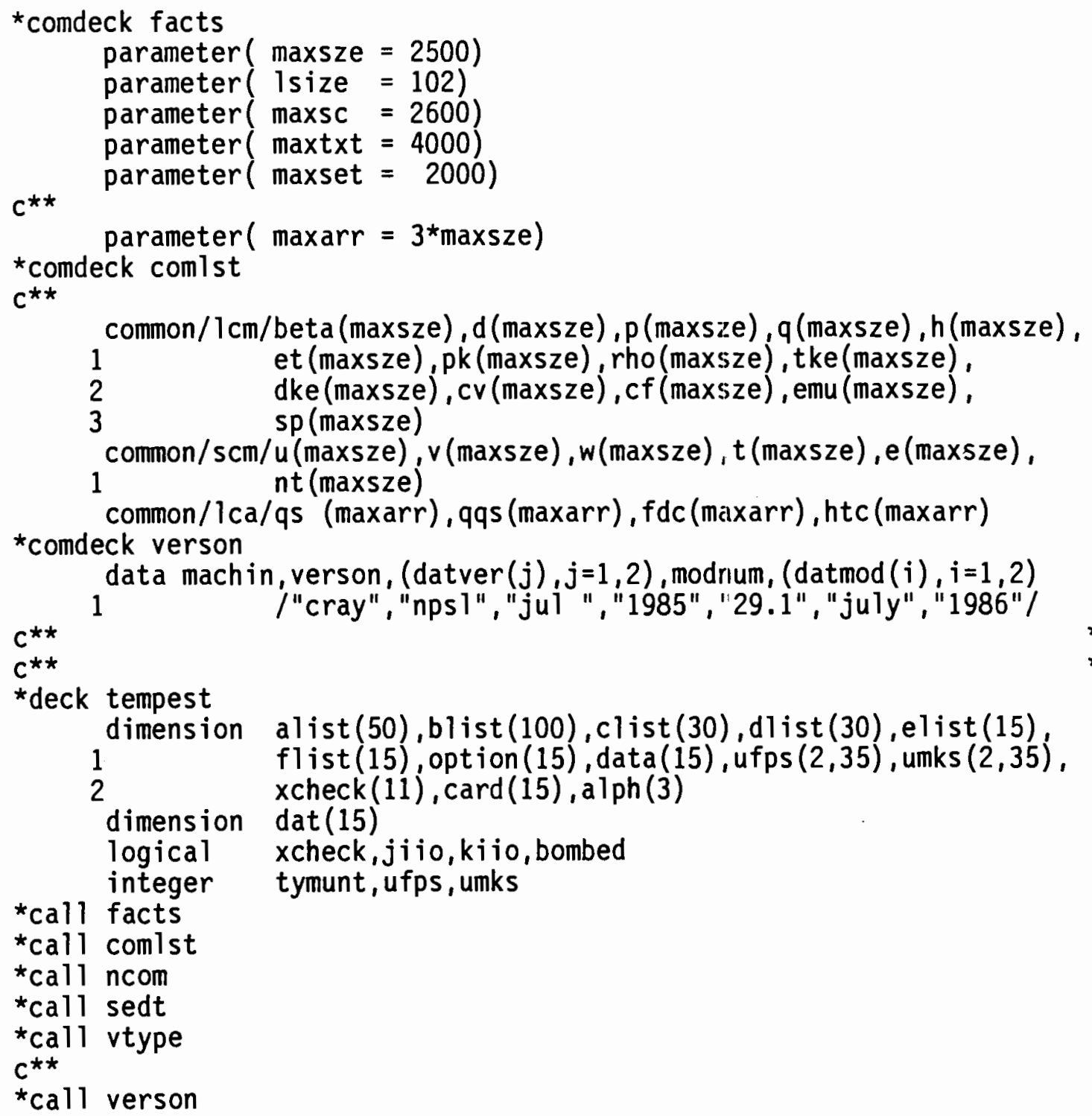

FIGURE C.2. HISTORIAN Source File Example 


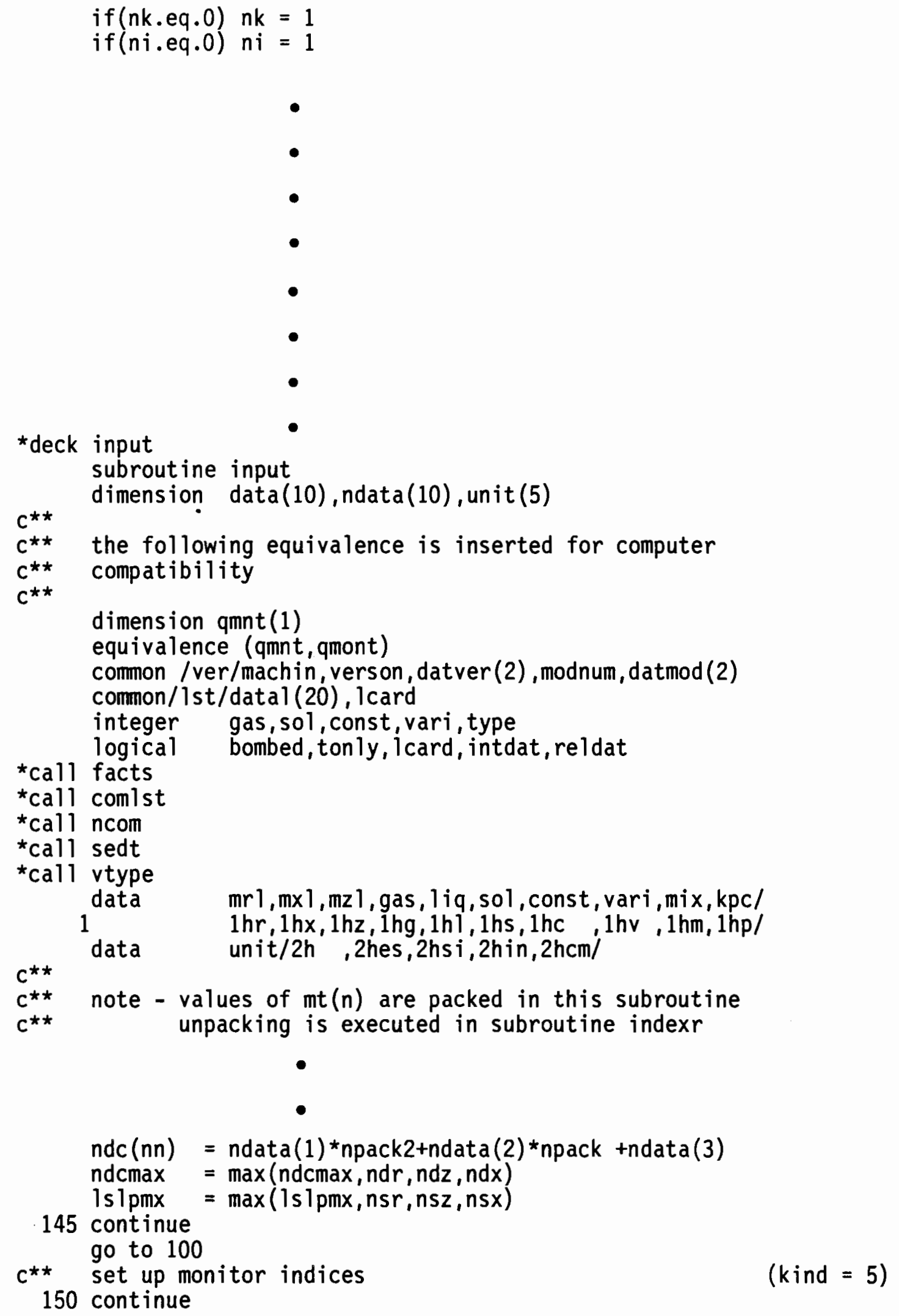

FIGURE C.2. (Contd)

C. 5 
do $152 n=1,10$

$\operatorname{mint}(n)=\operatorname{ndata}(n)$

$\operatorname{if}(\operatorname{mint}(n)$.eq.0) $\operatorname{mint}(n)=1$

152 continue

\section{FIGURE C.2. (Contd)}

unique efforts. Finally, HISTORIAN provides the continuity necessary for development on a big program. This makes the project somewhat independent of individual staff members and therefore minimizes problems arising from changes in project staffing.

When the audit feature of HISTORIAN is used, all information about previous insertions and deletions and how they were caused can be recovered. Thus, for the above reasons, HISTORIAN was chosen as the automated code version tracking tool. 


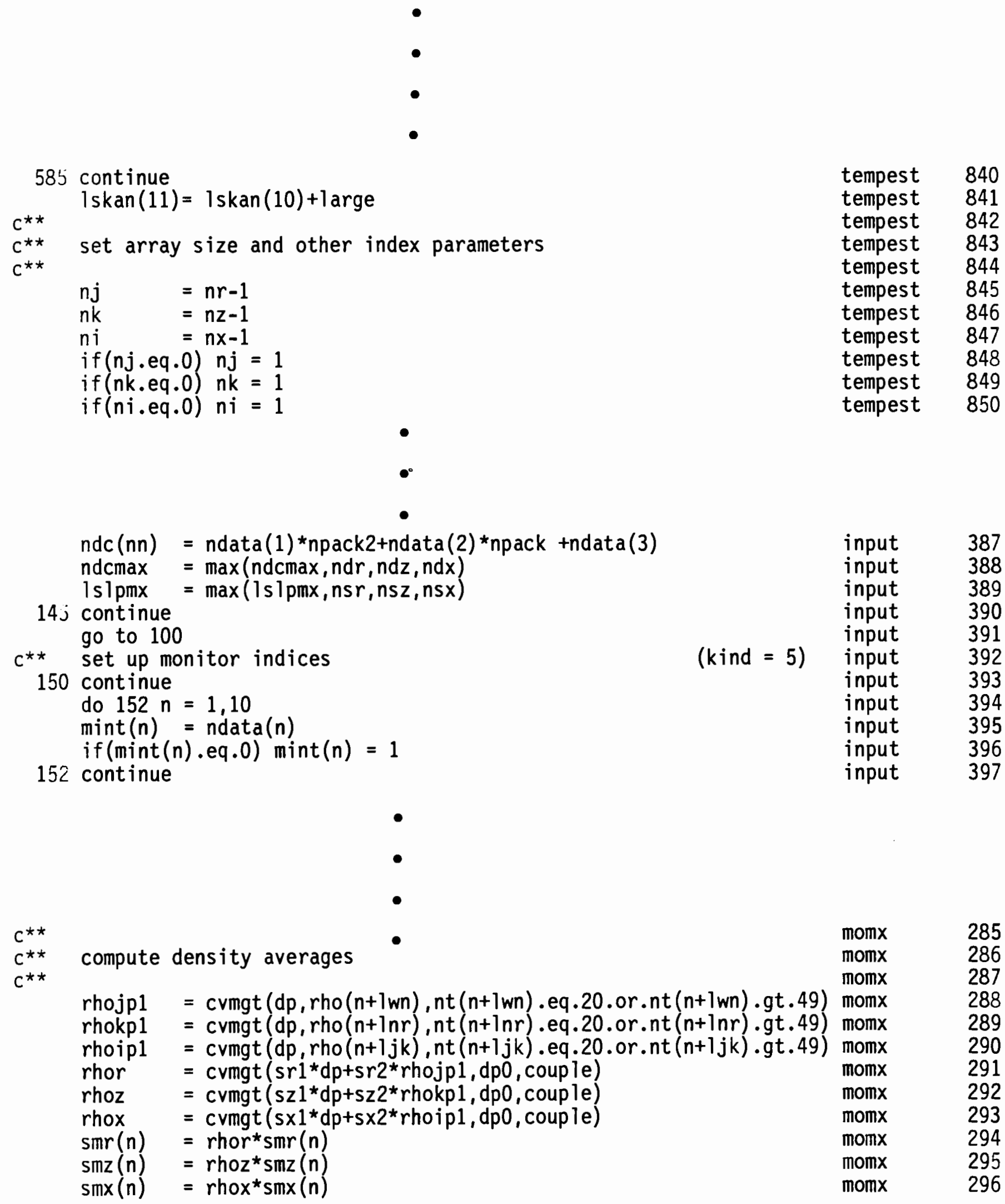

FIGURE C.3. HISTORIAN FORTRAN File Example 


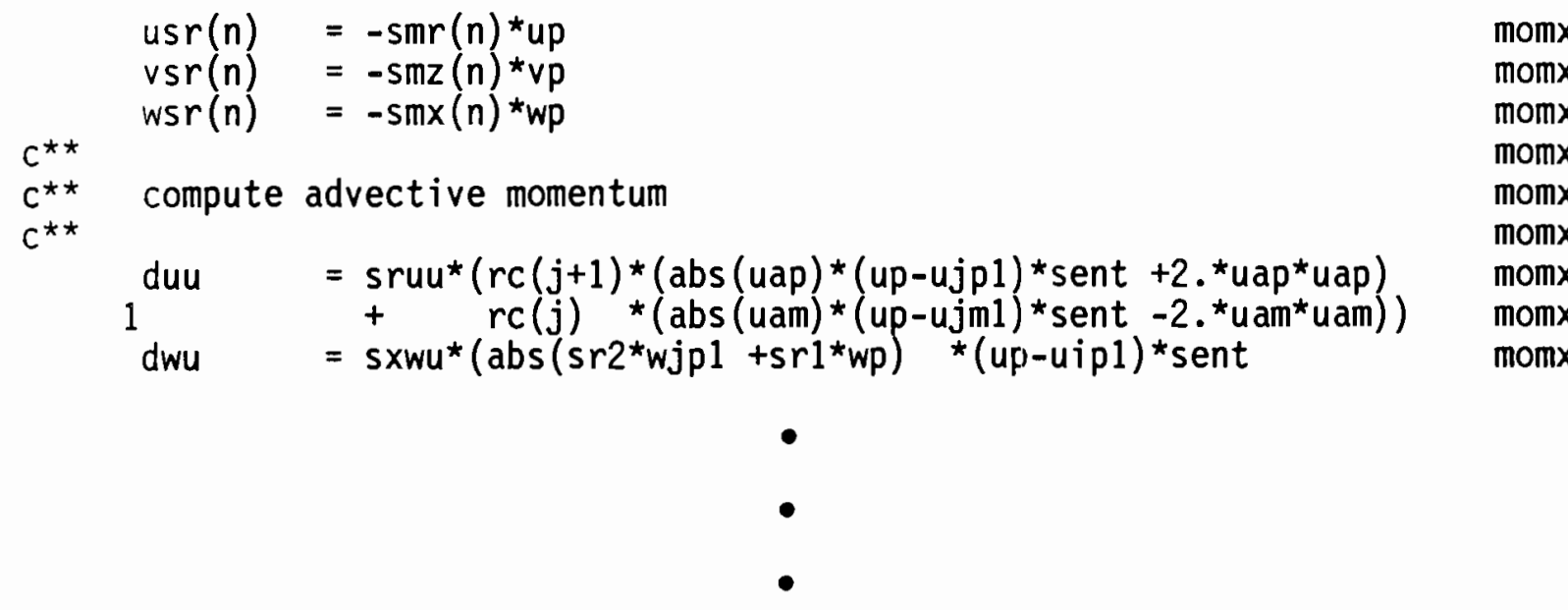

FIGURE C.3. (Contd) 


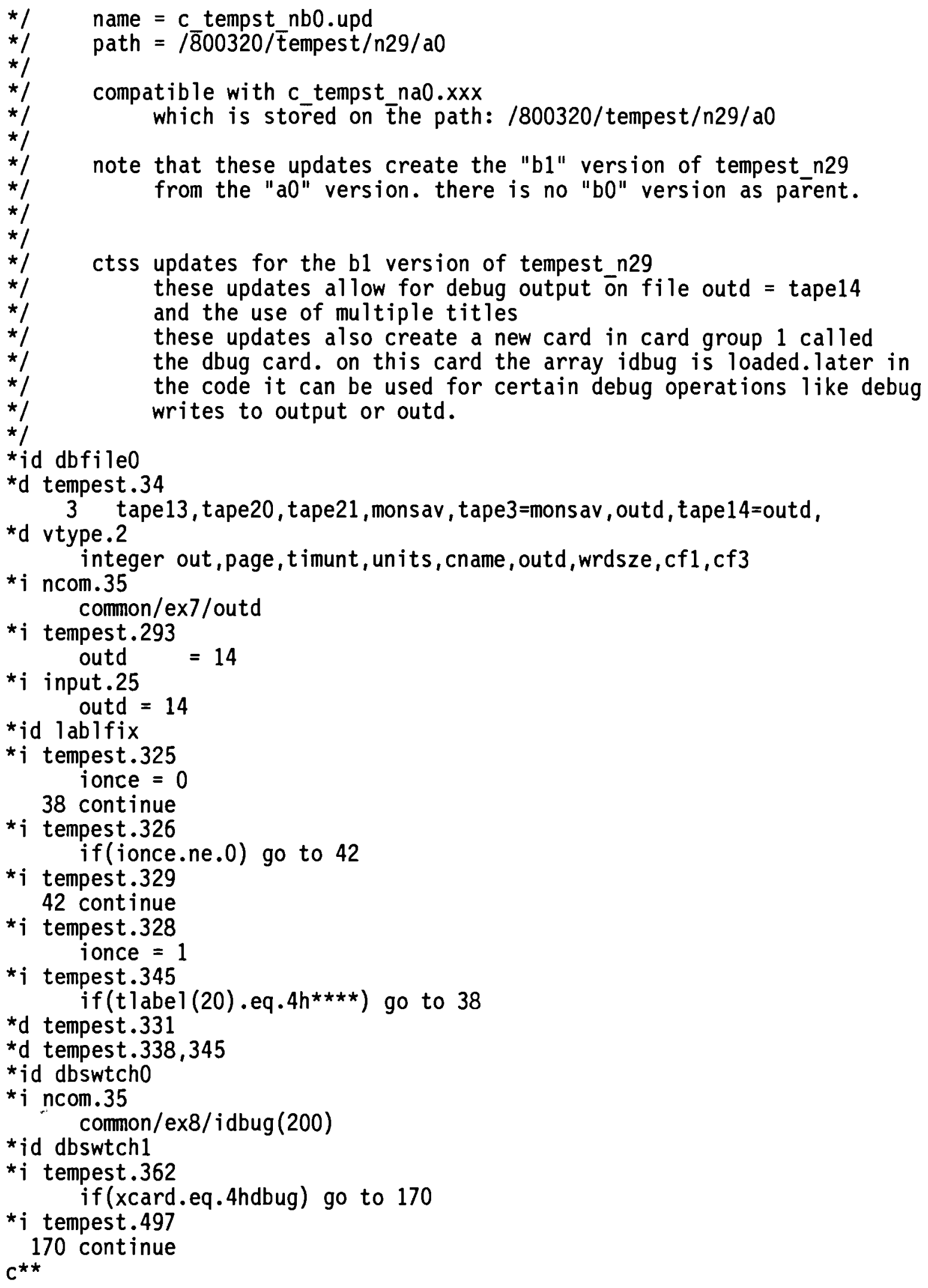

FIGURE C.4. HISTORIAN Update File Example C.9 


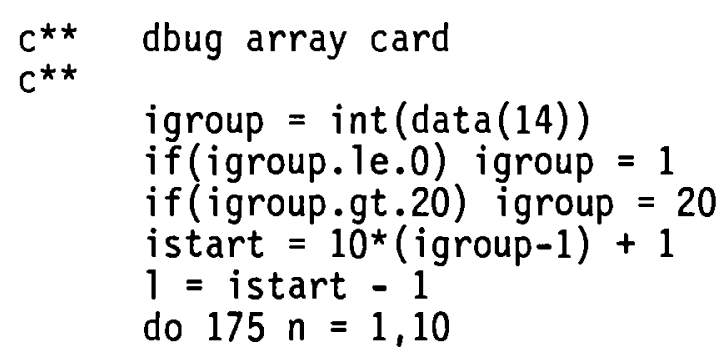

FIGURE C.4. (Contd) 


\section{DISTRIBUTION}

No. of

Copies

OFFSITE

10 DOE Office of Scientific and Technical Information

6 DOE Office of Civilian Radioactive Waste Management Forrestal Building Washington, DC 20575

ATTN: L. H. Barrett, RW-33

C. R. Cooley, RW-40

J. R. Hilley, RW-30

S. H. Kale, RW-20

D. E Shejor, RW-32

R. Stein, RW-23

3 DOE Office of Defense Waste \& GTN

Transportation Management

Washington, DC 20545

ATTN: K. A. Chacey, DP-123

G. H. Daly, DP-124

T. B. Hindman, DP -12

3 DOE Office of Terminal Waste

Disposal \& Remedial Action GTN

Washington, DC 20545

ATTN: J. A. Coleman, NE-24

T. W. Mc Intosh, NE-24

W. R. Voight, NE-20

H. F. Walter, NE-24

A. T. Clark

Division of Fuel Material Safety

Nuclear Regulatory Commission Washington, DC 20555

V. Ste 110

Office of the Executive Director for Operations

Mail Station 6209

Nuclear Regulatory Commission Washington, DC 20555
No. of

Copies

S. Meyers

Environmental Protection Agency Office of Radiation Programs ANR-458

401 M Street, S.W. Washington, DC 20460

J. M. McGough

DOE A1buquerque Operations Office

P. O. Box 5400

Albuquerque, NM 87185

P. G. Hagan

Joint Intergration Office

Carlmont Executive 1

4308 Carlisle N.E.

Suite 101

Albuquerque, NM 87107

E. Maestas

DOE West Valley Demonstration Project Office

P.0. Box 191

West Valley, NY 14171

3 DOE Idaho Operations Office

550 Second Street

Idaho Falls, ID 84301

ATTN: C. R. Enos

J. P. Hamric

S. T. Hinschberger

F. T. Fong

DOE San Francisco Operations

1333 Broadway

Oakland, CA 94612

M. R. Jugan

DOE Oak Ridge Operations Office P.0. Box E

Oak Ridge, TN 37830 
No. of

Copies

W. J. Goldston

DOE Savannah River Operations Office

P.0. Box A

Aiken, SC 29801

M. J. Steidler

Argonne National Laboratory 9700 South Cass Avenue

Argonne, IL 60439

C. S. Abrams

Argonne National Laboratory

P.0. Box 2528

Idaho Falls, ID 83401

3 Battelle Memorial Institute

Project Management Division

505 King Avenue

Columbus, $\mathrm{OH} 43201$

ATTN: W. A. Carbeiner

R. A. Nathan

Technical Library

L. D. Ramspott

Lawrence Livermore National Laboratory

University of California

P.0. Box 808

Livermore, CA 94550

D. T. Oakley, MS 619

Los Alamos Scientific Laboratory

P.0. Box 1663

Los Alamos, NM 87544

4 Oak Ridge National Laboratory

P.0. Box $Y$

Oak Ridge, TN 37830

ATTN: W. D. Burch

R. T. Jubin

L. J. Mezga

D. W. Turner
No. of

Copies

2 Sandia Laboratories

P.0. Box 5800

Albuquerque, NM 87185

ATTN: R. W. Lynch

Technical Library

J. R. Berreth

Westinghouse Idaho Nuclear

Co., Inc.

P. 0. Box 4000

Idaho Falls, ID 83401

6 E. I. du Pont de Nemours Company

Savannah River Laboratory

Aikerı, SC 29801

ATTN: R. G. Baxter

M. D. Boersma

J. G. Glasscock

J. R. Knight

M. J. Plodinec

C. T. Randall

A. D. Rodgers

Mail Stop 2411

EG\&G Idaho

P.0. Box 1625

Idaho Falls, ID 83415

R. Shiaw

Electric Power Research Institute

3412 Hillview Avenue

P.0. Box 10412

Palo Alto, CA 94304

4 West Valley Nuclear Service Company

P.0. Box 191

West Valley, NY 14171

ATTN: J. C. Cwynar

J. E. Krauss

S. J. Marchette

J. M. Pope 
No. of

Copies

J. L White, Chairman

Energy Research and Development Authority

Empire State Plaza

Albany, NY 12223

ONSITE

9 DOE Richland Operations Office

E. A. Bracken

C. E. Collantes

C. R. DeLannoy

J. R. Hunter

0 . L. 01 son

J. M. Peterson

A. J. Rizzo

M. W. Shupe

J. J. Sutey

8 Westinghouse Hanford Company

J. M. Henderson

R. E. Lerch

H. E. McGuire

J. L. Scott

D. A. Turner

D. D. Wodrich

R. D. Wojtasek

B. A. Wolfe

50 Pacific Northwest Laboratory

C. R. Allen

W. W. Ballard, Jr.

W. F. Bonner

D. J. Bradley

R. A. Brouns (2)

M. J. Budden (5)

H. C. Burkholder

C. C. Chapman

T. T. Claudson

R. D. Dierks

M. R. Elmore

L. L. Eyler

D. W. Falleti (5)

R. K. Farnsworth (5)
No. of

Copies
R. W. Goles
W. 0 . Heath
D. K. Hilliard
D. E. Knowlton
M. R. Kreiter/J. E. Mendel
W. L. Kuhn
L. T. Lakey
D. E. Larson
J. L. McElroy
R. K. Nakaoka
J. M. Perez, Jr.
M. E. Peterson
W. A. Ross
D. H. Siemens
S. C. Slate
Publishing Coordination (2)
Technical Report Files (5) 


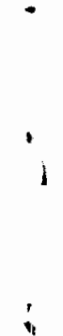

1

4

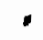

4

, (⿸丆口 